Schulich School of Law, Dalhousie University

Schulich Law Scholars

Research Papers, Working Papers, Conference

Papers

Faculty Scholarship

$12-16-2014$

\title{
A New Regulatory Framework for Low-Impact/High-Value Aquaculture in Nova Scotia
}

\author{
Meinhard Doelle \\ World Maritime University, mdoelle@dal.ca \\ William Lahey \\ Dalhousie University, william.lahey@dal.ca
}

Follow this and additional works at: https://digitalcommons.schulichlaw.dal.ca/working_papers

\section{Recommended Citation}

Doelle, Meinhard and Lahey, William, "A New Regulatory Framework for Low-Impact/High-Value Aquaculture in Nova Scotia" (2014). Research Papers, Working Papers, Conference Papers. 4. https://digitalcommons.schulichlaw.dal.ca/working_papers/4

This Working Paper is brought to you for free and open access by the Faculty Scholarship at Schulich Law Scholars. It has been accepted for inclusion in Research Papers, Working Papers, Conference Papers by an authorized administrator of Schulich Law Scholars. For more information, please contact hannah.steeves@dal.ca. 


\section{A New Regulatory Framework for Low-Impact/High-Value Aquaculture in Nova Scotia}

The Final Report of the

Independent Aquaculture Regulatory Review for Nova Scotia

[The Doelle-Lahey Panel]

2014

Meinhard Doelle \& William Lahey

Schulich School of Law

Dalhousie University 
(C) Crown copyright

Province of Nova Scotia, 2014

ISBN: 978-1-55457-647-0

This document is available on the Internet at http://www.aquaculturereview.ca/ 


\section{CONTENTS}

Acknowledgements $\quad$ v

Executive Summary vii

Core Conclusions vii

Foundational Elements of the Regulatory Framework ix

Coastal Planning $\quad x$

Regulatory Goals and Principles $\quad$ xi

Key Regulatory Design Issues $\quad$ xi

Site Selection and Utilization for Fin-Fish Aquaculture $\quad$ xV

Licensing (Site Approval) Process xvii

Changes in the Leasing of Aquaculture Sites xix

Security of Tenure for Operators in Good Regulatory Standing xix

Transfers, Expansions, Other Changes $\quad$ xx

Protection for Wild Salmon $\quad$ xx

Monitoring Compliance and Enforcement Provisions $\quad$ xxi

Ongoing Development and Review of the Regulatory Framework xxi

Other Issues $\quad$ xxii

Implementation and Transition xxii

1. Introduction 1

2. Policy Context and Issues 4

2.1 Regulation, Aquaculture and Nova Scotia's Long-Term Economic, Social and Environmental Objectives 4

2.2 What We Heard about Aquaculture in Nova Scotia in a Nutshell 7

2.3 Environmental Impacts 8

2.4 Request for a Permanent Moratorium on Marine-Based Fin-Fish Aquaculture $\quad 14$

2.5 Fin-Fish versus Shell-Fish 16

2.6 Regulation and Scale of Operation 17

$\begin{array}{ll}2.7 \text { Prescriptive versus Performance-Based Regulation } & 18\end{array}$

3. Foundational Elements of the Regulatory Framework 20

3.1 Attitudes 20

3.2 Social Licence $\quad 22$ 
3.3 Discretion 23

3.4 Capacity 24

3.5 Emphasis on Compatibility with Other Uses 25

3.6 Promoting, Enabling and Using Research 26

3.7 Regional Cooperation 29

3.8 Sustained Commitment 29

4. Coastal Planning 30

5. Goals of the Regulatory Framework 32

6. Guiding Principles 35

7. Role of and Cooperation with Federal Regulators 39

$\begin{array}{ll}7.1 \text { Background } & 39\end{array}$

7.2 The Vital Importance of Intergovernmental Regulatory Collaboration 42

8. Departmental Responsibilities for Regulating Aquaculture 45

9. Restructuring the Administration of the Regulatory Framework 48

10. Environmental Monitoring Process 49

11. Statutory Standards 51

11.1 Obligation to Maintain Oxic Conditions 52

11.2 Anti-fouling Technology 52

11.3 Standard Reporting Obligations for Each Kind of Aquaculture, Including the Following Matters for Fin-Fish Aquaculture: $\quad 53$

11.4 Standard Requirement Regarding Accommodation of Navigation 53

11.5 Other Standard Terms

12. Experimental or Developmental Licences 54

13. Regulatory Transparency 56

14. Provisions on Aquatic Animal Health and Well-being 61

$\begin{array}{ll}14.1 \text { Fish Health } & 61\end{array}$

14.2 Fish Welfare $\quad 65$

15. Disease Control, Management Procedures and Capacity 68

16. Site Selection and Utilization for Fin-Fish Aquaculture $\quad \mathbf{7 1}$

16.1 Nature and Rationale for a Classification System 71

16.2 Classification Criteria $\quad 74$

16.3 Processes for Classifying Coastal Areas for Fin-Fish Aquaculture $\quad 77$

16.4 Effect of Classification as a Green, Yellow or Red Area 79 
16.5 Relevance to Classification of Differences between Kinds of Fin-Fish Aquaculture 80

17. Strategic Assessment of Coastal Areas 81

18. Licensing (Site Approval) Process 83

18.1 Introduction 83

18.2 Licensing and Environmental Assessment $\quad 84$

18.3 Statutory Licensing Principles 85

18.4 Universal Elements of the Licensing (Assessment) Process 87

$\begin{array}{ll}\text { 18.5 Variations in the Licensing Process } & 97\end{array}$

$\begin{array}{ll}\text { 18.6 Licensing and Strategic Assessments } & 101\end{array}$

19. Changes in the Leasing of Aquaculture Sites 103

20. Licensing and Leasing Fees 105

21. Security of Tenure for Good Operators and Sites 107

22. Transfers, Expansions and Other Changes 109

23. Protection for Wild Salmon Populations 110

24. Monitoring Compliance and Enforcement Provisions 114

25. Independent Aquaculture Review Board 117

26. Emerging Issues 119

27. Site Closure and Cleanup 120

28. Relationship of Regulation to Industry Codes of Practice 121

29. Relationship of Regulation to Third-Party Certification 123

30. Bay Management 125

31. Ongoing Regulatory Advisory Committee 126

32. Science Advisory Committee/Network/Mechanism 127

33. Role for Industry Associations in Supporting Compliance 128

34. Working Capital (Aquaculture Loans Board) 129

35. Mandatory Independent Five-Year Review (with Advisory Committee) 130

36. Implementation and Transition 132

36.1 Introduction 132

36.2 Resourcing and Prioritization 133

36.3 Early Actions 134

36.4 Options for Efficient Adoption of Legislative Changes 137

36.5 An "Implement as Ready" Approach to Implementation 138 
36.6 The Respective Roles and Interaction of Administrative and Legislative Action

36.7 Ongoing Improvement beyond Initial Implementation of the Framework

36.8 Applying the New Framework to Applications for New Fin-fish Licences and Leases

36.9 Applying the New Framework to Existing Operations

36.10 Transparency

143

36.11 Consultations with the Mi'kmaq 143

References

144 


\section{ACKNOWLEDGEMENTS}

The regulatory framework proposed in this report is the work of the two Panel members; however, it could not have been completed without the contributions of the Advisory Committee, the Roundtable, the Knowledge Roster, the Panel's Secretariat and countless participants in the Panel's 18-month process. As Panel members, we came into this process with expertise in environmental law and policy, and in regulation in the natural resource sector as well as in some other sectors, but with no particular knowledge of the aquaculture industry or its condition in Nova Scotia. We have benefited greatly from the generous support we have received from the many participants in our process, from academics, from government officials, from community groups, from environmental groups, from members of the public and from those involved in the industry, with many contributing their time, knowledge and perspectives on a volunteer basis without compensation.

From our appointment in April of 2013 until April of 2014, Dr. Vimy Glass of the Department of Fisheries and Aquaculture provided indispensable administrative support, both to us and to our process. When Vimy had to move on to accept a new position with the Department of Economic Renewal, Tourism and Rural Development, her place was ably taken by Holly Amirault. We are deeply indebted to them both.

Four law students played key roles in our work. In the summer of 2013, Nick Conlon and Kira Misiewicz travelled the province with us as we each chaired more than 20 public meetings in coastal communities. Their notes from those meetings were instrumental to our ability to accurately document what we heard in those meetings, not only in our "What We Heard" document, but also in this report. As part of his law studies, Mathieu Poirier completed his placement in environmental law by preparing a very helpful report for us on the various certification programs that exist in the aquaculture industry. During the summer of 2014, Ted Murphy provided research assistance and worked with us on the complex task of assembling, organizing and producing this report and the draft version of it that we released for public comment on July 3. He also assisted us with the meetings we held in Yarmouth, Tatamagouche, Baddeck and Halifax to receive direct feedback from Nova Scotians on the draft report. We are very grateful to these four law students for their talented contributions to our work.

Our knowledge of how the aquaculture industry is regulated in other jurisdictions was greatly aided by the assistance we received from Cecilia Engler, a doctoral student at the Schulich School of Law, and from East Coast Environmental Law (ECELAW). Cecilia provided us with a detailed report on Scotland's regulatory framework, while ECELAW, under the leadership of Lisa Mitchell and Jamie Simpson, provided us with jurisdictional overviews for New Brunswick, Prince Edward Island, Newfoundland and Labrador, British Columbia and Maine.

Much of our work, including more than 20 stakeholder meetings, took place on the premises of the Schulich School of Law. We are very appreciative of the support of the School and of our Dean, Kim Brooks.

Lesley Griffiths was instrumental to the success of our Roundtable in producing under tight timelines a very useful report that we have used in preparing our own recommendations. The Roundtable process demonstrated that, in this as in other fields of contested public policy on the 
development and protection of natural resources, inclusive dialogue among those who hold strongly differing views can do much to bridge and reduce those disagreements and to improve understanding where disagreement remains. We are very grateful to all of the members of the Roundtable for their dedication to the Roundtable's work and to their universally shared determination to produce a report that would be helpful to us in the fulfillment of our mandate. For making this success possible, we owe a particular debt of gratitude to Lesley.

With only a few exceptions, we met monthly with our Advisory Committee, from our first meeting in May of 2013 to our last meeting in September of 2014. The compliments we have received on our engagement with Nova Scotians in an open and transparent process and on our consultations with stakeholders of the industry and with members of the academic, local and knowledge communities owes much to the solid, thoughtful and always balanced advice we received from the Advisory Committee. Our particular thanks is therefore also due to the members of that Committee: Brian Blanchard of the Nova Scotia Aquaculture Association (who replaced Bruce Hancock in the early days of the process), Mark Butler of the Ecology Action Centre, Lisa Fitzgerald of the Nova Scotia Fisheries Sector Council, Roderick Murphy of the Union of Nova Scotia Municipalities, Carl Purcell of the Nova Scotia Salmon Association, Chief Terry Paul of Membertou, and Karen Traversy of the Coastal Coalition of Nova Scotia.

Our understanding of the scientific and especially of the biophysical issues was immeasurably assisted by the many experts who dedicated four days from their busy schedules, many travelling from considerable distances, to participate in our three Knowledge Workshops and the original organizing meeting of our Knowledge Roster. An organizing sub-committee of that Roster, consisting of Fred Whoriskey (Dalhousie), Peter Tyedmers (Dalhousie), Cyr Couturier (Memorial) and Charlie Dennis (Unama'ki Institute), played a critical role in getting us ready to participate in and benefit from the workshops. In addition, a number of members of the Knowledge Roster took the time to provide written answers to science questions posed by the Roundtable.

We would like to thank the Department of Fisheries and Aquaculture for the trust and confidence it placed in us to carry out our mandate and for the resources it provided to us to make our work possible. We were appointed by Minister Sterling Belliveau, who was a member of the NDP government of Premier Darrell Dexter. We continued to be supported by Minister Keith Colwell, who was appointed Minister of Fisheries and Aquaculture in the Liberal government of Premier Stephen McNeil. What we particularly wish to acknowledge is that we were left alone from the beginning of our process to its conclusion to carry out our work without interference of any sort and to follow the path indicated to us by our consultations, our research and our analysis. In this regard, we also want to acknowledge the support we have received first from Deputy Ministers Rosalind Penfound, Brian Rogers and Kim MacNeill, as well as from other members of the Department.

Finally, and again, we wish to thank every Nova Scotian and the numerous people from beyond Nova Scotia who spent time with us sharing their perspectives, knowledge, experience and advice. From many, we got the clear impression they thought we had been given a unique opportunity to give advice that could make things better for all concerned, directly and indirectly, with aquaculture in Nova Scotia. We have tried our best to live up to those expectations. 


\section{EXECUTIVE SUMMARY}

\section{Core Conclusions}

In this report, we conclude that a fundamental overhaul of the regulation of aquaculture in Nova Scotia is called for. We conclude that this overhaul should be guided by the idea that aquaculture that integrates economic prosperity, social well-being and environmental sustainability is one that is low impact and high value. By this, we mean aquaculture that combines two fundamental attributes: it has a low level of adverse environmental and social impact, which decreases over time; and from the use of coastal resources it produces a positive economic and social value, which is high and increases over time.

A number of participants in our process urged us to conclude that marine-based fin-fish facilities and more particularly, salmon farms - cannot be sustainably operated, and to recommend that a permanent moratorium be imposed on this kind of aquaculture. Our conclusion, after careful consideration of the state of the science and opportunities to reduce impacts through effective regulations, is that the regulatory framework should not be prohibitory at a provincial scale. Instead, we recommend fundamental changes to the regulation of aquaculture, which we conclude can address the serious and legitimate concerns raised without foreclosing the opportunity associated with this sector of the industry. Our reasons include the following:

a. The risks and impacts can be significantly reduced through effective regulation.

b. Through incremental development and continuous improvement to minimize negative impacts and risks while maximizing benefits, marine-based fin-fish aquaculture has the potential to make an important contribution to sustainable prosperity in Nova Scotia.

c. A diverse industry that includes marine-based operations and land-based facilities is more likely to be resilient to future changes, including changes in market conditions and climate change.

d. In the context of our mandate to develop a regulatory framework that integrates environmental, social and economic objectives and the conclusions of the One Nova Scotia Commission on the state of Nova Scotia's economy, the potential contribution of marinebased fin-fish aquaculture to Nova Scotia's economy calls for a policy approach that addresses the risks through responsible development and robust regulation rather than prohibition.

We recognize that fin-fish operations, even if well regulated and operated, are not appropriate in all coastal waters around Nova Scotia. We conclude that a new regulatory framework must ensure that marine-based fin-fish farming occurs only in coastal waters that are suitable for that kind of aquaculture and where it is compatible with other important uses of those waters. For that reason, one of our core recommendations is the creation of a classification system under which coastal areas would be rated as Green, Yellow or Red based on their relative suitability for fin-fish aquaculture. Under this system, the classification of a coastal area would determine how applications for a fin-fish licence would be evaluated and the likelihood of an application for such a licence being approved. It would also play a central role in determining the terms and conditions under which licences would be issued. 
The regulatory framework we propose would also allow applications to the Minister (or to an independent aquaculture review board) to have a lease revoked if it has become clear through experience that the site is not suitable for a particular type of operation. The licensing process we have proposed also identifies the need to consider, at the renewal stage, whether a site is being responsibly operated and whether the site is suitable for continuing operation of the type and scale previously permitted on the site. Finally, we make clear that existing operations will have to be brought under the new regulatory system as soon as practical, and that any new facilities should be processed under the new regulatory system we have recommended. In other words, the province should continue its commitment not to process applications for new fin-fish licences until the new regulatory system is in place.

For fin-fish and other kinds of aquaculture, the regulation of aquaculture will change in fundamental ways under the proposed framework. For example:

a. The regulation of aquaculture will be functionally separated from the promotion of the aquaculture industry.

b. Responsibility for administering the Environmental Monitoring Program will be moved to the Department of the Environment from the Department of Fisheries and Aquaculture.

c. Important regulatory standards that are currently only addressed in the terms and conditions of individual licences written under statutory discretion will be addressed in legislation.

d. More generally, the regulatory process will be much less discretionary than it currently is under the Fisheries and Coastal Resources Act.

e. There will be a pervasive emphasis on openness and transparency, both in the licensing and leasing process and in the monitoring of compliance by licensed operations and the enforcement of regulations.

f. The health and well-being of farmed fish will become a central concern of the regulatory process and a core mechanism for ensuring the compatibility of aquaculture with its coastal environment.

g. The public will have multiple opportunities, including a mandatory hearing on every application for a licence, to contribute to decision making in the licensing process.

h. The licensing and leasing process will be conducted as a kind of specialized environmental assessment that incorporates an integrated understanding of environmental, social and economic issues into licensing and leasing decisions;.

i. Licensing will be guided by statutory licensing principles and subject to a requirement for written reasons that together will require licensing decisions to be justified in terms of regulatory objectives and the compatibility of aquaculture with public rights of navigation, fishing, local biophysical conditions, other uses of the waters proposed for aquaculture; the cumulative effect of aquaculture in the area; and the contribution of the proposed operation to net community socio-economic benefit.

j. Subject to standardized safeguards to ensure openness, transparency and participatory fairness in decision making, the licensing process will vary to reflect the differences between shell-fish and fin-fish aquaculture as well as the differences between fin-fish aquaculture in Green, Yellow and Red areas. 
k. Salmon farms will be required to institute a comprehensive containment system to prevent escapes, such as is required in the state of Maine.

l. Compliance monitoring and enforcement will be strengthened in multiple ways, including by

0 increasing the monitoring and enforcement staff and other resources

o unscheduled inspections

o targeting oversight to higher risk operations

o penalizing violations with prosecutions and licence and lease revocation where warranted

m. A standing Regulatory Advisory Committee - which includes Mi'kmaw representatives and stakeholders such as coastal communities, municipalities, the aquaculture industry and environmental organizations - will be created to provide ongoing advice on the implementation of the regulatory framework and the continuing improvement of regulation in the face of new and changing conditions, challenges, opportunities and learning.

In developing our recommendations, we have been mindful that a regulatory system for Nova Scotia's diverse aquaculture industry must reflect the differences between fin-fish and shell-fish aquaculture and between large and small business while strengthening the regulation of the industry in a comprehensive way. We note three options for addressing this concern in the design and implementation of the new regulatory system.

One is to ensure - in an effort to minimize the additional burden the framework places on small operators - that the requirements imposed by the regulatory framework on large and small operators are proportionate to the risks that the framework is intended to control. A second option is to ensure that the framework leaves regulated organizations with reasonable levels of flexibility as to how they implement or meet the regulatory requirements. The third option is for the regulatory agency, often in partnership with industry associations, to invest in programs that assist small and medium-sized enterprises (SMEs) in meeting their regulatory obligations. We have carefully considered these options in our work, and urge the province to give due consideration to these issues in the design and implementation of the new regulatory framework, as we see great value in a diversity of operators and in the size and type of operations.

\section{Foundational Elements of the Regulatory Framework}

The success of the regulatory framework we have proposed will depend on the creation of a number of fundamental enabling conditions:

a. The attitude that informs regulation must take the concerns of those who live in coastal communities seriously and at face value.

b. The critical role that effective regulation plays in constituting social licence and in building upon social licence once it is established must be embraced by government and the industry.

c. The pervasive discretion built into the current regulatory framework must be limited in a new regulatory framework if the new framework is to enjoy the trust and confidence it needs to be successful.

d. The capacity of the Department of Fisheries and Aquaculture (DFA) to carry out its regulatory mandate must be significantly enhanced. 
e. There must be a fundamental emphasis in the regulation of the industry on the compatibility of licensed aquaculture with other uses of coastal waters.

f. The DFA must become more proactive in promoting, enabling and using the results of research in its regulatory activities and, in particular, in supporting the research that will improve collective knowledge of the interaction of aquaculture and the specific biophysical and socio-economic conditions of coastal Nova Scotia.

g. Nova Scotia must work to ensure that regional cooperation in the regulation of aquaculture is consistent with Nova Scotia's policy and regulatory objectives and includes cooperation on matters, such as the capacity to address and manage disease outbreaks, that require regional cooperation because of the limited scale of the industry in each province.

h. The commitment to improvement in the regulation of aquaculture must be sustained for the long term.

This report lays particular stress on the need for research and on the role that the DFA should play in taking advantage of and contributing to growth in Nova Scotia's and Atlantic Canada's research capacity in aquaculture. On some matters, such as the possible impact of fin-fish aquaculture on lobsters, there is concern in Nova Scotia about questions that have received very little research attention in or beyond Nova Scotia. On other issues, there has been limited research to evaluate the applicability of findings reached elsewhere to the Nova Scotia context. The ultimate effectiveness of the regulation of aquaculture in Nova Scotia will depend on research being done to address such gaps.

Of course, any regulatory system has to function in the face of uncertainty while research to reduce the uncertainty is underway. In the case of the potential impact of aquaculture on lobster and in similar cases of uncertainty, our recommended approach is that the DFA should

a. identify opportunities to reduce or eliminate the source of the risk, where this can be reasonably be done through changes in the operation of fin-fish aquaculture (for example, as set out elsewhere in the report, by eliminating the use of chemical anti-fouling agents);

b. where risks cannot be readily eliminated, proceed with a clear understanding that there is an unknown risk associated with the operation, and make the quantification of the risk a priority through specific monitoring and research efforts; and

c. ensure that the scale of development is in line with the risk involved, by ensuring incremental development and by retaining the ability to adjust to new information expected from the additional monitoring and research.

\section{Coastal Planning}

We heard a broad range of views on coastal planning. Our conclusion is that an integrated coastal plan for Nova Scotia would be a very useful tool that could do much to improve the efficiency, effectiveness and fairness of the regulatory process. At the same time, we are not in a position to determine what time and resources would be needed to complete such a process, and we cannot predict whether or when such a process would yield results, or what the outcomes of such a planning process would be. We have therefore decided to design the regulatory framework for aquaculture in the absence of a coastal plan. If such a plan is developed in the future, certain aspects of the regulatory process could be significantly streamlined. 


\section{Regulatory Goals and Principles}

We stress the importance of the articulation of regulatory goals and principles both to guide regulation and strengthen the accountability of regulators. We conclude that the regulatory framework for aquaculture should have the following goals:

a. Environmental protection and sustainable use of environmental services

b. Fairness in allocation of public resources; i.e., coastal waters

c. Productive use of coastal resources in the direction of low impact for high value

d. Compatibility with other sectors of the economy

e. Ensuring social and economic benefits proportionate to the value of the resources used

f. Protection of wild salmon populations

g. Meaningful public participation in decision making

h. Attentiveness to plans, objectives, needs and priorities of local communities

i. Supporting the efforts of the industry to grow by combining business success with higher environmental performance

j. Regulation that is achievable, is enforceable, incorporates incentives to comply, and is efficient, timely, predictable and affordable for taxpayers and for industry

We similarly conclude that seven guiding principles should guide the design and implementation of the regulatory framework:

1. Effectiveness

2. Openness

3. Transparency

4. Accountability

5. Proportionality

6. Integration

7. Precaution

\section{Key Regulatory Design Issues}

\section{Role of and Cooperation with Federal Regulators}

Federal regulators play a critical role in regulating aspects of the industry. In particular, Fisheries and Oceans (DFO), Health Canada, the Canadian Food Inspection Agency (CFIA) and Transport Canada each contribute in important ways to the regulation of the industry. It will continue to be important for the province to work closely with federal regulators to ensure effective coordination. Therefore, we conclude that Nova Scotia should continue to work with the DFO and other federal regulators through the mechanism of an MOU to ensure that the entire regulatory framework for aquaculture in Nova Scotia is as effective, cohesive, coordinated and streamlined as possible despite the division of regulatory authority between the two levels of government. A strong and clear delineation of roles built on a clear articulation of shared regulatory objectives would help to achieve desired levels of cohesion. The province should not, however, treat federal decisions on 
issues subject to federal regulation as reason to preclude additional provincial action to ensure the comprehensive effectiveness of the regulation of aquaculture in Nova Scotia.

\section{Departmental Responsibilities for Regulating Aquaculture}

The dual role of the DFA as promoter and regulator of the industry was a matter of concern to many participants. We were urged to recommend a regulatory framework under which responsibility for regulating aquaculture would be moved to the Minister of Environment. The issue goes to the heart of the lack of trust that is at the centre of much of the dissatisfaction with the current regulatory framework. Nonetheless, we have concluded that responsibility for regulation of aquaculture should remain with the DFA. The proviso to this conclusion is that it depends on acceptance and implementation of our proposed regulatory framework, many aspects of which are designed to address by other means the palpable distrust and potential for conflict that exists with the current regulatory framework. We have reached this conclusion for the following reasons:

a. Although the regulation of aquaculture is largely concerned with environmental protection, it also concerns the use of a public resource - coastal waters - and the place of aquaculture in the development, use and protection of coastal resources.

b. The result of reallocating the environmental aspects of provincial regulation of aquaculture to the Department of Environment would add to the already complex regulatory landscape in the sector.

c. Provincial regulation of aquaculture already suffers from a lack of regulatory capacity. We think that the capacity gap is more likely to be addressed cost-effectively if the increased capacity is concentrated as much as possible in one department rather than divided between departments.

d. Dividing regulatory functions between departments might complicate Nova Scotia's collaboration on aquaculture with other governments in Atlantic Canada, all of which combine industry promotion and support with regulation in one government department that is also responsible for the fishery mandate.

e. While separating the regulatory role from the industry-development role might improve confidence in the independence and trustworthiness of the regulatory process, it may not result in improved regulatory effectiveness.

f. Even if we were otherwise inclined to assign the regulatory responsibility to the Department of Environment, the approval process and the environmental assessment process in Parts IV and V of the Nova Scotia Environment Act would require significant enhancement to serve as useful regulatory tools for aquaculture.

\section{Restructuring the Administration of the Regulatory Framework}

One of the critical provisos to our conclusion that the regulation of aquaculture should stay in the DFA is that it should be more strongly separated from the Department's role in industry promotion. To facilitate this, responsibility for the administration of legislation should be assigned to a statutory official instead of to the Minister. This change will have other benefits, including greater independence for those who have regulatory functions and responsibilities, and a less political and a more professionalized regulatory process. 


\section{Environmental Monitoring Process}

An effective environmental monitoring process (EMP) is critical for effective regulatory oversight of regulated facilities. We recommend the following:

a. The process should be established in legislation.

b. The parameters of the process should be prescribed in regulations rather than in departmental policy.

c. The legislation should make compliance with the process a term and condition of all licences. The mandatory nature of the process should not depend on whether or not it is written into the terms and conditions of specific licences.

d. The responsibility for administering the EMP should be transferred to the Department of Environment to improve public confidence in the independence and objectivity of the oversight that government brings to bear on industry's compliance with the EMP.

e. The regulatory monitoring of compliance of operators with the EMP has to be strengthened. There needs to be more auditing of compliance. The auditing process needs to include random unannounced audits. Directly or through contracted third parties who are independent of industry, regulators need to more frequently collect their own samples for analysis, and again, this needs to be periodically done on an unannounced random basis subject only to the advance notice that is required to address biosecurity concerns.

f. The results from the EMP for each site must be made available to the public in a timely manner.

\section{Statutory Standards}

In an effort to replace discretion with clear standards where appropriate, we conclude that certain matters now addressed in the terms and conditions to specific licenses should be addressed in legislation. The legislation should in addition specify regulatory standards in certain key areas of operation that are currently not addressed in the regulatory framework. The following matters should be addressed more specifically in legislation:

a. The conditionality of each licence on compliance with the Act and regulations, as well as with the terms and conditions of the lease and licence.

b. Compliance with the EMP.

c. Obligation to maintain oxic conditions.

d. The prohibition of use of anti-fouling processes that discharge toxic substances into the environment.

e. Standard requirements regarding fallowing, age class and separation between facilities.

f. Standard reporting obligations for each type of aquaculture.

g. Standard requirements regarding accommodation of navigation.

\section{Regulatory Transparency}

Lack of transparency about the regulatory process and its operation in general and in relation to specific sites was a frequently voiced concern in our process. 
Regulatory transparency will be critical to the effectiveness of the proposed regulatory framework. In particular, it is a crucial enabling condition for our conclusion that responsibility for regulation should largely stay with the DFA.

As a starting point, comprehensive and easy-to-understand information on the regulatory framework should be readily accessible to anyone interested. This will address the real frustration and irritation we heard from many, including some in the industry, about the difficulty they have experienced in obtaining clear information about matters such as the steps in the regulatory process, the obligations of applicants for leases and licences and of operators once licensed, their opportunities to participate in the regulatory process and the actions the DFA can or will take to ensure compliance with the regulations.

Transparency and openness have to extend beyond general information about the regulatory process. They must extend to the application of the regulatory framework to each application for a lease and a licence and to the DFA's ongoing oversight of each approved operation. As nearly as possible, the objective should be to make application of the entire regulatory framework an open book.

We therefore recommend that the basic principle should be that information relevant to understanding the operation and effectiveness of the regulatory process as it applies to each proposed and approved site should be readily available to the public. This principle should be set out in legislation to ensure that it is binding on the DFA and to ensure that public access to information covered by the principle does not require the making of an application under the Freedom of Information and Protection of Privacy Act (FOIPOP) process.

Information that is truly confidential business information should be excluded from this principle under a definition of confidential business information set out in the legislation. However, the assumption should be that information is public information unless a regulated business clearly establishes that it is confidential business information within the scope of the statutory definition.

The objective of our transparency recommendations is a level of transparency and openness that would allow a member of the public to readily ascertain the status of an application for a lease and licence (or for a change or renewal of a lease and licence) or the standing of an approved operation relative to its regulatory responsibilities at any given time.

\section{Provisions on Aquatic Animal Health and Well-Being}

We heard persuasive presentations that the key to aquaculture's future as a sustainable industry that enjoys social licence is a focus on the health and well-being of farmed animals.

Fish health is one of the objectives of various elements of the framework that have a range of objectives. These elements of the framework include

a. biophysical site conditions that make a site suitable for a particular operation

b. conditions on number of fish on site and on permitted stocking densities

c. fallow period requirements

d. the mixing of species on sites

e. limits on the number of and separation between permitted farms in particular bays 
f. coordination of production on sites within defined geographic areas

g. vaccination requirements

In addition, the regulatory framework should deal more explicitly and extensively with a number of matters specific to fish health, including

a. reporting of diseases

b. the elements of disease surveillance

c. the DFA's authority in relation to the management of disease outbreaks

d. biosecurity procedures to be followed to prevent the spread of infectious disease

e. regulation of the movement of fish to or from a site

We have also concluded that the regulatory framework should more clearly define the animal welfare standards that are required in fin-fish aquaculture. It should do this at three levels:

1. By outlining the animal welfare standards that should generally be met on water quality, stocking levels, feeding rates, general husbandry and cage design, construction and maintenance.

2. By better defining distress (i.e. neglect) as it applies to fin-fish aquaculture.

3. By better defining what practices of animal management, husbandry and slaughter will be regarded as "reasonably and generally accepted" in aquaculture in Nova Scotia for the purpose of determining the applicability of the statutory provision that creates the offence of causing distress.

In addition, we also draw attention to improvements required in the industry's capacity to respond to and manage disease outbreaks.

\section{Site Selection and Utilization for Fin-Fish Aquaculture}

We propose that decision making on applications for licences to conduct fin-fish aquaculture be guided by a classification system under which coastal areas would be classified as Green, Yellow or Red areas. The objective of this classification system is to address the critical importance of proper site selection and utilization to the effectiveness of a regulatory framework for marine-based fin-fish aquaculture.

In general terms, these designations in the proposed classification system would have the following meaning:

- Green areas would be areas found to be generally suitable for fin-fish aquaculture.

- Yellow areas would be areas that have the potential to be suitable but are not ideal and would require a more careful approach to site selection, a more rigorous assessment in the licensing and leasing process, stricter or more limiting terms and conditions for approval and additional regulatory oversight.

- $\quad$ Red areas would be areas found to be generally unsuitable for fin-fish aquaculture.

The criteria for classifying areas as Green, Yellow or Red would be biophysical suitability and the presence or absence of conflicts with other important uses or values and, where conflicts exist, the nature and extent of conflicts with other uses and values. A Green area would be one in which there are biophysical suitability and no serious conflict issues. A Red area would be one at which 
conditions show that it is highly unlikely that environmental standards could be met at the site or that serious conflict issues with other uses could be avoided or suitably addressed through terms and conditions of an approval and regulation. The classification of a coastal area may be different for different kinds of fin-fish aquaculture, reflecting differences in the potential of different kinds of fin-fish aquaculture to cause adverse impacts.

Regulatory approval for fin-fish aquaculture would be unlikely in Red areas and less likely in Yellow areas than in Green areas. Whether regulatory approval would be given for a site in a Yellow or Red area at all would depend on whether the applicant for a licence and lease in such an area is proposing a fin-fish operation that is suitable for a site having Yellow or Red area characteristics. Although Red areas would be generally off limits for the kinds of fin-fish aquaculture for which the Red area designation is applied, the regulatory framework would not preclude the possibility that fin-fish aquaculture could in exceptional circumstances be authorized in a Red area. However, the onus of showing that this is appropriate would be a difficult one to meet.

\section{Process for Applying the Classification System}

An area (or site) could be classified in one of three ways:

1. Through a proactive and general process of classification that operates in parallel to the licensing process,

2. Through a strategic assessment in the nature of a strategic environmental assessment of particular coastal regions, or

3. In the licensing process where an application for a fin-fish licence is made in respect of a site located in a previously unclassified coastal area.

The relationship among these prongs of the process of classification is envisaged to be dynamic. Classification choices made in the general process or through strategic assessment will be taken into account as a fundamental input to the licensing process. Classification choices made through strategic assessment or in the context of an application for a licence would add to the overall progress toward comprehensive classification of the coastline, which will be the main concern of the general or overall classification process. No matter which process is used to apply the classification system, the critical thing will be that classification happens before the application of the licensing process so that classification can be an input to the licensing process.

\section{Effect of Classification as Green, Yellow or Red Area}

Designation of a part of Nova Scotia's coastline as Green, Yellow or Red for a particular form of aquaculture will have the following implications for the regulatory process:

a. First, a proposed operation in a designated area will not have to go through a classification process during the licensing process. Operations proposed for areas that have not been designated will require a determination from the regulator at the start of the licensing process as to whether the proposed site is in a Green, Yellow or Red area.

b. Second, the designation of an area as Green, Yellow or Red will have implications for the process of reviewing individual applications for a licence and associated lease. The 
regulatory process in Green areas will be more streamlined, whereas the process in Red areas will be most onerous.

c. Third, the likelihood of the success of an application will differ. In Green areas, it would be reasonable to expect that licences would be granted for well-designed operations that are sensitive to other users and are proposed in suitable locations. The likelihood of a successful application in a Red area would be low - only projects that were very carefully designed to meet the limitations of the site would have a prospect of being approved.

d. Finally, the terms and conditions under which aquaculture facilities would be licensed to operate would vary. Because of the biophysical constraints and potential social and economic concerns in Yellow and Red areas, operations that do get approved will have to meet additional terms and conditions, such as additional monitoring and reporting obligations.

\section{Strategic Assessment of Coastal Areas}

In addition to being available as a tool for classification of coastal areas as Green, Yellow or Red for fin-fish aquaculture, strategic assessment would also be available for assessing the suitability of coastal areas for shell-fish aquaculture.

The details of the process would vary from application to application, but transparency and full engagement of all interested parties, including the Mi'kmaq, potential operators, other users of the coastal area, other industries, local residents and all levels of government would be required. A key goal of the process would be to integrate biophysical, social and economic analysis for the purpose of evaluating suitability of the area for aquaculture development.

Where strategic assessment does identify areas suitable for aquaculture, the DFA will have the option of proactively encouraging development in those areas. Licensing could happen on a streamlined basis where this is stated to be a possible outcome at the beginning of the strategic assessment and where the assessment determines that development enjoys significant community support.

\section{Licensing (Site Approval) Process}

The licensing mode of regulation should continue to be the mode of regulation used in Nova Scotia. However, we recommend a range of improvements.

We recommend that assessments of an application for a licence should be conducted on the understanding that the assessment must cover all of the ground that an environmental assessment would cover. The licensing process should in other words be conducted as a kind of specialized environmental assessment.

The legislation governing the licensing process should set out the principles that are expected to guide the process. The principles should address the following matters:

a. Compatibility with public rights of navigation

b. Compatibility with fisheries activities, including the lobster fishery

c. Compatibility of the nature and scale of a proposed operation relative to the biophysical, oceanographic and community context 
d. Compatibility with the activities of other users or beneficiaries of the public waters in question

e. Responsiveness to the cumulative effect of aquaculture in the area

f. Contribution of the proposed project to net community socio-economic benefits

We recommend a licensing process that consistently includes the following key elements.

With limited exceptions, the licensing process will start with the issuance of an "option to lease." While in effect, this limited authorization will provide the developer of an aquaculture project with the exclusive right to apply for a licence and lease for the site covered by the option to lease. This is intended to address the concern of industry that requiring a developer to seek input from the community before applying for a lease will give competitors an opportunity to apply for the preferred site ahead of the developer.

The public will be notified by the DFA that an option to lease has been issued. This ensures that the community is made aware of the proposed project from the very earliest stages of the licensing process. This is the first element of the transparency that will be consistently implemented throughout the balance of the licensing process.

To apply for a licence, the holder of an option to lease will be required to participate in a preapplication scoping process that engages with, and seeks input from, the community.

For an application for a licence to be complete, it will have to include a background (or scoping) report that includes information on the scoping process such as overall levels of community support or opposition and community views on proposed location, scale, species, operator and technology; compatibility with existing uses; impacts, benefits, risks and uncertainties; and what the operator should do to minimize adverse impact. The Background Report will also be required to include a detailed description of the proposed operation, a description and analysis of biophysical conditions at the site, the presence of any endangered species, and specific measures to be taken or required to address potential impacts. It will be a public document. It will serve the same purpose as an impact statement in environmental assessment.

The DFA will conduct an application screening process. Input from the public will be received in the form of comments on the application file, including the Background Report. Input will also be received from other regulators, such as the DFO, at this stage of the process. Decision options available at this stage would be to send the application forward for a hearing, to reject it as having no prospect of success at a hearing, or to send it back to the applicant for further work. For fin-fish applications in relation to sites previously classified as Green, Yellow or Red, that classification would be taken into account at this stage of the process. For unclassified sites, the screening will assess whether the information needed for classification is included in the application.

For applications that proceed past the screening stage, a hearing will be conducted on all applications. The hearing will be either an administrative hearing wherein public participation is primarily carried out through the provision of written comments and submissions, or it will be an adjudicative hearing, which includes a more formal in-person hearing. The hearing will be adjudicative where the application is for a fin-fish licence in a Yellow or Red area. Depending on the circumstances, the hearing will be either administrative or adjudicative for shell-fish applications and for fin-fish applications in Green areas. 
The DFA will be required to give reasons that explain how the decision addresses the licensing principles, the regulatory goals and the issues raised at the hearing.

At each stage of the process, the DFA will have the ability to utilize independent third parties in the conduct of the process. A third party could be mandated to conduct the pre-application screening process, to conduct a later consultation, to do an independent study or analysis, to provide advice or to conduct some or all of the hearing.

Licensing decisions will be subject to appeal to the Minister, or alternatively to an independent quasi-judicial Aquaculture Board. From either the Minister or the Board, there would be a further appeal to the Supreme Court of Nova Scotia.

At the application screening stage, the DFA will be required to specify the maximum duration for the overall licensing process and for the completion of the hearing within the overall licensing process. Unless an application is withdrawn, the DFA will be required to complete the hearing and give a decision within the specified time frames.

The DFA's decisions will be subject to appeal, in the first instance to the Minister or the independent aquaculture review board, and in the second to the Nova Scotia Supreme Court.

At the end of this Executive Summary (pages xxiii to xxv), we have included three flow charts that visually show the proposed licensing system process for marine-based salmon operations, marinebased fin-fish operations, and marine-based shell-fish operations.

\section{Changes in the Leasing of Aquaculture Sites}

We recommend the following changes in the administration of leases for aquaculture:

a. Make it clear that holding a lease depends on holding and using a licence.

b. Unused leases should revert to the Crown, at which point they would become available to other potential developers of aquaculture. It should be clear that where an aquaculture operation is discontinued, the lease of the operator reverts to the Crown.

c. A system should be instituted to make information on the location and breadth of existing leases much more readily available to landowners and users of the coastal waters than is currently the case.

d. Lease boundaries should be appropriately enforced even if according to the Coast Guard they do not cause problems for navigation.

e. The exclusivity of the rights of leaseholders needs to be clarified and limited to what is necessary for the purpose of the function of an aquaculture lease. It should be understood that waters that are leased for aquaculture continue, subject to the lease, to be public waters.

f. Protection for rights of navigation should be built into leases.

g. The transfer of leases should be subject to Crown approval.

\section{Security of Tenure for Operators in Good Regulatory Standing}

In response to concerns of the industry that one of the major problems caused to the development of the industry by the current regulatory framework is the limited tenure it provides to licensed operators, we recommend that the tenure of approved aquaculture operations be structured as follows: 
h. The initial licence granted should continue to be for 10 years, and the initial lease should be granted for 20 years, subject to holding a corresponding licence.

i. The initial licence would be reviewed after one growing cycle to determine the success of the operator in establishing and conducting a site that generally meets regulatory requirements, including environmental performance requirements.

j. Renewals should be decided upon through an open, transparent and participatory licensing renewal process.

k. The length of licence renewals should in general be for a term that is comparable to the maximum term for which aquaculture is licensed in other Atlantic Canadian provinces, subject to variation in either direction to reflect environmental performance and the compliance record of the operator.

1. Any licence would always be subject to cancellation for regulatory infractions that would make revocation an appropriate, fair and just sanction.

\section{Transfers, Expansions, Other Changes}

It is important that the process for transferring licences and leases or changes in terms and conditions be clear and also that it be open and transparent.

There should be a requirement for public notification when an application for a transfer of a lease has been made. The public should have the opportunity to submit comments to the Minister on the proposed transfer.

Key factors in deciding whether to approve a transfer should be whether the proposed new owner or operator has a good compliance record, and is likely to deal constructively with other coastal users and affected communities. Similar considerations should guide the process and decisions on expansions, changes in species, and other significant changes to the terms and conditions of an existing licence.

\section{Protection for Wild Salmon}

The legitimate concerns about how the growth and conduct of the industry might impact wild salmon are among the concerns that have led us to make recommendations on a number of core elements of the regulatory framework, including site selection and utilization, fallowing and stocking densities, and fish health and well-being.

The regulatory framework we propose also includes a number of elements that are more specifically directed to the protection of wild salmon. To that end, protection for wild salmon would be listed in legislation as one of the criteria to be considered in leasing and licensing decisions.

The regulatory framework should be clear and explicit about the need for appropriate physical separation between marine-based aquaculture and salmon rivers and known salmon migration routes. While the DFA should continue to rely on the DFO's advice and requirements under the Fisheries Act and the federal Species at Risk Act, it should be a clear element of the regulatory framework that the DFA will go beyond what is recommended by the DFO where the DFA determines that an additional level of protection for wild salmon is appropriate or called for. 
The regulatory framework should deal more extensively with the prevention of escapes, generally along the lines of what has been implemented in Maine, through a requirement for adoption by salmon farms of a comprehensive and integrated containment management system.

\section{Monitoring Compliance and Enforcement Provisions}

In this section of the report, we reiterate the recommendations made in other parts of the reports that will strengthen monitoring or enforcement, or both, while also addressing other issues. We then outline additional enhancements to monitoring and enforcement, as follows:

a. More inspectors fully trained for aquaculture

b. More inspections and more unannounced inspections

c. More capacity to investigate complaints about the compliance of a facility

d. More capacity to carry out aerial surveillance and access to vessels to carry out inspections

e. A broader range of compliance measures and a clear policy on how they are used to ensure compliance, including increased reliance on prosecutions

f. Complete transparency about violations regardless of what compliance action is taken

g. A clear link between compliance performance, and the licensing process, including terms of licences, issuance of new licences, monitoring and reporting obligations, and renewal of licences.

\section{Ongoing Development and Review of the Regulatory Framework}

\section{Ongoing Regulatory Advisory Committee}

We recommend that an ongoing Regulatory Advisory Committee (RAC) be struck and continue to meet at least once a year to advise the DFA on the implementation of aquaculture regulations, on possible changes to the regulatory framework in the future, on significant policy issues relating to regulation as they arise and on the overall effectiveness of the regulatory framework. The RAC could also be a forum for the discussion of emerging issues in the regulation of aquaculture. The RAC should be made up of approximately 10 members, including representation from the Mi'kmaq and the following stakeholders:

- Municipalities

- Aquaculture industry

- Fishing industry

- Coastal communities

- Environmental and conservation organizations

- Economic development and tourism interests

\section{Science Advisory Committee/Network/Mechanism}

We recommend that the DFA establish an ongoing mechanism for consulting with experts on the science of aquaculture and its regulation. However constructed, the idea would be that a standing mechanism would link the DFA with a community of experts in the science of aquaculture to facilitate the DFA's access to their combined expertise. Invited experts should include those who 
hold relevant local and traditional knowledge. Those who agree to participate would have a channel through which to contribute to the effectiveness of regulation, and to decision making in the aquaculture sector more broadly. Our experience suggests that many experts across Atlantic Canada are fully prepared to make this kind of contribution and would welcome an avenue to do so on a continuing basis. This mechanism could also help to identify and support the research needed to fill information gaps and reduce uncertainty and disagreements in understanding of the impacts of aquaculture and the options for addressing them.

\section{Mandatory Independent Five-Year Review}

In Nova Scotia legislation similar to the Fisheries and Coastal Resources Act, a mandatory fiveyear review has proven to be useful in making legislation better. In our view, the same can be expected from a review of a broader regulatory framework - a review that would include any amendments made to the Act and regulations to implement the framework. The review should also encompass the role of the DFA in making the framework operational through licensing and leasing, monitoring and enforcement, and working with the DFO and other federal regulators and scientific and regulatory advisory groups.

\section{Other Issues}

This report deals with a number of other issues:

- Experimental or developmental licences

- Licensing and leasing fees

- The constitution, composition and powers of an independent aquaculture review board

- The site closure and cleanup obligations of licensees

- The relationship of the regulatory framework to industry codes of practice

- The relationship of regulation to third-party certification

- Bay management

- The access of the industry to working capital through the Fisheries and Aquaculture Loan Board or the provincial government

- Emerging issues that the regulatory framework will or may have to face in the near future

\section{Implementation and Transition}

We have concluded that the regulatory framework we propose can be implemented through amendments to the Fisheries and Coastal Resources Act and regulations made under the Act. Applications for new fin-fish aquaculture licences should be processed under the proposed regulatory framework. The proposed regulatory framework should be applicable to the operation of already licensed aquaculture.

The development and implementation of a new regulatory framework for aquaculture should be discussed with representatives of the Mi'kmaq in the forums that exist for those kinds of discussions. 


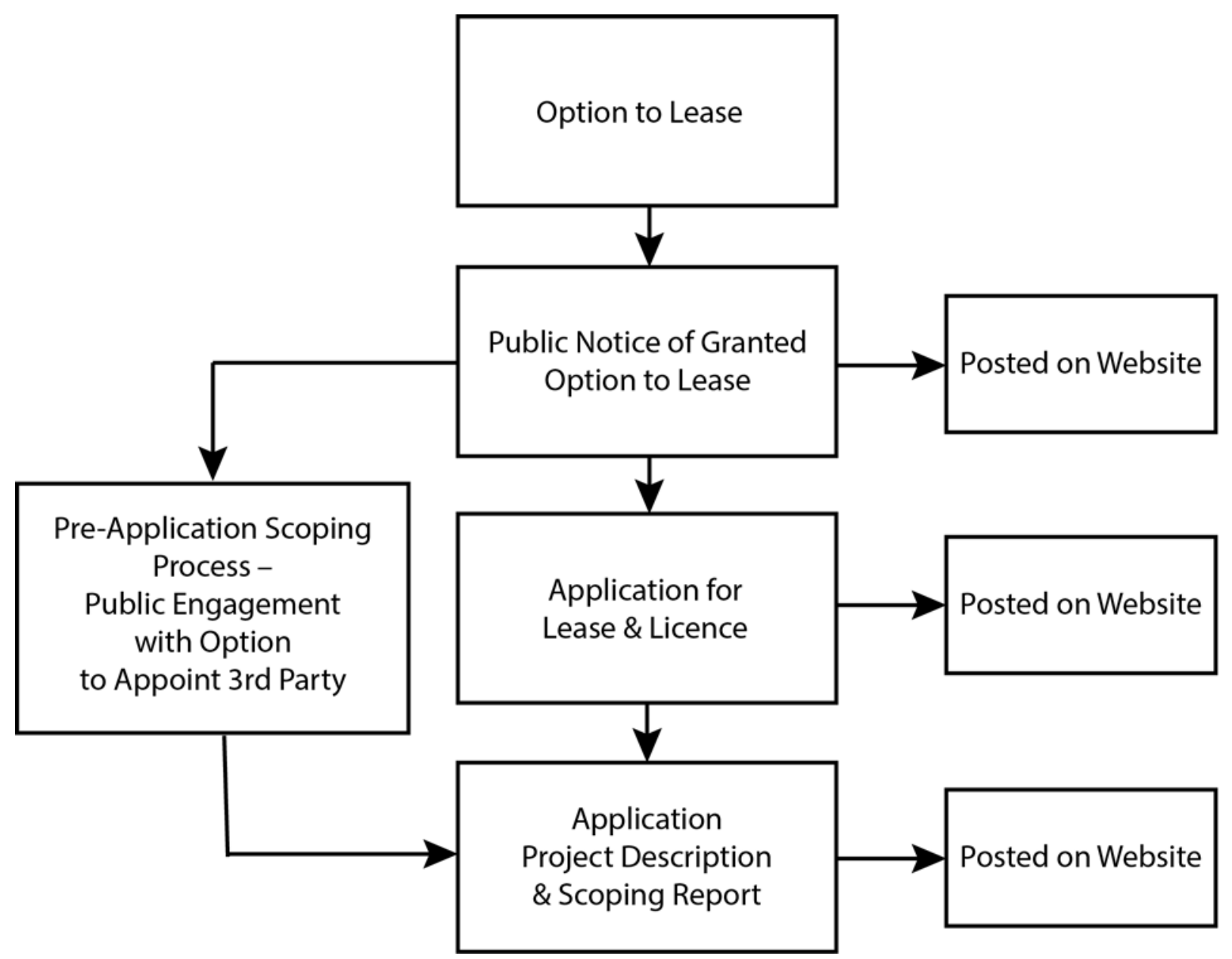

Figure 1: The Pre-licensing Process 


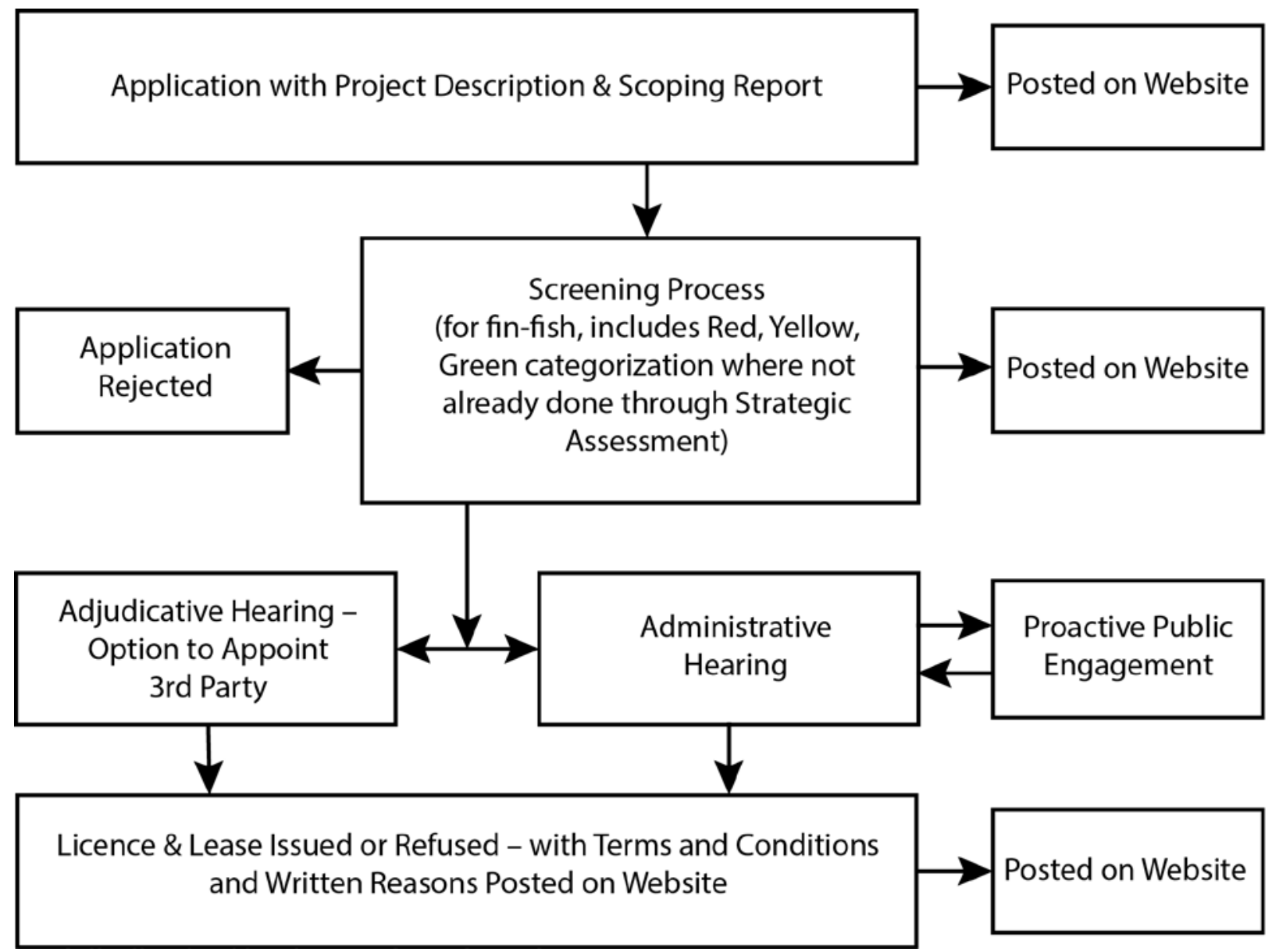

Figure 2: The Licensing Process 


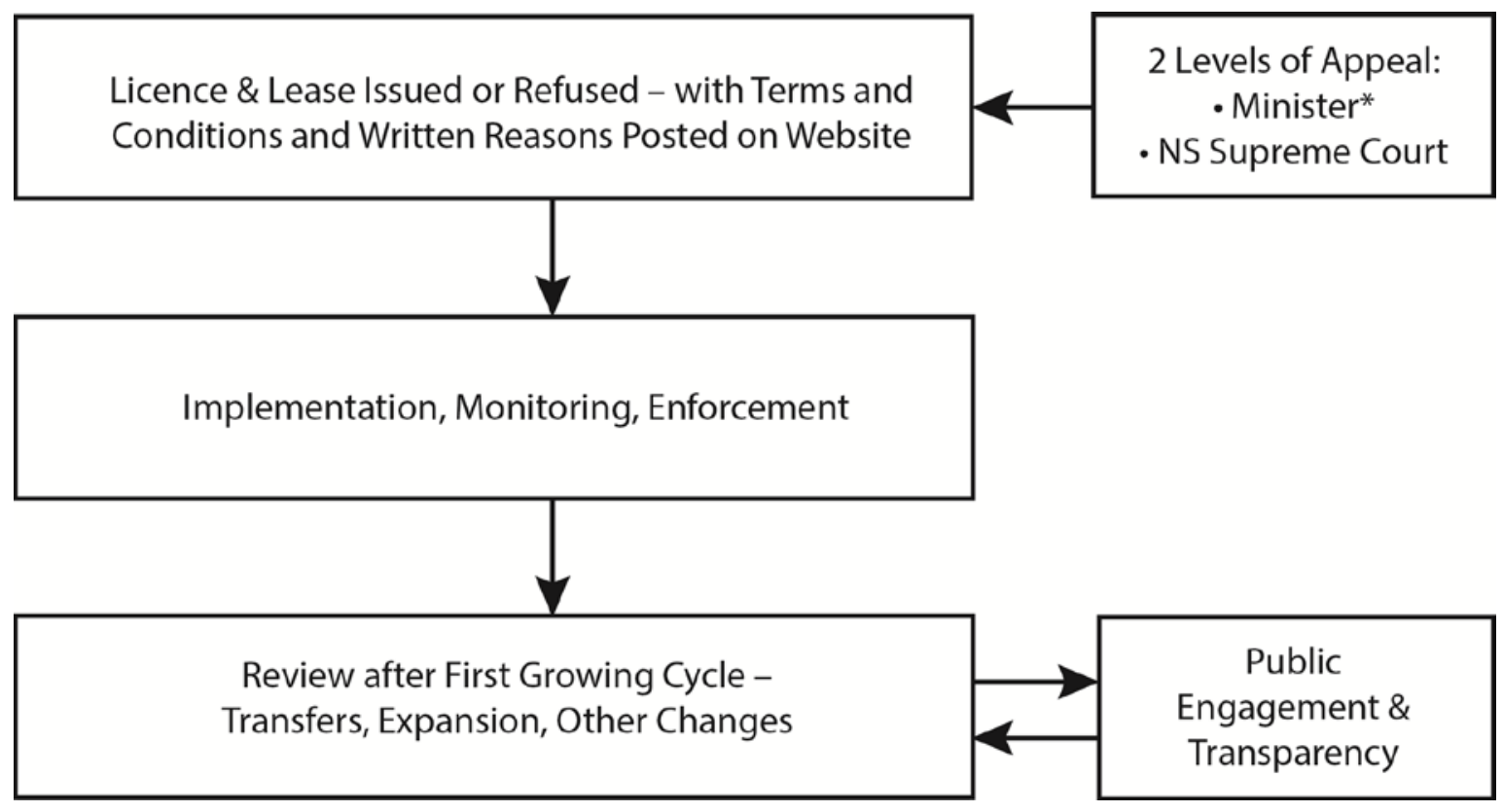

Figure 3: The Post-licensing Process (* This appeal would be to the Aquaculture Review Board if such a board were established.) 
Electronic copy available at: https://ssrn.com/abstract=2463759 


\section{INTRODUCTION}

In April of 2013, we were appointed as a two-person independent panel to "lead the development" of a "regulatory framework for the aquaculture industry that will be state of the art in integrating and advancing environmental protection, social well-being and economic opportunity." ${ }^{1}$ Our mandate, which is available on our website at www.aquaculturereview.ca, encompassed the whole of the industry, including fin-fish, shell-fish and plant-based aquaculture, and both marinebased and land-based operations. Our mandate stressed that we were to develop and follow "a process for carrying out the work of the Panel that is independent, transparent, consultative, collaborative, analytically rigorous and evidence-based.” In designing the process for our work, we were instructed by our mandate to seek advice from "key industry sectors, conservation groups, the Mi'kmaq and subject matter experts.”

Of particular note is that our mandate made specific reference to the Environmental Goals and Sustainable Prosperity Act (EGSPA) ${ }^{2}$ and its goal of integrating environmental protection with economic and social prosperity. Our work was also significantly influenced by the work of the One Nova Scotia Commission, which released its report partway through our process. The conclusions reached by the Commission reinforced the need for us to be conscious in our work of the importance of rural development to the prosperity of the province.

Throughout our process, we met monthly with our Advisory Committee, consisting of Brian Blanchard of the Nova Scotia Aquaculture Association (who replaced Bruce Hancock in the early days of the process), Mark Butler of the Ecology Action Centre, Lisa Fitzgerald of the Nova Scotia Fisheries Sector Council, Roderick Murphy of the Union of Nova Scotia Municipalities, Carl Purcell of the Nova Scotia Salmon Association, Chief Terry Paul of Membertou, and Karen Traversy of the Coastal Coalition of Nova Scotia. The primary role of the committee was to provide us advice on the design and implementation of our process, particularly in the conduct of community meetings, meetings with stakeholders, and establishing and organizing the Roundtable. Notes from the meetings of the Advisory Committee are available on our website.

During the summer of 2013, we held two meetings in each of 21 coastal communities throughout Nova Scotia to learn about the issues people in coastal communities felt we should consider in our work. A summary of what we heard at these meetings, as well as the more-detailed notes we took during the meetings, is available on our website. In very broad terms, we heard a range of concerns about the impact of marine-based salmon aquaculture on the marine environment, ${ }^{3}$ on wild salmon

\footnotetext{
${ }^{1}$ The mandate can be found at http://www.aquaculturereview.ca/sites/default/files/TOR_Panel.pdf.

2 SNS 2007 c 7, as amended by SNS 2012 c 42 [hereinafter "SNS 2012 c 42"].

${ }^{3}$ Throughout this report, we refer to salmon farming as well as fin-fish aquaculture. In many places, we distinguish fin-fish and shell-fish aquaculture as to the two main kinds of aquaculture. In reality, the kind of fin-fish aquaculture we heard about most and by a large margin was marine-based salmon farming, which is why we sometimes use salmon farming and fin-fish aquaculture as interchangeable terms. Where we think that the differences between salmon farming and other kinds of fin-fish aquaculture are important to our recommendations, we have made the distinction between the two. In addition, in the feedback to our draft report, including the feedback received from the Ecology Action Centre (EAC), concern was expressed that we had not explicitly stated that many of the issues associated with marine-based salmon farming are also
} 
populations and on lobsters, lobster fishers and the lobster industry. We heard concerns about how both fin-fish and shell-fish aquaculture can interfere with or disrupt the activities of other users of coastal waters and the character and quality of coastal communities. We heard distrust of and lack of confidence in the industry, the Department of Fisheries and Aquaculture (DFA) other regulators, and the current regulatory framework.

In August of 2013, we established a "Knowledge Roster” of more than 20 people. Members included university professors, scientists who work in industry or for environmental organizations and holders of community and traditional knowledge. At a meeting held at the Schulich School of Law, the Roster created an inventory of the issues to be considered in the development of a new regulatory framework for aquaculture in Nova Scotia. From the Roster, we formed a smaller organizing committee that helped us identify the issues that were most in need of more detailed attention, including what we heard in community or stakeholder meetings or in discussions taking place at the Roundtable. These issues were discussed in Knowledge Workshops to which the broader Knowledge Roster was invited, which we convened in early 2014. Three workshops were held: one on interactions with species other than wild salmon, one on aquaculture and pollution, and the third on interaction with wild salmon. The notes from these workshops are available on our website. ${ }^{4}$ Many members of the Roster also provided written answers to questions posed to the Roster by the Roundtable.

Starting in October of 2013, we conducted more than 20 stakeholder meetings - i.e., meetings with individuals or organizations who either asked to meet with us or were asked by us to meet. Notes from these meetings are available on our website. ${ }^{5}$ We also met in person or via telephone with representatives of the three key governmental organizations involved in regulation of aquaculture in Nova Scotia: the Nova Scotia Department of Fisheries and Aquaculture, the Department of Fisheries and Oceans and the Canadian Food Inspection Agency. In addition, we held telephone meetings with aquaculture regulators in New Brunswick, Prince Edward Island and Newfoundland and Labrador.

In November, we convened the Nova Scotia Aquaculture Regulatory Review Roundtable. The role of the Roundtable was to provide us advice on (a) issues relating to the future sustainable development of aquaculture in Nova Scotia with respect to environmental protection, social wellbeing and economic opportunity and (b) the development of recommendations regarding a new regulatory framework. The Roundtable included Mi'kmaw representatives as well as representatives from the aquaculture industry, the fishing industry, tourism, municipalities, coastal communities, the Nova Scotia Salmon Association, the Ecology Action Centre, and the broader public. Lesley Griffiths facilitated the Roundtable and wrote the report that sets out the

applicable to marine-based trout farming. In our process, it was more typical for participants to refer to salmon farming, but there were also many comments to the effect that salmon farming and trout farming raised the same or similar questions. To the extent that these two kinds of salmonid farming are similar, we intend that our proposed framework would apply to trout farming as well as to salmon farming.

${ }^{4}$ See the "Updates" section.

${ }^{5}$ See the "Updates" section. 
Roundtable's conclusions and recommendations. A copy of the Roundtable's report can be found on our website. 6

Throughout the process, we carried out our own reading and analysis of the grey and academic literature on the aquaculture industry, the issues that regulation of aquaculture should address and the approaches that are being taken in different jurisdictions, or that could be taken, to the regulation of the industry. We commissioned Cecilia Engler, a doctoral student at the Schulich School of Law, to prepare a paper for us on the regulation of aquaculture in Scotland. We commissioned East Coast Environmental Law (ECELAW) to provide us with reports on the regulatory frameworks in place in New Brunswick, Prince Edward Island, Newfoundland and Labrador, British Columbia and Maine. Both Ms. Engler's report and the reports prepared for us by ECELAW are available on our website. ${ }^{7}$

On July 3 we released a draft of this report for public and stakeholder feedback, after receiving feedback from the Advisory Committee on an earlier version of the draft report. We held public meetings to receive feedback on the report in Yarmouth (July 21), Tatamagouche (July 22), Baddeck (July 23) and Halifax (July 24). With the assistance of Chief Terry Paul, we also met on the draft report with representatives of the Mi'kmaq Rights Initiative. We also held meetings with the Department of Fisheries and Aquaculture. In addition, throughout July, August and September, we received written feedback on the draft report. ${ }^{8}$

\footnotetext{
${ }^{6}$ www.aquaculturereview.ca/sites/default/files/RT_Final(VG).pdf. In the feedback to our draft report, we received comments on how we had utilized the report of the Roundtable. Many of these comments were positive and expressed appreciation for the extent of our responsiveness to the Roundtable's recommendations. One comment was negative, expressing concern that we had on various issues adopted recommendations of the Roundtable instead of making our own recommendations. The suggestion seemed to be that we had inappropriately delegated our role to the Roundtable. To be clear, where we adopt a recommendation made to us by the Roundtable, we do so because our own analysis has led us to agree with the Roundtable. In deciding whether we agree with a Roundtable recommendation, one of the factors we have taken into account is the level of agreement for the recommendation that was achieved at the Roundtable itself. For example, it has mattered to us that on a number of matters, the Roundtable made unanimous recommendations. At the same time, based on our own analysis, we make recommendations that are like ones on which there was either qualified or only partial agreement at the Roundtable. Finally, we note that throughout this report, we draw attention to the connections between our conclusions and recommendations and those reached or considered at the Roundtable; we do this solely for the purpose of documenting those connections, whether or not we have made a recommendation like or different from the one made or considered by the Roundtable.

${ }^{7}$ The Scotland report is available under "Updates." The ECELAW reports are available at www.ecelaw.ca/ecelaw-projects/aquaculture.html and at our website under "Updates."

${ }^{8}$ Throughout this report, we address feedback we received on the draft report. We have not tried to be exhaustive in doing so. Instead, we have largely limited ourselves to responding to feedback that indicated a need for (a) greater clarity or elaboration on our part; (b) an adjustment or change to what we had proposed in our draft report; (c) consideration of issues we had not addressed in our draft report; or (d) explanation of the rationale for our conclusions or recommendations.
} 


\section{POLICY CONTEXT AND ISSUES}

\subsection{Regulation, Aquaculture and Nova Scotia's Long-Term Economic, Social and Environmental Objectives}

This document lays out our conclusions and recommendations on a new regulatory framework for aquaculture in Nova Scotia. From the length and detailed nature of the document, it is obvious that we have concluded that the regulatory framework that is needed is fundamentally different from the current one. In other words, we have concluded that the regulation of aquaculture in Nova Scotia needs to be completely overhauled. This is particularly true for fin-fish aquaculture but it is true in important respects for the industry as a whole, especially its role in the life of the communities where it is located or nearby.

In its nature, regulation is about the prevention or reduction of harm. Accordingly, most of this document deals with how the aquaculture industry should be regulated to prevent or reduce the risk of harm that can occur if aquaculture is conducted without due regard for the environment, local communities and the protection and productive use of public coastal resources.

Our mandate, however, was broader. In proposing "a state-of-the-art regulatory framework for the aquaculture industry in NS," the Panel was asked to "strive to make its recommendations in light of the best long-term environmental, social and economic interests of the province, in accordance with priorities, principles, and interests as articulated in relevant Nova Scotia legislation, including the Environmental Goals and Sustainable Prosperity Act.” We approached this broader aspect of our mandate with the awareness, which is built into the Environmental Goals and Sustainable Prosperity Act, that regulation is only one of the tools of governance that governments and societies use to advance long-term environmental, social and economic interests.

Not surprisingly, we heard more in our process about the adverse impact of aquaculture that people wanted the regulation of aquaculture to address than we did about the potential economic or social benefits of aquaculture or its future. Nevertheless, we did hear quite a bit about what the industry was contributing or could contribute to Nova Scotia's economy and about the determinants of the industry's economic success. For example, we heard about the importance of scale to the industry's competitiveness in national and global markets. At the same time, we heard about the importance of diversity, between and within sectors of the industry, to the resiliency and sustainability of the industry and to its ability to create opportunities for entrepreneurs and for rural communities to benefit from the efforts of entrepreneurs. As another example, we heard about innovation that has happened or is occurring in Nova Scotia's industry and about the difficulties - including uneven, uncertain and inadequate support from government - that the industry has faced in growing in Nova Scotia despite that innovation. We heard both about the need of the industry to be current with global trends in productivity and in reducing its environmental footprint and about the importance of avoiding prescriptive regulations that can stymie the industry's evolution and development. 
During our process, the One Nova Scotia Commission completed its work and issued its final report, Now or Never: An Urgent Call to Action for Nova Scotians. ${ }^{9}$ Several of the central messages to be taken from that work are relevant to the broader aspect of our mandate to make recommendations on regulation that address Nova Scotia's long-term environmental, social and economic interests as articulated in the Environmental Goals and Sustainable Prosperity Act. ${ }^{10}$ One of these messages is that Nova Scotia's prosperity depends on businesses that produce value from the province's natural resources. Another is the crucial importance of innovation and entrepreneurship in and beyond the natural resources sectors. A third is the recognition that Nova Scotians expect economic prosperity to be combined with environmental stewardship. A fourth is that Nova Scotia must be prepared to say yes to the economic opportunities it has if it is to reverse the current trend toward long-term economic and social decline.

Putting these core messages of Now or Never together, a larger conclusion is that Nova Scotia's prosperity requires Nova Scotians to excel at developing the natural resources of the province in ways that combine wealth creation with the continuing productivity of those resources and the well-being of the broader environment. This is similar to the philosophy that underlies the Environmental Goals and Sustainable Prosperity Act. ${ }^{11}$ The Act says that the long-term objective of Nova Scotia is to achieve sustainable prosperity, which the Act defines as "seizing today's opportunities without compromising tomorrow, while working together for a strong, competitive economy, a healthy environment and vibrant, thriving communities.” Moreover, Subsection 3(2) of the Act proclaims a number of foundational principles that, like Now or Never, call for integration between economic, environmental and social well-being through innovation, as follows:

3 (2) This Act is based on the following principles:

(a) the health of the economy, the health of the environment and the health of the people of the Province are interconnected;

(b) environmentally sustainable economic growth that recognizes the economic value of the Province's environmental assets is essential to the long-term prosperity of the Province;

(c) the environment and the economy of the Province are a shared responsibility of all levels of government, the private sector and all people of the Province;

(d) the environment and economy must be managed for the benefit of present and future generations, which is in keeping with the Mi'kmaw concept of Netukulimk, defined by the Mi'kmaq as the use of the natural bounty provided by the Creator for the self-support and well-being of the individual and the community by achieving adequate standards of community nutrition and economic well-being without jeopardizing the integrity, diversity or productivity of our environment;

(e) innovative solutions are necessary to mutually reinforce the environment and the economy;

\footnotetext{
${ }^{9}$ The report is available at https://drive.google.com/file/d/0B48TTKtbWS0kQ0syOHZaZW9xaWs/edit?pli=1.

${ }^{10}$ SNS 2012 c 42.

${ }^{11}$ Ibid.
} 
(f) a long-term approach to planning and decision making is necessary to harmonize the Province's goals of economic prosperity and environmental sustainability;

(g) the management of goals for sustainable prosperity, such as emission reduction and increasing the amount of legally protected land will preserve and improve the Province's environment and economy for future generations. ${ }^{12}$

Applying these principles and the concepts underlying both the Act and Now or Never to our mandate leads us to conclude that the kind of aquaculture that fits with the Act and with Now or Never is low-impact/high-value aquaculture. In our view, this is aquaculture that combines two fundamental attributes:

1. A low level of adverse environmental and social impact, which decreases over time.

2. A positive economic and social value from the use of Nova Scotia's coastal resources, which is high and increases over time. ${ }^{13}$

In addition to being consistent with the Act and Now or Never, our work suggests that this may be the only kind of aquaculture Nova Scotia can have if it is to have a successful and growing aquaculture industry. We say this for two reasons.

First, significant market forces are at play suggesting that the growth in demand for farmed fish and seafood, particularly for farmed salmon, will be for fish and seafood that have been produced with low and sustainable levels of environmental impact. These forces include new global certification programs agreed to by major producers of farmed salmon and leading international environmental organizations. They include the move toward higher and more demanding levels of regulation in many of the high-producing jurisdictions such as Norway, Scotland, Chile, New Brunswick and Maine.

Most fundamentally, the forces include growing consumer demand for sustainable fish and seafood products that either drives or is supported by the sourcing of sustainable fish and seafood products by major retailers. No doubt the impact of these forces in the short term can be overstated. But the longer-term direction of change in the market in favour of products that can be credibly branded as sustainable seems self-evident. Although we do not doubt that there will continue to be a market for low-cost high-volume production, we doubt Nova Scotia's competitive advantage in that market or that Nova Scotians would accept aquaculture conducted in a manner required to be competitive in that market.

This brings us to our second reason for suggesting low-impact/high-value aquaculture may be the only option for the industry's future in Nova Scotia. It is unlikely that any other approach to aquaculture can enjoy or maintain the social licence, particularly in coastal communities, that aquaculture must enjoy in Nova Scotia if it is to grow and prosper. While this is true of all

\footnotetext{
${ }^{12}$ Ibid., at s 3(2).

${ }^{13}$ These two fundamental attributes of the proposed framework are broadly consistent with an ecosystem approach for aquaculture (EAA), as articulated in the paper Building an Ecosystem Approach to Aquaculture - FAO Fisheries and Aquaculture Proceedings 14, a report based on a workshop organized by the Food and Agriculture Organization of the United Nations in 2007. There, the ecosystem approach is characterized as "a strategy for the integration of the activity [aquaculture] within the wider ecosystem in such a way that it promotes sustainable development, equity, and resilience of interlinked social and ecological systems.” (iv)
} 
aquaculture, we think it is particularly true of marine-based salmon farming. We base this conclusion largely on what we heard from Nova Scotians who live close to aquaculture, but also on our discussions with national and provincial regulators of aquaculture, on our understanding of the strengthening of regulations taking place in other jurisdictions, on the market forces listed above and on the conversations we have had with a number of people in the aquaculture industry or who work closely with the aquaculture industry.

For these reasons, our conclusion is that a regulatory framework that is both "world class" and consistent with Nova Scotia's long-term environmental, social and economic interests as articulated in the Environmental Goals and Sustainable Prosperity Act is one that is decidedly on the side of low-impact/high-value aquaculture. That is the kind of regulatory framework that is intended by the recommendations set out in the balance of this document. ${ }^{14}$ In consequence, the regulatory framework we propose is intended not only to control the impact of aquaculture but also to contribute to the value that aquaculture can yield. ${ }^{15}$

\subsection{What We Heard about Aquaculture in Nova Scotia in a Nutshell}

Our regulatory review process included a number of opportunities to hear from stakeholders and members of the public. We do not intend to provide a detailed account of what we heard through these various forums, as this information is readily available on our website at www.aquaculturereview.ca. We do think, however, that it is important to offer a summary of some of the high-level views we heard most consistently and are most important for setting the stage for the proposed regulatory framework. ${ }^{16}$ These views include:

- Generally positive views of shell-fish aquaculture

- Many concerns about marine-based fin-fish aquaculture and potential growth of that kind of aquaculture

\footnotetext{
${ }^{14}$ In the feedback received on our draft report, there was generally positive response to our conclusion that the objective of the regulatory framework should be an industry characterized by low impact and high value. We were, however, urged to define what we meant by low impact and high value. For example, the Ecology Action Centre asked us to provide a formula for calculating low-impact/high-value aquaculture and some key indicators. It is therefore important that we clarify that it is not our intent that the phrase low-impact/highvalue aquaculture be used and applied as a free-floating regulatory standard in addition to or independently of the specific regulatory standards we have recommended for specific parts of the regulatory framework, such as licensing or enforcement. Rather, the idea is that the regulatory framework as whole, together with other factors such as changes in the market, must work together to make Nova Scotia's industry one that is increasingly characterized by low impact and high value.

${ }^{15}$ Our thinking here is that the regulation of aquaculture will be more effective if it is guided by a broader vision of economic, social and environmental governance such as that set out in the EGSPA and in Now or Never. This is an approach broadly similar to that set out for the governance of aquaculture in Nathanael Hishamunda et al., Policy and Governance in Aquaculture: Lessons Learned and Way Forward, FAO Fisheries and Aquaculture Technical Paper 577.

${ }^{16}$ For a more complete description of the issues raised and views expressed in the community meetings, see the document entitled "Summary of Issues Identified by Participants in Community Meetings," which is available on our website under "Updates." The notes taken at these meetings by the students who assisted the Panel at those meetings is also available in a separate document on the website under "Updates."
} 
- Many calls for an end to marine-based aquaculture or at least to any further growth in marine-based aquaculture

- Significant support for limiting fin-fish aquaculture to land-based facilities

- Significant support for the view that government should not be subsidizing marine-based aquaculture by funding its development with taxpayer dollars, by compensating operators for destruction of diseased fish or by permitting discharge of waste into the marine environment

- Widespread concern about the capacity and will of the DFA to effectively regulate the industry and especially marine-based fin-fish aquaculture

- Range of industry concerns that the current approach to regulation of the industry is stymying growth

Although there are very different views as to what a better regulatory framework would be, there was widespread support for a better regulatory framework.

\subsection{Environmental Impacts ${ }^{17}$}

As part of our regulatory review process, we engaged with the Knowledge Roster on the key concerns identified in community and stakeholder meetings and by the Roundtable and the Roster itself on the environmental impacts of aquaculture. The key concerns all involved fin-fish operations in coastal waters, specifically salmon farms. The following section summarizes our conclusions on three key areas of concern: benthic impact, water pollution and impact on wild salmon. ${ }^{18}$

\subsubsection{Benthic Impacts of Fecal Matter and Waste Feed}

With respect to benthic impacts from fin-fish operations in coastal waters, the accumulation of fecal matter and waste feed were the concerns most frequently raised by participants in our process. We consulted with members of the Knowledge Roster on these issues as part of a workshop on the

\footnotetext{
${ }^{17}$ In responding to our draft report, the Atlantic Canada Fish Farmers Association (ACFFA) expressed its strong disagreement with this section of the report. It stated, "Contrary to what is stated in the Report, there is, in fact, a body of science that has accumulated over the past ten years that shows that environmental impacts, benthic impact and water pollution are minimal and are being routinely assessed and managed.” Our view is that the impacts in each of these areas are acceptable from a public policy perspective only when aquaculture is conducted responsibly in appropriate locations subject to effective regulation and ongoing efforts to further reduce these impacts.

${ }^{18}$ There are many papers and reports on aquaculture and the environment. We have found the following two documents particularly useful because of their recent publication and because they both survey the voluminous literature: J.A. Hutchings et al., Sustaining Canada's Marine Biodiversity: Responding to the Challenges Posed by Climate Change, Fisheries, and Aquaculture (The Royal Society of Canada: The Academies of Arts, Humanities and Sciences of Canada); and Carol Seals Price and James A. Morris, Jr., Marine Cage Culture and the Environment: Twenty-First Century Science Informing a Sustainable Industry, NOAA Technical Memorandum NOS NCCOS 164. We have also benefited from being referred to many sources on specific aspects of fin-fish aquaculture's relationship to the environment by members of the Knowledge Roster, and in particular by Fred Whoriskey, Cyr Couturier, Inka Milewski and Barry Hargrave, all of whom were particularly generous and helpful in bringing to our attention useful sources. Of course, we alone are responsible for what we have taken from those sources.
} 
impact of aquaculture on marine species other than salmon, which in turn was the subject of a separate Knowledge Workshop.

A key concern with waste feed is that it can contribute to anoxic conditions of the benthic environment below fin-fish cages. It does so because it contains nutrients for bacteria in the benthic environment that then use up oxygen, reducing the availability of oxygen in the benthic environment, which in turn creates less-favourable conditions for a number of marine species.

We learned that waste feed can be reduced significantly through best practices in feeding methods, but it seems clear that some feed will still fall through the cages. The overall impact of waste feed on oxic conditions (containing adequate levels of oxygen) is largely a function of the size of the operation and feeding method in relationship to water depth and flushing, in combination with fallowing periods. The impact of waste feed on the oxic conditions of the benthic environment is relatively smaller than the impact from fecal matter, though waste feed interacts cumulatively with fecal matter.

The amount of fecal matter that reaches the benthic environment below a site is largely a function of the number of fish per site, the age class of the fish and the biophysical conditions of the site. Fecal matter deposit is greatest toward the end of the growing cycle. Of course, as was pointed out to us by a number of participants, the deposit of fecal matter from fish is a natural process. The main issue is the concentration of fecal matter in a given location as a result of an intensive fin-fish operation. The environmental impact from fecal matter is therefore largely a function of stocking and density levels in relation to water depth and flushing, in combination with fallowing periods. ${ }^{19}$

There is also concern about the accumulation of non-natural substances in the benthic environment, which can have adverse impacts on marine life. Possible pollutants include medication from waste feed (antibiotics, SLICE), zinc and copper from waste feed and from anti-fouling agents, and pesticides used to treat sea lice. ${ }^{20}$ As we discuss later in this report, we feel that risks and uncertainties around these impacts warrant a regulatory approach that seeks to minimize, and where possible to prevent, the release of these substances.

\subsubsection{Water Pollution}

Throughout our process, participants expressed concern to us about the impact of fin-fish aquaculture operations on water quality. In particular, we heard concerns about the release of chemicals (such as anti-fouling agents), medication and pesticides into coastal waters. Concerns were also raised by some about fuels and operational discharges, as well as debris and surface wastes from aquaculture operations.

Fin-fish operations in coastal waters contribute to increased levels of zinc and copper through waste feed and from anti-fouling agents used in aquaculture operations. There was general agreement among participants in the Knowledge Workshop on pollution that increased levels of

\footnotetext{
${ }^{19}$ In the NOAA report Marine Cage Culture and The Environment (Price \& Morris), it is stated that "at well flushed sites in deep water and with efficient feed management, ecological impacts tend to be minimal and confined to the area just beneath the cages.” (iv)

${ }^{20}$ See Knowledge Workshop on Pollution report, at pages 3-4, and Knowledge Workshop on Species Other Than Salmon report, at page 2 (under "Updates" at www.aquaculturereview.ca).
} 
zinc and copper are of concern in the marine environment. ${ }^{21}$ There were different opinions as to the extent of the harm posed from the releases of these substances from aquaculture. The contribution each of the two major sources makes to the levels of zinc and copper will very much depend on conditions at the site, and on operational details, such as the feeding method, and the manner in which anti-fouling agents are used. It seems, however, that anti-fouling agents are generally the more significant contributor to the release of zinc and copper into the marine environment, particularly in the water column.

Our conclusion, based on the information we received from the Knowledge Roster, is that the release of these chemicals should be minimized and eliminated where possible. As elaborated later in this report, the chemical treatment of aquaculture equipment to prevent fouling should be prohibited under the new regulatory framework. This, in combination with best practices in feeding methods, should minimize the release of zinc and copper from aquaculture operations. An ongoing goal of further reducing and to eventually eliminate the release of all chemicals, medication and pesticides into the environment should be an objective of the regulatory framework.

Another concern we heard from a number of participants is the release of antibiotics from waste feed and fecal matter into coastal waters. ${ }^{22}$ Concerns associated with this release range from contamination of wild fish to the increase of antibiotic resistance of bacteria. We learned that four classes of antibiotics are approved for use in aquaculture by Health Canada: oxytetracycline, florfenicol, and two types of trimethoprim sulfas. ${ }^{23}$ We were told that oxytetracycline and florfenicol are used but that the trimethoprim sulfas are not. Provincially regulated veterinarians oversee the use of antibiotics.

There was general agreement at the Knowledge Workshop on pollution that bacterial resistance can occur over time and that the accumulation of antibiotics, particularly in the sediment, is a concern. ${ }^{24}$ Minimizing the release of antibiotics, through a combination of feeding practices that minimize feed waste, and minimizing or eliminating the need to use antibiotics, is therefore clearly desirable.

Many participants were similarly concerned about the release of pesticides, both in feed and in the form of "bath treatments." When pesticides are used it is to treat sea lice infestations. The main concerns with pesticides are their acute toxicity, their persistence, and the compounds they break down into. Participants in the Knowledge Workshop on pollution generally agreed that the pesticides approved for use in aquaculture are designed to break down quickly into less harmful substances. Only a few pesticides are approved for sea lice treatment in aquaculture operations in Canada. The number is smaller than in other jurisdictions. Some pesticides approved in other

\footnotetext{
${ }^{21}$ See Knowledge Workshop on Species Other Than Salmon report, at page 2.

${ }^{22}$ On antibiotics, other medications and pesticides, the contributions of Dr. Larry Hammell of the University of Prince Edward Island at the Knowledge Workshops were incredibly helpful to our understanding of the applicable science and veterinarian medicine, as well as of the applicable regulatory systems.

${ }^{23}$ See Knowledge Workshop on Pollution report at page 4.

${ }^{24}$ See Knowledge Workshop on Pollution report at page 1 (summary of discussion).
} 
jurisdictions are not approved in Canada due to concern about their persistence in the environment. ${ }^{25}$

The overall conclusion appears to be that while Canada seems to be taking a more cautious approach to the approval of pesticides for use in aquaculture than some other jurisdictions, there is good reason to make every effort to minimize the use of pesticides. There has not been a confirmed application of pesticides to treat sea lice in Nova Scotia for at least a decade. In other jurisdictions, including New Brunswick, operators have had difficulties managing sea lice infestations at their operations. The use of SLICE (a commercial chemical treatment) in feed has become ineffective in New Brunswick, leaving operators to push for the approval of "bath treatments" of pesticides. Furthermore, an unauthorized application in New Brunswick resulted in a significant kill of lobster. Our conclusion is that the regulatory framework in Nova Scotia must manage the sea lice problem through proper site and species selection, separation distances, and responsible operation of sites, with the goal of avoiding the need for either medicinal treatments or the application of pesticides by "bath treatment."

Other pollution concerns raised include fuels and operational discharges from service vessels, and surface wastes and marine debris from operations. In our view, there is no reason why a well-run operation would result in any significant impact. There is every reason to think that a well-designed and implemented regulatory system will address these concerns.

\subsubsection{Impact on Wild Salmon}

Many of those who participated in our process were very concerned that the growth of marinebased fin-fish aquaculture in Nova Scotia is one more threat to the already threatened Atlantic salmon populations of Nova Scotia's rivers. ${ }^{26}$ This concern was strongly and unequivocally articulated by organizations that are dedicated to the conservation and protection of the Atlantic salmon, including the Atlantic Salmon Federation and the Nova Scotia Salmon Association, and by many local salmon conservation associations across the province. It was also communicated to us by the Ecology Action Centre and by many anglers. These participants in our process were among the strongest advocates for a policy that limited salmon farming to closed-containment systems located on land.

In our Knowledge Workshop on the impact of aquaculture on wild salmon, it was emphasized that wild Atlantic salmon face a range of threats that pose greater danger to the survival and recovery of wild salmon populations than could be posed by marine-based aquaculture, particularly as it is currently practised. It was also emphasized that there is no research showing that the continuing decline in the numbers of wild Atlantic salmon at a population scale is significantly caused by

\footnotetext{
${ }^{25}$ See Knowledge Workshop on Pollution report at pages 1, 3, \& 4.

${ }^{26}$ In the feedback we received on our draft report, the EAC expressed a concern that we had not identified the risk that farmed salmon represent to sea trout populations. Because we heard little on this issue in our process, including at our Knowledge Workshops where participants were given an open opportunity to identify wild species that could be harmed by salmon farming, we are not able to say that the concerns about the potential impact of salmon farming on wild salmon populations apply or do not apply to sea trout populations. All we can do at this point in our process is to acknowledge the feedback we received on this point so that it can be considered and addressed appropriately in the development and implementation of the regulatory framework we propose.
} 
salmon farming. ${ }^{27}$ Rather, the combined effect of more fundamental factors, such as loss of habitat, acid rain, the legacy of historic overfishing and low population numbers, was stressed. ${ }^{28}$

On the other hand, our Knowledge Workshop indicated that particular sub-populations of wild Atlantic salmon have been negatively impacted by marine-based salmon farming. ${ }^{29}$ Research in New Brunswick’s Magaguadavic River has shown that wild salmon were entirely displaced from that river by the late 1990s through the interbreeding of wild salmon with escaped salmon and their offspring. ${ }^{30}$ It was said that this happened when the industry had a much higher number of escapes than it now does. Some debated this on the basis of the number of escapes they believe have recently happened in Nova Scotia. Our view is that even accepting that prevention of escapes is greatly improved, the research shows that salmon farming can seriously harm wild salmon if escapes are not prevented. It is important in this connection that the adverse impact of interaction between escaped farmed fish and wild fish is not only a function of the number of escapes but also of the number of fish in the wild population. With a smaller population of wild fish, a smaller number of escapes may be sufficient to cause an adverse impact on the genetic composition of the wild fish population. This is relevant because the number of salmon left in many of Nova Scotia's rivers is very small compared to the number of fish that would have been present in the Magaguadavic when salmon aquaculture started in southwestern New Brunswick.

In our Knowledge Workshop, the discussion of the concern that marine-based fin-fish aquaculture can harm wild salmon by increasing their exposure to sea lice infestation and to infectious salmon anemia (ISA) was similarly nuanced. On sea lice, it was stated that sea lice levels in Nova Scotia are below the levels at which treatment for sea lice would be required. ${ }^{31}$ It was said that this allows aquaculture to be conducted in Nova Scotia, at least for the time being, without use of the treatments for sea lice that generate some of the concerns about aquaculture's broader impact on the environment and other species. It might also be concluded from our Workshop that ISA may be primarily a concern for the health and well-being of farmed fish. ${ }^{32}$

On the other hand, the harm that sea lice are capable of causing to wild salmon was not questioned in our Workshop or, for the most part, in any other part of our process. It is also possible, as some suggested to us, that the current low prevalence of sea lice is, at least in part, due to the relatively

\footnotetext{
${ }^{27}$ This assessment appears to be broadly consistent with the conclusions of the Cohen commission on the decline of the sockeye salmon population in the Fraser River Valley, which are that the decline could not be clearly attributed to salmon farming or to any other specific cause: see The Honourable Bruce I. Cohen, The Uncertain Future of Fraser River Sockeye: Volume 2 - Causes of the Decline (Commission of Inquiry into the Decline of Sockeye Salmon in the Fraser River, 2012).

${ }^{28}$ See Knowledge Workshop on Salmon report at pages 1-7.

${ }^{29}$ See Knowledge Workshop on Salmon report at page 2.

${ }^{30}$ See J.W. Carr et al., "The occurrence and spawning of cultured Atlantic salmon in a Canadian river," ICES Journal of Marine Science 54: 1064-73.

${ }^{31}$ See Knowledge Workshop on Pollution report, at page 4, and Knowledge Workshop on Salmon report, at pages 5-7. In response to our draft report, some contested the accuracy of this statement, while others stated we had given inordinate and unjustified attention to sea lice, given that it is not a problem in Nova Scotia. In providing feedback to our draft report, the ACFFA noted that the Aquaculture Activity Regulations to be adopted under the Fisheries Act will require public reporting on all sea lice treatments.

${ }^{32}$ See Knowledge Workshop on Salmon report at pages 3-5.
} 
limited scale and wider distribution of the industry in Nova Scotia. In any event, Nova Scotia's objective should be to ensure that sea lice do not become a problem for farmed salmon or wild salmon in Nova Scotia.

On ISA, we were told that current research suggests that farmed salmon are more likely to contract pathogenic strains of ISA from wild salmon than the other way around and that wild salmon have greater resistance to ISA than do farmed salmon. We heard that ISA is not easily transmitted between farmed and wild fish. On the other hand, the Workshop discussion also made it clear that there is no definitive knowledge as to how the disease moves between farmed and wild populations or as to the severity of the risk it presents to wild salmon. ${ }^{33}$

On both the sea lice and ISA risk, we attach importance to the statements made in our Workshop and elsewhere in our process that the risk to wild salmon (as well as to farmed salmon) may increase and become more difficult to control if salmon farming is allowed to develop in too concentrated a fashion. There was also broad agreement with the view that both of these risks, along with the risk of genetic disruption through interbreeding, warranted some level of physical separation between fish farming and wild salmon habitat and migration routes. While this point was made in the context of a discussion about protection of wild salmon from farmed salmon, it seems to us that it may also be important to the protection of farmed salmon from wild, at least where the number of wild salmon is large enough to increase sea lice or ISA risk to farmed salmon.

Another consideration is important to our conclusions on the emphasis that the regulatory framework should place on the protection of wild salmon. It is crucial to keep in mind the threatened status of the wild Atlantic salmon population. Some populations of Atlantic salmon have been declared an endangered species, and other populations, including some in Nova Scotia, either are or are likely to be considered for the same designation. But whether individual populations are or are not formally declared to be endangered, all wild salmon populations in Nova Scotia are clearly in jeopardy. In our view, this calls for a precautionary protective approach to all human activities that potentially add to the difficulty facing the wild salmon population, including aquaculture. ${ }^{34}$ The fact that other activities also need to be better controlled if salmon populations are to be protected and have a chance to recover is a good argument for better management or regulation of those activities but not a good argument for developing or conducting aquaculture on the basis that the risk it poses to wild salmon populations is small or unimportant. If the cumulative adverse impact is significant, any human activity that contributes to the cumulative impact is of concern.

\footnotetext{
33 Ibid.

${ }^{34}$ In their response to our draft report the ACFFA stated, "It is not accurate or science-based to conclude that salmon farms have had a significant impact on wild salmon populations in Nova Scotia.” We have not reached that conclusion, nor do we base our recommendation on that conclusion.
} 


\subsection{Request for a Permanent Moratorium on Marine-Based Fin-Fish Aquaculture}

We were urged by many to recommend a permanent moratorium on licensing of additional fin-fish aquaculture sites in coastal waters. ${ }^{35}$ Almost as often, we were urged to recommend the discontinuation of existing marine-based fin-fish operations. We were told that these recommendations were warranted for multiple reasons, including the adverse impact of fin-fish aquaculture on the marine environment and coastlines; the risk that fin-fish operations pose to wild salmon populations; the incompatibility of fin-fish aquaculture with the fishing industry, particularly the lobster fishery; the negative impact of fin-fish aquaculture on the lives of those who live on the coastline in proximity to fin-fish sites; and the inability of regulation, even of good regulations effectively enforced, to address the problems. ${ }^{36}$

Usually, those who proposed a permanent moratorium argued that fin-fish aquaculture should be restricted to contained facilities located on land. ${ }^{37}$ The primary rationale was to avoid the pollution of the marine environment associated with marine-based operations, and concern about risk to wild salmon populations. ${ }^{38}$ In effect, proponents of limiting fin-fish aquaculture to land argued that because of the adverse impacts of marine-based operations and the technical and economic viability of contained land-based systems, the latter should be the only kind of fin-fish aquaculture allowed. ${ }^{39}$ In opposition to these views, some people in the industry argued that a land-based industry was not technically or economically viable, at least not at the scale needed to replace the marine-based salmon farming industry. 40

\footnotetext{
${ }^{35}$ There was partial support at the Roundtable for the recommendation that "the Province should not approve new open-pen finfish operations until the new regulatory regime is in place.” (Roundtable Final Report, 22)

${ }^{36}$ See the ECELAW report Aquaculture Regulation in Nova Scotia: Overview of the Regulatory Framework and Considerations for Regulatory Reform, at pages 7-11, for more discussion of the calls for a moratorium and about public concern about for aquaculture projects more generally, particularly within the context of the need for more transparency.

${ }^{37}$ This view was not adopted by the Roundtable, as a recommendation along these lines ("No new open-pen operations should be approved, and all existing open-pen operations should be removed from coastal waters within five years") was not supported, with more no votes than yes and maybe votes combined. (Roundtable Final Report, 23)

${ }^{38}$ This can be seen in the recommendation, which received partial support at the Roundtable, that "the regulatory framework should encourage and facilitate the development of closed containment aquaculture operations to reduce waste, disease and parasite transfer to wild fish populations.” (Roundtable Final Report, 22)

${ }^{39}$ There was partial support for a recommendation that the province "commission a detailed comparison of the economic, social and environmental impacts of closed containment and open pen fish farming to include true cost evaluation.” (Roundtable Final Report, 16)

${ }^{40}$ There is a range of views on the viability of land-based systems. The Gardner Pinfold study Feasibility of Land-Based Closed-Containment Atlantic Salmon Operations in Nova Scotia noted that closed-containment salmon aquaculture is recognized to be technically feasible, but concluded that it is not financially feasible, "given current cost estimates and price assumptions used in this report" (p. i). The DFO studied closed containment in the context of British Columbia in 2010 and found "a positive net income" for both closedcontainment and marine-based aquaculture but noted that the former is "considerably more sensitive to market forces" largely as the result of "high initial capital investment and subsequent associated costs" (p. vi). The Conservation Fund's Freshwater Institute and the Atlantic Salmon Federation looked at feasibility in
} 
Our mandate assumes the continuing existence of an aquaculture industry to be regulated. Nova Scotia can, however, have an aquaculture industry with or without marine-based fin-fish aquaculture and with or without expanding this sector of the industry. We have carefully considered the views expressed to us, particularly those from people with residences close to marine-based fin-fish aquaculture sites, that Nova Scotia's new regulatory framework should regulate marine-based fin-fish aquaculture by prohibiting it or its expansion.

Our conclusion is that the regulatory framework should not be prohibitory. Our reasons are as follows:

- The risks associated with this kind of aquaculture, while serious, do not warrant a prohibitory approach, provided that they are otherwise addressed by responsible operation and by a robust regulatory framework.

- The risks and impacts associated with marine-based fin-fish aquaculture can be significantly reduced through effective regulations. ${ }^{41}$

- Through incremental development and continuous improvement to minimize negative environmental and social impact while maximizing benefits, marine-based fin-fish aquaculture has the potential to make an important contribution to sustainable prosperity in Nova Scotia.

- A diverse industry that includes marine-based operations and land-based operations is more likely to be resilient in responding to future changes, including changes in market conditions and climate change.

- A prohibitory approach would apply a different standard to aquaculture than is applied to other industries that pose comparable levels of risk and that are regulated under regulatory frameworks that do not prohibit but regulate.

- In the context of our mandate to develop a regulatory framework that integrates environmental, social and economic objectives and the conclusions of the One Nova Scotia Commission on the state of Nova Scotia's economy, the potential contribution of marinebased fin-fish aquaculture to Nova Scotia's economy calls for a policy approach that addresses the risks through responsible development and robust regulation rather than prohibition.

their report Freshwater Growout Trial of St John River Strain Atlantic Salmon in a Commercial-Scale, LandBased, Closed-Containment System (Summerfelt et al.) and concluded that closed containment was technically feasible, finding that "Atlantic salmon can be reared from port-smolt ( 340 g) to harvest size (4$4.6 \mathrm{~kg}$ ) within approximately 12 months in a land-based, freshwater, closed-containment system.” (p. 6)

${ }^{41}$ A good deal of the feedback we received on our draft report questioned our conclusion that marine-based fin-fish aquaculture can be effectively regulated, but we stand by that conclusion. It seems clear to us that it is a conclusion reached by many others, as indicated by the NOAA report Marine Cage Culture and The Environment (Price \& Morris), which notes that concerns about the "potential impacts to water quality, sediment chemistry, benthic communities, marine life and sensitive habitats" (ii) can be addressed in the context of the Agency's role in implementing "policies and regulations which safeguard our marine and coastal ecosystems" (i), and other documents. The critical issue is the effectiveness of the regulation. 
At the same time, we conclude that the regulatory framework for aquaculture needs to be greatly strengthened in preventing fin-fish aquaculture from taking place in coastal waters that are not suitable for that kind of aquaculture.

In reaching these conclusions, we have not accepted the argument made by some that land-based closed-containment systems are not a viable option in salmon aquaculture. Based on all we have heard, we think this sector holds considerable promise, and the viability of such systems is still in the process of being determined as market conditions evolve and innovative entrepreneurs work to respond to the growing market demand for sustainably produced salmon. In that context, we think Nova Scotia is fortunate to have significant activity taking place in its aquaculture industry on landbased closed-containment systems. Through our process, we heard often about the activities of Sustainable Blue, which is working with new technology to become one of the first companies in the world to grow salmon at a commercial scale in a land-based system. We also learned that the Nova Scotia industry includes people who worked on some of the earliest projects done anywhere in the world on the application of closed-containment systems to salmon farming, which happened in Nova Scotia. Meanwhile, land-based systems are being used in Nova Scotia to produce Arctic char, trout, halibut (juveniles and adults) and Atlantic salmon smolt. Assuming viable commercialscale closed-containment systems are going to be developed somewhere, it could be a tremendous benefit to Nova Scotia's future in aquaculture if that were to happen in Nova Scotia. For that reason, we think one of the objectives of Nova Scotia's efforts to develop its aquaculture industry should be to establish the Nova Scotia industry as a leader in the development and deployment of closed-containment systems for salmon aquaculture.

We do not, however, accept the argument that marine-based fin-fish aquaculture should be prohibited if and when closed-containment systems are shown to be technically and commercially viable. What we have heard leads us to conclude that even if the commercial viability of closedcontainment options is established, it will be a long time, if ever, before they are capable of producing the volume of salmon currently demanded by the market and produced by the marinebased industry. Provided that Nova Scotia's marine-based industry is conducted responsibly subject to robust regulation, we do not think Nova Scotia should limit itself to one kind of salmon aquaculture when and if the commercial viability of land-based systems is established. Instead, we agree with those who submitted to us that the relationship between marine-based and land-based systems could be economically synergistic if Nova Scotia were to aim to be at the leading edge of developing closed-containment systems and low-impact marine-based salmon farming. This would build and reinforce Nova Scotia's brand as a leader in the sustainable farming of salmon, whether done at sea or on land. In that world, Nova Scotia's closed-containment and marine-based farmers might both sell more product than each might otherwise.

It is critical that we stress the following point: our conclusion that we should not recommend a permanent moratorium assumes the adoption and effective implementation of the regulatory framework we have outlined in this report.

\subsection{Fin-Fish versus Shell-Fish}

Our mandate was to develop a regulatory framework for the whole of aquaculture, not just for finfish aquaculture. This means our mandate extends to the shell-fish industry, which includes the producers of oysters and mussels. It also extends to plant aquaculture, where Nova Scotia is a 
leader largely due to the success of Acadian Seaplants. However, although we heard lots about finfish aquaculture and a good deal about shell-fish aquaculture, we heard very little about plant aquaculture.

Currently, the legislative framework for the regulation of aquaculture found in the Fisheries and Coastal Resources Act subjects fin-fish and shell-fish aquaculture to the same regulatory framework. The differences between the two branches of the industry, particularly in the nature and level of risk each poses to the environment, is addressed in the administration of the regulatory framework through the licensing process. Specifically, they are reflected in the different terms and conditions that get written into the licences for each.

Our process suggested that concerns about the environmental impact of aquaculture are largely focused on fin-fish aquaculture. More broadly, it suggested that opposition to growth in aquaculture is concentrated on fin-fish aquaculture and is much more intense in relation to fin-fish aquaculture than to shell-fish aquaculture. In addition, we heard positive things about how shellfish aquaculture is perceived much more frequently than we heard positive things about the perception of fin-fish aquaculture.

At the same time, we heard similar concerns about how shell-fish and fin-fish aquaculture are regulated in relation to the impact of aquaculture on communities and other users of coastal waters. For example, although the concerns were more intensely and consistently expressed relative to finfish aquaculture, we heard concerns in communities close to both kinds of aquaculture regarding inadequate transparency about proposed aquaculture developments, inadequate opportunities for community participation in the regulatory process, and inadequate response to community concerns about the impact of aquaculture on boating and other recreational activities, fishing and the beauty of coastal waters.

The regulatory framework for aquaculture needs to treat fin-fish and shell-fish aquaculture differently as regards their respective potential impacts on the environment. We also think, however, that improvements in the regulatory framework relative to the potential impact of aquaculture on communities, including the opportunities the framework provides to citizens to be informed about and to participate in the regulatory process, should in general be applicable to both kinds of aquaculture. Even there, however, some attention needs to be given to the differences between the two kinds of aquaculture, including the smaller scale of many shell-fish operations.

\subsection{Regulation and Scale of Operation}

A related but distinct issue is the interaction between regulation and the structure of the aquaculture industry. On the one hand, we heard that the salmon farming industry is increasingly dominated by industrial-scale operations. This scale of operation can increase the nature and scale of environmental risk associated with salmon and others kinds of fin-fish aquaculture. It therefore leads to calls for increases in regulatory oversight and for tighter and more demanding regulatory requirements.

On the other hand, we heard that heightened regulatory requirements tend to be much more burdensome for smaller operators than for larger ones. The result of across-the-board increases in regulatory requirements designed to address the risks associated with larger-scale operations can be to increase the competitive advantage that large-scale operators already have over smaller-scale 
operators. It was pointed out to us that this could be somewhat ironic in a Nova Scotia context, given the level of support we heard for smaller-scale indigenous companies that many people say are the kinds of companies that should be supported.

The dynamic relationship between operational scale and regulatory responses to operational scale are well recognized in the literature on regulatory design and administration. ${ }^{42}$ Particular attention is paid to the problem that heightened regulatory requirements present to small and medium-sized enterprises (SMEs). Any good regulatory framework needs to grapple with these dilemmas, while recognizing that there are no simple or comprehensive solutions. Large-scale operators must be appropriately regulated. At the same time, regulation must be feasible not only for them but for smaller operators too.

A range of options is available to achieve and maintain the necessary balance between these objectives. One is to ensure that the requirements imposed by the regulatory framework on large and small operators are proportionate to the risks that the framework is intended to control. This minimizes the extent to which the additional burden the framework places on small operators is unnecessary. A second option is to ensure the framework leaves regulated organizations with reasonable levels of flexibility as to how they implement or meet the regulatory requirements. This gives smaller operators the opportunity to adopt approaches to implementation that are more feasible for them than the approaches followed by larger organizations. A third option is for the regulatory agency, often in partnership with industry associations, to invest in programs that assist SMEs in meeting their regulatory obligations. This responds directly to the issues of capacity that often are the core barriers faced by smaller organizations when they are faced with higher regulatory requirements. ${ }^{43}$

Each of these options has informed the development of our proposed regulatory framework for aquaculture on Nova Scotia, and needs to inform the more-detailed design and implementation of the regulatory system for aquaculture.

\subsection{Prescriptive versus Performance-Based Regulation}

Above, we note that use of regulations that require performance (i.e., outcomes) rather than compliance with prescriptive rules is one of the options for designing a regulatory framework that works for both large- and small-scale businesses. In the feedback we received to our draft report, we were urged to reconsider the extent to which we had then proceeded to recommend a regulatory

\footnotetext{
${ }^{42}$ See, for example, Neil Gunningham, “Regulating Small and Medium Sized Enterprises,” Journal of Environmental Law (2002) 14(1): 3-32.

${ }^{43}$ We think it is important that we stress the option that is not considered in this paragraph, which is to design different regulations for large companies and for small companies. This is because in the feedback we received on our draft report, it was clear that some thought this is what we were suggesting or asked for clarification as to whether this is what we were suggesting. We agree with the concern that prompts this feedback: that treating small and large companies engaged in activity that presents the same risk of adverse impact differently on the basis of company size is unfair, leads to arbitrary and hard-to-justify distinctions and is also likely to distort business decision making. On the other hand, we think that differences in the scale of operations, whether the operations are owned and operated by large or small companies, can be relevant to what is required by regulation to the extent that differences in scale mean differences in the nature and extent of the risk of adverse impact.
} 
framework that was viewed as being too or unnecessarily prescriptive. We therefore think we should make a few comments on the general question of prescriptive and performance-based regulation.

First, it is obvious to us that the regulation of aquaculture must unavoidably include a significant element of performance-based regulation. Licensed operators are in control of aquaculture sites, not DFA or federal regulators, and no increase in the intensity of regulation could change that. The Environmental Monitoring Program that currently exists in Nova Scotia, which is like the monitoring programs that exist in other jurisdictions, reflects this reality. It is the core tool the regulatory system uses to hold operators accountable for exercising their control over licensed sites in ways that achieve the outcomes the regulatory system wants in the area of environmental performance. It is also a very good example of performance-based regulation.

Second, contrary to the view of some that either prescriptive regulation (often called command and control regulation) or performance-based regulation is inherently and always superior to the other, the literature suggests that each mode of regulation has a different combination of strengths and weaknesses that makes one of them more suitable or called for than the other in different circumstances. ${ }^{44}$ Further, the literature suggests that the effectiveness of regulation often depends more on how prescriptive and performance-based regulation are combined to work together than on whether a regulatory system is in general a prescriptive or a performance-based system. ${ }^{45}$ These points being made, we recognize that performance-based regulation plays an important role in industries that, like aquaculture, are not generally amendable to point-source discharge regulation and in which interaction between the regulated activity and the environment varies significantly with site-specific conditions. ${ }^{46}$ Another relevant advantage of performance-based regulations is their generally greater capacity to evolve as knowledge, conditions and technology evolve.

Third, what is prescriptive and what is performance-based is often a subjective thing. For example, we understand we are proposing changes to the licensing process for aquaculture in Nova Scotia that will make the process of licensing more prescriptive then it currently is. At the same time, the process we propose is performance-based in multiple ways. It will, for example, require applicants for a licence to show high performance in engaging with, and building constructive relationships with, communities.

Fourth, for reasons laid out throughout this report, we think the regulatory framework for aquaculture in Nova Scotia needs to be more prescriptive in a range of its elements than it currently is. This is particularly important in respect to the process of regulation and the basic standards or outcomes that the regulatory system should achieve. At the same time, it is critical to the framework's success that it continue to be performance-based in light of the key reality that

\footnotetext{
${ }^{44}$ See, for example, Gunningham, “Environment Law, Regulation, and Governance,” Journal of Environmental Law (2009) 21(2): 179-212.

${ }^{45}$ William Howarth, "Global Challenges in the Regulation of Aquaculture," in David VanderZwaag and Gloria Chao (eds.), Aquaculture Law and Policy: Towards Principled Access and Operations, p. 13.

${ }^{46}$ Neil Craik, Subsidiarity and Environmental Federalism: The Emergence of "New Governance” in Finfish Aquaculture in Canada."
} 
aquaculture's success in meeting the objectives of the framework will ultimately depend on how it is developed, managed and conducted by the industry.

Finally, in light of the feedback we received on performance-based versus prescriptive regulation, we have adjusted some of our specific recommendations in order to ensure we have the right combination between the two kinds of regulation. Specifically, in recommending a change of the basic architecture of the system from one extensively based on administrative discretion to one more strongly based on legislated responsibilities, we have adjusted, where appropriate, the language we use to leave appropriate and necessary scope for administrative decision making, adaptability and flexibility. The key rationale for these adjustments, which are noted where they have been made, is to ensure that the proposed regulatory framework has both the strength of a more-detailed statutory foundation and the necessary scope to deal with the variable and changing conditions in a diverse industry.

\section{FOUNDATIONAL ELEMENTS OF THE REGULATORY FRAMEWORK}

A regulatory framework includes, but is much more than, the rules of regulation. Regulation encompasses rules (and other kinds of regulatory standards), but it also encompasses the policy choices behind those rules and standards and the entire process by which the rules and standards are implemented and enforced.

The effectiveness of a regulatory framework therefore depends on many variables and factors in addition to the content of the rules and standards. Our process leads us to conclude that the current regulatory framework is not working optimally because of a number of factors that will not be addressed by changing the rules of aquaculture in Nova Scotia. Although we think changes in the rules are also required, these changes will not be effective in producing the improvement in regulation that we think is required unless these other factors are addressed.

\subsection{Attitudes}

The regulation of aquaculture in Nova Scotia reflects an attitude within the provincial government that needs to change if regulation is to become effective and trusted as being effective. The attitude in question is one that assumes that the concerns held by members of the public and local communities about the impact of the industry, especially about the environmental impact of marine-based fin-fish aquaculture, are overstated, unsubstantiated and based on a not-in-mybackyard syndrome. It is an attitude that is too quick to blame opposition to the industry on those complaining and not sufficiently critical of the industry's responsibilities for the opposition it faces. In the regulatory process, these attitudes manifest themselves as insufficiently rigorous and transparent regulation, which often ends up being understandably perceived as more concerned with defending the industry from its opponents than keeping the industry accountable for its performance and impact.

Within the industry, we saw evidence of a similar set of attitudes at play. To be fair, we heard many people from the industry speak of the industry's accountability for the opposition it faces, 
and also to the role that the industry must play in gaining and maintaining public and community support. But we also detected a tendency to portray opposition as illegitimate, in some cases because it came from those who summer in Nova Scotia but do not live here year-round or because it was perceived as being orchestrated or bankrolled by national and international environmental groups that are dedicated to the destruction of the industry for ideological reasons. Sometimes, it was suggested to us that the difficulty the industry faces in getting new sites approved by regulators is the reason why the industry has lost social licence, overlooking the more likely possibility that the industry's loss of social licence accounts for the difficulties the industry increasingly faces in a regulatory process that seems to us to be geared to support the growth of the industry.

From the community perspective, we of course recognize the right of members of the public to hold whatever views they wish to hold about the industry or the role of the government in promoting it or regulating it. We are particularly aware that many who spoke to us live close to aquaculture operations while we do not, and that for many, frustration with the current regulatory process has understandably shaped their current view of the industry. That said, we are left with the view that the demonization of the industry we sometimes heard occasionally came close to overshadowing the very real problems we heard about that the regulatory framework must clearly address.

Some of the calls for regulatory protection that were conveyed to us were disproportionate to the risks posed by aquaculture and to how comparable levels of risk created by other industries are addressed. We not only understand the inability of regulators to meet those expectations, we also question whether it would be sensible public policy for them to do so given the level of resources such an effort would require. We also must comment that although there are very real and legitimate concerns about the impact that certain kinds of aquaculture may have on other ways of making a living, we question the unwillingness we sometimes heard to acknowledge any value in the wealth and jobs created by aquaculture, an industry that has been in the province for at least 40 years and that is currently worth almost $\$ 50$ million dollars in annual sales. ${ }^{47}$

Sometimes, this unwillingness seemed to reflect the kinds of attitudes to economic development that the One Nova Scotia Commission concluded are working against Nova Scotia's very viability as a province. It seems clear to us that for the benefit of all Nova Scotians, it will be critical that a new regulatory approach to the industry be accepted by those suspicious of the industry - both as a fresh start and as an opportunity by government and industry to establish constructive relationships with local communities and other users of coastal waters. While changes in attitude within government and industry are a precondition for progress, an openness to change among those who have felt disenfranchised by the regulatory process in the past will be a critical ingredient to reaching the goal of ensuring that aquaculture contributes to sustainable prosperity, particularly in rural Nova Scotia.

\footnotetext{
${ }^{47}$ As was pointed out to us during the public meetings we held to receive feedback on our draft report, this number does not reflect the net economic benefit to Nova Scotia. It is merely a number that offers a sense of the size of the industry.
} 


\subsection{Social Licence}

Social licence refers to the informal permission that society or a segment of society, such as a local community, does or does not give to an industry, an activity or a project. The relationship between social licence and formal regulation is complex. On the one hand, effective regulation can help to create, reinforce and sustain social licence. On the other hand, the presence or absence of social licence can be one of the key determinants of the effectiveness of regulation.

Our conclusion is that the aquaculture industry in Nova Scotia, particularly marine-based salmon farming, has a social licence problem. ${ }^{48}$ Fair or unfair, this reflects a perception that the industry is a significant polluter of the marine environment, using practices that are not sustainable for ecosystems, or the health of the fish that are farmed, or the wild fish or other aquatic life that comes into proximity with "open-net pens," frequently called "feed lots" by their detractors.

In our process, we heard polarized views on the question of social licence. From an industry perspective, the message sometimes seemed to be that social licence depends on industry and regulators staring down the unreasonable opposition and working with those in society who are prepared to have an open mind and to accept the facts. From an oppositional perspective, we sometimes were flatly told that no amount of regulation could solve the social licence problems of an inherently unsustainable industry. But from both perspectives, we also heard many more nuanced opinions that recognized the vital contribution that regulation could make in helping the industry's social licence problem by helping the industry avoid or fix the problems it has encountered in the past.

Our conclusion is that for fin-fish aquaculture to develop in Nova Scotia, the social licence problem will have to be addressed. If the development of fin-fish aquaculture continues in the absence of improved social licence, there is a real possibility that the social licence of aquaculture in general may come into doubt. Already, we see some evidence of that happening. Our process leads us to the conclusion that the social licence problem is deeper than the ineffectiveness and non-responsiveness of the current regulatory framework. But it also leads us to conclude that the social licence issue cannot be addressed unless the effectiveness of the regulatory framework is significantly improved and is seen to be improved in visible and tangible ways.

This does not mean additional levels and layers of regulation and oversight for the purpose of showing an increase in regulation. Even if that approach mitigated the social licence gap, which is unlikely, it would cause other kinds of barriers to the health of the industry. What it does mean, at a

\footnotetext{
${ }^{48}$ In our draft report, we said, "There seems to be widespread agreement that marine-based fin-fish aquaculture does not currently enjoy high social licence in Nova Scotia or across Canada.” The ACFFA stated that this was incorrect because research commissioned by the aquaculture industry shows high support for aquaculture in the communities in which the industry operates and because opinion surveys conducted by Corporate Research Associates shows that the majority of Nova Scotians support the expansion of salmon farming. We do not agree that this shows our original statement was incorrect, but we do accept that it was worded too broadly. Meanwhile, given all that we heard in our process, including from most of those we spoke to from the industry, we can and do conclude that the industry has a social licence problem. What differs is what people attribute this problem to, as we indicate in the following sentences. For some, it is the conduct or track record or business model of the industry. For others it is because of well-financed ideological campaigns of opposition and/or weak or inconsistent government policy or decision making.
} 
minimum, is regulation that deals directly and responsively with the real and legitimate issues that the industry must address if it is to enjoy better social licence.

We think, however, that Nova Scotia should aim higher than the minimum. Our mandate asked us to consider the regulation of aquaculture in light of the Environmental Goals and Sustainable Prosperity Act ${ }^{49}$ and the priority it places on development that is sustainable because it integrates economic, social and environmental aspirations. In that context, we propose below that one of the goals of the new regulatory framework should be to contribute to a Nova Scotia brand of sustainable aquaculture that produces the highest-value products for the lowest possible environmental impact while maximizing social value.

\subsection{Discretion}

All regulatory frameworks give discretion to the regulator. In complex regulatory frameworks that govern the conduct of an industry, it is typical for the regulator to be given considerable discretion by the legislation that implements the framework. This is essential to the ability of regulators to deal with variations among the nature, scale and context of the activities that are regulated. It is also essential to the ability of the regulatory framework to evolve and change to reflect changing conditions driven by economics, technological innovation, new scientific knowledge or changing social values.

There is, however, a balance to be struck between the extent of the reliance on discretion and the laying out of the basic elements of the regulatory framework in legislation, whether it be in the statute enacted by the legislature or in the regulations that get made as authorized by the statute. Too much reliance on discretion can mean that the regulatory framework is little more than the sum total of the specific decisions made by the regulator. This is a problem on multiple levels. Regulators are provided with little guidance in how they are to carry out their work. Regulated businesses can be unsure of what is expected of them and uncertain of when and how those expectations will change. The protection provided to the people and the values the regulations are intended to protect can be uncertain and variable. Most broadly, there can be a concern that the framework is delegating not just administrative but law-making authority to regulators without making them subject to the kinds of transparency and accountability generally applied to lawmaking.

Our conclusion is that the regulatory framework currently in place under the Fisheries and Coastal Resources $A c t^{50}$ and Regulations is too heavily dependent on regulatory discretion. ${ }^{51}$ We believe that a number of the concerns we heard from communities and from industry about the current

\footnotetext{
${ }^{49}$ SNS 2012 c 42.

${ }^{50}$ SNS 1996 c 25; as amended by SNS 1999 c 2; as amended by SNS 2001 c 6, s 108; as amended by SNS 2005 c 50, s 1; as amended by SNS 2010 c 51; as amended by SNS 2012 c 22 [hereinafter "SNS 2012 c22"].

${ }^{51}$ This conclusion is also reached by ECELAW, which recommends that "government regulators should consider establishing a regulatory framework for aquaculture that reduces Ministerial discretion, providing a more consistent and predictable regulatory approach" in the report Aquaculture Regulation in Nova Scotia: Overview of the Regulatory Framework and Considerations for Regulatory Reform, 22-23. In providing feedback on our draft report, the ACFFA questioned this conclusion, saying it was not supported by evidence and facts. All we can say is it is one of the core conclusions we came too over the course of our mandate, and it is supported by feedback we have received throughout our process from a broad range of stakeholders.
} 
framework are exacerbated by the extent to which the framework operates almost entirely through regulatory discretion. For example, community concerns about the content and adequacy of the rules under which aquaculture operates is understandable given that those rules are overwhelmingly found in the terms and conditions of each operators lease and licence. Similarly, industry concerns about the predictability and dependability of regulatory decision making is partly a result of the open-ended nature of the discretion the legislation gives to the Minister of Fisheries and Aquaculture.

In the regulatory framework we have proposed, regulatory discretion would be limited in various respects. Where discretion necessarily remains, it would be subject to clearer and more specific legislative guidance as to how it is to be exercised.

\subsection{Capacity}

Throughout our process, a recurring theme was inadequacy of the regulatory resources at the disposal of the DFA to carry out effective regulation. Frequently, it was pointed out that the Department had only a single boat at its disposal and that it often depended on operators for transportation to and from aquaculture sites.

Another aspect of the capacity issue was the dependency of the DFA on the DFO for the science the DFA needs to understand and address the issues that the regulators of aquaculture must address if they are to be "world class."

Our discussions with regulators in other jurisdictions served to confirm the widespread concern about the Department's regulatory capacity. These discussions confirmed that it is not just regulators in jurisdictions such as Norway that have significantly more resources at their disposal but also neighbouring jurisdictions like New Brunswick and Newfoundland and Labrador. We were particularly impressed by what we heard about the level of commitment to building policy, science and regulatory capacity in the latter province, where there seems to be a clear understanding that a strategy to support significant growth in the industry would fail if it were not accompanied by proportionate growth in the capacity of government to regulate a growing industry.

In discussions of regulatory effectiveness, there is tendency to emphasize issues such as the relative merits of different kinds of regulation. For example, a typical debate will be between a model of regulation that requires performance or outcomes (usually supported by industry) and a model of regulation that prescribes the rules that industry must follow and stresses the punishments industry will face when the rules are broken (often supported by environmentalists). While these debates are important, it is equally important to recognize that both kinds of regulation depend for their effectiveness on the level of resources put into their implementation. In fact, in the academic literature on regulatory design and practice, there is growing recognition that adequate regulatory capacity is a foundational, and perhaps the foundational, determinant of regulatory effectiveness. ${ }^{52}$

\footnotetext{
${ }^{52}$ For example, in a report on a comprehensive framework for regulating agriculture, it has been observed that "whilst improved regulatory practices are vitally important, these will only deliver the promised benefits if they sit within an institutional architecture that is efficient, and if they are appropriately resourced" - Paul
} 
It follows that a critical component of a new regulatory framework for aquaculture in Nova Scotia is a significant increase in the capacity of regulators to implement the framework. We are not in a position to quantify the scale of the increased capacity required. But we can with confidence say significant increased capacity is needed at least in the following areas: in the number of knowledgeable and experienced regulators in the field, in the equipment available to the officers in the field, in the capacity of the Department in the area of veterinary medicine and fish health and welfare more generally, and in the access of the Department to scientific research capacity.

Our last comment in this regard is that although the required capacity building will entail a cost, it will also represent an opportunity. Through our process, we were struck by the number and range of experts on aquaculture doing world-class work in Atlantic Canada. We were also struck by what we were told by these experts, which was that much of the available research on the impacts of aquaculture has been done on other parts of the world, leaving many unanswered questions about its applicability to Atlantic Canada and to Nova Scotia in particular. If Nova Scotia is serious about building a world-class regulatory framework, it needs to fill these knowledge gaps. It can do so by developing deeper and longer-term collaborations with the scientific community that is already present in the region. If it did so, it would make a major contribution to building that base of expertise and to deriving another layer of economic and social benefit from the industry. Moreover, the results of the collaboration would undoubtedly be research that would be of value not only to regulators but to the industry and its capacity to make environmentally sustainable and socially valuable contributions to Nova Scotia's economy.

\subsection{Emphasis on Compatibility with Other Uses}

In our process, we heard from a broad range of participants about the compatibility (or incompatibility) of various forms of aquaculture with other uses of public resources, particularly in coastal waters. We heard concerns from industry members who felt that private property owners treat coastal waters as their exclusive domain, refusing to share this public resource with the industry. We also heard from the aquaculture industry that there are many land-based threats to coastal waters that also threaten the aquaculture industry, such as nutrient runoff from agriculture operations, and inadequate sewage treatment.

We heard from some members of the fishing community that they depend on this public resource, and that they are concerned that aquaculture may pose an unacceptable risk to the inshore fishing industry. We heard from tourism operators that they rely on pristine coastal waters to attract tourists to their operations, and that aquaculture is a threat to their industry.

Others see opportunities for collaboration and synergies. We heard from some members of the inshore fishing industry that they see opportunities to combine fishing and aquaculture as a way to diversify opportunities in rural communities. Similar comments were made by some tourism operators, who saw mussel farms as tourist attractions.

In some cases, the divergent views on the compatibility between coastal aquaculture and other uses of coastal waters are a result of scientific uncertainty about the impacts of the various activities,

Martin et al., Developing a Good Regulatory Practice Model for Environmental Regulations Impacting on

Farmers, at ix. [emphasis added] 
how these activities interact with each other and how they cumulatively affect natural systems. In many cases, however, compatibility is a matter of mutual adjustment and accommodation in the best interest of all. This requires a willingness to engage with one another openly and to look for mutually acceptable solutions that ensure compatibility and maximize synergies.

We were frequently reminded in our process that the waters on which aquaculture is conducted are public waters. We were told that aquaculture had the effect of privatizing the benefit of this public resource by depriving others of its use, particularly those who live in communities close to aquaculture operations. We were also told that the lease payments and licensing fees charged to aquaculture businesses were not proportionate to the value these businesses obtained from using and, in the view of many, damaging, a public resource.

The regulatory framework we have proposed responds to these valid perspectives in multiple ways. It does so keeping in mind that coastal waters do not belong to those to whom they are leased for aquaculture or to those who live in proximity to or are licensed to fish in them. They belong to everyone in Nova Scotia, and it is the responsibility of the government to ensure they are used and managed for the benefit of the people of Nova Scotia as a whole.

\subsection{Promoting, Enabling and Using Research}

The effectiveness of regulation in aquaculture is greatly dependent on research that allows the environmental and socio-economic impacts to be understood, mitigated and ameliorated where they are negative, and accentuated where they are positive. In our process, we heard quite different views as to whether the current regulatory framework was properly and defensibly grounded on what science and local and traditional knowledge ${ }^{53}$ say about the potential impacts of aquaculture, especially of marine-based fin-fish aquaculture. There were frequently asked questions about the capacity of the DFA to apply research evidence in the regulatory process. Often, the context for these questions was the perception that the DFO is doing less aquaculture research than it has historically, making the provincial role in research all the more important. ${ }^{54} \mathrm{~A}$ recurring theme in our conversations with researchers was that what is most needed is research on the interaction of aquaculture with the environment in Nova Scotia, which is different in important respects from the environments in which a lot of the research on aquaculture has been carried out. ${ }^{55}$ The result is that on a range of scientific questions for which there is a significant body of research, the research has not been done to confirm the applicability of that research to Nova Scotia.

We think the future effectiveness of the regulation of aquaculture in Nova Scotia will depend on an increase in the DFA's capacity to identify the questions on which it needs research to be done and in its capacity to make regulatory decisions on the basis of its own independent understanding of

\footnotetext{
${ }^{53}$ There was qualified support at the Roundtable for the recommendation that, "Mi'kmaw traditional knowledge should be used throughout the regulatory process. Processes should be put in place to ensure that research issues are addressed through Mi'kmaw knowledge studies that include land and water use, cultural use and tools to identify indicators.” The Roundtable recognized that this is part of a larger process of discussions between the Mi'kmaq in relation to rights and treaty obligations. (Roundtable Final Report, 18)

${ }^{54}$ The representatives of the DFO we met with stated that this perception was a mistaken one.

${ }^{55}$ By this we do not mean that research conducted elsewhere cannot be applied or relied upon. We simply mean that it would be better if the applicability of research conducted elsewhere could be validated by research conducted in Nova Scotia.
} 
the research evidence. In particular, the DFA must take a more proactive role in funding or otherwise enabling research to fill the gaps in the peer-reviewed literature that are relevant to improving the regulation of aquaculture in Nova Scotia's particular environmental context. ${ }^{56}$

One of the areas of research to be given priority should be the interaction between fin-fish operations and lobster in coastal waters. ${ }^{57}$ This is one of the compatibility issues of particular relevance to Nova Scotia that is suffering from a lack of sufficient scientific information. Many members of the inshore fishing industry expressed concerns about the impact of fin-fish aquaculture on lobster. Concerns range from displacement of individual fishers from their traditional lobster fishing grounds to contamination of lobster through feed, medication, pestcontrol products and chemicals used in aquaculture operations, and to the effect of benthic contamination on the abundance of lobster in a given area.

There are some peer-reviewed papers that consider these issues from a social science perspective, assessing when and how the two industries have found ways to coexist in harmony in New Brunswick, for example. ${ }^{58}$ There are also peer-reviewed studies that consider the biophysical impact of fin-fish aquaculture on lobster. ${ }^{59}$ In addition, there was considerable discussion in our process of a lobster-trap survey study carried out by Louchs and Smith and other members of the Friends of Port Mouton Bay (2014). The study tracks lobster-trap results from local fishers in the Port Mouton area during various phases of a fin-fish operation in the bay. The study concludes that the number of lobster in the vicinity of the fin-fish operation increased during a fallowing period and then decreased when fin-fish operations recommenced.

We heard a number of perspectives on this study, both from scientists who have reviewed the study and from stakeholders who have views on what action should be taken as a result of this study. Some of the scientists who reviewed the study are supportive and view it as a credible study, while others asked serious questions about the reliability of the data, the methodology used to conduct the research and how much weight can be given to a single study, the results of which had not been

\footnotetext{
${ }^{56}$ There was partial support at the Roundtable for the recommendation to "develop a process to pose clear research questions to support sustainable management. Make questions available to guide research by students.” (Roundtable Final Report, 19)

${ }^{57}$ Participants in the February 10, 2014, Knowledge Roster generally agreed that little research has been conducted about the interaction of fin-fish aquaculture and lobster. Our interpretation of the discussion is that some thought this reflected factors such as the lack of any basis for suspecting that a negative interaction exists, the fact that lobsters are "waste feeders," the healthy and growing stocks of lobster and the observation of lobsters doing well in close proximity to salmon and other fin-fish farms. Others were of the view that the research hasn't been done because there is simply not enough known about how lobster and aquaculture interact to prompt research interest, or simply because the interaction between aquaculture and lobster has not been given priority in research.

${ }^{58}$ See Bradley B. Walters, "Competing use of marine space in a modernizing fishery: salmon farming meets lobster fishing on the Bay of Fundy," The Canadian Geographer 51(2) (2007): 139-59; and Melanie G. Wiber et al., "Impact of aquaculture on commercial fisheries: fishermen's local ecological knowledge," Human Ecology 40(1) (2012): 29-40.

${ }^{59}$ A peer-reviewed paper in Aquaculture, "Dispersion and toxicity to non-target crustaceans of azamethiphos and deltamethrin after sea lice treatments on farmed salmon, Salmo salar," found "no substantive effect after the treatment solution was released," though "longer exposures $(48 \mathrm{~h})$... produced toxicity in samples taken up to $850 \mathrm{~m}$ from the net pens.” (Ernst et al., 104)
} 
published in a peer-reviewed journal when the study was discussed at one of our Knowledge Workshops. Some stakeholders have asked us to dismiss the study outright, while others view it as a smoking gun that warrants shutting down fin-fish aquaculture in coastal waters.

In our view, the study, which has now been accepted for peer-reviewed publication, raises questions about the interaction between fin-fish aquaculture and lobster populations that should not be ignored. They are questions that are particularly important in Nova Scotia, where the lobster fishery is vital to the economy of coastal communities and the province more broadly. The fact that considerable work is left to be done by the scientific community before we will have clear answers to these questions is not a reason for inaction but rather for action that will ensure that this work is undertaken. The Friends of Port Mouton Bay have done tremendous work to try to fill information gaps that are of significant general interest, and it is critical that their work lead to further research in this area. The DFA, with or without support from the DFO, should act to promote this research and to support those who are qualified to undertake it.

Of course, any regulatory system has to function in the face of uncertainty while research to reduce the uncertainty is underway. In the case of the potential impact of aquaculture on lobster and in similar cases of uncertainty, ${ }^{60}$ our recommended approach is that the DFA should do the following:

- Identify opportunities to reduce or eliminate the source of the risk where this can be reasonably done through changes in the operation of fin-fish aquaculture (for example, as set out elsewhere in the report, by eliminating the use of chemical anti-fouling agents).

- Where risks cannot be readily eliminated, proceed with a clear understanding that there is an unknown risk associated with the operation, and make the quantification of the risk a priority through specific monitoring and research efforts.

- Ensure that the scale of development and regulatory oversight are in line with the risk involved, by supporting incremental development and by retaining the ability to adjust to new information expected from the additional monitoring and research.

In providing feedback to our draft report, the Ecology Action Centre (EAC) expressed concern that we had said very little about climate change. This reflects the fact that we heard much less about this significant issue than we did about the many issues we have addressed more extensively. We have noted, however, the relevance of climate change to the operation and evolution of the proposed regulatory framework in several areas, including the classification of coastal areas for suitability for fin-fish aquaculture. This said, we agree that the relationships between climate change and aquaculture, particularly in the context of coastal conditions in Nova Scotia, is another area in which research will be very important to ensure that the regulatory framework operates and evolves in accordance with evidence.

\footnotetext{
${ }^{60}$ There was qualified support at the Roundtable for a recommendation to "support evidence-based regulatory decision-making” with "continuing research supported both directly by the Province and industry, and through federal-provincial partnerships." Areas of research identified include the impacts of aquaculture on lobster, the impacts of escaped salmon and of ISA on wild stocks, and the impacts of sea lice. The Roundtable noted that research should not be limited to these areas and additionally targeted knowledge gaps identified by the Knowledge Roster. (Roundtable Final Report, 19)
} 


\subsection{Regional Cooperation}

We heard about regional cooperation from a number of the regulators we met with from Nova Scotia, New Brunswick, Prince Edward Island and Newfoundland and Labrador. The existing Regional MOU is clearly a step in the right direction in this regard. It is important to note, however, that there are likely to be limits to regional cooperation. Prince Edward Island, for example, has a very different regulatory system and a differently structured industry that operates in different biophysical conditions. It is not surprising therefore that the industry and its regulation have developed differently in PEI. New Brunswick's industry is much more geographically concentrated than Nova Scotia's, is perhaps less diverse and is operating at a larger scale than in Nova Scotia. Newfoundland and Labrador's industry is also quite concentrated geographically, is dealing with very different biophysical conditions and is far removed from Nova Scotia, making cooperation in certain areas more difficult. 61

We heard from federal regulators about the imperative of improved regional cooperation. There is concern within the CFIA, for example, that the capacity of any one jurisdiction in Atlantic Canada to properly respond to a disease outbreak is inadequate, and building that capacity in each province may be prohibitively expensive given the size of the industry. This issue is explored in more detail below (Sec. 15), but regional cooperation in this area clearly seems warranted.

In our view, regional cooperation more generally is an important consideration to enhance the regulatory process in all Atlantic provinces. However, it should not drive the design and implementation of the regulatory process in Nova Scotia. We have recommended a particular approach to the regulation of aquaculture for Nova Scotia that is based on our assessment of biophysical, social and economic conditions in Nova Scotia, provincial priorities as expressed through the Environmental Goals and Sustainable Prosperity Act and the One Nova Scotia Report, which may not have the same application or resonance in other provinces.

Nova Scotia should look for opportunities to harmonize where there are common interests and to pursue its own course where interests and priorities diverge. More broadly, it should look for cooperation opportunities as well as harmonization opportunities. Among the areas where regional cooperation would seem particularly critical would be disease control, production of feed, and processing. There are opportunities for regional cooperation in regulatory requirements, branding and marketing, but this would be contingent on other provinces embracing the approach we have recommended in this report.

\subsection{Sustained Commitment}

Mandating a comprehensive review of the regulation of aquaculture and establishing this Panel to recommend a new regulatory framework represented a commitment on the part of the DFA, and the provincial government more broadly, to significantly improve the regulation of aquaculture in Nova Scotia. As a Panel, we were mandated to recommend a "world class" regulatory framework,

\footnotetext{
${ }^{61}$ For more analysis of the differences in the regulation of aquaculture among the Atlantic provinces, see ECELAW's report Comparative Analysis of Five Aquaculture Regulatory Frameworks in Canada (which also includes British Columbia). The report can be accessed on our website, under ”Updates.”
} 
drawing on the ideas in the Environmental Goals and Sustainable Prosperity Act ${ }^{62}$ and from the example of leading jurisdictions in the regulation of aquaculture. We were specifically mandated to conduct an open and transparent process.

Our impression was that, in general, people who participated in our process appreciate the opportunity the DFA had created for an open, transparent, independent and fundamental review of the regulatory system. There was, however, a good deal of scepticism expressed as to whether our work would be one more report left to gather dust once the focus on improving the regulation of aquaculture dissipated after our process had run its course. Some even suggested that the motivation of government in establishing the Panel was not really to improve the regulation of aquaculture but to defuse the opposition to the expansion of the marine-based fin-fish industry.

It will be critical that the commitment to improving regulation of the aquaculture industry that was exhibited in the creation and mandating of the Panel be maintained as the issue becomes the implementation of the framework we have proposed. Good regulation obviously depends on the design or architecture of the regulatory framework, but it depends equally on the diligence, commitment and effort with which it is implemented and operated on a continuing basis.

We have made a number of recommendations that will help to ensure that the commitment and the momentum for improvement is maintained through the process of implementation. For example, we have called for a new culture of regulatory openness and transparency that will, if adopted, help to keep the DFA accountable for acting on our recommendations or for explaining why our recommendations have not been adopted or effectively implemented. We have also recommended the creation of an ongoing Regulatory Advisory Committee both to monitor the implementation of the proposed framework and to contribute to its development and implementation on a continuing basis. We have also recommended the creation of a formalized mechanism through which the DFA would access the knowledge and research capacity of the broader knowledge community outside of government to ensure that the development and implementation of the framework is evidencebased.

In the end, the crucial question will be whether the DFA and its leadership remain committed to the essential goal of improved regulation through the creation of a new regulatory framework. The broader and equally important question will be whether the DFA is supported by the broader government in moving forward with the implementation of the framework, which will require an increase in the resources the DFA has to work with.

\section{COASTAL PLANNING}

We were asked by some participants in our process to recommend an integrated coastal planning process as a necessary context for making siting decisions for aquaculture operations in coastal

${ }^{62}$ SNS 2007 c. 7, as amended by SNS 2012 c. 42. 
waters. ${ }^{63}$ Recommendations for integrated coastal planning and for integrated coastal management have been made before, including in the 2007 report of the Joint Review Panel for the Whites Point Quarry project in Digby Neck. ${ }^{64}$ Other participants were strongly opposed to linking the regulatory system for aquaculture to coastal planning. The main concern was that comprehensive and integrated planning processes can take a long time and yet fail to produce a comprehensive plan for coastal development and protection. A number of participants in our process had previous experience with the Eastern Scotian Shelf Integrated Management (ESSIM) process, which was led by the Department of Fisheries and Oceans, and expressed frustration about the effort and time involved, and the fact that in the end the results were not implemented. Others reminded us that previous efforts to develop a comprehensive provincial strategy have not been successful. 65

Clearly, an up-to-date integrated coastal plan for Nova Scotia that comprehensively considers biophysical, social and economic factors and includes a plan for the most effective long-term use and protection of the coastal zone would be a valuable tool for the regulation of aquaculture. It would be valuable both for proper site selection and for considering how aquaculture fits with current and potential future uses of the coastal area in question.

We have therefore concluded that an integrated coastal plan for Nova Scotia would be a very useful tool that could do much to improve the efficiency, effectiveness and fairness of the regulatory process. At the same time, we are not in a position to determine what time and resources would be needed to complete such a process successfully, particularly given that it would ideally have the support of all levels of government. While a coastal planning process would be very helpful to the regulatory process, we cannot predict whether or when such a process would yield results, or what the content of such a planning process would be. We have therefore decided to design the regulatory framework for aquaculture in the absence of a coastal plan. If such a plan is developed in the future, ${ }^{66}$ certain aspects of the regulatory process could be significantly streamlined.

Because we are assuming that there will not be a coastal plan in place for the foreseeable future, we have identified other ways for regulators to determine how aquaculture fits with other current and

\footnotetext{
${ }^{63}$ For example, the Ecology Action Centre made a submission arguing that coastal planning should be regarded and carried out as a foundation for the regulation of aquaculture.

${ }^{64}$ This report is available at www.ceaa.gc.ca/B4777C6B-docs/WP-1837_e.pdf

${ }^{65}$ At the Roundtable, there was vigorous discussion of a recommendation that "the province together with federal partners should, within a reasonable period of time, develop an overall coastal planning process to address the location of aquaculture operations in the context of environmental suitability and other marine resource uses." In the end, the recommendation received only partial support by the "narrowest of margins." An alternative, that the province should collate existing coastal planning information and make it publicly available to assist with decision making regarding aquaculture siting, likewise received only partial support. The recommendation that "Improvements to the aquaculture regulatory system should proceed in a timely fashion, independent of progress made with developing a coastal planning framework" received qualified support. (Roundtable Final Report, 12)

${ }^{66}$ There was partial support at the Roundtable for a recommendation that "the Bras d'Or Lakes would be a suitable location for a pilot coastal planning project in consultation with First Nations. The existing Bras d'Or Lakes Collaborative Environmental Planning Initiative (CEPI) could provide valuable information and input into this process." There may be other areas suitable for pilot coastal planning projects as well, such as the Bay of Fundy, and there may be other ways to move coastal planning forward. (Roundtable Final Report, 13)
} 
future uses of a given coastal area. ${ }^{67}$ One is the strategic assessment process we have recommended as one of the processes for determining Green, Yellow and Red areas for siting aquaculture operations. Other processes that can help fill the gap left by the absence of a coastal plan include our proposed Regulatory Advisory Committee and the potential revival of Regional Aquaculture Development Advisory (RADA) Committees, or the creation of a new forum to facilitate comprehensive planning around aquaculture at the local level. Our understanding is that the RADA committees were either led or supported by DFO but that they are now no longer used. In our view, it would be ideal if they could be reactivated by the DFA and the DFO working in collaboration with each other and interested municipalities for communities in which such a process could serve a useful purpose of integrating the development of aquaculture into other local planning processes. Even if the participation of the DFO cannot be secured, the DFA should consider whether a similar kind of process could play a useful role either in conjunction with the strategic assessment process we recommend for assessing the potential of coastal areas for community-supported aquaculture or independently of strategic assessment.

\section{GOALS OF THE REGULATORY FRAMEWORK}

Regulation should have clear goals. This helps to ensure that it is conducted with a shared understanding of its objectives. It helps to ensure that each element of the regulatory framework is designed and administered to contribute to the accomplishment of the framework's overall goals. It provides guidance to regulators as to how they should exercise their discretion. It gives business a better understanding of what the regulatory process is trying to accomplish and the opportunity to integrate those objectives into how business is conducted. It helps to ensure that members of the public have a clear understanding of what they can expect of regulators and business, which in turn enables them to better contribute to the regulatory process.

In all of these ways, clear goals can help to ensure that the resources for making, administering and complying with regulations are optimally used. In addition, clear goals facilitate the evaluation of the effectiveness of regulation. Evaluation in turn is critical to improvement of regulation over time.

The Fisheries and Coastal Resources Act ${ }^{68}$ currently contains a list of goals or objectives. This approach should be retained. The list of goals should, however, be explicitly connected to the regulation of aquaculture. In addition, the list of goals should be more comprehensive and include a number of goals that are more specific than the goals currently found in the Act. The goals of the regulation of aquaculture should be stated to include the following:

\footnotetext{
${ }^{67}$ The Roundtable considered a recommendation as an alternative to a more comprehensive coastal planning approach: that "the Province should collate existing coastal planning information and make it publicly available to assist with decision-making regarding aquaculture siting.” This recommendation received partial support among Roundtable members. Also of note during Roundtable discussions, it was on the one hand suggested that much of this information already exists and on the other hand cautioned that keeping publicly available inventories of information up to date can be very difficult. (Roundtable Final Report, 13)

${ }^{68}$ SNS 2012 c 22.
} 
a. Ensuring aquaculture is conducted under conditions and in accordance with controls that will protect the environment by preventing significant harm to the environment or to the continuing availability in the short, medium and longer term of unimpaired environmental services to aquaculture and to other users of those environmental services ${ }^{69}$

b. Ensuring equity, fairness and compatibility in access to, and utilization of, public water resources in the coastal zone by aquaculture and other users of the coastal zone

c. Ensuring that the regulation of aquaculture contributes to the productive development of Nova Scotia's coastal resources in the direction of low impact for high value

d. Ensuring that aquaculture is developed and conducted to establish its compatibility with the well-being and prosperity of other sectors of the Nova Scotia economy, including the lobster fishery, the tourism industry and the fly-fishing industry ${ }^{70}$

e. Ensuring that the people of Nova Scotia, including the residents of communities in proximity to aquaculture sites, have opportunities to receive direct and indirect economic and social benefits from the development and operation of the aquaculture industry that are proportionate to the value of the public water resources and the environmental services utilized by the aquaculture industry ${ }^{71}$

f. Ensuring that aquaculture is developed and conducted with due regard to the health, wellbeing and recovery of the wild Atlantic salmon population in Nova Scotia rivers as well as any endangered species that may be affected by aquaculture operations ${ }^{72}$

g. Ensuring that members of the public have meaningful opportunity to be informed about and to participate in the regulatory process, including early notification of proposed aquaculture operations, proposed expansions of existing sites and proposed transfer of ownership of existing sites ${ }^{73}$

h. Ensuring that the regulation of aquaculture is attentive to the developmental plans, objectives, needs and priorities of local communities

\footnotetext{
${ }^{69}$ This goal is closely related to two of the guiding principles suggested by the Roundtable for the regulatory framework: that it "ensure the maintenance of long term ecosystem health in the areas where aquaculture takes place" and that it "ensure that the net environmental impact of an aquaculture operation, from startup to decommissioning, does not exceed the ecological carrying capacity of its location." Both received unanimous support from the Roundtable. We agree with both of these recommendations but think they are better understood as different ways of expressing a critical goal of the framework than as one of the principles to be followed in the pursuit of that and other goals.

${ }^{70}$ The Roundtable proposed a guiding principle with unanimous support that the regulatory framework should "prevent or minimize negative impacts on other marine resource industries and users." Again, we agree with the recommendation but think it works better as a goal of the framework than as one of its guiding principles. (Roundtable Final Report, 7)

${ }^{71}$ This proposed goal is roughly similar to the guiding principle suggested by the Roundtable that the regulatory framework "deliver net benefits, which can include environmental, economic or social benefits, to Nova Scotia.” (Roundtable Final Report, 7)

${ }^{72}$ This goal was interpreted by the ACFFA as making aquaculture responsible for recovery of wild Atlantic salmon and other endangered species. That is not the intent. Rather, the intent is to ensure that the industry does not adversely affect wild salmon or endangered species.

${ }^{73}$ There was qualified support at the Roundtable for a similar guiding principle, which states, "Include public input and local knowledge throughout the regulatory process.” (Roundtable Final Report, 7)
} 
i. Ensuring that the regulation of aquaculture supports the efforts of the Nova Scotia aquaculture industry to develop and grow through innovation and through the adoption of aquaculture and business practices that combine business success with higher environmental performance ${ }^{74}$

j. Ensuring that regulations are achievable, contain incentives for compliance and can be enforced 75

k. Ensuring that the regulation of aquaculture in Nova Scotia is efficient, timely, dependable, predictable and affordable for both taxpayers and businesses ${ }^{76}$

More generally, the underlying concept of the regulatory framework should be that strong regulations make for a stronger industry. ${ }^{77}$ Here, it is relevant to reiterate our view that, for aquaculture, the Environmental Goals and Sustainable Prosperity Act should be interpreted and applied to mean that the industry should be regulated on the basis that Nova Scotia's objective is to host an industry that creates the highest-value products with the lowest possible environmental impact, while maximizing social value. Put somewhat differently in the context of our mandate to recommend a world-class regulatory framework, the ultimate regulatory goal is for the regulatory framework to contribute to and support Nova Scotia's development as a world leader in low-impact aquaculture and to market this success so that Nova Scotia exports can achieve the highest possible value in the marketplace. ${ }^{78}$

These objectives should apply to all forms of aquaculture, and they should guide the development, application and evolution of the regulatory system developed for the industry.

\footnotetext{
${ }^{74}$ A guiding principle with some shared elements received partial support from the Roundtable. (Roundtable Final Report, 8)

${ }^{75}$ This was proposed by the Roundtable as a guiding principle with unanimous support. We think it fits better here as one of the goals of the regulatory framework (Roundtable Final Report, 7). The ACFFA expressed concern that a regulatory framework that contained "incentives for compliance" would undermine rather than decrease public confidence and add discretion to the regulatory system. We think this concern can be addressed if incentives for compliance are structured and applied in accordance with the open, transparent and accountable regulatory framework we have proposed. Moreover, we think a good regulatory system includes carrots as well as sticks.

${ }^{76}$ See the Australian Farm Institute's report, Developing a Good Regulatory Practice Model for Environmental Regulations Impacting on Farmers (Martin et al.) for a more thorough discussion of the role of well-designed and implemented regulatory measures in the profitable and sustainable operation of businesses. See also the OECD’s "Principles for Regulatory Quality and Performance” for a discussion of efficient and effective regulators, and how "good regulatory outcomes depend on more than well designed rules and regulations.” (p. 2)

${ }^{77}$ Stefan Ambec, Mark Cohen, Stewart Elgie, and Paul Lanoie, The Porter Hypothesis at 20: Can Environmental Regulation Enhance Innovation and Competitiveness? (Resources for the Future, 2011).

${ }^{78}$ We have adjusted the wording here to reflect the reality that the regulatory framework cannot accomplish this economic objective but only contribute to it. To that extent, we agree with the feedback we received on this point from the ACFFA, although we do not agree with its view that this is not a regulatory goal at all. We also think the EGSPA is based on this understanding of the role between regulatory and economic goals.
} 


\section{GUIDING PRINCIPLES}

In addition to clarity on goals, a regulatory framework should be clear on the principles that have guided the development of the framework and that will guide its continuing evolution and its administration. Such principles do not supersede the specific content of the regulations. They do not give regulators the authority to ignore specific regulatory requirements. Rather, they form the backdrop to the operation of the regulatory framework and inform how it is interpreted and applied to specific situations where there is room for legitimate questions as to how it should be interpreted and applied.

The relationship between guiding principles and goals can be a source of confusion. One of the goals of a regulatory framework can be that it operate in accordance with its guiding principles. Conversely, the guiding principles can be stated to include attributes that can also be stated as goals. Our approach is to think of the goals of the framework as the high-level outcomes that the framework is designed and administered to achieve. The guiding principles are the attributes the regulatory process should live up to while those high-level outcomes are being pursued.

Principles that would be relevant to regulation in general (including aquaculture) can be differentiated from principles that are specific to regulation in a particular sector (like aquaculture). The list that follows is a combination of these two kinds of principles. In general terms, generic principles relate to issues of regulatory design and administration that arise in all or most regulatory contexts, whereas principles specific to a sector relate more closely to the objectives of regulation in that sector.

There are many lists of "good regulation principles" available from other settings or jurisdictions. ${ }^{79}$ Although there is considerable overlap between them, there is no list that is universally accepted as the right or best list. The differences between lists can be of a technical nature, but they can also reflect a difference in understanding of the purpose of a list of regulatory principles. While some lists are weighted toward ensuring the effectiveness of the protective function of regulations, others are weighted in favour of avoiding or minimizing regulations' adverse impact on business and the markets. In general, lists weighted in favour of protection are lists specific to particular fields of regulation, whereas lists weighted in favour of minimizing the adverse impact of regulation on business are lists developed to apply to regulation in general.

\footnotetext{
${ }^{79}$ Examples include: “OECD Principles for Regulatory Quality and Performance,” in OECD, Regulatory Policy and Governance: Supporting Economic Growth and Serving the Public Interest.

OECD, Governance of Regulators, which "seeks to develop an overarching framework to support initiatives to drive further performance improvements across regulatory systems in relation to national regulatory bodies or agencies (regulators)," at p. 2.

Better Regulation Task Force, Principles of Good Regulation, which sets out the five principles of good regulation that have been used by regulators in multiple sectors in the UK: proportionality, accountability, consistency, transparency, and targeting.

Victoria State Services Authority, Review of the Rationalization and Governance of Regulators, which is singled out for praise on regulatory principles by the OECD.

Paul Martin et al., Developing a Good Regulatory Practice Model for Environmental Regulations Impacting on Farmers, in particular the discussion in Appendix 1 of regulatory principles (pp. 27-28).
} 
The list that follows includes the principles that appear on a number of other lists plus a number of the guiding principles proposed to us by the Roundtable. We have reflected on the literature on regulatory principles, the experience of other jurisdictions (including Nova Scotia), the advice we have received from the Roundtable and all that we have heard in our consultations with Nova Scotians and others, to conclude that the regulatory framework for aquaculture in Nova Scotia should be based on the following principles:

a. Effectiveness - The foundational regulatory principle is effectiveness. Effectiveness in serving regulatory objectives must be the core consideration in the design, implementation and enforcement of a regulatory framework. Clarity on the broad objectives of the framework as a whole and on the more specific objectives of individual elements of the regulatory framework is therefore critical. ${ }^{80}$

b. Openness - This principle is often included with transparency. We think it should be separately identified because it emphasizes that the regulatory process should not just be transparent to those outside of it but participatory and inclusive of those who have interests that the regulatory process could affect. At the Roundtable, there was qualified support for a guiding principle to "include public input and local knowledge throughout the regulatory process." 81

c. Transparency - Transparency is one of the principles that appears on most lists of regulatory principles. ${ }^{82}$ The Roundtable concluded that one of the guiding principles of the regulatory framework should be to "Provide for transparency throughout the regulatory cycle." 83 The perceived lack of transparency in how aquaculture has been regulated to date was one of the concerns raised most consistently during our consultations. 84

d. Accountability - Generally, this principle calls for accountability from regulators, both to those directly affected by their decisions and to the broader public that pays for regulation and either does or does not benefit from it depending on how it is implemented. One aspect of this principle is that there be clarity (transparency) on who makes what decisions and on what basis. Another aspect calls for accountability on the overall success of the regulatory process in achieving progress toward its goals and the costs to government and business for that success. So understood, this principles overlaps with one of the guiding principles suggested by the Roundtable - that there be "clear roles, responsibilities and accountability.” 85

\footnotetext{
${ }^{80}$ The Roundtable gave unanimous support to several related guiding principles, including "Numerical Requirements included in indicators, standards and thresholds should have clear justification" and "Ensure that regulations are achievable, contain incentives for compliance and can be enforced." There was also qualified support for a recommendation to "Improve regulatory certainty." (Roundtable Final Report, 7)

${ }^{81}$ See Roundtable Final Report, 7.

${ }^{82}$ See, for example, the OECD's Governance of Regulators paper.

${ }^{83}$ This guiding principle received unanimous support from the Roundtable. (Roundtable Final Report, 7)

${ }^{84}$ This concern was analyzed and discussed in ECELAW's report Aquaculture Regulation in Nova Scotia. The report concludes that "an informed citizenry is key to ... ensuring an industry that is sustainable both economically and environmentally.” (p. 11)

${ }^{85}$ This guiding principle received unanimous support from the Roundtable. (Roundtable Final Report, 7)
} 
e. Proportionality - Regulation should be proportionate to the risks it seeks to control. Higher risks should be more heavily and aggressively regulated, whereas lower risks should attract less attention and effort, even though they may be serious to those who could be affected by them. ${ }^{86}$ The idea is to calibrate regulatory effort to the relative seriousness of risk to prevent over-regulation of smaller (less serious) risks and under-regulation of higher (more serious) risks. Proportionality is also concerned with ensuring that the costs imposed by regulation on business are proportionate to the seriousness of the risks that regulation is controlling. ${ }^{87}$

f. Integration - The Roundtable proposed that the regulatory framework should recognize that "the health of the economy, the environment and the people are interconnected" as one of its guiding principles. We agree. Building such a principle into the regulatory framework for aquaculture is consistent with our mandate, which was to make recommendations "in light of the best long-term environmental, social and economic interests of the province, in accordance with priorities, principles, and interests as articulated in relevant Nova Scotia legislation, including the Environmental Goals and Sustainable Prosperity Act.” The objective of this legislation is to guide environmental policy, and public policy more generally, to make it more supportive of development that is sustainable, because this serves economic, environmental and social objectives. In this legislative context, it is appropriate to include a guiding principle that recognizes the interconnectedness of the economy, the environment and society in the regulatory framework for Nova Scotia's aquaculture industry.

g. Precaution - The Roundtable proposed that the regulatory framework should "embody the precautionary principle as defined in the Rio Declaration on Environment and Development, 1992: 'Where there are threats of serious or irreversible damage, lack of full scientific certainty shall not be used as a reason for postponing cost-effective measures to prevent environmental degradation.' " 88 This is the definition of the principle already in the Environment Act, ${ }^{89}$ and we agree that precaution should be an explicit part of the regulatory framework for aquaculture.

We think, however, that it should be thought to have a broader application in this context than the precautionary principle is often interpreted to have. Often in discussions of the principle, it is assumed that its only application is to the decision of whether to allow an activity to happen or to continue. Given the nature of the aquaculture industry, its current state of development, and the degree of uncertainty about its impacts on the receiving environment, we feel that a more general application of a precautionary approach is warranted. ${ }^{90}$ We use the term "precautionary approach" deliberatively, because it signals an

\footnotetext{
${ }^{86}$ The level or severity of a risk (harm) is a function of the probability of its occurring multiplied by the potential impact of the risk in the event that it occurs.

${ }^{87}$ Two of the guiding principles that received qualified support at the Roundtable are related to proportionality. The first is a principle to "avoid undue regulatory burden on smaller operations while staying within the limits of environmental carrying capacity." The second is the principle to "address issues of regulatory equity between aquaculture and other industries.” (Roundtable Final Report, 7)

${ }^{88}$ This guiding principle received unanimous support from the Roundtable. (Roundtable Final Report, 6)

${ }^{89}$ SNS 1994-95, c 1, s 2(b)(ii).

${ }^{90}$ There was partial support at the Roundtable for the recommendation that "the precautionary approach should be employed when data is limited or absent.” Due to time constraints, the Roundtable was unable to
} 
application of precaution that goes beyond the limited wording of the precautionary principle. We do not feel that the precautionary approach should be tied to some threshold of scientific knowledge or level of risk. Rather, it should be more generally followed with the specific actions taken to give it effect in particular situations linked to the degree of risk and uncertainty. Where there is risk and uncertainty, incremental development in combination with monitoring and research to gain a better understanding of impacts and risks should be the preferred approach. This does not mean, of course, that there will not be circumstances where a precautionary approach suggests no development, such as in case of clear conflict with the recovery of endangered species. Instead, it means that the precautionary approach continues to apply where development is permitted, in shaping the terms and conditions under which the approval for development is given as well as the ongoing regulation of the approved site. Our point also is that the precautionary approach should not be thought of as relevant only or even primarily as a free-floating guiding principle that applies only where the regulatory framework does not deal specifically with an issue or question. As with each of the other guiding principles we have proposed, the precautionary approach should be applied in developing and applying each element of this regulatory framework. It is only in this way that a regulatory framework can be said to "embody" the precautionary approach.

This proposed list of guiding principles does not include all of the guiding principles proposed by the Roundtable. It also does not include a number of regulatory principles that have been proposed in the academic and policy literature or that have been incorporated into the regulatory principles adopted in various jurisdictions. We think, however, that to be useful a list of guiding principles needs to be relatively manageable and that a list with more than seven guiding principles is likely to become unwieldy and unhelpful. In addition, our list of seven principles covers much of the ground that is covered by most lists of regulatory principles. They are also, in our opinion, the seven principles that are most important and responsive to the improvements needed in the regulation of aquaculture in Nova Scotia.

Further, it is to be noted that many of the guiding principles suggested by the Roundtable but that we have not included in our list of guiding principles are addressed in our proposed list of goals for the regulatory framework. The same can be said for a number of the regulatory principles found in the literature that we have not included in our list of guiding principles. A number of these are encompassed by two of the proposed goals: "Ensuring that regulations are achievable, contain incentives for compliance and can be enforced" 91 and "Ensuring that the regulation of aquaculture in Nova Scotia is efficient, timely, dependable, predictable and affordable for both taxpayers and businesses.”

fully discuss the difference between the precautionary principle and the precautionary approach (Roundtable Final Report, 19). See also the ECELAW report Aquaculture Regulation in Nova Scotia, at pp. 7-8 in particular, for more discussion of the precautionary approach and its specific application to aquaculture in Nova Scotia.

${ }^{91}$ As a guiding principle, this goal received unanimous support from the Roundtable. (Roundtable Final Report, 7) 


\section{ROLE OF AND COOPERATION WITH FEDERAL REGULATORS}

\subsection{Background}

The DFO plays a range of roles in the regulation of aquaculture across the country. In British Columbia, it is the primary regulator of aquaculture pursuant to a court ruling that aquaculture in that province fell under federal fisheries jurisdiction. ${ }^{92}$ The DFO regulates aquaculture in BC through regulations made under the Fisheries Act. ${ }^{93}$ Under these regulations, the federal Minister of Fisheries plays the same role in licensing as provincial ministers for fisheries and aquaculture play in most other provinces.

Another model is found in Prince Edward Island, where the federal Minister of Fisheries is the licensing authority. However, unlike in BC, the federal Minister carries out that responsibility in accordance with an MOU with the province, under which a committee of federal and provincial officials reviews the applications and advises the Minister on whether they should be granted or refused and on all associated matters, such as the terms and conditions to be included in licences. The Minister consistently follows the advice of this committee. The regulatory process in PEI can therefore be described as one of federal-provincial co-regulation. ${ }^{94}$

In Nova Scotia, New Brunswick, and Newfoundland and Labrador, the aquaculture industry is comprehensively regulated by the provincial minister responsible for aquaculture, who in each province is the minister responsible for fisheries as well as aquaculture. ${ }^{95}$ Under this model, federal regulators participate in the regulatory process largely by providing input to the provincial licensing process. This input can consist of advice or guidance that the province takes into account in its licensing decisions. However, it can also consist of requirements that the federal regulator must have addressed to conclude that the project is going forward in compliance with the requirements of federal law. In this way, federal-provincial MOUs in these provinces can result in a delegation of federal regulatory authority to the provincial level.

Typically, the federal input to the provincial licensing process comes from the DFO and relates to the compatibility of the proposed project with fisheries or fish habitat protected under the Fisheries Act. ${ }^{96}$ Where applicable, the DFO will also take the Species at Risk Act ${ }^{97}$ into account in providing

\footnotetext{
92 Morton v. British Columbia (Minister of Agriculture and Lands) [2009] B.C.J. No. 193, 92 B.C.L.R. (4th) 314 (B.C.C.A). See also ECELAW's report Comparative Analysis of Five Aquaculture Regulatory Frameworks in Canada at pages 26-28 for more discussion of this decision. Finally, for analysis of this decision, see Dwight Newman, Natural Resource Jurisdiction in Canada, at pages 156-160, and Neil Craik, "Subsidiarity and Environmental Federalism," arguing that the decision gives inadequate weight to regulatory need for both levels of government to be engaged in the regulation of aquaculture.

93 RSC 1985, с F-14.

${ }^{94}$ See again ECELAW's Comparative Analysis at pages 22-25 for more discussion of PEI's regulatory framework.

95 Ibid., at pages 9-12 (NS), 13-17 (NB), and 18-21 (NL).

${ }^{96}$ RSC, 1985, c. F-14, and OECD, “Principles.”

${ }^{97}$ SC 2002 с 29.
} 
input to the provincial licensing process. The other kind of input received from the federal government comes from the Coast Guard, which is part of the Department of Transport, under the Navigation Protection Act, ${ }^{98}$ which recently replaced the Navigable Waters Protection Act.

Federal regulation also applies to the aquaculture industry in Nova Scotia in more direct ways. For example, the Coast Guard can intervene to address obstacles to navigation or compliance with the terms of a lease that reflect the Coast Guard's requirements relative to navigation. We frequently heard about the applicability of regulations under the Fisheries Act, which control the transfer and movement of fish stock between bodies of water or from bodies of water to market. The purpose of these regulations is to prevent the transfer of disease or parasites and to prevent harvesting activities that threaten wild stocks.

We heard from people in the industry their view that federal regulations are sometimes applied to aquaculture in ways that do not reflect the differences between wild and farmed stocks. The example we were given was the application to growers of cocktail oysters, which are deliberately grown to be smaller than other cultivated oysters, of Fisheries Act regulations that prohibit the harvesting of small oysters as a means of protecting wild oyster populations.

These examples of direct regulation of the industry by federal regulators notwithstanding, the core feature of the relationship between the federal and provincial governments under the MOUs in place in each of these provinces (as opposed to PEI) is that federal regulators seek to achieve their regulatory objectives primarily through their contributions to the provincial licensing process. From an industry perspective, the advantage here is that the regulatory process is more coordinated and streamlined than it otherwise might be. Comparable coordination and streamlining could presumably be achievable by adoption of the BC model, under which the DFO is the comprehensive regulator of aquaculture, but this might reduce the responsiveness of the regulatory framework to Nova Scotia's specific conditions. In addition, different arguments on the jurisdictional limits of the two levels of government than those considered in BC ${ }^{99}$ would arise in the Nova Scotia context. Finally, representatives of the DFO were very clear in our meeting with them that the DFO is not interested in becoming the comprehensive regulator of aquaculture in Nova Scotia.

The Canadian Food Inspection Agency (CFIA) and Health Canada also play important roles in the regulation of aquaculture. The CFIA is responsible for developing and implementing the National Aquatic Animals Health Program (NAAHP). ${ }^{100}$ This program is Canada's response to its obligations as a member of the World Trade Organization (WTO) to implement a program of aquatic animal health that complies with standards issued by the World Organization for Animal Health (WOAH). Under the NAAHP, the mandate of the CFIA is to ensure that wild and farmed aquatic animals are protected from the introduction of infectious diseases from other countries as well as from movement of diseases within Canada. The website of the NAAHP states, "Although the aquatic animal pathogens regulated by the NAAHP pose no health risk to humans, they can be

\footnotetext{
${ }^{98}$ RSC 1985 c N-22.

${ }^{99}$ See the Morton decision, as well as the analysis of it in Newman and in Craik.

${ }^{100}$ The program is explained at http://www.dfo-mpo.gc.ca/science/aah-saa/National-Aquatic-Animal-HealthProgram-eng.html.
} 
potentially devastating both economically and ecologically to wild fisheries and aquaculture operations.” It goes on to say,

The NAAHP enables Canada to certify fish and seafood exports free of pathogens of international importance and to require similar health certification from countries wishing to export fish and seafood to Canada. This prevents the transfer of pathogens of international concern from Canada to other countries, but also protects Canada from the introduction of pathogens not found here.

According to feedback we received from the CFIA on our draft report, the exports certified by the CFIA pursuant to the NAAHP are "live aquatic animals and their germplasm as well as a wide range of aquatic animal products for many various end uses including aquaculture, feed production, bait, stocking and enhancement.” The CFIA certifies the health status of Canadian aquatic animals "on the basis that it is considered the Competent Authority for aquatic animal health and has the regulatory framework to meet international standards which include surveillance, and early detection system (mandatory notification) as well as control of international imports.” The diseases kept under surveillance and control under the NAAHP are not limited to those that have been identified to be of international importance but also include diseases Canada has decided to control.

The implementation of the NAAHP depends on the operation of a comprehensive system of surveillance for the pathogens included on the lists of reportable and notifiable diseases established by the CFIA. This system of surveillance must satisfy the CFIA. In the Nova Scotia aquaculture industry, a central part of the system of surveillance is the role the provincial veterinarian plays as both the provider of veterinary services to the industry and the regulator of the industry on matters relating directly to the health of farmed fish.

Two branches of Health Canada also play a regulatory role in aquaculture. The Pest Management Regulatory Agency (PMRA) decides which pesticides may be used in Canada. Like other industries, aquaculture is prohibited from using pesticides not approved for use in Canada by the PMRA. The Veterinary Drugs Directorate (VDD), which is part of the Health Products and Food Branch of Health Canada, decides which drugs may be used in treating or preventing illness and disease in food-producing animals. Like farming, aquaculture cannot use drugs that are not approved for use in Canada by the VDD.

The provinces also have jurisdiction over aspects of the regulation of the use of pesticides and veterinary drugs. In Nova Scotia, approved pesticides must be used in accordance with any regulations that the province adopts or authorizes relating to issues such as permitted methods and frequencies of application, the training that must be provided to applicators, the notifications that must be given before application and the separation distances that must be maintained between the area of application and residences or other activities. Similarly, approved drugs must be used as prescribed by a veterinarian who is licensed to practice veterinary medicine under provincial legislation.

Two other aspects of the involvement of the federal government in aquaculture require mention. The first is that until recently, aquaculture requiring a permit or approval under federal legislation could require, or "trigger," an environmental assessment under the Canadian Environmental 
Assessment Act. ${ }^{101}$ In all cases, this assessment was conducted as a screening-level review by the federal regulator called upon to decide the application for a permit or approval in which the public could participate. Typically, these reviews were triggered under the Navigable Waters Protection Act. Under a new version of the Canadian Environmental Assessment Act adopted in 2012, federal consideration of aquaculture projects will no longer involve an environmental assessment. Indeed, for practical purposes, this would have occurred even if the Canadian Environmental Assessment Act had not been changed, given the replacement of the Navigable Waters Protection Act with the Navigation Protection Act. Under the latter act, aquaculture projects would in most cases not have triggered an environmental assessment under the version of the Canadian Environmental Assessment Act in force until 2012. ${ }^{102}$

The second additional element of the federal role relates to the reliance of provincial regulators on the expertise of DFO scientists and on scientific studies produced by scientists funded or employed by the federal government, and in particular by the DFO. Through our process, we heard frequent concern about the extent to which the federal government and the DFO in particular are perceived to be reducing investment in the science that policy makers need, to better understand the impact of aquaculture (and the impact of the environment on aquaculture), and that regulators need to improve their regulation of aquaculture. In our meeting with the DFO regulators, we were strongly assured that these concerns were unfounded, and we were told that the DFO has actually received increased funding to work on the science needed for effective regulation of aquaculture.

\subsection{The Vital Importance of Intergovernmental Regulatory Collaboration}

It was not within our mandate to consider if jurisdiction over the regulation of aquaculture in Nova Scotia should or can be reallocated. Nevertheless, it is obvious that one of the difficulties to be addressed in developing an effective regulatory framework is the division of regulatory authority between federal and provincial regulators.

Conceptually, there are two kinds of solutions to this problem. One is for either the province or the federal government to become the exclusive regulator. The other is for the two levels of government to effectively collaborate in carrying out their respective functions to ensure that the regulation of aquaculture is as coordinated and seamless as it can be when part of it is provincial and part of it is federal.

The first option may not be available for legal or practical reasons. Given the nature of the relevant competing jurisdictions, it could only be achieved by having the DFO become the lead and comprehensive regulator of aquaculture, as it has in British Columbia. However, it is not clear whether the DFO would have the same jurisdictional authority to do so in Nova Scotia. This is because it cannot be assumed that the Morton decision would be followed if the question of jurisdiction over aquaculture in Nova Scotia's coastal waters were brought before the courts.

\footnotetext{
${ }^{101}$ SC 2012 c 19, s 52.

${ }^{102}$ In some of the feedback we received from the industry on our draft report, we were told that environmental assessment for aquaculture was discontinued - under the Canadian Environmental Assessment Act before the Act was changed and before the Navigable Waterways Protection Act was replaced by the Navigation Protection Act - on the basis of a determination that aquaculture did not in general warrant environmental assessment.
} 
Moreover, it does not appear to us that the DFO wants to take on the same role in Nova Scotia that it has British Columbia. ${ }^{103}$

Moreover, a wholesale federalization of the regulatory framework may not be desirable from Nova Scotia's perspective. The responsiveness of the regulatory framework to Nova Scotia's specific conditions might be reduced. In addition, Nova Scotia would lose the opportunity it currently has to make effective regulation of the industry part of a broader strategy to develop the industry in accordance with Nova Scotia's own economic, environmental and social objectives. Third, the opportunity to integrate regulation of aquaculture with other processes of coastal resource planning and management that are fully within Nova Scotia's jurisdiction could be lost or impaired.

The second option - regulatory collaboration - only addresses the complications that arise from the division of regulatory responsibility between the two levels of government if regulatory collaboration between provincial and federal regulators is a central element of the regulatory framework for both levels of government. The vehicle Nova Scotia and Canada currently use to coordinate their regulatory activities is an MOU. We heard many positive things about the working relationships that exist under this MOU. Nevertheless, our conclusion is that it may not be achieving the level of coordination and collaboration that can be achieved or that is needed for optimal regulatory effectiveness.

From an industry perspective, we heard concerns about the number of regulators, regulatory processes and regulatory requirements the industry must deal with. From a broader regulatory effectiveness perspective, we heard concerns that perceived weaknesses in the current regulatory process were linked to the way jurisdiction over the regulation of the industry is currently divided and managed. For example, some of those who expressed concern that regulation is not sufficiently informed by or grounded in science also expressed the view that this is because the regulatory process is largely in the hands of the province rather than in the hands of the DFO. As another example, the view that the regulatory process lacks rigour was often linked with the view that it lacks rigour because it is in the hands of the province rather than the federal government. This interpretation flows from the perception that the province is not equipped or resourced to regulate rigorously and, in any event, may be too close to the industry to be willing to do so. The representatives of the DFO we met with did not question the will or regulatory capacity of the province, but they did state unequivocally that the growth of the industry depends on public confidence that the industry is being properly regulated.

Our own analysis leads us to a related but distinct concern - that issues that may require regulatory attention might not receive that attention because they are being allowed to fall through the cracks

\footnotetext{
${ }^{103}$ See the new proposed Aquaculture Activities Regulations. For some information on these proposed new regulations, see http://www.gazette.gc.ca/rp-pr/p1/2014/2014-08-23/html/reg1-eng.php and http://www.dfompo.gc.ca/aquaculture/management-gestion/aar-raa-proposition-eng.htm. Our reading of these proposed regulations is that they will mean that the DFO may now generally treat compliance with provincial approvals of aquaculture as determinative of the compliance of the approved aquaculture with the Fisheries Act. If this is an accurate understanding, it emphasizes the importance of the point we make below, that the DFA must take full responsibility for ensuring that its regulation of aquaculture addresses all of the adverse impact that aquaculture might cause, including on matters within federal jurisdiction but which the federal government is leaving to the province.
} 
between federal and provincial regulatory responsibility. This may be because of the tendency of the province to regard certain regulatory issues as more exclusively federal than they actually are.

For example, one of the frequently expressed concerns about aquaculture activities is the impact they can have on commercial and residential boating. The federal government has jurisdiction over navigation, and the province is bound by any limitations the federal government places on aquaculture to address navigational concerns. But there is no constitutional impediment to the province imposing additional limitations to address concerns about navigation that are not addressed by the federal government. The same can be said about the role of the limitations the DFO places on aquaculture to protect wild fish stocks; depending on how these limitations are expressed by the DFO, they may be binding on not only operators but also the province. This does not mean, however, that the province cannot impose additional limitations it decides are appropriate to protect wild fish stocks.

In examples such as these, the province may be failing to fully consider its regulatory authority and responsibilities by taking the view that there are only navigational issues or wild fish issues to be addressed if the relevant federal regulators say there are navigational or wild fish issues to be addressed. Assuming the province has the jurisdiction over aquaculture it claims to have, this ignores its ancillary jurisdiction to deal incidentally with matters in federal jurisdiction when it does so as part of its regulation of aquaculture. Moreover, we believe that Nova Scotia's role as the primary and comprehensive regulator of aquaculture means that Nova Scotia is responsible for using this ancillary jurisdiction (in ways that are compatible with federal law) to ensure that the regulatory framework is fully responsive to the issues that the regulatory framework needs to address. On the navigational issues, Prince Edward Island illustrates how this can be done; it has adopted legislation requiring all operators to provide a standardized navigational channel or space to boaters. This is in addition to any limitations respecting navigation that may be imposed on specific operators by the Coast Guard. 104

Our conclusions based on this discussion for the regulatory framework in Nova Scotia are as follows:

a. Nova Scotia should continue to work with the DFO and other federal regulators through the mechanism of an MOU to ensure that the entire regulatory framework for aquaculture in Nova Scotia is as effective, cohesive, coordinated and streamlined as it can be despite the division of regulatory authority between the two levels of government. The objective should be to make this division of regulatory authority as irrelevant to the regulation of the industry as it can possibly be. Specifically, Nova Scotia's goal should be to ensure that shared jurisdiction over aquaculture does not make compliance with regulation more difficult or costly than it otherwise would be. It should also be to ensure that shared jurisdiction does not minimize or reduce the overall effectiveness of regulation in achieving environmental protection and other regulatory objectives.

b. In order to achieve the desired level of cohesion between federal and provincial regulation, Nova Scotia should work to ensure that federal-provincial regulatory collaboration is based on a strong and clear delineation of roles and responsibilities and a clear articulation of the

${ }^{104}$ See ECELAW, Comparative Analysis of Five Aquaculture Regulatory Frameworks at page 25. 
regulatory objectives of each level of government. ${ }^{105}$ Nova Scotia should work to ensure that collaboration is strengthened by the development of common or shared regulatory objectives that stress regulatory rigour and the avoidance and elimination of unnecessary regulation and of unnecessary regulatory cost, process or administrative burden. To the extent that concerns expressed to us about the unwarranted application of wild fish regulations to aquaculture are valid, Nova Scotia should encourage the DFO, and the federal government more broadly, to take the differences between aquaculture and fishing fully into account in the making or interpretation of federal fisheries laws.

c. Nova Scotia should work with the DFO, and the federal government more broadly, to develop a common list of priorities for the scientific research needed to support and improve the effectiveness of regulation in Nova Scotia's aquaculture industry. Nova Scotia should offer to collaborate with the DFO in developing and implementing a plan for research on these priorities by government or by scientists in the broader research community. In both regards, Nova Scotia should be a leader in proposing a regional rather than a provincial approach that emphasizes

o the importance of aquaculture to all of Atlantic Canada;

o the need for research that reflects the particular biophysical, geographic and socioeconomic conditions of Atlantic Canada; and

o the research capacity in Atlantic Canada.

d. To the full extent allowed by constitutional law, Nova Scotia should be willing and prepared to exercise its authority as the primary comprehensive regulator of aquaculture in Nova Scotia to regulate incidentally on matters primarily within federal jurisdiction where it is necessary to ensure the completeness and effectiveness of the regulatory framework.

\section{DEPARTMENTAL RESPONSIBILITIES FOR REGULATING AQUACULTURE}

In carrying out our review of the current regulatory framework, our understanding was that the activities of the Nova Scotia government in relation to aquaculture are comprehensively housed within the DFA. It seemed to us that this was an understanding shared by those who participated in

\footnotetext{
105 At the Roundtable, there was qualified approval for the recommendation that "the Province should continue discussions with the Government of Canada to clearly delineate areas of responsibility for the planning, regulation and management of aquaculture.” The expressed reason given by some who qualified their support for this recommendation focused on the types of discussions presently ongoing and therefore the precise meaning of "continue discussions." There was also qualified support for a recommendation that "the regulatory framework should define the roles and responsibilities for the province, federal government, First Nations, the aquaculture industry, communities and other parties directly impacted.”
} 
our process. This means the same minister, deputy minister and department have responsibility for supporting the industry as well as for regulating the industry. Both lines of activity take place under the same statute, the Fisheries and Coastal Resources Act. ${ }^{106}$ The content and tone of this legislation is heavily weighted in the direction of the Minister's role in promoting the economic development of the fishery and aquaculture industries. Putting the combined mandate of the Minister together with the legislation, one could conclude that the Minister is the minister for the industry and likewise that the Department is the industry's department.

The regulation that is applied to aquaculture is overwhelmingly concerned with minimizing or mitigating the industry's impact on the environment. It would therefore not be inaccurate to say the regulatory framework for aquaculture is a kind of specialized environmental regulation. In other words, whereas other industries are subject to environmental regulation under the Environment Act, the environmental consequences of aquaculture are addressed in aquaculture regulations.

This legislative, regulatory and organizational model is used across Canada. In British Columbia, where the regulation of aquaculture is largely federal, the DFO is both regulator and supporter of the industry; the same mechanism applies throughout Atlantic Canada, where regulation is either provincial or, in the case of Prince Edward Island, federal with significant provincial involvement.

This also appears to be how the regulation of aquaculture is addressed in jurisdictions outside Canada. In Norway, Scotland, Chile and Maine, the regulation of aquaculture is largely the responsibility of the same government entity that promotes and supports the growth of the industry.

Moreover, this model is a very common approach to regulation across the natural resources sectors of farming, fishing, and forestry. Historically, it was also the approach taken to the regulation of mining, but for many decades, the environmental regulation of mining has been by environmental regulators acting under "generic" environmental legislation.

Concerns about the dual mandate of the Minister and DFA were frequently raised in our process. ${ }^{107}$ Many expressed concern about what they perceived to be an unavoidable conflict between the two roles that undermined confidence in the independence, objectivity and rigour of the regulatory process. To put it very bluntly, many told us flatly and unequivocally that they could not trust a regulator of the industry who was also responsible for promoting and supporting the development and growth of the industry. Frequently, we were told that the distrust was accentuated where government provided significant economic development funding to a specific aquaculture business.

We were urged by many to recommend a regulatory framework under which responsibility for regulating aquaculture would be moved to the Minister of Environment. We have thought very seriously about the matter, as in many ways it goes to the heart of the lack of trust at the centre of much of the dissatisfaction with the current regulatory framework. In the end, however, subject to

\footnotetext{
${ }^{106}$ SNS 2012 c22.

107 There was partial support at the Roundtable for a recommendation that "the regulatory framework should ensure that responsibility and accountability for the regulation of aquaculture is clearly separated from the function of industry promotion and marketing to prevent actual or perceived conflict of interest. This may be accomplished by moving regulatory responsibility to a different department or by other means to be determined by the Panel.” See also the ECELAW report Aquaculture Regulation in Nova Scotia at pages 20 21, which discusses this dual mandate and expresses the same concern.
} 
what we say below (Sec. 10) on the issues of environmental monitoring, we have concluded that responsibility for regulation of aquaculture should otherwise remain with the Minister of Fisheries and Aquaculture. There is, however, an important proviso to this conclusion; it depends on acceptance and implementation of the other elements of our proposed regulatory framework, many aspects of which are designed to address by other means the distrust that exists with the perceived conflict of DFA roles under the current regulatory framework.

We have reached the conclusion that DFA should continue to be responsible for the regulation of aquaculture for the following reasons:

a. First, it is important to note that although the regulation of aquaculture is largely concerned with environmental protection, it is not exclusively concerned with environmental protection. It also concerns the use of a public resource - coastal waters - and the place of aquaculture in the development, use and protection of coastal resources. It may not make sense to reallocate these aspects of the regulatory framework to the Department of the Environment. It would give that department a different relationship to aquaculture than it has to other industries.

b. The result of reallocating the environmental aspects of provincial regulation of aquaculture to the Department of Environment would add to the already complex regulatory landscape that exists within the sector. It would mean that regulatory authority was not only divided between the federal and provincial governments, but then sub-divided between two provincial departments. This might deal with the institutional trust issue but make regulation less cohesive and organized.

c. As discussed earlier, provincial regulation of aquaculture already suffers from a lack of regulatory capacity. We have concluded that the province's regulatory capacity must be increased if Nova Scotia is to have a viable and trustworthy regulatory framework. We think that the capacity gap is more likely to be addressed cost-effectively if the increased capacity is largely concentrated in one department rather than divided between two departments. It is important to recognize that the Department of Environment may currently have very little of the capacity and expertise it might need to become an effective regulator of aquaculture. If the Department were given a broad regulatory responsibility for aquaculture and this lack of capacity and expertise were not addressed, it might have little choice but to rely extensively on the DFA for advice. To avoid this outcome, the Department of Environment might require such a large percentage of the province's increased regulatory capacity as to leave the DFA unequipped to deal with its continuing responsibilities.

d. Dividing regulatory functions between two departments might complicate Nova Scotia's ability to collaborate on aquaculture with other governments in Atlantic Canada, all of which combine industry promotion and support with regulation in one government department that is also responsible for the fisheries mandate.

e. While separating the regulatory role from the industry-development role might improve confidence in the independence and trustworthiness of the regulatory process, it may or may not result in improved regulatory effectiveness. Meanwhile, we are confident that regulatory effectiveness can be improved by the DFA's adoption and implementation of the regulatory framework we have proposed. 
f. Even if we were otherwise inclined to recommend assignment of regulatory responsibility to the Department of Environment, the approval process and the environmental assessment process in Parts IV and V of the Nova Scotia Environment Act would require significant enhancement to serve as useful regulatory tools under the enhanced regulatory framework we have proposed for aquaculture. Public engagement, and transparency in particular, would have to be enhanced significantly in both processes.

\section{RESTRUCTURING THE ADMINISTRATION OF THE REGULATORY FRAMEWORK}

While we conclude that the regulatory framework should continue to be administered by and on behalf of the Minister of Fisheries and Aquaculture, we also conclude that important changes need to be made to how the regulatory framework is administered by DFA to address legitimate concerns about its independence, objectivity, dependability and effectiveness. The changes required include much greater levels of openness, transparency and clarity; a transfer of responsibility for the monitoring component of the Environmental Monitoring Program to the Department of Environment; and legislative changes that reduce the regulatory process's dependency on ministerial discretion.

Each of those aspects of the proposed regulatory framework is discussed elsewhere in this report. Here we focus on another set of changes we think will be important to restoring and maintaining confidence in a regulatory framework that is primarily administered by the DFA. These changes are intended to create greater and clearer operational separation between the Department's regulatory responsibilities and the other functions it performs relative to aquaculture, and to formalize the role of departmental officials in the regulatory process.

Regarding the separation of functions, there should be a clear organizational demarcation within the DFA between those who have decision-making responsibilities in the regulatory process and those who are involved in working to grow and develop the industry. To implement and reinforce this, the regulatory function should be led by an official or officials who report directly to the Deputy Minister or to an Associate Deputy Minister as the Deputy Minister’s designate.

On the formalization of the role of departmental officials in the regulatory process, we believe the legislation should assign responsibility for leading and managing the regulatory program to a statutory officer who would, by statute, belong to the public service. The position would report directly to the Deputy Minister or to the Associate Deputy Minister as the designate of the Deputy Minister. The Act should set out the mandate of this official with sufficient detail to accomplish three objectives: to make it clear that the mandate is a statutory one, to make it clear the mandate is limited to regulation, and to ensure the mandate encompasses the whole of the regulatory function, subject of course to the general authority of the Minister over the work of the Department as a whole.

We believe that the mandate of the statutory official responsible for regulation should include responsibility for decision making on aquaculture licences. This is the model used in New 
Brunswick. ${ }^{108}$ Legislation would continue to confer broad powers, ultimate authority and accountability for oversight and policy-making on the Minister. It would, however, assign administrative responsibilities for the regulation of the industry to an "Administrator." Such a legislative model, in which licensing is a public service function subject to ministerial oversight and policy-making, would bring the regulation of aquaculture into line with modern approaches to environmental regulation. Under the Environment Act (and environmental legislation throughout Canada), decision making on industrial permits is handled by bureaucratic officials, whereas in the 1970s and 1980s, it would more typically have been done by ministers of environment.

We understand that this will be less of a separation than can be created by placing responsibility for regulation in another department. We also understand that some will say that an organizational separation within a government department will be artificial and therefore ineffective. We do not reject these concerns out of hand but instead contend that they understate the benefits that can come from greater legislative differentiation between the regulatory and industry-development functions of the DFA and legislative allocation of regulatory responsibility to the bureaucratic level. Specifically, we think these benefits can include

a. greater clarity for officials in both branches of the Department's mandate, as well as for those they work with, as to which "hat" they are supposed to be wearing

b. meaningful protection against regulatory responsibilities being subordinated to industrydevelopment objectives and priorities

c. increased independence of decision making by those who have regulatory functions and responsibilities

d. a less political and more professionalized regulatory process

\section{ENVIRONMENTAL MONITORING PROCESS}

In 2003, the Nova Scotia DFA implemented an environmental monitoring process (EMP) for finfish aquaculture. In our process, no one questioned the need for such a process and in our view, it should be continued. We believe, however, that it should be strengthened in six important respects:

1. First, the EMP should be established in legislation. In other words, existence of the EMP should not depend on a decision to be made by the DFA.

2. Second, the parameters of the process should be prescribed in regulations rather than in departmental policy. 109

\footnotetext{
${ }^{108}$ For more discussion of this concept as it operates in New Brunswick, see the ECELAW report Comparative Analysis of Five Aquaculture Frameworks at page 14.

${ }^{109}$ We have chosen the wording here - "the parameters of the process" - deliberately. We would not want the substance of the EMP defined in such detail in legislation that the program ceases to have the flexibility it needs to evolve and change to deal with changing circumstances. Instead, it is the responsibility to comply with the procedural aspects of the EMP that should be defined in legislation.
} 
3. Third, legislation should make compliance with the process a term and condition of all licences. The mandatory nature of the process should not depend on whether or not it is written into the terms and conditions of specific licences. By "compliance with the process" we refer to the steps a licensee has to take to implement and conduct the environmental monitoring required by the legislation and the regulations. The regulatory action to be taken in light of whatever environmental monitoring reveals about the environmental performance of the site would apply to the compliance of the site with its environmental performance obligations rather than to its compliance with the requirement to conduct environmental monitoring.

4. Fourth, the responsibility for monitoring compliance with the EMP should be transferred to the Department of Environment in order to improve public confidence in the independence and objectivity of the oversight that government brings to bear on industry's compliance with the EMP. ${ }^{110}$ This is New Brunswick's approach, and we think it is one that should be adopted in Nova Scotia. This means that capacity and expertise will have to be built up in the Department of Environment. To some degree, this could cause some of the problems associated with multiple regulators and dividing resources between two departments that lead us to conclude that general regulatory responsibility should not be transferred from DFA. Nevertheless, we think these issues will be manageable if the transfer of responsibility is limited to the EMP. In addition, the avoidance of these issues is not important enough to outweigh the importance to the whole regulatory process of the credibility and trustworthiness of the EMP.

\footnotetext{
${ }^{110}$ During our consultations on our draft report, we were encouraged to consider additional measures to ensure adequate separation between the regulation of the industry and government's non-regulatory work to enable the development of the industry. One particular option was a proposal to move all of the nonregulatory functions from the DFA to the Department of Economic Development and Rural Development and Tourism, thus limiting the DFA to a purely regulatory role. Independently of our receiving this feedback, we were told by the DFA that the movement of responsibility for industry support and development to the Department of Economic and Rural Development and Tourism has largely already happened and that it will be completed in the near future. This led us to think carefully about whether we should reconsider our recommendation that responsibility for administration of the EMP should be moved to the Department of Environment. We recognize that our rationale for this recommendation, which is to create institutional separation between industry promotion and the environmental monitoring part of regulation, could be said to be addressed by the movement of non-regulatory functions away from DFA. In other words, we recognize that institutional separation between environmental monitoring and non-regulatory functions can be achieved either by removing the non-regulatory functions from the DFA or by moving responsibility for environmental monitoring to the Department of Environment. We also recognize that confidence in the option that would see monitoring stay in the DFA as a purely regulatory department could be strengthened if the independent body we recommend later in this report to receive and consider citizen applications to have licences revoked were also given the authority and responsibility to conduct a periodic review of the functioning of the monitoring process through a process that sought public input. Indeed, such an approach might provide greater assurance of the rigour, reliability and transparency of the monitoring process than would movement of the function to Environment. In the end, however, we have concluded that our original recommendation to move administration of the monitoring program to Environment responds more directly to the concern we heard from many that trust and confidence in the EMP was critical to trust and confidence in the overall regulatory process and that a move of the monitoring function to Environment would do much to restore trust and confidence in this critical aspect of the regulatory process. At a later date, assuming trust and confidence in the overall regulatory process has been restored, a different institutional configuration might be appropriate.
} 
5. Fifth, the regulatory monitoring of compliance of operators with the EMP has to be strengthened. More auditing of compliance is required. The auditing process should include random, unannounced audits. Whether directly or through contracted third parties who are independent of industry, regulators should more frequently collect their own samples for analysis - on an unannounced random basis subject only to the advance notice that is required to address biosecurity concerns.

6. Sixth, results from the EMP for each site should be made available to the public in a timely manner. Ideally, this would be done by posting the results to a common governmentcontrolled website.

We were urged to also recommend an expansion of the scope of the EMP. ${ }^{111}$ Specifically, it was suggested that the EMP should monitor heavy metal levels in addition to sulphide levels. We have concluded we are not able to make such a recommendation, primarily because of the different views we heard about the cost and feasibility of this monitoring, as well as its usefulness. ${ }^{112} \mathrm{We}$ do, however, think that expansion of the EMP warrants further consideration, including the possibility of additional parameters. ${ }^{113}$ In the meantime, we have made recommendations elsewhere in this document that will require significant reduction of the discharge of heavy metals into the environment.

\section{STATUTORY STANDARDS}

Our understanding of the current regulatory framework is that there are a number of licensing terms and conditions that go into every licence and a number of leasing terms and conditions that go into every lease. There may also be terms and conditions that go into most licenses and leases. There are, in other words, a number of standard terms and conditions for licences and leases. We think that these standard terms and conditions should be set out in law to improve the transparency of the regulatory framework and general knowledge and understanding of the nature and range of controls that they place on the industry. Two of the most obvious ones would be

- the conditionality of each licence on compliance with the Act and regulations and the terms and conditions of licence and lease, and

- compliance with the Environmental Monitoring Process.

\footnotetext{
${ }^{111}$ There was partial support at the Roundtable for the recommendation that "the regulatory framework should require a move away from a narrow focus on sulphides to include the use of a more extensive list of environmental indicators for monitoring. These may include metal contamination, bacterial layers, dissolved oxygen and biodiversity of sediment life. Far-field effects and biological recovery should also be addressed."

112 See, in part, the notes from the Knowledge Workshop session on February 10, 2014, and the session on March 28, 2014. In response to our draft report, we heard strong disagreement with the view expressed at our Workshop that it would be cost-prohibitive to expand the parameters of the EMP to include monitoring for heavy metals.

${ }^{113}$ Although it was not stated perfectly clearly, some of the feedback we received from the industry suggests this might be regarded as a preferred option to the recommendation we make later to prohibit the use of antifouling methods or substances that disperse heavy metals or chemicals into the environment.
} 
In addition, we think the following issues should be addressed in legislation (either in the Act or the regulations made under the Act):

\subsection{Obligation to Maintain Oxic Conditions}

It should be a basic and fundamental condition for the licensing of fin-fish aquaculture in a marine setting that oxic conditions (normal or specified levels of oxygen in the water column) can be and have been maintained. ${ }^{114}$ This would not mean that isolated temporary failures to meet oxic conditions would warrant revocation of a licence. It would, however, warrant taking action to bring conditions back to the oxic level and to be maintained there on a consistent basis.

To ensure that oxic conditions are maintained and that licence conditions are properly calibrated to achieve and maintain that objective, there should be a legislative requirement that terms of the licence will be reviewed following the conclusion of each growing cycle to ensure that the site conditions are suitable for another growing cycle, and to ensure that appropriate adjustments are made to fallowing periods, stocking density and other terms and conditions of the licence.

Where experience suggests that a difficulty in maintaining oxic conditions lies not with the operation of the licensed operation or with its compliance with regulatory requirements, but rather with the biophysical conditions of the site, it should be clear that the appropriate regulatory response is to require removal of the operation from the site or its conversion to a kind or level of aquaculture that is appropriate to the site. For operators who lose their sites in such circumstances, the regulatory framework should be committed to make an alternative and appropriate site available to the operator. This could be facilitated by the proactive identification by the DFA of Green areas for fin-fish aquaculture, using the process for the strategic assessment of coastal areas that we recommend below (Sec. 17)

\subsection{Anti-fouling Technology}

In marine-based fin-fish aquaculture, nets and other equipment must be regularly cleaned to prevent the build-up or persistence of materials, such as fish waste or uneaten food, that can cause disease to both farmed and wild fish. One of the methods of anti-fouling that have been used is to spray nets and other equipment with anti-fouling substances that contain copper and other heavy metals. We were told by some members of the industry that where anti-fouling is applied it is no longer applied by spraying but by a dip process conducted on land. They also told us that the industry is in the process of transitioning to mechanical cleaning technology. ${ }^{115}$

Copper is a toxic substance, and its release into the marine environment should be minimized or, ideally, avoided. To accelerate the transition already taking place in the industry toward antifouling methods that avoid the release of copper and other toxins into the environment and to ensure that the industry in Nova Scotia operates at the leading edge of environmental protection practices, we recommend that Nova Scotia's regulatory framework should prohibit the use of any

\footnotetext{
${ }^{114}$ It was suggested at the Roundtable that another or different approach would be needed for bodies of water that were not oxic in their natural state. The Bras D’Or Lakes were given as the example.

${ }^{115}$ See Knowledge Workshop notes from February 10, 2014, at page 2.
} 
substance or method of anti-fouling that results in the dispersal of copper, other heavy metals or potentially harmful chemicals into the environment. 116

\subsection{Standard Reporting Obligations for Each Kind of Aquaculture, Including the Following Matters for Fin-Fish Aquaculture:}

The legislation should specify the reporting obligations that will apply either to all operators or to all operators licensed to conduct kinds of aquaculture to which standardized reporting obligations on the specified subjects should apply. For fin-fish aquaculture, these standard reporting obligations should cover

- escapes

- fish mortality events and levels

- damage to equipment

- monitoring results

- disease and sea lice outbreaks

- use of permitted treatments to address disease or sea lice

Putting reporting obligations on these subjects into legislation will ensure that they are maintained and enforced on a consistent and continuing basis. It will also contribute to transparency and accountability of the regulatory process and to public knowledge of the regulatory process.

\subsection{Standard Requirement Regarding Accommodation of Navigation}

We recommend that the legislation require accommodation for boaters to be built into every lease. Where feasible, this could be done by including a "navigational channel" in every lease, which is the approach followed in Prince Edward Island to avoid or at least minimize conflict between aquaculture and other users of coastal waters. We recognize, however, that all or virtually all leases in Prince Edward Island are for shell-fish aquaculture and that this approach may not work with fin-fish leases. ${ }^{117}$ If that is the case, an alternative method or methods for ensuring that fin-fish leases do not unduly and unnecessarily impinge on boaters should be considered.

\footnotetext{
${ }^{116}$ We make no assumption here that heavy metals are present in the benthos because of aquaculture. We are saying instead that as a matter of environmental policy, the cleaning of nets should be done, because it can be done, without discharging heavy metal into the benthic region.

${ }^{117}$ In the feedback it provided to us on our draft report, the ACFFA stated that a navigational channel through "the middle of a lease" was impracticable because movement restrictions are determined under federal legislation, due to biosecurity protocols and the physical structure (cages, grids, anchor lines) on sites. We suggest that in the development of the proposed regulatory framework, work be done to identify options for better accommodating the interests of boaters in ways that address the legitimate concerns of fin-fish lease holders having boaters on or near leases.
} 


\subsection{Other Standard Terms}

The legislation should clearly specify the matters that have to be addressed in the terms and conditions of each licence and lease. ${ }^{118}$ These mandatory items would include but not be limited to terms and conditions on the following matters:

- Species to be grown

- Stocking density

- Fallowing period requirements

- Duration of lease and licence

- Any specific operational procedures and technologies identified during the regulatory review process that could reduce the environmental impact of the operation

- Clear rules for use of medication and pest-control products

By specifying the matters that are required to be addressed in each licence, the legislation will ensure that they are addressed in all licences on a consistent and continuing basis. It will also help to contribute to the transparency and accountability of the regulatory process and to public knowledge and understanding of the regulatory process and the content of regulatory requirements.

\section{EXPERIMENTAL OR DEVELOPMENTAL LICENCES}

In our draft report, we did not address the question of whether the proposed regulatory framework would provide for experimental licences or developmental licences; that is, for licences that would be granted to applicants who wanted to conduct aquaculture to test or develop new technology or methods or to carry out basic research. In the feedback we received on the draft report, particularly at the public feedback meeting we held at Tatamagouche, we were asked to consider adding an explicit provision for an experimental or developmental aquaculture licence to our proposed regulatory framework.

\footnotetext{
${ }^{118}$ Some of the feedback we received on our draft report suggests we were not clear in expressing our intent with this recommendation. For example, we were told that our proposed statutory standards were too prescriptive and that a performance-based approach was better-suited to deal with matters such as stocking density and fallowing periods. This feedback suggests that some may have interpreted our recommendation to be that matters such as stocking densities and fallowing periods for specific sites were to be fixed in legislation. That is not our recommendation. Instead, our recommendation is that legislation be explicit in requiring these matters to be addressed in every licence, taking account of variable factors such as velocity of currents, water depth, species and age class. Nor is our recommendation that such matters as stocking densities or fallowing period be fixed irrevocably in each licence. We recognize that the terms and conditions of a licence must be subject to variation if the regulatory framework is to be functional and effective. Our recommendation is that requirements of a licence at any given time on matters such as stocking densities and fallowing periods be clearly stated so that the public can know what they are, and also that terms and conditions be changed, where change is determined to be appropriate, in a way that is transparent to the public.
} 
The Fisheries and Coastal Resources Act currently provides for experimental licences. It states that the Minister may grant "a special experimental licence upon such terms and conditions as the Minister deems appropriate.” It also states that an experimental licence "shall not be granted for commercial purposes.”119

We think there is a clear rationale for an experimental licence option where the purpose of the licence would be to allow academic or communal research to proceed. Where that is the purpose of the proposed aquaculture, the regulatory framework should authorize the granting of an experimental licence by way of a simplified application procedure. There should be public notice and an opportunity for public input, but otherwise researchers should not be required to go through as detailed an application process as those who are applying for a commercial licence. Instead, what matters with such a licence is that it comes with terms and conditions that ensure that the aquaculture to be conducted is of limited scale and duration and closely tied to the research question or program. There should also be conditions requiring the results of the research to be made public, ideally through peer-reviewed journals.

We think there is also a rationale for an experimental licence option where the proposed aquaculture is to be carried out by an aquaculture company that wishes to test a new technology or method of aquaculture. The opportunity to engage in such applied and commercially-motivated research may be critical if the industry in Nova Scotia is to become a truly low-impact and highvalue industry. In particular, such research can be very important to the ability of the industry to develop technologies and approaches that are better adapted to Nova Scotia's particular biophysical and coastal conditions than are technologies and approaches imported from elsewhere.

The concern with research or developmental aquaculture of this nature is that it not become a way of obtaining a commercial licence without having to go through and comply with the application process that applies to commercial operations. The limitation that an experimental licence should not be granted for commercial purposes should therefore also apply to this kind of experimental or developmental aquaculture. Similarly, as with a licence given to authorize academic or communal research, the aquaculture authorized by an experimental licence given to someone who wishes to test or develop technologies or approaches for commercial deployment should be of limited scale and duration as well as being closely tied to the research question or program.

Ideally, commercially oriented research should also be conducted under an expectation that the results be made public, preferably through peer-reviewed publications. Where that approach is followed, we see no reason why an experimental licence could not be given for such research through a simplified process similar to the one that would be applicable to an application for an experimental licence to conduct academic or communal research.

We understand, however, that private companies invest in research of this sort to gain a competitive advantage. Making an academic approach mandatory could mean that valuable research of potential importance to the development of the industry in Nova Scotia might thereby be precluded. To address this problem, we suggest that the DFA could use the strategic assessment tool we recommend later in this report to conduct one or more strategic assessments to identify

${ }^{119}$ SNS 2012 c22 at s 55(1) and 55(2). 
coastal areas that would be suitable for the conduct of experimental or developmental aquaculture under an experimental licence. As we explain later, provided that the strategic assessment were conducted on the clear basis that it could result in the issuing of one or more experimental licences, and provided that the process gives the public an opportunity to participate - equivalent to any opportunity they would receive through the licensing process - a strategic assessment could lead to the issuing of one or more experimental licences through a streamlined licensing process.

The DFA would have the option of going one step further. Assuming an interest from the industry, it could conduct a strategic assessment to identify a suitable location for a fixed aquaculture test facility that would then be available to participants in the industry to carry out small-scale aquaculture for the purpose of testing or developing new technology, management practices or approaches. This could be done in partnership with industry associations. It could perhaps be modelled on the test-site approach taken by Fundy Ocean Research Centre for Energy (FORCE) to the testing and development of tidal power technology in the Bay of Fundy. ${ }^{120}$ This approach would, however, be a decision for DFA to make; we are not proposing it as something that DFA would be expected to do under the proposed regulatory framework.

Where an applicant for an experimental licence to conduct commercial research does not wish to abide by the conditions that would allow it to access the simplified application process for experimental licences, and where an applicable strategic assessment has not been completed, the standard licence application process for commercial licences would apply. However, the scale and duration of the aquaculture proposed to be undertaken would typically be expected to be taken into account in the exercise of the procedural discretion provided for in that process. For example, unless the licence sought were to conduct a kind of fin-fish aquaculture in a Red area for that kind of aquaculture, it would be expected that an administrative rather than an adjudicative hearing would be appropriate.

\section{REGULATORY TRANSPARENCY}

Lack of transparency about the regulatory process and its operation in general, and in relation to specific sites, was a frequently voiced concern in our process. At the Roundtable, there was qualified approval for the following recommendation: "All licence application information pertaining to environmental impact and impacts on other marine resource use and users should be made publicly available.” ${ }^{121}$ For members of the Roundtable who qualified their support for this recommendation, the concern was protection of confidential business information.

In addition to concerns about the current lack of transparency and openness, we heard quite a bit about the positive value of transparency and openness in contributing to the effectiveness of

\footnotetext{
${ }^{120}$ A description of the FORCE test site and how it is governed and operates can be found at http://fundyforce.ca/.

${ }^{121}$ See page 14 of the Roundtable Final Report. Also, there was qualified support at the Roundtable for a similar recommendation that "all Environmental Monitoring Program data should be made publicly available on a website in a timely manner.” (Roundtable Final Report, 29)
} 
regulation. We heard that it is critical to maintaining the regulators' independence of the regulated sector. In other words, it reduces the danger of regulatory capture. We heard that transparency helps to ensure the answerability of regulators for their choices and actions, to regulated businesses as well as to the public, including those who benefit most directly from regulation. We heard that transparency improves both the public's and the regulated sector's understanding of the regulatory process, helping each to contribute positively to regulatory success. In this regard, a number of people expressed the view that greater transparency is a good thing for regulators who regulate effectively and for businesses that comply with the regulations, as it demonstrates that regulation works and makes it difficult for critics to unfairly portray the regulatory process in an inaccurate negative light.

In addition, it is important to note that current distrust and lack of confidence in the regulation of aquaculture in Nova Scotia stems from the perception that the current process is not transparent and open. For a new regulatory framework to enjoy a positive level of trust and confidence, it must be defined by transparency and openness.

Transparency should start by ensuring that comprehensive and easy-to-understand information on the regulatory framework is readily accessible to anyone who wants it. This will address the real frustration and irritation we heard from many, including some in the industry, about the difficulty they had experienced in obtaining clear information about matters such as the steps in the regulatory process, the obligations of applicants for leases and licences and of operators once licensed, their opportunities to participate in the regulatory process, and the actions the DFA can or will take to ensure compliance with the regulations.

The difficulty people experience getting basic information on these and other aspects of regulation is one more factor undermining confidence in the current regulatory process. It contributes to the impression people have that information is withheld and only provided when the right questions are asked. It appears to result in different people being given different information, depending on whom they ask and how they ask for it.

It should be recognized that some of the difficulties being experienced in this regard may reflect the number of agencies involved in the regulation of aquaculture and the appropriately variable nature of the regulatory process. Some of the frustration may also be caused by the probability that not everyone who works for the DFA or in the industry has all of the same information on the regulatory process. Also, our impression is that more information on the process and the operation of the process is available than many people appreciate or are in a position to appreciate because of the less than user friendly way in which it is made available through the government's website.

Nevertheless, we think that much more can be done to make information on the regulatory process and how it works readily available to the public, including through the DFA's website. For example, the DFA should work with other provincial and federal regulators to produce a single shared document that comprehensively describes and explains the entire regulatory process as it works in Nova Scotia. The DFA could work with the Regulatory Advisory Committee, which we recommend in a later section of this report, on improving and better disseminating information about the regulatory process. The DFA should work with the network of existing coastal community organizations with an interest in aquaculture to ensure that good and comprehensive information on the regulatory framework and its operation is regularly shared through that network. 
We also think that the DFA needs to ensure that DFA employees have a consistent level of knowledge about how the regulatory process is structured and operates. The DFA also needs to ensure that DFA staff are mandated to share that knowledge in their dealings with those they interact with in the course of their jobs. Instead, or in addition, the DFA could ensure that questions about the regulatory process are consistently fielded by the same members of staff. This is the approach that has been taken by other regulatory agencies.

Transparency and openness should extend beyond general information about the regulatory process. It has to also be the rule in the application of the regulatory framework to each application for a lease and a licence, and to the DFA's ongoing oversight of each licensed operation. As nearly as possible, the objective should be to make application and operation of the regulatory framework an open book.

In keeping with the spirit of the recommendation that received qualified support at the Roundtable, we therefore recommend that the basic principle should be that information relevant to understanding the operation and effectiveness of the regulatory process as it applies to each proposed and approved site should be readily available to the public. This principle should be set out in legislation to ensure that it is binding on the DFA and to ensure that public access to information covered by the principle does not require the making of an application under the Freedom of Information and Protection of Privacy Act ${ }^{122}$ (FOIPOP) process.

Information that is truly confidential business information should be excluded from this principle under a definition of confidential business information set out in the legislation. But the assumption should be that information is public unless a regulated business clearly establishes that it is confidential business information within the scope of the statutory definition. In other words, the onus to show that information should be kept confidentially in the hands of the DFA because of its confidential business nature should lie with the business that claims that the information is confidential business information.

We do not have the information we would need to give precise advice on how confidential business information should be defined. The definition should, however, be a narrow and precise one, as otherwise the exception might become the rule. In that scenario, legislative provisions intended to require and enable transparency and openness might then end up being a legal barrier to transparency and openness. The concept that should guide the drafting of the definition of confidential information is that information is confidential to a business where, realistically, its release could expose the business or associated businesses to economic harm.

We anticipate that discussion of this approach to limiting the information that can be withheld because of business confidentiality will raise the question of whether companies will be able to withhold information about the kind and quantity of antibiotics that are used in fish feed. The use of antibiotics is one of the significant issues of controversy in relation to marine-based fin-fish aquaculture. We were told by people in the industry and by knowledge experts on the industry that the use of antibiotics is limited and declining. ${ }^{123}$ We were also told that releasing information on

\footnotetext{
122 SNS 1993 с 5.

${ }^{123}$ In addition, we were told by people in the industry and by knowledge experts on the industry that far less medication is used for aquaculture than for any other farmed animal. This was reiterated to us in the feedback
} 
antibiotics would allow competitors to figure out the feed formula being used, which is regarded as proprietary information in the industry.

We also anticipate another issue that may be of concern to the industry - that open transparency on information pertaining to fish health will adversely affect competitiveness and marketing by creating the false impression that fish farmed in Nova Scotia are susceptible to illness while those farmed elsewhere are not.

We are not dismissive of these concerns. However, we are strongly of the view that the current approach undermines trust and confidence in the industry, the DFA and the regulatory process. The industry's social licence and its ability to respond to and address concerns suffers in consequence.

However confidential business information is defined and protected, we think the principle of transparency and openness should generally apply to the process of applying for a licence and lease or for a variation or renewal of a licence and lease. As a general principle, and subject only to the protection of information that is clearly demonstrated to be confidential business information, the DFA's file on each application should be open and accessible to members of the public. The intent would be to make the information provided by the applicant, and all of the information provided in respect of the application by third parties, open to public scrutiny. It would also be to make all of the documentation generated in the DFA as part of its assessment of an application part of the public record of the application. The conclusions reached on the application, and the reasons for those conclusions, should also be "on the record.” The same would apply to the consideration and decision of any appeal that follows from a decision on a licence or lease.

Similarly, once a licence and lease are issued, the ongoing application of the regulatory framework to the approved operation should be, as nearly as possible, an open book. Subject to the protection of information that is established to be confidential, all of the data, information and reports that the operator is required - by the legislation, by the terms and conditions of its licence or by order of an inspector - to submit to the DFA or to the Department of Environment ${ }^{124}$ should be accessible to the public. Likewise, all documentation relating to the monitoring by the DFA of compliance with the regulatory framework, or to actions taken by the DFA to ensure compliance or to enforce the regulations, would become part of the file of material available to the public. This would include a copy of all inspection reports and any warning letters or orders written to address instances of noncompliance. The publicly available information should also include all documentation pertaining to complaints received about an approved operation and the action taken by the DFA in response to the complaints.

The objective of our recommendations is a level of transparency and openness that would allow a member of the public to readily ascertain at any given time the status of an application for a licence and lease (or for a change or renewal of a licence and lease) or the standing of an approved operation relative to its regulatory responsibilities. We recognize that implementation of such a

we received from the ACFFA to our draft report. The ACFFA feedback also stated that "less than three (3) per cent of salmon feed in Canada is medicated," which is the kind of information we refer to in saying that industry and knowledge experts told us that "use of antibiotics is limited and declining."

${ }^{124}$ This assumes acceptance of our recommendation that the administration of the Environmental Monitoring Program should be moved to the Department of Environment. 
high level of transparency and openness could divert resources away from regulation and into providing information about regulation. We also recognize that this level of openness and transparency can inhibit the open flow of information between regulators and the regulated, and among regulators, in ways that can be harmful to regulatory effectiveness. Nevertheless, we think the level of transparency and openness we have proposed is what is called for.

First, what we have heard from Nova Scotians leads us to conclude that it will be essential to the trust and confidence they place in any new regulatory framework that it operate under conditions of high transparency and openness. We would go so far as to say that of all that must be fixed with the current regulatory framework from a community perspective, this one is a precondition for the other improvements to be accepted, effective and worthwhile. In fact, the level of transparency and openness we are proposing is an essential complement to other parts of the framework we have proposed. For example, our recommendation that regulatory responsibility remain primarily with the DFA assumes that the DFA will operate under the very high level of transparency and openness that we have recommended here. We would reconsider this and other recommendations if this assumption were mistaken.

Second, our analysis of the regulatory framework in other jurisdictions leads us to conclude that a high level of regulatory transparency and openness has been a core feature to the reforms adopted in recent years in other jurisdictions, including Scotland and Maine. These were the two jurisdictions most frequently cited to us as models to follow, by those who were generally in favour of significant change in how aquaculture is now regulated in Nova Scotia. More broadly, most of the regulators we spoke to in order to learn about their role in the regulation of aquaculture emphasized the importance of transparency and openness, even if they did not work in regulatory systems that have gone as far as Scotland and Maine have gone to make transparency and openness into operational reality.

Third, although we are not dismissive of the administrative concerns about diversion of resources and barriers to the flow of information, we think these issues can be managed. If resources are put into creating good systems that make transparency and openness standard operating procedure, including information systems that make good use of technology, the ongoing diversion of resources can be mitigated. As for concerns that high levels of transparency and openness will inhibit the flow of information, our experience suggests that this is often less of a problem for administrative systems than people responsible for those systems assume it will be. Participants in the regulatory process will adjust their behaviour and interactions to reflect the awareness that they are participating in a process of public administration to which high standards of transparency and openness are applicable. When this happens, the benefits that can flow from transparency and openness will outweigh any challenges it creates.

Finally, because the regulation of aquaculture is a process of public administration relating to the use of public resources by private businesses, it should be conducted under high standards of transparency and openness so that it can be held accountable by Nova Scotians. 


\section{PROVISIONS ON AQUATIC ANIMAL HEALTH AND WELL- BEING}

The conditions under which fin-fish facilities operate, from site selection to stocking density to cage design and maintenance requirements, should be addressed with fish health as a priority objective. It was suggested to us on a number of occasions that ensuring the health of farmed fish is the very best way to avoid, eliminate or reduce the environmental impacts of fin-fish aquaculture that give rise to the greatest concern. It was also suggested that fish health is crucial to the productivity of the Nova Scotia industry as well as to its reputation in the market, and thus to its competitiveness compared to the aquaculture industry in other jurisdictions.

At the Roundtable, there was only partial support for the recommendation that

the Province should develop an appropriate protocol to address all aspects of fish health and should ensure appropriate expertise is involved. Fish with reportable diseases should be removed from ocean pens as soon as possible. No grow-out should be permitted. Harvesting controls should be instituted until the site has been declared free from the specific pathogen.

However, the reservation expressed by some Roundtable members was not about the idea of a comprehensive approach to fish health. Rather, it was about the prescriptiveness of the recommendation on how that should be done in all cases. In particular, reservation was expressed about an absolute obligation to remove from the water all fish with a reportable disease. There was also concern to ensure that this recommendation would be made in the context of marine-based farming and would not be applicable to shell-fish operations.

In our view, the focus of the regulatory framework on fish health and well-being should definitely be on the outcomes rather than on the specific mechanisms to be used to achieve those outcomes. The goal should be to design and operate fish-growing operations that grow healthy fish, fish that never or very rarely require medication or pest-control treatment, and that have the lowest mortalities in the industry. We understand that it may take some time to reach this ideal. It is important, however, that every pest or disease outbreak be treated as a learning opportunity to reflect on the conditions under which fish are grown in these facilities and to improve those conditions to improve fish health. This will include learning about appropriate versus inappropriate sites, learning about appropriate stocking densities and species at given sites, learning about barriers to minimize disease transfers from wild to farmed fish, and so on.

\subsection{Fish Health}

Currently, the MOU between the DFA and the DFO states that Nova Scotia will have "the lead role in fish health management and extension work and in intra-provincial surveillance, detection, prevention, control, and regulation of fish diseases in cultured stock.”

The legislative foundation for the DFA's work in aquatic animal health is limited. It includes Section 5 of the Aquaculture Licence and Lease Regulations, which requires licensees to maintain accurate records on "the presence of diseases," "the type and amount of food used in relation to aquacultural produce” and "the type of medication, dosage, treatment date, and duration of 
veterinarian treatments." 125 It also includes Section 9, which states, "The Provincial Fish Health Veterinarian may isolate, quarantine, order treatment for, restrict the movement of, or destroy cultured fish infected or thought to be infected with a disease that the Provincial Fish Health Veterinarian considers a significant risk to wild or cultured fish stocks.”

The DFA's current program in fish health has four components: disease surveillance and the provision of veterinary services, emergency services (where there is unexpected or elevated mortality or abnormal behaviour) and laboratory services to the industry. The DFA acts primarily as an advisor to operators. It provides advice on operational improvements to improve fish health, on treatment of disease and on prevention. These advisory services are undoubtedly an important benefit to the industry. They also foster a relationship of cooperation between the Provincial Fish Veterinarian (PFV) and operators, which the Veterinarian uses to enhance the industry's understanding of and response to health problems affecting the sector.

The DFA's approach also has a regulatory component under Sections 5 and 9 of the Regulations. A key question is whether the DFA needs to increase its regulatory activity in relation to animal health in aquaculture. An associated question is whether this could or should be done while maintaining the advisory approach that is currently the focus for the PFV. These questions arise out of concern that the rigour of an expanded regulatory role might be compromised if the office of the $\mathrm{PFV}$ is the provider of veterinarian services to those it also regulates. Conversely, there is a concern that the effectiveness of the advisory service in gaining the cooperation of the industry in addressing fish health would be compromised if the advisory service were provided by veterinarians who also wear a regulatory hat.

In our view, there is really no doubt that the regulatory framework has to deal much more expansively and in greater detail with the health of animals raised in aquaculture. Some of the most persuasive presentations we received argued that the key to aquaculture's future as a sustainable industry that enjoys social licence is a focus on the health and well-being of farmed animals. ${ }^{126}$ All of these presentations, which were made from a range of perspectives, recognized that the health of the animals being raised in aquaculture was the ultimate and fundamental barometer of whether aquaculture is or is not being conducted in harmony with its surrounding environment. ${ }^{127}$ Put simply, healthy fish mean the health of the surrounding environment is being maintained while sick fish suggest the opposite. Conversely, the nature and extent of the aquaculture industry's use of some of the practices that raise the most concern about the industry's impact on the environment depend very much on the health of the animals raised in aquaculture. When animals are healthy, use of these practices can be reduced or eliminated. When fish are sick or in danger of becoming sick, use of these practices increases.

\footnotetext{
${ }^{125}$ N.S. Reg. $15 / 2000$.

${ }^{126}$ One of the most compelling of these was the submission we received verbally and in writing from Mr. Roger Hunka, with the assistance of Mr. Tim Martin, on behalf of the Native Council of Nova Scotia.

${ }^{127}$ This is also broadly consistent with the Ecosystem Approach for Aquaculture articulated by the FAO in Building an Ecosystems Approach to Aquaculture, which explicitly examines the issue of animal health standards. See, in particular, pages 76-77, 83-87, 101, and 121-22.
} 
Here, we cannot describe the regulatory provisions we think are needed in detail. We limit ourselves to outlining the matters that we believe should be addressed within these provisions.

First, it has to be understood that the maintenance of health and the prevention of disease are the foundations of the proposed regulatory framework. Although the provisions we are proposing to deal specifically with fish health would deal with the matter more extensively and explicitly than the current regulatory framework does, these elements of the framework are secondary to those intended to keep farmed fish healthy in the first place. Among the elements of the proposed framework that have fish health among their fundamental objectives are those dealing with the following matters:

- Biophysical site conditions that make a site suitable for a particular operation

- Conditions on number of fish on site and on permitted stocking densities

- Fallow period requirements

- The mixing of species on sites

- Limits on the number of and separation between permitted farms in particular bays

- Coordination of production on sites within defined geographic areas

- Vaccination requirements

In addition to all the general preventive measures, the regulations should deal more comprehensively and explicitly than the current legislation does with the mandatory reporting of infectious diseases. Consistent with applicable federal requirements, they should set out the diseases of concern to the province that must be reported to the DFA if identified by labs, farmers, veterinarians or anyone else in the care and control of the animals suspected of having the disease. The regulations should clearly state the time frame within which notification has to be given once the evidence of a notifiable disease is detected. There should be clear penalties stated for breach of reporting obligations, and there should be vigilant enforcement of the obligations, including through prosecution.

The regulations should explicitly address the elements of the disease surveillance system. They should outline the responsibility and authority of the DFA to determine the type, frequency, lots and numbers of animals to be sampled, and to define the tests to be used for detecting the diseases of concern. This can be done in multiple ways and has to be done so as to preserve flexibility and adaptability that a good surveillance system requires. For example, as suggested by CFIA in response to our draft report, the regulations can require the use of a "validated" or licensed" test or a "test prescribed by the Provincial Aquaculture Veterinarian." As to the sampling method to be used, the regulations could mandate the use of a method that is capable of detecting the absence of disease with a high percentage of certainty. The important thing from our perspective is that the elements of the surveillance system - as opposed to the specific tools that are used to implement those elements - not be left to policy but are instead laid out in legislation.

The regulations should also deal more comprehensively with management of disease outbreaks. We discuss the industry's capacity to manage disease outbreaks in greater detail below (Sec. 15). Here, our focus is on the responsibilities and associated authority of the regulator. In our view, the regulatory framework should define (or give the regulator authority to define) what constitutes a confirmed positive. The regulations should give broad powers to regulators to access records, to 
seize and test animals from at-risk populations, to trace pathogen movements from and to farms, and to isolate, quarantine, treat or destroy diseased fish or fish suspected to be diseased or in danger of becoming diseased. They should impose, or authorize regulators to impose, requirements for biosecure disposal of infected fish and materials and for cleaning and disinfecting infected equipment, other objects and places. There should also be provisions dealing with fallowing, restocking and retesting of sites after an outbreak of disease leads to destruction of diseased fish. The regulations should define breaches of obligations in this area as punishable offences.

The regulations should contain provisions on the biosecurity procedures to be followed to prevent the spread of infectious disease. ${ }^{128}$ These should include provisions on biosecurity procedures to be followed on aquaculture sites during harvesting, during transport of animals, and in fish processing. These procedures should cover personnel and equipment, including equipment such as well boats, trucks, grading gear and wharves used in moving fish. The regulations should provide for biosecurity compliance auditing procedures. Non-compliance with biosecurity requirements should be defined to constitute an offence.

Under the regulations, movement of animals to or from a site should be subject to a certificate of health for transfer. The regulations should set out the number, or the authority to determine the number, of veterinary site visits and the types of tests to be conducted before such a certificate can be issued. There should be brood stock testing requirements, requirements on records management relative to the movement of fish and mandatory reporting requirements relative to transfers.

The role of the PFV has caused us some difficulty. On the one hand, the PFV provides veterinarian services to the industry. He or she is, in effect, the industry's veterinarian. This model is similar to the role that provincial veterinarians have played in the agriculture sector. On the other hand, the DFA relies on the PFV in its application, interpretation and enforcement of regulatory requirements relating to fish health. If the regulatory framework becomes more extensive and explicit on fish health, as we recommend it should, this reliance is likely to become more important to the DFA. The perceived conflict between the dual roles of the PFV would seem to be accentuated in a regulatory framework like the one we recommend, which places greater emphasis on the regulation of fish health management and protection as a critical component of the overall framework.

We can understand that the role of the PFV as the veterinarian of the industry enables the PFV to build relationships of trust and confidence with the industry, thus allowing the PFV to proactively identify and address issues before they become problems. In other words, we can understand that the dependency of the industry on the PFV provides the PFV with considerable opportunity to ensure that the industry operates in accordance with the regulations and with fish health best practices. In addition, the current position of the PFV as the veterinarian of the industry is

\footnotetext{
${ }^{128}$ CFIA feedback to our draft report noted that other sectors had developed national standards on biosecurity and suggested that Nova Scotia should promote this approach for aquaculture. It also brought to our attention that other jurisdictions, Denmark in particular, require aquaculture operators to develop biosecurity plans as a condition for licensing. Both points were made in the context of a broader one - that effective protection for biosecurity cannot be achieved solely by unduly restrictive regulations but also requires industry-developed standards, codes of practice and plans to deal with many of the necessary details. We accept the wisdom of this input but at the same time remain of the view that the nature and scope of responsibilities in the area of biosecurity must be framed in legislation.
} 
undoubtedly an important part of the DFA's system of disease surveillance. A more exclusively regulatory role for the PFV may make crucial surveillance information less available to the PFV than is currently the case. It is also relevant to the discussion that the PFV carries out his or her mandate as a regulated member of the veterinarian profession.

For these reasons, we would not be comfortable recommending that the role of the PFV become an exclusively regulatory one. ${ }^{129}$ We are, however, strongly of the view that it can only continue to be a service provider and a regulator if our recommendations on transparency and openness are adopted and if a system of independent third-party periodic review of the compliance of the industry with regulatory requirements relating to fish health is instituted as part of the regulatory framework. This review could be carried out by the independent board that we later recommend should be created to hear and decide applications from members of the public who believe that licences should be revoked because of a site's failure or inability to meet regulatory standards.

\subsection{Fish Welfare}

Overlapping with the issue of fish health is the issue of the well-being of farmed fish. Only one person spoke to us directly on this concept, 130 but it was implicit in the concern that others voiced about the health of farmed fish.

As under Nova Scotia's Animal Protection Act, ${ }^{131}$ legislation on the well-being of farm animals typically aims to ensure they receive adequate care. This includes receiving necessary veterinarian care and protection from neglect and abusive treatment. Under the Nova Scotia Act, the definition of "farm animal" includes "fin-fish raised in an aquaculture site for commercial purposes." Our understanding is that the Minister of Agriculture is designated as the minister responsible for the Act in its applicability to fin-fish. Among other things, this makes the Minister responsible for investigations where farm animals may be in distress. It also gives the Minister the authority to appoint inspectors to "carry on such activities and exercise such powers as are necessary or

\footnotetext{
${ }^{129}$ In response to our draft report, the CFIA communicated to us that it did not support our conclusion that there is no conflict between the role of the PFV as both service provider and regulator or our conclusion that the PFV "must continue" as both service provider and regulator. To be clear, our recognition of the existence of the conflict is precisely why we make the recommendations we do in this paragraph. Also, we did not conclude that the dual role of the PHV "must continue"; rather, we concluded that it could continue if steps were taken to safeguard against the conflict that can arise between the two mandates. CFIA told us that an expanded role for the private sector veterinary community "is crucial to the maintenance of a transparent and vital aquaculture sector" and that the experience of CFIA is that "the involvement of the private sector actually increases disease detection and acts as an early warning system.” It also told us, "This concept and the vital role of the private fish health sector is clearly recognized in international standards and is in fact codified.” It is not clear to us whether these comments suggest a wider role for the private sector or an exclusive one. From our perspective, the objective is to ensure that the industry is properly served with veterinary services and properly regulated for compliance with fish health management practices. Our main point is that the status quo is not acceptable because it combines the two functions in one office without sufficient protection against the risk that this will adversely affect one or the other or both of them.

130 At the Halifax community meeting on April 9, 2013, Professor Vaughn Black of the Schulich School of Law stated that the perception that the welfare of framed fish was less important than other regulatory issues is contradicted by the fact that the applicable law already addresses the welfare of farmed fish, although in his view inadequately.

${ }^{131}$ SNS 2008, с 33.
} 
conducive to preventing, ending or remediating distress to farm animals,” including by investigating cases of farm animals in distress, promoting the humane treatment of farm animals and formulating and coordinating the establishment of industry customs and codes of practice supporting the humane treatment of farm animals.

In addition, the federal Health of Animals Act requires humane transportation of all species, including aquatic animals, into, within and out of Canada. ${ }^{132}$

This legislative framework is primarily concerned with the prevention of neglect and abuse. This is an important aspect of animal welfare. It is covered not only by provincial and federal animal welfare legislation but also by Sections 445.1 and 446 of the Criminal Code. ${ }^{133}$

It was pointed out to us that there have been no prosecutions under the Animal Protection Act (or the Criminal Code) for violations in relation to fish. This might raise questions about whether existing legislation is being enforced with sufficient diligence and rigour. Our expectation, however, is not that prosecutions should be pursued for the sake of demonstrating that the Act is being strongly enforced. Instead, our concern would be that prosecution is not being considered, where it may be warranted on the facts of particular cases, due to a general view that the matters addressed in the Act are not serious enough to warrant prosecution. Actions should be taken to ensure that such an attitude is not guiding the administration of the Act and that prosecution for violation of the Act is actively considered where circumstances suggest it is the appropriate and proportionate response to a situation of non-compliance.

Our attention was also drawn to Subsection 21(4) of the Animal Protection Act, which states that the provisions of the Act that create the offence of causing distress to an animal do not apply if the distress is caused by an activity carried on "in accordance with reasonable and generally accepted practices of animal management, husbandry or slaughter or an activity exempted by the regulations." The key words of this provision are not defined in the Act. They are therefore left to be defined in the administration of the Act. This can result in the words being defined in ways that do not accord with the objectives of the Act, which is to provide animals with meaningful protection against treatment that causes them distress.

A similar but broader concern is that the Act defines distress in Subsection 2(2) in quite general terms. To some extent, this is unavoidable, given the wide range of situations and circumstances the Act must cover. It does, however, mean that the Act provides limited guidance either to farmers (meaning fish farmers in this context) or to regulators. In the case of fin-fish aquaculture, the lack of guidance may be more problematic given that the Act's definition of distress may apply more straightforwardly to terrestrial animals than it does to aquatic animals. For example, the definition refers to adequate water, shelter, ventilation and "reasonable protection from injurious heat or cold." What these parts of the definition require may be easier to determine for terrestrial animals than it is for aquatic animals. Even their applicability to fin-fish may be doubtful, although by the words of the Act they are as applicable to fin-fish as to other kinds of farm animals.

\footnotetext{
${ }^{132}$ S.C. 1990 c. 21.

${ }^{133}$ RSC 1985, c C-46.
} 
There is a third area of concern. Although the Act contemplates industry customs and codes of practice supporting the humane treatment of animals, it is primarily about protecting animals from neglect and abuse. It says little about the positive level of care that animals are to be provided. All it says in effect is that it must be above the level at which it would cause distress.

We conclude that the regulatory framework should more clearly define the animal welfare standards required in fin-fish aquaculture. It should do this at three levels:

a. By outlining the animal welfare standards that should generally be met and maintained in areas such as

o water quality

o stocking levels

0 feeding rates

o cage design, construction and maintenance

o general husbandry

b. By better defining distress (i.e., neglect) as it applies to fin-fish aquaculture

c. By better defining what practices of animal management, husbandry and slaughter will be regarded as "reasonably and generally accepted" in aquaculture in Nova Scotia for the purpose of determining the applicability of the statutory provision that creates the offence of causing distress ${ }^{134}$

In feedback to our draft report, the CFIA pointed out that other livestock industry sectors have developed industry sector codes for best management practices relating to animal welfare. It noted that such codes can be referenced in regulations and suggested this is a more effective way to make industry responsible for animal welfare. It also noted that codes can change and evolve as new science becomes available more easily than regulations are likely to change. The CFIA also suggested that the Aquatic Animal Health Code could be referenced in Nova Scotia's regulations until such time as a provincial or national code of practice is developed.

We see the role that industry codes of practice can play in this area. They are contemplated by Nova Scotia's Animal Protection Act, and we agree with the CFIA that they should be developed for aquaculture. At the same time, we continue to think that the legislative framework for aquaculture should be more specific in outlining the standards that should be generally met, including by better defining distress and by better defining the practices that will be "reasonably and generally accepted." We also think that to the extent that a code of practice is relied upon for elaborating the applicable standards, the issue of accountability for compliance with the code must

\footnotetext{
${ }^{134}$ Guidance may be provided here by the Aquatic Animal Health Code, which was developed by the World Organisation for Animal Health and is available online: http://www.oie.int/international-standardsetting/aquatic-code/access-online/. Section 7 of the Code deals with "Welfare of Farmed Fish," and more particularly with standards and practices on the welfare of farmed fish during transport, in the stunning and killing of farmed fish for human consumption and in the killing of farmed fish for disease control purposes. We have also been told about developments in New Zealand (which has adopted an animal welfare code dealing specifically with commercial slaughter) and in Europe (where the European Commission has said that farmed fish are covered by EU legislation on the protection of animals during transport and at the time of killing).
} 
be clearly addressed. It is important that the industry's regulatory responsibilities be clearly established and kept separate from the important role that a code of practice can play in ensuring compliance with those obligations. Finally, we note that the CFIA commented to us that its "significant experience in development and use of codes of practice" show that "these codes have more credibility if the development team includes academia, governments and environmental groups in addition to industry.”

\section{DISEASE CONTROL, MANAGEMENT PROCEDURES AND CAPACITY}

In the previous section, we made recommendations on fish health and fish welfare. A related issue is the regulation of the industry by the CFIA, which is responsible under the Health of Animals Act for control of aquatic animal diseases as part of its broader mandate over the health of all owned animals and wild aquatic animal populations. ${ }^{135}$ To discharge this mandate, the CFIA is in the process of implementing the National Aquatic Animal Health Program. ${ }^{136}$

The CFIA maintains several lists of diseases: reportable, immediately notifiable and annually notifiable. The diseases on these lists reflect international requirements (i.e., diseases that Canada is required to have under surveillance and control) and diseases that Canada has decided to keep under surveillance and control.

Diseases on all three lists must be reported to the CFIA. The difference between the lists is who must report and the time frame in which the reporting must occur. Reportable diseases must be reported to CFIA immediately by anyone who suspects them. Diseases on the immediately notifiable list must be reported by laboratories on suspicion of the presence of disease. Diseases on the annually reportable list must be reported by laboratories on an annual basis.

The DFA operates a system of surveillance for diseases that must be reported to CFIA. This role of the DFA appears to be contemplated by its MOU with the DFO, which had the federal mandate to control aquatic animal diseases before it was transferred to the CFIA.

The system of surveillance and control operated by the CFIA is part of an international system of animal disease surveillance and control based on international agreements. One objective is to prevent the spread of disease across boundaries. In doing this, the system protects international trade by providing assurance that it will not result in the movement of disease across boundaries. Under this system, Canada assesses the systems of surveillance and control in place in other countries to satisfy itself that they are strong enough to permit imports into Canada from those countries. For the same purpose, other countries make the same assessment of Canada's systems of surveillance and control. These assessments, whether by Canada of other countries or by other

\footnotetext{
${ }^{135}$ Health of Animals Act, S.C. 1990, c. 21. For provisions relating specifically to the health of aquatic animals, see Part XVI of the Health of Animal Regulations, C.R.C, c. 296, ss. 190-202.

${ }^{136}$ Information on this program is available at http://www.dfo-mpo.gc.ca/science/aah-saa/National-AquaticAnimal-Health-Program-eng.html.
} 
countries of Canada, are carried out with guidance provided by the World Organization for Animal Health.

Under the Health of Animals Act, the Minister responsible for the CFIA has the authority to order destruction of diseased fish. ${ }^{137}$ Where the Minister exercises this authority, the Minister has the authority to compensate the grower of the fish that are destroyed. Under current practice, the authority to compensate is exercised whenever the authority to order destruction is exercised.

We heard a high level of anger about the compensation that CFIA pays when the Minister orders the destruction of farmed fish, something that has happened and attracted a lot of media attention in Nova Scotia in recent years. ${ }^{138}$ For many, this is using taxpayer money to reward farmers for the bad practices that allowed their fish to become diseased in the first place. Similarly, many expressed the view that if farmers know they will be compensated for producing sick fish, they will be content to make a profit by producing sick fish and collecting compensation after they are ordered destroyed instead of taking the more difficult, expensive and uncertain route of doing what has to be done to produce healthy fish that can be sold for a profit on the market.

We understand and respect the strength with which these views are held. Nevertheless, we think the role of the CFIA in compensating farmers for the fish it orders them to destroy should be put in context. The system under which aquaculture is compensated for fish destroyed by order is similar to the one under which farmers in the agriculture sector are compensated for animals they are required to destroy for disease-control purposes. In both cases, the rationale for the obligation to compensate is the same: to ensure that the awareness that reporting could lead to an order to destroy does not lead to failure to report. This would be more likely if operators knew there was no compensation for destroyed animals or if compensation was not certain. In other words, compensation is paid to protect the effectiveness of the surveillance and control system from the financial incentive to conceal regulated disease that would exist in the absence of compensation.

We were advised by CFIA officials that provinces and the aquaculture industry have been informed that the current approach to compensating for loss due to disease is not sustainable and that a stricter approach will soon be implemented. Under that approach, orders to destroy will not be issued where the disease identified is in an area in which the presence of the disease has been determined to be enzootic, or endemic. The reason is that the purpose of the NAAHP is not to eradicate regulated diseases from areas (watersheds) where they already exist but to prevent their spread to other areas. In that context, an order to destroy serves no purpose where a disease is found in an area in which the disease is endemic. With no order to destroy, there will be no authority to pay compensation. Moreover the rationale for paying compensation - to ensure that

\footnotetext{
${ }^{137}$ Health of Animals Act, S.C. 1990, c. 21.

138 There was qualified approval at the Roundtable for a recommendation that "publicly funded compensation for catastrophic loss related to disease should not be available except where the effect is industry-wide or the compensation is otherwise required under international agreements relating to reportable diseases."

(Roundtable Final Report, 26)
} 
reporting happens when it serves a disease surveillance and control function - will not be applicable. ${ }^{139}$

This stricter approach to eligibility for compensation may provide some assurance to the public that where compensation is given it is because it is serving a disease-control purpose and not simply fixing a problem for a farmer who loses fish. For the public in provinces or areas of provinces where compensation is paid, the payment of compensation is perhaps more likely to be seen as indicating that the disease that has led to the destruction of fish is not endemic in their province or area but generally under effective control.

For the industry as well as provincial governments, the implication of the new approach would seem to be that they will have additional reason to effectively control the incidence and prevalence of regulated diseases. Access to compensation when disease strikes despite best efforts to prevent it will depend under the new approach on whether the disease has generally been kept under effective control. In addition, it would seem to us that aquaculture located in areas designated as endemic for certain regulated diseases might face difficulty in maintaining its markets or in gaining new markets. ${ }^{140}$

The impending changes to the CFIA approach reinforce the rationale for all the recommendations we have made that can play a role in fostering, maintaining and protecting the health of farmed fish. In addition, they show how important it is for industry and government to have the capacity to conduct effective surveillance for disease and to effectively manage outbreaks when they occur, to ensure that disease does not become endemic.

Our understanding of what we were told by CFIA officials is that the CFIA was confident in the strength of the surveillance systems in Nova Scotia, and the Maritimes more broadly, and with their functioning. We understood the agency to express less confidence in the readiness of the industry in the region to manage outbreaks.

To illustrate this concern, CFIA officials explained the difficulties they have observed in the handling of the limited ISA events that have occurred. In the view of the CFIA, necessary equipment was not readily available or readily procurable. For example, there were no boats in the region dedicated to this function and no arrangements made to take boats used for other purposes

\footnotetext{
${ }^{139}$ In our draft report, we suggested that providing compensation where stock is ordered destroyed for disease control purposes was required by Canada's international obligations. We were advised by CFIA that this was not correct. Our understanding of the correct position is that providing compensation for stock that is ordered destroyed as a means of ensuring reporting of disease is an important part of Canada's disease surveillance and control system that is subject to evaluation for its consistency with international standards and for its effectiveness by Canada's trading partners.

${ }^{140}$ In the feedback we received on our draft report, it was questioned whether this would be the impact for farmed salmon. We were told that the majority of farmed salmonid produced in Canada is gutted/eviscerated in Canada and exported to the United States, and that this trade is generally regarded as safe because the Unites States has no disease restrictions on eviscerated animals. For this reason, we were told that the statement made in our draft report, that producers could lose much of their market if their geographic area were designated as being one in which disease was endemic, was false as applied to farmed salmon. We take it from this feedback that our statement was accurate as applied to other kinds of fin-fish and to shell-fish, and also that it might be accurate as applied to salmon if US policy changes or if the market for Canadian farmed salmon changes.
} 
out of their normal service to prevent cross-contamination. There were also no arrangements made in advance for biosecure access to docks, which caused undue reliance on land transportation. Another kind of difficulty was in requisitioning the equipment needed to harvest diseased fish. Another was the unavailability of pre-approved disposal sites. This raised concerns about the treatment that would be applied to the effluent from the rendering of destroyed fish. The CFIA has also found that the expertise needed to write the standard operating procedures needed for a response plan and process was generally not available.

CFIA officials expressed concern about an absence of urgency in addressing these gaps in capacity and readiness. They expressed concern that the cooperation needed to ensure that the needed capacity and infrastructure is in place and available to all is not evident, even though the scale of the industry is, in their view, such that the needed capacity and infrastructure can be available only if it is developed and maintained on an industry scale. We were told that this collective approach has been taken on the west coast, where the industry is much larger and is a primary reason why the readiness to effectively manage disease outbreaks is more advanced on the west coast than it is on the east coast.

\section{SITE SELECTION AND UTILIZATION FOR FIN-FISH AQUACULTURE}

\subsection{Nature and Rationale for a Classification System}

We have been told by industry, community members and other stakeholders that proper site selection and utilization is critical for an effective regulatory framework for marine-based fin-fish aquaculture. ${ }^{141}$ We agree. A suitable site is one that has appropriate biophysical conditions while being compatible with other economically, socially, and culturally important activities. Using concepts from the Environmental Goals and Sustainable Prosperity Act, it is a site that can make a net contribution to sustainable prosperity if it is responsibly developed and managed in a manner that maximizes benefits while minimizing risk and negative impacts.

Biophysical conditions in Nova Scotia are different than in many other jurisdictions with marinebased fin-fish aquaculture operations. We have many geographically protected coastal waters around Nova Scotia as well as areas with strong tidal currents, but we also tend to have shallower waters than other jurisdictions, and water temperatures are not always suitable. Wild salmon populations in Nova Scotia have traditionally had economic and social significance, but are in a perilous state. In addition, many of our rural communities have long-standing economic reliance on coastal waters for their livelihoods, largely in terms of fishing and tourism. Compatibility with

\footnotetext{
${ }^{141}$ There was partial support at the Roundtable for the recommendation that "the regulatory framework should establish siting criteria to include water depths, current flows, distances from wild fisheries and harvest areas for Irish moss, sea urchin, shellfish, etc., distances from salmon rivers, migration paths, fishing grounds, other marine resource uses, natural conservation areas, and spacing of aquaculture sites.”

(Roundtable Final Report, 20)
} 
other uses of coastal waters and social acceptance of the industry are therefore critically important considerations in site selection.

Under the current regulatory framework, the suitability of coastal areas for fin-fish aquaculture is determined largely if not exclusively through the licensing process. This approach may be inefficient and resource-intensive for both industry and regulators. It may also lead to avoidable conflict to the extent that it results in applications for licences and leases being made for sites that would be identifiable as being generally unsuitable if a more general process of characterization and categorization of the suitability of coastal areas for fin-fish aquaculture were carried out. In addition, too much reliance on the licensing process to determine the suitability of coastal areas for fin-fish aquaculture may lead to mistakes that could be avoided or reduced if the licensing process were supplemented by a classification of coastal areas for fin-fish aquaculture suitability either before a licence is applied for or before an assessment of an application for a licence begins.

Following the approach that is central to Scotland's relatively new regulatory framework, the basic approach we recommend is a process of evaluation of coastal areas for the purpose of determining whether they are generally suitable, marginally suitable or generally unsuitable for fin-fish aquaculture. ${ }^{142}$ The result of this process would be a designation of coastal areas as being either Green, Yellow or Red areas for the purposes of fin-fish aquaculture. ${ }^{143}$ In general terms, these designations would have the following meaning:

- Green areas would be areas found to be generally suitable for fin-fish aquaculture.

- Yellow areas would be areas that have potential to be suitable but are not ideal and would require a more careful approach to site selection, a more rigorous assessment in the licensing and leasing process, and stricter or more limiting terms and conditions for approval and additional regulatory oversight.

- $\quad$ Red areas would be areas that are unlikely to be suitable (i.e., that are generally unsuitable) for fin-fish aquaculture.

The basic idea is that regulatory approval for fin-fish aquaculture would be unlikely in Red areas and less likely in Yellow areas than in Green areas. ${ }^{144}$ Whether approval would be given for a site

\footnotetext{
${ }^{142}$ For a detailed analysis of Scotland's regulation of aquaculture, see Cecilia Engler's paper, Analysis of Aquaculture Legislation and Regulation in Scotland, available on our website under "Updates." See especially pages 15-32, which discuss, among other things, Scotland's development plan with regard to aquaculture. "Development plans should identify areas which are potentially suitable for new or modified fish farm development and sensitive areas which are unlikely to be appropriate for such development; sensitive areas are unlikely to be suitable for fish farm development unless adverse impacts can be adequately mitigated.” (p. 20)

${ }^{143}$ In rudimentary form, a similar concept is currently provided for in the Fisheries and Coastal Resources Act, which permits the Minister of Fisheries and Aquaculture, with cabinet approval, to designate sub-aquatic lands as a "closed area ... not suitable for aquaculture." Also, the broad concept of some kind of red, yellow, and green classification system for decision making with regard to aquaculture siting has been proposed before: see Barry T. Hargrave, “A Traffic Light Decision System for Marine Finfish Aquaculture Siting,” Ocean and Coastal Management 45: 215-35.

${ }^{144}$ One of the reactions we received to our draft report was the concern that our use of Green, Yellow and Red as the labels for our three proposed classifications would cause confusion and mistaken expectations. The concern was that people would assume that a Green designation for a certain kind of aquaculture would
} 
in a Yellow or Red area at all would depend on whether the applicant for a licence and lease in a Yellow or Red area is proposing a fin-fish operation that is suitable for a site having Yellow or Red area characteristics. For example, a small-scale or low-density operation might be suitable in a Yellow area, whereas a larger-scale and higher-density operation would not be. It would be less likely that even small-scale and low-density fin-fish aquaculture would be found suitable for Red areas. But to be suitable, it would have to be an operation with less impact than the operations that would be suitable for Yellow areas. For example, an operation that is smaller scale and lower density than those suitable for Yellow areas, and which also is required to operate under stricter regulatory control, might be suitable in some Red areas. ${ }^{145}$

Another key consideration in application of the coastal classification system would be the kind of fin-fish aquaculture that is proposed. 146 This is addressed below under the heading "Relevance to Classification of Differences between Kinds of Fin-Fish Aquaculture.”

The starting point for considering which of the three categories a coastal area of Nova Scotia falls under should be the biophysical conditions, such as water depth, current speed, oceanographic and benthic circulation patterns, proximity to salmon rivers, etc. Social, cultural, and economic implications would also be considered in categorizing Nova Scotia's coastal waters based on its suitability for fin-fish aquaculture; however, these considerations will feature more prominently in the review of individual proposals for aquaculture operations. Finally, understanding of what makes for a suitable site will undoubtedly evolve with science, changing conditions as a result of climate change, new technologies, changes in industry practice, changing markets and the industry's evolving place in rural communities. This means that the categorization must remain

mean that all applications for that kind of aquaculture would be approved (even though we have made it clear that an application in a Green area must still meet the criteria and standards applicable to licensing) and that a Red classification would mean that no aquaculture would be approved (even though we have made it clear that licensing of aquaculture in an area designed Red for that kind of aquaculture would be unlikely but possible). It was suggested that these mistaken assumptions could be avoided or minimized by using more neutral terminology to describe our classification system, such as Level 1 (instead of Green), 2 (instead of Yellow) and 3 (instead of Red). The key consideration is not the terminology but the underlying concept, which is that coastal areas will be found to be generally suitable, marginally suitable or generally unsuitable for specific kinds of fin-fish aquaculture, and classified accordingly. We would note however that use of a more neutral terminology would have to address the opposite concern that the result of an area's classification as generally suitable, marginally suitable or generally unsuitable might not be taken seriously enough if it were expressed in neutral language rather than in the "traffic light" language we have proposed.

${ }^{145}$ In providing feedback on our draft report, some asked us to recommend a prohibition of fin-fish aquaculture in Red areas. We continue to think the better course is to leave open the possibility that aquaculture could be permitted in a Red area if it were designed to appropriately address the limited suitability of the area for fin-fish aquaculture. This is because the purpose of the classification system is not to absolutely bar aquaculture from coastal areas based on their classification but to ensure that licensing decisions appropriately reflect the relative suitability of different coastal areas for different kinds of fin-fish aquaculture. In Red areas, this will generally mean that fin-fish aquaculture will not be approved, but it will not mean that fin-fish aquaculture cannot be approved.

${ }^{146}$ In the feedback we received on our draft report, we were asked on a number of occasions to clarify that our proposed classification system for fin-fish aquaculture might apply differently to different kinds of aquaculture, depending on the level and nature of risk of adverse impact associated with particular kinds of fin-fish aquaculture. We have therefore strengthened the clarity of our description of the classification system on this point. 
open to adjustment but based on strong, open and transparent processes; clear criteria; and good evidence.

\subsection{Classification Criteria}

It will be critical to apply the classification system on the basis of clearly established criteria. Concern was expressed in the feedback we received to our draft report that a lack of clear criteria would produce conflict that could be avoided or minimized. Another concern was that a lack of clarity would delay and prolong decision making. A third kind of concern expressed was that a lack of clarity in the criteria of classification would lead either to licensing where it was inappropriate or to unwarranted refusal to license.

In light of these concerns, we were asked, at the public feedback meeting we held on our draft report in Yarmouth, to include specific classification parameters in our final report. For example, it was suggested that we should specify the objective water depth and current-speed parameters that would lead to a coastal area being designated as Green, Yellow or Red. It was also proposed by the EAC that we should develop a list of general criteria for each classification and a mechanism to weight certain criteria more heavily where necessary or warranted to achieve the protective purposes of the classification system.

We agree that clear and reasonably fixed criteria for differentiating between coastal areas for classification purposes will be critical to the workability of the classification system we have proposed. We also agree that greater clarity should be possible relative to the biophysical criteria than those of a socio-economic nature.

We are, however, also very aware of the limits of our expertise relative to the specific parameters that should be built into the criteria and how they should be weighed against one another in specific situations. Therefore, we limit ourselves to indicating the kinds of parameters that should be included in the classification criteria and the standards that should be applied to evaluating those parameters

This is also our response to the feedback we received from some in industry, and in particular from the Atlantic Canada Fish Farmers Association (ACFFA). From that perspective, our draft report was criticized for suggesting biophysical conditions for classification that were based on opinion and not science, as well as for proposing a system in which classification would depend on single determinative factors rather than on the cumulative impact of multiple factors. Our response to these points is that we are only proposing the kind of parameters that should be used in the classification criteria, in the full understanding and expectation that more work is needed to develop the more specific criteria required to make the classification criteria fully functional. We have proposed a general breakdown between biophysical parameters and socio-economic parameters (absence, presence and nature and level of conflict with other uses and values) because these were the two categories of factors that virtually everyone who spoke with us during our process said were relevant to good site selection.

At the same time, we stress three points:

1. The development of the specific parameters for classification should be evidence-based, precautionary, and transparent. Where science indicates a specific parameter that can be used 
to ensure that the classification system achieves its objectives, that parameter should be adopted until further development of scientific knowledge suggests a better parameter.

2. Our concept of classification is not one in which a single variable determines classification but rather one in which classification is determined by the combined effect of the multiple variables that are relevant to determining biophysical and socio-economic suitability.

3. The Regulatory Advisory Committee and the mechanism for advice from knowledge experts on a continuing basis that we recommend later in this report could both play important roles in the further work that will have to be done to develop the criteria we propose into fully functional criteria.

\subsubsection{Classification Criteria for Green Areas}

It is our recommendation that Green areas for fin-fish operations in coastal waters for salmon or for other fin-fish species be determined based on criteria that include the following:

a. Biophysical conditions such as water temperature, water depth, current speed, frequency and other hydrological and bottom conditions show that fin-fish aquaculture can be conducted in the area with confidence that it will meet or exceed environmental standards; and

b. Coastal conditions show that fin-fish aquaculture can be conducted in the area with confidence that it will not significantly conflict with other uses or values, ${ }^{147}$ such as

0 the recovery effort of an endangered species

o a clearly competing use that is of significant economic, social or cultural value ${ }^{148}$

o the protection of wild salmon

o the protection of land that is under legal protection

For clarity, the intended effect of (a) and (b) is that a Green area would be shown to be suitable for fin-fish aquaculture under both criteria because it possesses suitable biophysical conditions and because of the absence of significant conflicts with other uses and values. ${ }^{149}$

\footnotetext{
${ }^{147}$ In providing feedback to our draft report, the Mi'kmaq Rights Initiative pointed out that the meaning given to the word "significant" would be critical. We agree. We do not, however, believe we are in a position to propose a specific definition, for much the same reasons as we do not think we can recommend the specific biophysical parameters that should be used in the classification criteria. We can, however, say that "significant" would have to be interpreted and applied in a way that is consistent with achieving the overall objectives of the proposed regulatory framework, which is to provide a high level of protection against adverse impacts.

${ }^{148}$ In the feedback received on our draft report, concern was expressed that specific industries were not listed. For example, we were asked to confirm that interference with tourism or a lobster fishery would be interference relevant to deciding on the classification of a coastal area. Our choice not to list the uses that would be capable of being considered competing uses is a deliberate one, as we think this has to be worked out in the detailed development of the regulatory framework and in the operation of the framework once it is implemented. However, given what we say in the rest of this report relative to the lobster fishery and tourism, we have little difficulty in being explicit that the impact of fin-fish aquaculture on lobster fishing and on tourism would be taken into account in the classification process.

${ }^{149}$ In providing feedback to our draft report, some expressed concern that the designation of a coastal area as a Green area would result in that area being inundated with aquaculture. This outcome would be prevented by the regulatory framework we have proposed, which would require licensing in Green areas to address a
} 


\subsubsection{Classification Criteria for Yellow Areas}

Yellow areas would be coastal areas where there is reason for caution, but there may still be potential for productive low-impact fin-fish aquaculture, provided that it is conducted on terms, or subject to limitations, that specifically address the area's limited suitability for salmon or another kind of fin-fish aquaculture. Conditions that would result in an area being designated as a Yellow area would include the following:

a. Biophysical conditions show (for example) that fin-fish aquaculture for salmon or another species should not be authorized unless it is authorized on terms and conditions (such as terms and conditions on scale and density) that address the specific biophysical limitations of the area.

b. The presence of significant potential for conflicts between fin-fish aquaculture for salmon or another species and other uses or values would have to be addressed before aquaculture could be authorized or conducted. Examples include

0 a reasonable fear that a fin-fish operation for salmon or another species would interfere with the recovery effort of an endangered species

o interference with a clearly competing use that is of significant economic, social or cultural value

o proximity to a salmon river or to land that is under legal protection

c. Both the biophysical conditions and the potential for conflict with other significant uses or values indicate that the area is properly classified as a Yellow area.

\subsubsection{Classification Criteria for Red Areas}

Red areas would be coastal areas considered to be unlikely to be suitable for salmon or another kind of fin-fish aquaculture. Conditions that would result in an area being designated as a Red area would include the following:

a. Biophysical conditions show that it is highly unlikely that fin-fish aquaculture for salmon or another species can be conducted in the area in accordance with environmental standards, particularly in light of current technology and aquaculture practices.

b. The presence of serious conflicts between fin-fish aquaculture for salmon or another species and other significant uses or values, such as

0 a clear risk to the recovery effort of an endangered species

o a proven threat to an important industry in the area

o immediate proximity to a salmon river or to land that is under legal protection

c. Both the biophysical conditions and the presence of serious conflicts with other significant uses or values indicate the area is properly classified as a Red area.

Although Red areas would be generally off limits for fin-fish aquaculture, the regulatory framework should not preclude the possibility that fin-fish aquaculture could in exceptional

range of factors or conditions, including the cumulative effect of aquaculture already approved, which would be harder to satisfy as the number of aquaculture projects in a Green area increased. 
circumstances be authorized in a Red area. It would, however, place a heavy onus on the DFA in its assessment of an application for a licence and lease to satisfy itself and to demonstrate that any aquaculture project proposed for a Red area fully addresses the conditions or the combination of conditions that warrant designation of the area a Red area and generally off limits to fin-fish aquaculture. This approach is consistent with the approach taken in Scotland.

\subsubsection{Potential Conflict with Mi'kmaw Fisheries and Protection of Submerged Archaeology}

In the feedback we received on our draft report from the Mi'kmaq Rights Initiative, concern was expressed that we did not specify the relevance to the classification process of protection for Mi'kmaw fisheries conducted for food, social or ceremonial purposes, or for submerged archaeology of importance to the Mi'kmaq. This is an important issue that should be addressed in discussions between the province and the Mi'kmaq as the DFA proceeds with developing the regulatory framework we propose. In addition, it should be emphasized that protection for these important interests is relevant not only to the classification of coastal areas but also to the licensing process.

\subsection{Processes for Classifying Coastal Areas for Fin-Fish Aquaculture}

The ultimate objective of the regulatory framework should be a comprehensive classification of the suitability of the coastal areas of Nova Scotia for fin-fish aquaculture. To achieve that objective, the DFA should take a three-pronged approach.

First, it should undertake a proactive classification process that operates in parallel to the licensing and leasing process. Although we are not in a position to say exactly how we think this process should be organized and conducted, we can say that the process should have the following characteristics or elements:

a. The process should be evidence-based, open and transparent. People with local and traditional knowledge of coastal areas should have opportunities to contribute that knowledge to the process. They, along with all Nova Scotians, should have the opportunity to comment on the process as it proceeds.

b. The process should draw on the knowledge and research of experts in scientific and other disciplines from within and outside government, including those in the scientific community who have worked on classification systems such as the one we have recommended as well as on the work and knowledge of those who have done research relevant to developing and applying such a system. ${ }^{150}$ Knowledge experts could be asked, for example, to provide advice on how the criteria for Green, Red and Yellow areas could be refined and how they can be applied in a range of contexts and conditions.

\footnotetext{
${ }^{150}$ Later, we recommend that the regulatory framework include a mechanism such as a formal network, standing committee or "knowledge" roster, though which the DFA can receive advice from experts on science relating to aquaculture on a continuing basis. One of the uses of this mechanism could be to involve knowledge experts in the process of classifying the coastal areas of Nova Scotia relative to their suitability for fin-fish aquaculture.
} 
c. The process should build on the large body of existing research that has been done, in and outside government, on coastal conditions and on the relationship between diverse coastal conditions and the suitability of coastal areas for fin-fish aquaculture, particularly salmon aquaculture, when it is conducted at different scales, under different management systems and with different technologies. ${ }^{151}$ With as much transparency as possible, the process should utilize the modelling system for evaluating the environmental impacts of aquaculture, which is widely used in the regulation of aquaculture across Canada and in many other jurisdictions.

d. The process should build on previous successes in similar undertakings. One example is the success of the Colin Stewart Forestry Forum on development of a plan or framework for achieving Nova Scotia's objectives in wilderness conservation while ensuring the availability of fibre to the forestry industry.

Due to the high-level nature of such a process, it would likely only be useful for classification of coastal areas that can be classified with no or limited controversy. For example, it is more likely to be useful for areas that are clearly Red areas than it would be for Green areas. For the latter classification to be accepted, a more focused process is likely to be needed.

For this reason and because of the potential advantages of more targeted approaches, the regulatory framework should authorize the DFA to undertake strategic assessments of particular coastal zones on a more targeted basis. In the following section, we outline the process and function of such assessments. The process would be the second way in which coastal areas could be classified as Green, Yellow or Red for a particular kind of fin-fish aquaculture. It would be in the nature of a strategic environmental assessment, which has been effectively used in Nova Scotia in evaluating proposed development of the tidal power potential of the Bay of Fundy. ${ }^{152}$ With regard to function, such assessments may be especially applicable in differentiating between Green, Yellow and Red areas within a particular coastal region that cannot easily or sensibly be classified as entirely Green, Yellow or Red. More specifically, strategic assessments may be helpful in identifying Green areas in which the DFA can encourage fin-fish aquaculture, and in more clearly differentiating those areas from coastal waters in which fin-fish aquaculture is less likely to be suitable.

Lastly, until a comprehensive classification is completed, the DFA will have to classify sites on an individual basis whenever an application is made for a licence and a lease in an area that has not yet been classified either in the general classification process or through a strategic assessment. This is explained in more detail in Section 18 of this report on the licensing (site approval) process. The rationale for permitting classification to happen in response to an application for a licence is twofold. First, we do not think the regulatory process should be held in abeyance until the

\footnotetext{
${ }^{151}$ At the Roundtable, there was partial support for the recommendation that the province should "collate existing coastal planning information and make it publicly available to assist with decision making regarding aquaculture siting.” Despite its receiving only partial support, we believe this recommendation has merit when adopted in the context of a classification process that operates at the three different levels we propose. At the Roundtable, in contrast, the recommendation was discussed in the context of a larger discussion about making decision making about aquaculture part of a larger comprehensive coastal planning process.

${ }^{152}$ See Meinhard Doelle, "The Role of Strategic Environmental Assessments (SEAs) in Energy Governance: A Case Study of Tidal Energy in Nova Scotia’s Bay of Fundy” (2009) 27 Journal of Energy and Natural Resources Law 112.
} 
classification process has been completed. Second, we do not think the licensing process can go forward without regard to the important role that we think classification must play in the licensing process.

The relationship between each of these processes for making classification decisions should be dynamic. Classification choices made in the general process or through strategic assessment will be taken into account as a fundamental input to the licensing process. At the same time, classification choices made through strategic assessment or in the licensing process would add to the overall progress toward comprehensive classification of the coastline, which will be the main concern of the general or overall classification process. ${ }^{153}$

In addition, in light of the feedback we received to our draft report, we think it important that we stress what we are not recommending relative to the process of classification. Specifically, we are not recommending a prohibition on licensing until a complete and comprehensive classification of the entire coastline of Nova Scotia or of regions of the coastline have been completed. We are recommending instead that three distinct processes be used in parallel to achieve that comprehensive classification. One of them is the licensing process to be applied to individual applications for approval of specific fin-fish projects. Where classification happens in that process, it will be because the project is proposed for a location that has not already been classified in the general classification process through a strategic assessment or a prior licensing process. When classification happens in the licensing process, the critical point is that classification of the suitability of the site for the proposed kind of fin-fish aquaculture must happen before the licensing decision on the specific project. This is critical because the rationale for a classification system such as the one we have proposed is that classification must inform licensing and not be determined by licensing.

\subsection{Effect of Classification as a Green, Yellow or Red Area}

Designation of a part of Nova Scotia's coastline as Green, Yellow or Red for particular kinds of fin-fish aquaculture will have a variety of implications for the regulatory process as it applies to applications for approval of specific sites and projects.

First, if a proposed project is in an area designated in the general process or a strategic assessment, it will not have to go through a classification process during the licensing and leasing process. Projects proposed in areas that have not been previously designated will require a determination from the regulator in the licensing process as to whether the site is a Green, Yellow or Red area site. Such a designation of an individual site at the licensing and leasing stage may usefully serve as a starting point for initiating a designation process for the wider area, particularly if there is reason to believe that there is broader interest in operating aquaculture facilities in the area.

Second, the designation of an area as Green, Yellow or Red will have implications for the process of reviewing individual applications for a lease and licence to operate an aquaculture facility in the

\footnotetext{
${ }^{153}$ We agree with the suggestion we received from the EAC that data and mapping (if those are the correct terms) produced to determine an area's suitability for aquaculture should be accessible to the public and added or connected to other publicly available information in a way that permits people to integrate the information and use it for other planning and decision-making processes.
} 
area. As set out in more detail below, the regulatory process in Green areas will be more streamlined, whereas the process in Red areas will be most onerous.

Third, the likelihood of an application for operating an aquaculture facility being granted will differ. In Green areas, it would be reasonable to expect that licences would be granted for welldesigned operations that are sensitive to other users and are proposed in suitable locations. Conversely, the likelihood of a successful application in a Red area would be low.

Fourth, the terms and conditions under which aquaculture facilities would be licensed to operate would vary. Because of the biophysical constraints and the potential social and economic concerns in Yellow and Red areas, operations that do get approved in either will have to meet additional terms and conditions, such as additional monitoring and reporting obligations. They would typically also be approved on terms and conditions that would be more restrictive of the scale and/or density of the aquaculture that can be conducted than would typically apply in Green areas and require additional measures to reduce the higher risk of adverse impacts present in Yellow and Red areas.

Finally, in light of the feedback we received on our draft report, it is important that we be more explicit than we were in our draft report that we envisage that classification of a coastal area could change where there is a good and defensible reason for that to happen. To begin with, the regulatory framework needs the capacity to fix mistakes where it is realized that mistakes have been made. This is part and parcel of a regulatory framework that is committed to learning from experience and making corresponding improvements. In addition, classifications may have to change to reflect changing conditions, including those caused by climate change. Also, a reconsideration of classification decisions may be warranted because of changes in technology, business practices or research-generated understanding of the impacts of fin-fish aquaculture and the options for eliminating, reducing or mitigating those impacts.

\subsection{Relevance to Classification of Differences between Kinds of Fin-Fish Aquaculture}

Although we have outlined a process for fin-fish aquaculture, the reality is that the rationale for such a system is primarily found in the concerns associated with salmon farming or, more broadly, with the farming of salmonids. We have been told by experts in the field that a number of these concerns are not relevant at all or to the same extent to other kinds of fin-fish aquaculture, such as halibut or cod aquaculture.

In the classification framework we have proposed, these differences can be taken into account in either of the following ways. First, the framework can be applied by taking the differences between salmon and other kinds of fin-fish aquaculture into account in how the framework is applied. Under this option, the result could be that areas that may be Yellow or Red for the purpose of salmon aquaculture might be Green (or Yellow instead of Red) for other kinds of fin-fish aquaculture. Alternatively, other kinds of fin-fish aquaculture could, like shell-fish, be exempted from the classification system.

In our view, unless it can be said that the concerns that exist with respect to salmon aquaculture are non-applicable to other kinds of fin-fish aquaculture, the first option would be the better option. It would ensure that the differences between salmon farming and other kinds of fin-fish farming are 
taken into account in the application of the classification system without assuming that those differences justify an entirely different treatment of other kinds of fin-fish aquaculture.

\section{STRATEGIC ASSESSMENT OF COASTAL AREAS}

In this section, we will outline the process for evaluating and determining the suitability of coastal areas for aquaculture at a regional scale, using the strategic assessment process identified above as one of the three processes that can lead to the classification of a coastal area as a Green, Yellow or Red area for aquaculture of salmon or another fin-fish species. For shell-fish aquaculture, this process could be used to proactively identify areas that are or are not suitable for the development or growth of that kind of aquaculture.

We refer to this process as a strategic assessment of coastal areas because we think it could be used not only for assessing the suitability of coastal areas for fin-fish aquaculture but also for exploring their development potential. In contrast to the general classification process that might be used to classify areas that can be readily classified at a more regional scale and the classification that will happen as part of the licensing process, strategic assessment is a process to be carried out at a more intermediate scale, keeping in mind which areas are most likely to be of interest to operators, and which areas are connected from a social and ecological perspective.

In the case of fin-fish aquaculture, the strategic assessment process should have two primary goals in any locality in which it is carried out. One goal would be to identify Green, Yellow and Red areas for fin-fish aquaculture. A second goal would be to identify any specific sites that are particularly suitable and promising sites for the development of aquaculture because, in addition to meeting the criteria for Green areas, they are located in or close to communities in which there is significant support for fin-fish aquaculture development under the proposed regulatory framework. This second goal would also provide the rationale for strategic assessments in relation to shell-fish aquaculture.

For the process to be effective, it has to be transparent and flexible, and it also has to fully engage all interested parties in the region in question, including Mi'kmaw communities, ${ }^{154}$ potential aquaculture operators, other users of the coastal area, industries, interested residents and all levels of government. A key goal of the process should be to integrate biophysical, social and economic aspects, and their interactions, and to identify to what extent the area in question is a suitable area for aquaculture in light of the overall goal of ensuring that aquaculture in Nova Scotia minimizes environmental impacts while maximizing social and economic benefits to Nova Scotians.

\footnotetext{
${ }^{154}$ There was qualified support at the Roundtable for the following recommendation: "Both the Province and the proponent should carry out meaningful consultation with KMK, other First Nations umbrella groups, First Nations leaseholders and with First Nation communities near a proposed site to ensure a solid understanding of the proposed aquaculture venture and address community concerns and rights issues. The consultation should follow KMK guidelines." There was also unanimous support for the idea that "First Nations food, social and ceremonial fisheries must be addressed through the siting criteria and throughout the siting process.” (Roundtable Final Report, pp. 16 and 20, respectively)
} 
The process should be carried out in a manner consistent with the following principles and elements:

a. Broad scoping and information gathering to ensure that the full range of biophysical, social and economic impacts, benefits, risks and uncertainties of each form of aquaculture under consideration are identified ${ }^{155}$

b. Careful review and analysis of the information gathered to properly designate coastal areas within the study area in accordance with the classification criteria for Green, Yellow and Red areas

c. Documentation of the results of the analysis for public comment

d. Decision making in light of the analysis and comments received

e. Public engagement and transparency throughout

We recommend that the process be initiated with a background report prepared by the DFA (with input from relevant provincial and federal departments) that considers the general biophysical suitability of the area for each type of aquaculture under consideration. The Background Report should also include information about other users of the coastal area, and any other information that could be relevant to the consideration of the suitability of the area for aquaculture operations. The Background Report should focus on providing information. It should not seek to reach conclusions or suggest designation of areas as Green, Yellow or Red areas.

The report should be shared with communities, stakeholders, and members of the public in the area under consideration. This should be followed by a flexible process of engaging with all interested parties to assist in the designation of the coastal area under consideration according to the classification criteria. The process should consider whether any sites within the area are particularly suitable for aquaculture, so as to warrant a proactive call for proposals by the DFA to interested operators, the possible issuing of one or more experimental licences or the establishment of an aquaculture research or "test" facility. ${ }^{156}$

\footnotetext{
155 The information gathered for a strategic assessment would be like the information gathered for a strategic environmental assessment. Accordingly, a strategic assessment would be conducted in accordance with the recommendation that received unanimous support at the Roundtable: "Detailed habitat and water chemistry data for a proposed site must be provided as part of the EIA process and a reference site identified for comparison. The data should be applicable to the Environmental Monitoring Program process” (Roundtable Final Report, 17). Strategic assessments would also be broadly consistent with the related recommendation that "the EIA process should include a risk analysis for all existing fisheries in the proposed site area, followed by a bay carrying capacity study,” which received partial Roundtable support, and the recommendation that "the best available prediction model to assess site suitability" and "the best available prediction model to predict levels of settled organic wastes below fin-fish cages" be used in assessing sites for suitability for aquaculture, both of which received qualified support at the Roundtable. (Roundtable Final Report, pp. 17, 20 and 21, respectively)

${ }^{156}$ We note that a similar process - strategic environmental assessment - appears to have been used to identify suitable locations for aquaculture development areas in South Africa: see K. Hutchings et al., Strategic Environmental Assessment: Identification of Potential Marine Aquaculture Development Zones for Fin Fish Cage Culture, which was prepared for the Directorate for Sustainable Aquaculture Management: Aquaculture Animal Health and Environmental Interactions and the South African Department of Agriculture, Forestry and Fisheries.
} 
We do not want to be overly prescriptive on the nature of the engagement process once the background document is released, particularly in light of our recommendation that it be implemented at a local or regional level rather than at a provincial level. The process should be sufficiently flexible to be suitable and effective in different parts of the province and potentially at different scales. We do suggest, however, that the public and stakeholder engagement process used to develop this report and the 2008 Fundy Tidal Energy Strategic Environment Assessment process can serve as general guides on how to effectively engage with interested members of the public.

At the conclusion of the public engagement process, it will be up to the DFA to decide on the appropriate designations for the coastal area under consideration. The DFA would prepare a draft designation decision for public comment, after which the Minister would make the final decision. The designation should be reviewed periodically through a process that is similar to the process followed for the original designation.

Where strategic assessment identifies areas particularly suitable for the development of either kind of aquaculture and the DFA opts to put out a call for bids on those sites to proactively encourage their development, strategic assessment could lead to the designation of aquaculture development areas as currently contemplated by the Fisheries and Coastal Resources Act. ${ }^{157}$ Where bids are called, they could be called on the basis that the selected bidders would go through a more streamlined version of the licensing process described below. For this to happen, the strategic assessment process would have to provide residents in local communities with ample opportunity to participate in the assessment process, and it would have to be transparent from the outset that a streamlined licensing process was a potential outcome of the strategic assessment. In addition, the process would have to conclude not only that the area was a Green area (or an area suitable for shell-fish aquaculture) but that the development of the area for aquaculture enjoys high levels of community support. In other words, the absence of concerns about conflicts with other users would not be enough. Positive support for development would have to be established through a very open strategic assessment process before a licence could be issued outside the normal licensing process.

\section{LICENSING (SITE APPROVAL) PROCESS}

\subsection{Introduction}

Under the current regulatory framework, aquaculture is regulated through a licensing process that works in conjunction with a leasing process. Under this mode of regulation, aquaculture is prohibited unless licensed. Once licensed, it has to be conducted in accordance with the terms and conditions set out in the licence.

\footnotetext{
157 SNS 2012, с 22. We note that an important question was raised by the feedback we received from ACFFA on our draft report, which was whether the proactive development of aquaculture sites is an appropriate role for the DFA as a regulatory organization. Their concern is the involvement of the DFA very directly in the developmental aspect of the industry, with possible adverse consequence to public trust and confidence. We recognize the concern but on balance believe it is addressed by the transparency and accountability that would be applicable due to the requirement for a strategic assessment that establishes compliance with Green area classification criteria and the existence of significant community support.
} 
In addition to a licence, an operator needs a lease if the licensed aquaculture is to be carried out on Crown waters. Most marine-based aquaculture is conducted on Crown waters. A lease is not authorization to conduct aquaculture. Rather, it confers an exclusive right to use the leased space for aquaculture when and if a licence is obtained. Licensing and leasing tend to be used interchangeably in describing the process, perhaps because most sites need a lease as well as a licence and because the Fisheries and Coastal Resources Act provides that the lease is to be issued on the same terms and conditions as the licence.

Our review of regulatory frameworks for aquaculture in place across Canada and in other jurisdictions shows that the model of regulation consistently used is a licensing model. Under this model, aquaculture is prohibited unless licensed. Once licensed, the regulatory framework requires aquaculture to be conducted in accordance with the requirements and limitations that are either written into specific licences or present in the licensing statute, in which case they are applicable to all licensees operating within the scope of the statutory requirements.

The licensing mode of regulation should continue to be the mode of regulation used in Nova Scotia. However, we think it should be conducted in accordance with the following improvements.

\subsection{Licensing and Environmental Assessment}

As noted earlier, the regulation of aquaculture deals with many issues that otherwise would be addressed under environmental regulation. Determining the impact a proposed aquaculture project would have on the environment is a critical component of the evaluation that must be undertaken before a licence is issued, renewed or amended.

For this and other reasons, it was proposed to us that we should recommend that licensing be subject to environmental assessment conducted under the Environment Act. ${ }^{158}$ Some pointed out that until recent changes made to the Canadian Environmental Assessment Act, some aquaculture projects were subject to environmental assessment at the federal level. ${ }^{159}$ As this is no longer the case, some have suggested that this strengthened the case for a provincial environmental assessment under the Environment Act to assume the function of the federal environmental assessment that will no longer occur. 160

\footnotetext{
${ }^{158}$ There was qualified support at the Roundtable for the recommendation that "the regulatory framework should include a requirement for environmental impact assessment to be carried out by the Province as a part of the licensing process, including consideration of environmental, economic and social issues.”

${ }^{159}$ In the ACFFA feedback to our draft report, we were told that this was a mistaken understanding of the history, in that environmental assessments of aquaculture projects under $C E A A$ were discontinued before changes were made to $C E A A$ on the basis of a determination that aquaculture projects did not warrant environmental assessment. If so, the question in our view remains: should environmental assessment therefore be incorporated into provincial assessment of aquaculture projects? On that question, we understood ACFFA to be responding to our proposal that the aquaculture licensing process should be conducted as a kind of specialized environmental assessment by saying, in effect, that aquaculture does not warrant environmental assessment. We do not share this view and find support for the contrary view (that assessment for environmental impact should occur whether or not this is in a distinct environmental assessment process) in the literature. See, for example, the various chapters in VanderZwaag and Chao, Aquaculture and Law, and in particular, the chapters by VanderZwaag and by Howarth.

${ }^{160}$ ECELAW, Aquaculture Regulation in Nova Scotia.
} 
Our review of the regulation of aquaculture in other jurisdictions indicates that environmental assessment separate and apart from the licensing process is not typically part of the assessment of a proposed aquaculture project. ${ }^{161}$ In addition, it should be kept in mind that the federal environmental assessments that applied to aquaculture were typically conducted as screening reviews carried out by the same federal agency that was called on to make a regulatory decision in respect of the proposed project. They were not environmental assessments conducted by an independent third party.

Consistent with our conclusion that the regulation of aquaculture should generally continue to be the responsibility of the DFA, we have concluded that the provincial environmental assessment process should not be applied to the assessment of aquaculture projects. Instead, we think assessments of an application for a licence should be conducted by the DFA on the understanding that the assessment must cover all of the ground that an environmental assessment would cover, as well as whatever additional ground it must cover from a general licensing and resource utilization perspective. It should, in other words, be conducted and be understood as a kind of specialized environmental assessment, which, like the federal environmental assessments that have been conducted in the past, is conducted within the regulatory approval process.

So conducted and so understood, environmental assessment would be built into the regulatory framework in somewhat the same way as environmental assessment was built into federal decision making in respect of aquaculture before the recent changes to the Canadian Environmental Assessment Act were made. The end result should be one regulator that is in a position to integrate environmental, social and economic considerations in an overall determination on how to maximize net benefits to all Nova Scotians in a manner that is fair and equitable.

\subsection{Statutory Licensing Principles}

The legislation governing the licensing process should set out the principles that are expected to guide that process. Putting the principles in the legislation will mean that the DFA has a legal duty to address the principles in its assessment and decision making on applications for licences.

The principles would inform and guide but not determine the outcome in any particular licensing decision. They should be set out in the Act or the regulations using a non-exhaustive approach to drafting to avoid the implication that the listed principles are the only ones relevant to licensing no matter the circumstances of a particular licence application, variation or renewal. Our process leads us to conclude that the principles should address the following matters:

a. Compatibility with public rights of navigation

161 See the two reports prepared for us by East Coast Environmental Law, available on our website, under "Updates": Comparative Analysis of Five Regulatory Frameworks in Canada, comparing NB, PEI, NL and BC to Nova Scotia, and Comparative Analysis of Aquaculture Regulatory Frameworks in Maine and Nova Scotia. A much broader survey of environmental impact assessment practices in aquaculture is provided in A. Wilson et al., "Review of environmental impact assessment and monitoring in salmon aquaculture,” in Environmental Impact Assessment and Monitoring in Aquaculture: Requirements, Practices, Effectiveness and Improvements, FAO Fisheries and Aquaculture Technical Paper 527. This paper considers Canada, Chile, Ireland, New Zealand, Norway, the United Kingdom and the United States, and specifically notes the absence of explicit consideration of socio-economic costs and benefits in the EIA process of the jurisdictions covered, with the partial exception of Scotland (p. 524). 
b. Compatibility with fishery activities, including the lobster fishery

c. Compatibility of the nature and scale of a proposed operation relative to the biophysical, oceanographic and community context ${ }^{162}$

d. Compatibility with the activities of other users or beneficiaries of the public waters in question

e. Responsiveness to the cumulative effect of aquaculture in the area

f. Contribution of the proposed project to net community socio-economic benefits

For fin-fish aquaculture, the application of these principles would be framed by the classification of the area of the proposed operation as a Green, Yellow or Red area for the kind of fin-fish aquaculture being proposed in the application for a licence.

We received feedback on our draft report that licensing principles were redundant or unnecessary given our proposed regulatory principles. In our view, both are important. The regulatory principles apply to the design and operation of the whole regulatory framework and are therefore necessarily quite general. The licensing principles are more specific because they have a more specific function, which is to structure the discretion of the DFA to either approve or reject an application for a licence. Their role is to provide more specific guidance to licensing than the general principles by themselves could provide and also to enable and facilitate the accountability of DFA for its licensing decisions, including through the appeal process.

Our proposal is similar to the approach that has been taken in Maine. In that state, the Commissioner responsible for licensing is required by law to consider the following factors:

a. Impact on riparian owners

b. Interference with navigation

c. Interference with fishing or other water-related uses

d. Intensity and frequency of other aquaculture in the area

e. Impact on the ability to support wildlife or marine habitat

f. Fish health practices

g. Impact on public use and enjoyment of the area

h. Lighting, noise and visual impacts ${ }^{163}$

This approach is different from the one we have proposed in three respects: instead of licensing principles, it lays out the factors that must be considered; it lists the matters that must be taken into account in a more specific way than does our list of licensing principles; and it explicitly addresses some matters, such as lighting, noise and visual impacts, that might not be encompassed within our list of more general principles.

\footnotetext{
162 The Roundtable expressed unanimous support for the recommendation that "the regulatory framework should require the determination of the carrying capacity of a proposed site and its reference site, in order to maintain oxic conditions. Licensing should include maximum biomass levels based on carrying capacity." There was further qualified support for the recommendation of using "the best available prediction model to assess site suitability" in the context of a decision support system. (Roundtable Final Report, 20)

163 Maine Department of Marine Resources, Aquaculture Lease Regulations, 13188 CMR ch 2, at s 2.37.
} 
The advantages of a guiding principles approach is the flexibility it creates to address variation between cases, as well as change and evolution over time. It may also have greater capacity to encompass issues of concern that are relevant to particular cases but are not included in a specific list of the factors that must be considered in all cases, although this could be addressed by adding a "basket clause" to the list of specific factors. The other advantage of a guiding principles approach is that it goes beyond identification of the factors that should be considered, to indicating how those factors should be taken into account in the decision-making process.

Either approach would accomplish our core objective, which is to ensure that those interested in a decision on an application for a licence have a stronger basis than they do under current legislation to hold the DFA accountable for addressing the issues that licensing should, as matter of law, address. On balance, however, we favour a guiding principles approach.

\subsection{Universal Elements of the Licensing (Assessment) Process}

For all kinds of aquaculture, the licensing process would generally have the elements laid out in this section. The content of the elements would differ depending on whether the application is for a shell-fish or a marine-based fin-fish project and depending on whether the proposed fin-fish site is in a Green, Yellow or Red area. The content of the elements will also vary to reflect the differences between the risks of adverse impact associated with specific applications within these broad categories or branches of aquaculture.

In our draft report, the linkage or relationship between the licensing process and the strategic assessment process described above was not fully developed or explained. As a result, some of the feedback we received was that the licensing process we describe here would involve a repetition or duplication of much that would have already happened in strategic assessment. Two important points therefore should be stressed. First, the strategic assessment process will only be used where the DFA decides to use it for the purpose of applying the classification system to coastal areas. Where no strategic assessment has happened, there will by definition be no duplication between strategic assessment and the licensing process. Second, where a licence application does relate to an area already classified by a strategic assessment, the result may be that the steps in the licensing process will be adjusted or streamlined to take account of the ground already covered in the strategic assessment. This is explained in more detail below in subsection 18.6, Licensing and Strategic Assessment. ${ }^{164}$ In 18.6, it is also pointed out that even where strategic assessment does not lead to reduction in the number of steps in the licensing process, it will normally mean that there is less work to be done in many of the steps of the licensing process for an application for a licence in an area that has been classified in a strategic assessment.

164 As indicated in section 12, Experimental or Developmental Licences, a streamlined application process would also apply to applications for experimental or developmental licences to conduct aquaculture for academic or communal research purposes, as well as for commercial research where the results of the research are to be shared publicly. A streamlined process would also be followed where the application was for an experimental or developmental licence issued after a strategic assessment. 


\subsubsection{Introduction of an "Option to Lease"165}

One of the concerns pressed on us most strongly is that too many project proponents do not seek input from the public until they are required to do so by the licensing process. By then, a lease is in place and project plans are quite advanced. It was said that this denies the public a meaningful opportunity to make their views known when they are most likely to have the greatest impact on planning by proponents and decision making by regulators. It means that public participation occurs only when the community is faced with what looks like a done deal between the proponent and the regulator, which contributes to fostering distrust and community opposition. It may also mean that the project has been developed without input that could have improved the project in ways that would both make it more acceptable to the community and also a better project overall.

Industry representatives explained that proponents must do a lot of preparatory work to determine the suitability of a site for aquaculture and the kind or scale of aquaculture that would be suitable for a particular site. They explained that if proponents included open consultations with the community in this preparatory work before securing a lease, information about the site and the proponent's plans for the site would make its way to competitors, who could then use it to apply for a lease before the proponent has an opportunity to do so.

We think the process of developing aquaculture projects and the regulatory process would both work more smoothly and effectively if community involvement were able to start from early in the planning process and, in particular, before a lease is applied for. To facilitate this, we recommend that the regulatory framework should follow the recommendation that received qualified support at the Roundtable, that "there should be a regulatory requirement to notify the public early to incorporate local knowledge and public input into licence applications.”166

At the same time, we think this will be feasible only if proponents can inform the public of their intentions and engage with communities with reasonable confidence that competitors cannot use the information proponents share with communities to pre-empt the proponent in applying for a lease. In other words, the regulatory framework should address the main concern of those members of the Roundtable who qualified their support for the recommendation quoted in the previous paragraph, which was protection of the interests of a prospective operator if knowledge of their interest in, and plans for, a particular site become generally known prior to their application for a licence and lease.

To strike this balance, Nova Scotia’s regulatory framework should adopt the "option to lease” concept that is part of the regulatory framework for aquaculture in Scotland. ${ }^{167}$ Under this concept, except in circumstances where a streamlined licensing process applies, the regulatory process should always begin with an application for an option to lease. Once an option to lease is issued, only the holder of the option could apply for a lease of the site while the option is in effect. This

165 There are situations where the applicant for a licence does not require a lease because it owns the land on which its project is to be conducted. In that situation, the industry concern that the option to lease is intended to address does not arise because the proponent does not risk losing its site to a competitor.

166 See Roundtable Final Report at page 14.

167 For more analysis of this concept in the Scottish context, see the discussion of the "lease-option agreement” at pages 33-37 of Cecilia Engler's report on the aquaculture framework in Scotland. 
allows the holder of the option to engage with stakeholders in developing its project with security that competitors cannot use its work to apply for a lease ahead of the option holder. The basic idea is that an option to lease would give a particular proponent priority access to a particular site over all other proponents, without offering any guarantees that a lease or licence will ever be issued to the proponent for the site.

The option to lease would give proponents a limited period of time, during which they would have the exclusive right to submit a project for regulatory consideration. Based on what we have heard, this should remove a key barrier to engagement with communities in the early stages of project development and planning.

Given its limited effect and purpose, the option to lease should be easily obtained with minimal process. Essentially, it should be granted when it is applied for unless the DFA has some very specific reason to deny the application, such as the ineligibility of the applicant to apply for a licence and lease. To avoid the temptation businesses may have to "sit" on an option to lease, an option to lease should only be issued where there is reason to believe that the proponent has the intention and the capacity to move forward with their work on the site reasonably quickly. In addition, an option to lease should expire after a set period of time.

\subsubsection{Clearer/Stronger Notification and Information Provision Requirements}

As soon as the option to lease is issued, the public and interested stakeholders would be immediately notified by the DFA. The public notice of the option to lease in essence constitutes the initial public notice of the start of the licensing process. From this point on, the licensing process should be designed to proactively engage interested members of the public and of affected communities, and to be as transparent as possible. The commitment to openness and transparency should continue beyond the initial step of the lease and licensing process and endure for as long as the site is considered an active aquaculture site. The DFA should create a webpage for each aquaculture site under option or lease on the DFA website that provides all relevant information to interested members of the public about the status of the site and, for every approved site, the terms and conditions under which it is permitted to operate, monitoring results and any other relevant information. This same webpage could serve to facilitate full and timely transparency throughout the operation of the facility.

In these ways, the new regulatory framework will be responsive to several recommendations that received qualified support at the Roundtable: first, that there should be a regulatory requirement to notify the public early and to incorporate local knowledge and public input into the licence applications; second, that all licence application information pertaining to environmental impacts and impacts on other resource use and users should be made publicly available.

\subsubsection{Mandatory Pre-application Scoping Process}

To apply for a licence, the holder of an option to lease would be required to initiate and conduct a pre-application scoping process in the community or communities in close proximity to the proposed aquaculture project. The DFA would be responsible for ensuring appropriate notification of the process, but the process would normally be conducted by the proponent. The purpose of the scoping process would be twofold. First, it would address the desire for community members to know about and to have an opportunity to provide input to the development of the project before it 
goes too far into the regulatory process. The process would give local residents a chance to learn about the proposed project, to express their early support or opposition for the project to the proponent and to provide local knowledge to the proponent that may discourage or improve the application for a licence and a lease. ${ }^{168}$ The second objective would be to ensure that the proponent has access to local knowledge that may be relevant to its decision whether to proceed to the application stage and, where it does decide to proceed, to the content of its application. ${ }^{169}$

In broad terms, this new stage of the process, which is similar to what may happen informally and inconsistently under the current framework, is based on the Pre-Application Scoping Session that applicants must conduct before applying for a licence in Maine. ${ }^{170}$ Under that approach, the regulator must be satisfied that the applicant for a licence has fairly and seriously conducted the pre-application scoping process before it agrees that the application for a licence is complete and ready for consideration. We think this should be the approach adopted in Nova Scotia.

To that end, we recommend that applicants for a licence be required to include a section on how the pre-application process was conducted and what was learned from the process and from preparing the background document (or scoping report) that we say below should be a required part of every application. This portion of the report would be expected to address matters such as

- overall levels of support and opposition to the proposed operation

- views on the proposed location, scale, species, operator, technology, etc.

- views on compatibility with existing activities in the area

- views on impacts, benefits, risks and uncertainties

- views on what the operation should be required to do to minimize its impact on the natural environment and on other uses of the coastal area

By requiring information learned in the pre-application scoping process to be included in the report that the applicant must submit with an application for a licence and lease, the regulatory framework would be responsive to a recommendation that received qualified support at the Roundtable - that there should be a regulatory requirement to incorporate local knowledge and public input in licence applications.

\subsubsection{Filing of Background Document (Scoping Report)}

As in Maine, applicants for a licence and lease in Nova Scotia should be required to submit a background document (or scoping report), which would become the primary factual foundation for

\footnotetext{
${ }^{168}$ This is consistent with ECELAW's conclusion that "community members need to be engaged in the licensing process before a license is issued" in order to allow meaningful public engagement in the process: see Aquaculture Regulation in Nova Scotia), 21-22.

${ }^{169}$ The Roundtable expressed qualified support for a recommendation that "there should be a regulatory requirement to notify the public early and to incorporate local knowledge and public input into license applications," among general agreement that early public input was vital.

${ }^{170}$ For more discussion of this scoping session in the Maine context, see ECELAW's report Comparative Analysis of Aquaculture Regulatory Frameworks in Maine and Nova Scotia, at pages 18 and 21. This report is available on our website under "Updates." See also Maine Department of Marine Resources, Aquaculture Lease Regulations, at s 2.07.
} 
the application. The background document, or scoping report, would be a document available to the public. As such, one of its functions will be to enable meaningful public participation in the formal stages of the licensing process. One of the other functions of this report will be to enable the assessment of the application to encompass and address the matters and issues that would typically be covered in a process of environmental assessment. In the case of fin-fish aquaculture, another function of the report (in combination with public feedback on the report) will be to give the DFA as much as possible of the information it will need to either classify a proposed site in the Green, Yellow or Red classification system or, where the site has been previously classified, decide how an application will be assessed and decided given its prior classification in the Green, Yellow or Red classification system.

The information that a background document or scoping report will include will vary with the kind of aquaculture being proposed and with the location of the proposed operation. It should, however, include the information derived from the pre-application scoping process outlined above. It should also include information on the following matters:

a. A detailed description of the proposed lease site and of the proposed operation (including scale/size, location, species and stocking density)

b. Biophysical conditions at the proposed site of relevance to the suitability of the site for the proposed operation, including bottom characteristics, tide levels and current speed and direction, and resident flora and fauna

c. An overview of all current and recent activities in the area that have the potential to be affected by the proposed operation or that have the potential to interact cumulatively with coastal ecosystems that have the potential to be impacted by the proposed operation (including fishing, angling, tourism, recreation, land-based industrial and agricultural operations)

d. The presence of any endangered species in the area potentially affected by the proposed facility

e. Specific measures the proponent intends to take in terms of operational practice and technologies to reduce the environmental impact of the operation and to ensure the suitability of the proposed operation for the proposed site

f. Any other matter on which the DFA specifically asks for information ${ }^{171}$

The background document (or scoping report) requirement and the requirement that such a document be a public document will help to ensure that the regulatory framework responds in an organized and consistent fashion to the recommendation of the Roundtable, which received

\footnotetext{
${ }^{171}$ In developing this list of items to be addressed in the background document or scoping report, we have noted that in Maine, the application must address a description of the proposed lease site; a list of species to be cultured and the source of the organisms; an environmental evaluation of the site including bottom characteristics; resident flora and fauna, tide levels and current speed and direction; a description of the recreational and commercial fishing activity in the vicinity; evidence of technical and financial capability; and any other information the Commissioner may require.
} 
qualified support, that "all licence application information pertaining to environmental impact and impacts on other marine resource use and users should be made publicly available.”172

\subsubsection{Application Screening Process}

Once an application for a licence and lease is submitted to the DFA, the Department would carry out an initial screening. This screening would allow the DFA to consider whether the application is complete and ready for a hearing. But it would also determine whether the application has a reasonable prospect of success if it were moved on to the next stage of the process. The screening would take into account public comments made to the DFA on the application through a notice and comment process described below.

The decision options available to the DFA at this stage of the process would be to send the application back to the applicant if the DFA determines that the application is incomplete, to reject the application if the DFA determines it has no reasonable prospect of success, or to send the application on for a hearing. Where the decision was to send the application back or to reject the application on the basis that it had no prospects for success, the DFA would be required to explain the basis for its decision. A decision to reject an application at this stage on the basis that it has no prospects for success would be subject to appeal due to its final nature. Other decisions made at this stage would not be subject to appeal.

To address files where incompleteness or absence of prospects for success are clear, the DFA would have the authority to send back or to reject on a summary basis without seeking public input or input from other regulators. Otherwise, there would be a 30-day public comment period during this stage of the process. In other words, the public would have a 30-day period in which to give its comments to the DFA on the application submitted by the applicant. For that purpose, the screening period would be initiated by posting of the application to the DFA's website. Where an application passes the screening stage, the public comments received become part of the file for the purpose of the hearing.

The consultations of the DFA with other regulatory agencies would also happen at this stage of the process, again unless the DFA sends the application back or rejects the application solely on its own assessment. The consultations could become part of the basis of a decision to send back or to reject. Where they do not have that effect, the consultations would become part of the file for the purpose of the hearing.

For fin-fish applications that are in locations that have already been categorized as Green, Yellow or Red, that prior characterization would be taken into account at this stage for the purpose of deciding whether the application will proceed to a hearing. For fin-fish applications in locations that have not been categorized, part of the analysis to be done at the screening stage is whether the application includes the information needed to categorize the location as Green, Yellow or Red.

For applications that pass the screening process and on which there is a discretion to be exercised as to the kind of hearing that will be held, this discretion would be exercised in the application screening process. So, for example, if there were a discretion to choose between what we

\footnotetext{
${ }^{172}$ Roundtable Final Report, 11.
} 
subsequently call an administrative style of hearing and an adjudicative style of hearing, that discretion would be exercised at this stage.

The screening process will also give the DFA the opportunity to identify the issues that it believes must be addressed by the applicant in the hearing. This will help to ensure that the hearing is organized, productive and efficient.

\subsubsection{Mandatory but Variable Hearing}

Under the current regulatory framework, the Minister of Fisheries and Aquaculture is authorized but not required to conduct a hearing before licensing a project and issuing a lease. The Act is very open-ended as to the kind of hearing that the Minister can conduct when he or she decides to conduct a hearing.

Under the new regulatory framework, a hearing would be part of the process for every application for a licence. What would vary would be the kind of hearing conducted in each case. We envisage two basic kinds of hearings, with some room for variation as to how each is conducted in specific cases. One would be an administrative style of hearing and the other would be an adjudicative style of hearing. Administrative hearings would be conducted largely through a process in which participants are given the opportunity to comment, ask questions and make submissions in writing. Adjudicative hearings would be conducted through a process that includes a formal hearing conducted in person before the person who is designated to either make the decision or conduct the in-person portion of the hearing on behalf of the decision maker.

For shell-fish applications, the legislation would leave the choice of which of the two kinds of hearing will be used to the DFA, but it would lay out the kind of factors the DFA would be required to take into account in deciding on the form of hearing to be held in particular cases. We would anticipate that most hearings for shell-fish applications would be administrative hearings. The DFA would nevertheless have the discretion to order an adjudicative hearing in particular cases. Its exercise of this discretion would be subject to appeal.

In contrast, for fin-fish applications, the legislation would specify that the hearing to be held must be, with two possible exceptions, an adjudicative hearing. One exception would be for applications in Green areas where the classification of the area as Green has been determined through a strategic assessment or a previous licensing decision. In those cases, which would include applications being made in response to a call for proposals issued by DFA after a strategic assessment, the DFA would have the discretion to conduct the hearing for a fin-fish licence in a Green area as an administrative hearing. The exercise of that discretion would be subject to appeal. The second exception would be where the application was for an experimental or development licence, where the hearing would normally be an administrative hearing. In addition, in those cases, the hearing would be expected to be a streamlined administrative hearing where the research to be conducted is academic or communal research or commercial research to be conducted with public disclosure of the results.

Both kinds of hearings would be required to meet essential procedural protections to ensure fairness. For example, participants in both kinds of hearings would have access to the information needed to make their participation in the process meaningful. In other words, the access of participants to the application file would be the same in administrative and adjudicative hearings. 
In both kinds of hearings, the exception would be information that would be withheld because the applicant established that it is confidential business information. As explained in our earlier discussion of transparency, the onus of establishing the business confidentiality of information should be on the applicant, under a statutory definition of confidential information that is narrow and restrictive.

In both kinds of hearings, participants would have the opportunity to present whatever information or make whatever submissions they wanted, subject only to showing its relevance and adhering to reasonable limits required to ensure that the hearing is conducted efficiently and economically.

In both kinds of hearings, there would be two requirements: that the decision be made on the basis of the information considered at the hearing and that the reasons for the decision be released publicly and to everyone who participated directly in the hearing.

In these respects, the regulatory framework would be responsive to the Roundtable recommendation that "a public hearing should be a mandatory requirement with formal procedures." 173 We recognize that this recommendation only received partial support. We have tried, however, to address at least one of the reasons that prevented some from supporting the recommendation, which was "past experience with public meetings that were poorly run without formal procedures." We have not addressed the other reason that was given for those who were not able to support the recommendation, which was the view that a public hearing should not be necessary where a proponent had carried out effective consultation. Our view, however, is that such a proponent will usually be rewarded with an efficient and positive hearing experience.

Our recommendations on the openness of the hearing process respond to the Roundtable recommendation that, "all licence application information pertaining to environmental impact and impacts on other marine resource use and users should be made publicly available.” This recommendation received qualified support, the qualification relating to protection of sensitive business information. In addition to the protection for confidential information that we have proposed, we also note that the recommendation specifies public access to "information pertaining to environmental impact and impacts on other marine resource use and users.”

\subsubsection{Written Reasons for Decision}

The DFA would be subject to a statutory duty to give reasons for its decision following a hearing. The legislation would specify that the decision and the reasons for the decision must be posted on a website and otherwise made available to participants in the hearing and to the broader public. This would be consistent with the recommendation from the Roundtable, which received qualified support, that "government should be required to respond to the issues raised during the public hearing process."

This is another aspect of procedural rights that would be the same in administrative and adjudicative hearings. To ensure that it is a meaningful tool of accountability and transparency, the

\footnotetext{
${ }^{173}$ Roundtable Final Report, 11. This recommendation received qualified support, with the qualification reflecting the concern of some about the protection of business confidential information, which we have addressed to the extent we think it can be addressed given the overriding need for "open book" regulatory transparency.
} 
legislation would specify that the reasons for the decision would have to explain how the licensing principles were taken into account and how the decision advanced the principles and the goals of the broader regulatory framework. ${ }^{174}$

\subsubsection{The Role of Third Parties in Conducting the Process}

The DFA would have the authority to require a proponent to use a third party to facilitate the preapplication scoping process.

The DFA would have the authority (as it does now) to commission a third party to conduct a review of any application before rendering its decision on the application. This could be done before the hearing. In that case, the report from the third party would be considered in the hearing. Alternatively, a report by a third party could be commissioned after a hearing. In that case, participants in the hearing would be given an opportunity to comment on the report before it could be taken into account in deciding the application. In both cases, the report from the independent third party would be posted on the webpage created for the aquaculture site under consideration, located on the DFA website.

Utilized in this way, third-party reports would serve somewhat the same function as focus studies perform under the Environment Act. They would generally be of a fact-finding nature but could also be mandated to include recommendations. They would be a device the DFA could use where it requires additional information or information from a neutral source or from someone with a particular expertise. They could be used to assist with the rebuilding of trust where views have become polarized and where relationships have become adversarial. Third parties could also be engaged to consult with potentially affected communities, including Mi'kmaw communities, stakeholders and interested members of the public, to inform them of what is proposed and to solicit their views on the proposed facility.

Third parties could also play a role in the conduct of the hearing. The DFA could assign responsibility for the hearing to an independent third party or to a panel of independent third parties. Alternatively, an independent third party could be included in the conduct of the hearing with DFA members.

\footnotetext{
${ }^{174}$ In Maine, the Commissioner who is authorized to determine applications for leases can only grant a lease if satisfied that the lease will not unreasonably interfere with ingress and egress of riparian owners; the lease will not unreasonably interfere with navigation; the lease will not unreasonably interfere with fishing or other uses of the area; the lease will not unreasonably interfere with significant wildlife habitat and marine habitat or with the ability of the lease site and surrounding marine and upland areas to support existing ecologically significant flora and fauna; the applicant has demonstrated that there is an available source of organisms to be cultured at the site; the lease does not unreasonably interfere with public use or enjoyment within 1,000 feet of beaches, parks or docks owned by government; the lease will not result in unreasonable impact from noise or light at the boundaries of the lease site; and the lease complies with visual impact criteria relating to colour, height, shape and mass. This is a more prescriptive approach, which mirrors the list of things the Commissioner is required to consider. We have considered this approach since issuing our draft report and concluded that the more general approach we have proposed strikes a good balance between transparency, accountability, consistency, rigour and flexibility in decision making.
} 


\subsubsection{Appeal to the Minister (or to Independent Board)}

As under the current framework, proponents should have the statutory right to appeal to the Minister the decision to refuse a licence, and opponents of projects should have the opportunity to appeal to the Minister on a decision to grant a licence. ${ }^{175}$ Appeals would have to be made within 30 days of public notice of the decision being made, and the Minister would be required to decide the appeal within 60 days of receiving the appeal. While this is all a continuation of what is currently provided under the existing framework, the difference would be that under the new framework the Minister would not be both the licensing official and the person being appealed to. This is because under the proposed framework, the licensing and leasing decision would be made by the official in the DFA delegated the authority to make those decisions.

Later in this report, in response to feedback we received on our draft report, we propose the creation of a board to consider applications from the public to have a licence revoked where there is clear evidence of a site's biophysical unsuitability or of a pattern of substantial non-compliance with regulatory requirements. This is a change from our draft report, where we proposed that these applications would be to the Minister. Once created, this board could also be given the jurisdiction to hear appeals from licensing decisions. This would be consistent with our conclusion that the operation of the regulatory process should be separated from the Minister's general authority for the overall governance of the regulatory process and for policy matters.

\subsubsection{Appeal to the Nova Scotia Supreme Court}

Where an appellant to the Minister (or independent board) is unsatisfied with the Minister's (or the board's) determination of an appeal, they would have the right to appeal to the Nova Scotia Supreme Court within 90 days of public notice of a decision of the Minister. This is a change from the current situation, where a party dissatisfied with a ministerial decision has to apply for judicial review; that is, for the permission of the court to challenge the Minister's decision. It would make the legislative framework for review of aquaculture projects consistent with the Environment Act in this respect, except that we are recommending that people be given 90 days rather than the 30 days usually provided in legislation to decide whether or not they will appeal and to prepare their appeal.

\subsubsection{Procedural Clarity and Certainty}

One of the concerns about the current regulatory framework that we heard from industry is that it is procedurally uncertain and sometimes unwilling or unable to reach decisions or to stick with decisions once made. These concerns could increase under the proposed regulatory framework if it does not function in a predictable fashion, given the significant additional work the framework will require from proponents at the early stages of the process.

We heard a similar set of concerns from community members, even though it was often expressed from the perspective of those who perhaps expected different decisions from the process than

\footnotetext{
175 There was partial support at the Roundtable for a recommendation to this effect: "The public and the potential operator should have the right to appeal a decision to issue or renew a licence or a refusal to issue a licence.” (Roundtable Final Report, 31)
} 
would typically be expected by those in the industry. The unpredictability of the current process is a concern for everyone, even though different players may be concerned for different reasons.

We think the new regulatory framework should respond to these concerns. It should contain elements of process certainty for those who will have invested time and resources in the development of an aquaculture project under a licensing and leasing process that will impose higher demands and costs on applicants than the current framework does. At the same time, care must be taken to ensure that the regulatory framework addresses process certainty in ways that reflect and respect the differences that will exist between individual applications. Therefore, the approach should be to achieve certainty within the context of the relative scale, complexity and disagreement associated with each application.

To address these objectives, we recommend that the legislation subject the DFA to the following three procedural obligations:

- It must specify and abide by a maximum length of time for reaching a decision on an application once it concludes that an application passes the screening stage of the process.

- It must specify a maximum length of time for the completion of the hearing stage of the process at the commencement of that stage of the process, and it must complete the hearing stage of the process within that period of time.

- It must specify a maximum length of time within which a decision will be reached and released once a hearing is completed.

We also recommend that the legislation provide applicants with the option of applying to the Nova Scotia Supreme Court for an order requiring a decision to be made on an expedited basis where it has not been made within the time specified at the conclusion of the hearing for the making of the decision or where the time specified for the making of a decision at the end of the hearing is beyond the time specified at the screening stage of the process for the completion of the overall process.

\subsection{Variations in the Licensing Process}

\subsubsection{Between Fin-Fish and Shell-Fish Aquaculture and Between Shell-Fish Applications}

The licensing process will have the same elements (or steps) when applied to fin-fish aquaculture as it will have when it is applied to shell-fish aquaculture. The main procedural difference will be that the hearing will be an adjudicative hearing for fin-fish applications unless the application relates to a Green area that has been determined to be a Green area through a strategic assessment or a previous licensing process in which an adjudicative hearing was held. In that scenario, an administrative hearing may be held for a fin-fish application. In contrast, the hearing will typically be an administrative hearing for most shell-fish applications. ${ }^{176}$

\footnotetext{
${ }^{176}$ In its feedback to us on our draft report, the ACFFA objected to a "two-tier" system in which some licence applications are put through what we have described as an adjudicative hearing and others are put through what we have called an administrative hearing. We would agree if the difference were an arbitrary
} 
This will not, however, be the only difference in how the licensing process applies to fin-fish and shell-fish applications. The common elements of the licensing process will typically require more from the applicant and from the DFA where the application is for a fin-fish application than it typically will require from both parties where the application is for a shell-fish operation. For example, although both the proponents of a fin-fish operation and a shell-fish operation would be required to submit a background document with their applications, the document submitted for a fin-fish operation will typically be expected to identify more potential environmental impacts that have to be addressed than would the report submitted with a shell-fish application. This will mean that the applicant for a fin-fish licence will typically have to address more issues and more difficult issues in the screening and hearing stages of the process than most applicants for a shell-fish licence and lease.

It follows that the applicant for a fin-fish licence will typically have more work to do to show that the licence would be consistent with the statutory licensing principles, even though the licensing principles would be the same as for an applicant for a shell-fish licence. Similarly, although the onus the legislation would place on the DFA to justify a decision to licence would be legally the same in the consideration of fin-fish and shell-fish applications, it would in practical terms usually be more demanding where the application is for a fin-fish operation.

Such differences in what is practically demanded of applicants and of the DFA when the universal elements of the licensing process are applied to fin-fish and shell-fish applications will generally increase where the fin-fish application is for a licence in a coastal area that is Yellow or Red. In other words, there will typically be a greater difference between what is expected of applicants and the DFA in fin-fish and shell-fish applications where the fin-fish application is for an operation in a Yellow or Red area than there will be where the fin-fish application is in a Green area.

Nothing here should be interpreted as indicating that all shell-fish applications will be easily approved or that some shell-fish applications will not present difficult issues or face significant opposition. We heard directly from members of communities who are very concerned about shellfish aquaculture, and more particularly about its expansion and scale, particularly in relation to its potential to adversely affect other users of public waters and shorelines.

Here, our only point is that the licensing process we have proposed will generally operate differently when applied to fin-fish and shell-fish aquaculture in ways that reflect the differences that generally exist between those two branches of aquaculture, particularly as regards their respective potential to adversely affect the environment. Meanwhile, we believe the licensing process we have proposed is one that can accommodate the real differences that can exist between the potential impacts of different shell-fish operations, considering issues such as their different scales, the technology they use and the degree and nature of their potential impact on other users of public waters.

one, but we do not think it is - rather, we think it generally reflects the nature and level of the issues typically to be considered in the kinds of applications that will usually or always get adjudicative hearings and the kinds of applications that will normally get administrative hearings. The discretion that is left to the DFA to choose between which kind of hearing to conduct where a hearing could be adjudicative or administrative will provide scope to address situations where the rationale for generally allocating the two kinds of applications to the two kinds of hearings do not apply. 


\subsubsection{Between Fin-Fish Applications in Green, Yellow and Red Areas}

As already indicated, the licensing process will be different for fin-fish applications depending on whether they are in areas designated Green, Yellow or Red for the kind of fin-fish aquaculture proposed. This subsection discusses those differences in more detail. First, we point out again that the starting place for the licensing process will be different depending on whether or not an application relates to an area or a site within an area that has been previously classified. Where the site has been previously classified, that classification will be the starting place for the licensing process. Where the application relates to a site that has not been previously classified, the starting point for the licensing process is for the DFA to apply the criteria for identifying Green, Yellow and Red areas to classify the specific site that is the subject of the application.

The general rule should be that applications for the licensing of fin-fish aquaculture should be determined through an adjudicative hearing. As we have already indicated, an administrative hearing may instead be used where the application relates to a site that was previously classified, in either a strategic assessment or a previous licence application process, as a Green area or in a Green area. The rationale for this is that the level of public participation that would have been provided though the earlier process justifies the use of an administrative hearing in the subsequent process. The DFA would, however, have the discretion to conduct an adjudicative hearing and the duty to consider whether case-specific factors warrant an adjudicative hearing despite the earlier participation opportunities.

Regardless of whether an administrative or adjudicative hearing is used to consider an application in a Green area, the starting assumption for the licensing process in Green areas is that the proposed site is well suited for fin-fish aquaculture and that there are no significant competing use issues that cannot be resolved. One procedural consequence may be that the DFA sets a relatively expeditious timeline for the completion of the hearing process and a rendering of a decision. However, the process would be expected to address information brought forward or raised in the licensing process that calls into question the assumption of the site's suitability for the proposed fin-fish operation. Such issues could be identified by the DFA or by members of the public. In either case, the licensing process would have to address them just as it would if they arose in applications for sites in Yellow or Red areas.

For applications in areas previously classified as Yellow or Red areas, or for sites that are classified as Yellow or Red in the licensing process itself, an adjudicative hearing would be mandatory. The question will be what kind of adjudicative hearing is called for and what additional procedural steps should be taken to ensure that applications for sites in Yellow or Red areas are analyzed with sufficient rigour and opportunities for community and public input.

The starting assumption for Yellow areas would be that there are significant questions about the biophysical suitability of the proposed operation and/or with its potential impact on other resources or uses. The expectation is that no licence will be granted unless these significant questions are satisfactorily answered. At the same time, the assessment of applications in Yellow areas would be expected to take seriously the possibility that the concerns present in Yellow areas are capable of being addressed by operations that are carefully designed, implemented and managed to address the characteristics that warrant a Yellow area classification. 
The starting assumption for applications for Red areas is that fin-fish aquaculture will only be licensed in exceptional circumstances. This assumption reflects the rationale for a Red area classification, which is that it is biophysically inappropriate for fin-fish aquaculture or that there is clear proof that fin-fish aquaculture will harm other important activities. While the licensing process would need to be open to the possibility that an applicant has developed a proposal for a fin-fish operation in a Red area that satisfactorily addresses these serious concerns, it would require very convincing proof before a licence for a fin-fish operation could be issued in a Red area.

In short, the licensing process must give a level of scrutiny to applications for fin-fish licences in Yellow and Red areas that is proportionate to the questions, issues and concerns raised by such application. This is the primary reason why we have said an adjudicative hearing would be required for all such applications. In addition, the framework we have proposed will give the DFA additional tools to ensure such applications are scrutinized with appropriate rigour. Some examples:

- It could use the screening stage of the process to ensure that applications for Yellow or Red areas do not proceed to the hearing stage unless there is some prospect for their success at that stage of the process.

- It could engage in more-extensive and more-detailed consultations with other regulatory agencies than would typically be the case for applications in Green areas or for shell-fish applications.

- It could appoint an independent third party or parties to conduct consultations on the proposed aquaculture operation, provide independent analysis on the proposal's technical aspects, provide other kinds of specialized technical advice, or conduct some or all of the hearing.

- It could determine that assessment of an application requires focused and more-detailed scientific work on the biophysical conditions of the proposed site or on the site's broader ecosystem, or further socio-economic research on the potential impact on the uses and users of other resources.

- It could specify a longer timeline for the completion of the licensing process and for the completion of the hearing stage of the process than it typically would for fin-fish applications in Green areas or for shell-fish applications.

- It could provide greater latitude for participants in the hearing process to challenge the applicant than it might in a case involving an application for a licence in a Green area - by, for example, allowing wider cross-examination than would normally be allowed.

- Where it determines after a hearing that a licence may be appropriate, it could issue its decision in draft form to provide the public an opportunity to comment (for example, of 30 days duration) on the draft decision, after which the DFA would make its final decision.

In addition, the duty to give reasons for its decisions will of course be applicable to the DFA in Yellow and Red area applications just as it will be for Green area and shell-fish applications. In practical terms, however, it will impose a heavier burden of justification on the DFA where it decides to grant a licence, given that it will be harder to show that the licensing principles are addressed where a licence is given for a Yellow or Red area than it will be for a licence given in a Green area. This is simply because there will be more room to question the appropriateness of 
licensing in Yellow and Red areas. This means that there will typically be more room to question the justification provided by the DFA through the appeal processes, and outside those processes, than there would be in Green area or shell-fish licensing decisions.

It should also be kept in mind that in addition to adjusting the process for consideration of applications in Yellow or Red areas, the DFA will have the authority where it decides to licence an operation in a Yellow or Red area to do so on terms and conditions that go beyond the terms and conditions that would be applied to licences in Green areas or to shell-fish licences. Given the higher risk of harm to the environment or to other uses that will be present when fin-fish aquaculture is licensed in Yellow or Red areas, it is expected that these additional terms and conditions would impose a more stringent level of regulatory control than would be the case with operations in Green areas.

\subsection{Licensing and Strategic Assessments}

We have stated earlier that under the proposed regulatory framework, strategic assessment can be used not only for the purposes of applying the classification system for fin-fish aquaculture to a particular part of the coast line but also for the additional purpose of determining whether a proactive call for proposals for the development of aquaculture at a particular site should be issued by the DFA. This would be done only where strategic assessment shows not only that a site is suitable for the kind of fin-fish aquaculture in question but also that there is significant community support for the development of a site or locality's good potential for aquaculture development.

Similarly, we have indicated that strategic assessment might be used to evaluate the suitability of a site for the issuing of one or more experimental licences, with or without the establishment of a site that would be licensed for the limited purpose of testing new approaches to aquaculture, be they based on new technologies, new species, or new managerial or operational approaches.

In either of these cases, our concept is that licensing could happen through a licensing process that is streamlined to reflect the process completed and the participation opportunities already provided in the strategic assessment process. We have concluded that such streamlining would be appropriate because strategic assessment would, under the framework we have proposed, be akin to a process of strategic environmental assessment. It would therefore cover some of the ground that we see licensing covering once it is conceived - as we recommend it should be - as a kind of specialized environmental assessment for aquaculture.

However, as indicated above, the framework should permit the streamlining of the licensing process after strategic assessment only where it is made clear at the beginning of the strategic assessment process that the assessment could lead to streamlined licensing. Further, the regulatory framework should specify that the opportunity given to the public to participate in a strategic assessment and a streamlined licensing process should together provide participation opportunities equivalent to those that would have been received in the standard licensing process. In particular, it should be clear that from the two processes, members of the public will have notification of the process, access to file information, opportunity to participate, written explanation for the decision, and rights of appeal equivalent to what they would have had in the standard licensing process.

The extent and nature of the streamlining that might occur in a particular case could differ on the basis of a number of factors. For example, greater streamlining may be appropriate where the 
licence in question is an experimental or developmental licence. Where the licence at issue is for commercial operations in an area that has been identified as appropriate for proactive development of aquaculture, the streamlining would normally mean that applicants would not have to start at the option to lease stage, given the public awareness and input that would already have been accomplished through the strategic assessment. A scoping process and a scoping report would also be either unnecessary or limited to issues not already fully or adequately addressed in the strategic assessment. A hearing would typically be of the administrative variety, not of the adjudicative variety, in light of the process already conducted in the strategic assessment. The substance of the hearing might be limited to issues not already fully addressed in the strategic assessment process. It would also be expected that the timeline set at the beginning of the licensing process for its completion would be shorter than it would have been in the absence of a completed strategic assessment.

Three further points may help to avoid misunderstanding.

First, while we think the option of using strategic assessments to identify sites that could be proactively licensed through a calls-for-proposal process or that are suitable for licensing for "test sites” purposes should be part of the regulatory framework, we are not saying that strategic assessment should be used only for those purposes. The primary rationale for strategic assessment in the regulatory framework being proposed is that it is one of the processes that can be used to classify coastal areas as Green, Yellow or Red for the purposes of different kinds of fin-fish aquaculture.

Second, while the framework should provide that an experimental or developmental licence can be issued through a streamlined process following a strategic assessment, the availability of such licences should not depend on the willingness of the DFA to conduct a strategic assessment. Instead, an experimental or developmental licence should be a licence that can also be applied for through the normal licensing process. When that happens, the licensing process should apply in a way that reflects the differences between a site to be licensed on a limited scale for a limited time to conduct research or to test new technologies or approaches and a site being proposed for licensing for the conduct of commercial operations. For example, as indicated earlier, this would normally mean an administrative rather than an adjudicative hearing except in the case where the proposed site is in an area classified as a Yellow or Red area.

Third, the most important way in which a well-designed and -implemented strategic assessment will streamline the licensing process is by informing affected communities, by providing accurate and complete information to those with an interest in aquaculture development in a given area, and by resolving issues at the strategic level that otherwise could be in dispute at the project licensing stage. Care will have to be taken to balance appropriate streamlining with the importance of retaining the essential approach of full transparency and public engagement throughout the licensing process. 


\section{CHANGES IN THE LEASING OF AQUACULTURE SITES}

In our process, people referred to licensing and leasing as closely associated or even as interchangeable concepts. This makes a certain amount of sense given that a lease is currently required to include the terms and conditions contained in a licence. Presumably, this is to ensure that the DFA has the power to revoke a lease when a licence is revoked and vice-versa, although we think this could be done more directly by making the holding of a lease conditional on holding of a licence.

We heard a number of valid concerns that to our mind are distinct to leases and how and when they are issued, monitored and enforced. The following discussion summarizes the concerns and the corresponding recommendations.

First, concerns were raised about the number of leases that are issued and left in the hands of individuals and businesses that are not making active use of the leased waters. One part of the concern is that this practice prevents development of the site by others. Another is that it creates an apprehension in communities that they are surrounded by potential aquaculture development. There is a related concern that applications for a licence are predetermined when made by an applicant who already has a lease to the proposed aquaculture site.

To address these concerns, we recommend that a lease be issued after and only when a licence to conduct aquaculture has been granted. We also recommend that leases return to the Crown when a licence is revoked, lapses or is relinquished. ${ }^{177}$ This approach will emphasize that the licence is the fundamental authority to conduct aquaculture that and the distinct role of the lease is to give the licence holder possession of the site where they intend to conduct the aquaculture authorized by the licence.

Second, we heard concerns about the difficulty people have in obtaining information about the location and boundaries of leases. To use but one example of the kinds of difficulties created by the current inaccessibility of this information, purchasers of a residential property may learn that the property is immediately adjacent to an aquaculture lease only after they have completed the purchase of the property and the site is later activated or reactivated. Another kind of example we were frequently given related to the problems boaters have experienced in obtaining information about the extent of leases in relation to navigational routes.

The DFA must take steps to make information on the location and breadth of leases much more readily available to landowners and users of the coastal waters than is currently the case. Although leaseholders should be required to do more in this regard, the DFA should take a much more proactive role in making information on leases of what is a public space readily available to the public, such as through a map available on the Internet.

\footnotetext{
177 There was qualified support at the Roundtable for a related recommendation that "the current system of lease tenure should be reviewed to ensure that decisions to allow the maintenance of a lease on an inactive site balance the interests of the leaseholder, other aquaculture businesses that may wish to develop the site, the adjacent communities, and other marine resource uses and users.” The support for this provision was nearly unanimous.
} 
Third, greater clarity must be provided on the rights of leaseholders in relation to rights of others in leased waters. Although a lease of Crown waters for aquaculture gives a significant degree of control over those waters to the holder of the lease, it does not give the leaseholder ownership of the waters. In other words, waters that are leased for aquaculture continue to be public waters. In various community meetings and in meetings with a number of stakeholders, we were told that one of the problems with the current regulatory framework is that leases give, or are interpreted by leaseholders to give, leaseholders too much control over leased waters. Most frequently, the issue was the restriction of boating in or in proximity to the lease area.

From an industry perspective we heard that restricting access to the leased area was needed to protect equipment and stock and to comply with essential biosecurity protections.

Based on what we have heard, our conclusions on the rights of the holders of aquaculture leases and the limitations that those rights place on public access to leased waters by others are as follows:

- There is not as much clarity as there should be on exactly what rights are conferred by a lease and on the nature and extent to which those rights limit the rights of others in respect of what are still public waters even when leased. The extent and exclusivity of the rights of possession and use given under a lease relative to uses other than aquaculture is the key question. This should be one of the issues addressed in the terms of a lease, along with the requirement to hold and comply with a valid licence.

- There is not as much clarity as there should be on the rationale for the restrictions that aquaculture leases place on the rights of others, which in turn perpetuates the perception that the restrictions are arbitrary and unjustified.

- More care should be taken to ensure that the rights given to leaseholders to control public waters for the purpose of conducting aquaculture are only as restrictive of the continuing access of others to public waters as is necessary to address the legitimate needs of the industry.

- The law should require that all leases be configured in such a way as to provide reasonable accommodation for boaters. The approach used in Prince Edward Island, where a mandatory navigational channel is incorporated into every lease, may be an approach to emulate in Nova Scotia.

- Assertion by leaseholders of rights of control over public waters that go beyond their actual rights should be treated by the DFA as a regulatory issue.

Fourth, we also heard questions about lease boundaries and their enforcement. For example, in several communities, we were told that anchor lines for aquaculture pens extend beyond the boundary of the operator's lease but that neither provincial nor federal regulators have done anything about it. Those who raised this with us objected to what they saw as obvious noncompliance with the law. For those owning land in close proximity to aquaculture sites close to land, extending anchor lines beyond the lease area may mean that aquaculture is taking place closer to their land than might otherwise be the case. An additional concern is that aquaculture companies were being allowed to limit the use of public waters by others beyond what was authorized by their leases. 
We are not in a position to say what is or is not happening in the enforcement of leases. We think it obvious, however, that lease boundaries should be enforced whether or not the violation of the boundaries interferes with the activities of others. Moreover, we think it important to emphasize that the DFA is responsible for enforcing the boundaries of the leases it issues whether or not an alleged violation of those boundaries also violates laws enforced by the Coast Guard or other federal regulators.

We were also asked to consider a number of concerns about the transfer of licences. We deal with most of these later in the section headed "Transfers, Expansions, Other Changes." Here, we deal only with the concern expressed by some that the transfer of a lease (or a licence) should be something that has to be approved under the regulatory framework. We agree with that viewpoint.

\section{LICENSING AND LEASING FEES}

We heard complaints about the fees that aquaculture companies are charged for their leases and their licences. In general, the complaint was that the fees are woefully small relative to the exclusive control of a public resource that is given by a lease, and given the harm that aquaculture can cause to those resources and the interference it can create with other uses of coastal waters. In the feedback we received on our draft report, which did not deal with the level of licence and lease fees, we heard concern about the cost to taxpayers of the proposed regulatory framework. For some, this provided an additional rationale for higher licensing and lease charges. In the submissions made on our draft report, we were asked to recommend a linkage between the anticipated cost of the new framework and the level of fees charged to operators or, alternatively, to recommend an increase in fees sufficient to off-set the cost of the new framework to taxpayers, or at least of the cost of compliance oversight and actions.

Currently, the licence and lease fees charged are as follows: an annual licence fee of $\$ 386.50$ (subject to a rebate of \$120.95 for U-fish ponds); an annual lease fee of \$12.90 per hectare for leased areas; an application fee of $\$ 666.15$ for a lease or licence; an assignment fee of $\$ 257.65$ for a lease or a licence; a lease or licence renewal fee of \$386.50; and a lease or licence amendment fee of $\$ 128.80 .178$

We agree that these seem like low charges for licences and leases that give control over significant public resources to private interests. We agree with those who think they should be higher. However, we are not in a position to recommend the specific increase that would be appropriate. Instead, we recommend that the DFA carry out a review to determine the level of the licensing and leasing fees to be charged under the proposed framework. This review should include looking at the comparable charges levied in neighbouring jurisdictions.

In addition to reconsidering the level of the fees, the Department should articulate the rationale for the fees it proposes to charge after the review is completed. Our thought behind this recommendation is that much of what we heard about the fees currently charged is that they lack

${ }^{178}$ Aquaculture Licence and Lease Regulations, N.S. Reg. 103/2013, s. 6. 
any possible and defensible rationale. A closely associated view was that the current fees imply that the resources being leased, resources that are of high value to coastal communities, are not valued very highly by government or the industry. On this view, higher charges would better reflect the value Nova Scotia places in its coastal resources and may encourage operators in aquaculture to attach greater importance to their responsibilities as stewards of those resources.

Whatever the level of the applicable fees, we believe that people in coastal communities, and the public more generally, are entitled to know the basis on which the fees charged are determined. This is supported by one of the submissions we received on this issue after the release of our draft report, which was that a consistent framework or methodology should be developed and used for calculating "resource rents" in aquaculture and other resource industries.

While agreeing that the current fees should be reviewed and that there is a case to be made for an increase in fees, we think the following points should be kept in mind:

a. The level of the fees charged should not make participation in the industry cost-prohibitive to Nova Scotians that would like to start a business in the industry.

b. Similarly, the fees charged should not create a disincentive for those who want to start or operate a business in the industry that will be less profitable than others precisely because it operates in ways that have lower impact than is the norm with companies that may yield higher profits.

c. The cost of doing business under the regulatory framework proposed in this report will be higher than it is under the current regulatory framework. The combination of this increase in operating expense with an increase in fees will increase the financial barrier that Nova Scotians and others will face in doing business in aquaculture in Nova Scotia.

d. All things considered, while we agree that the industry should be paying higher fees, we think the more critical issue at the present time is to have the capacity of the industry concentrated on the implementation of the proposed regulatory framework.

e. On the other hand, there may be a valid concern that enterprises that are attracted to, or not discouraged from, participating in aquaculture due to licence and lease charges may not have the capacity to conduct aquaculture in accordance with the proposed framework.

f. Differential fees, reflecting differences in scale of operations and between kinds of aquaculture (i.e., between the nature and the extent of the use to be made of coastal waters), may be appropriate and helpful in creating an optimal balance among all the applicable considerations.

g. Differential fees based on the environmental performance of operations on clearly established parameters could be an effective way to further encourage careful site selection and innovation, and could motivate operators to make ongoing efforts to reduce environmental impacts beyond regulatory compliance.

h. Finally, caution should be exercised in linking the level of licence and lease charges too closely to the cost to the government in developing and implementing the proposed regulatory framework, as some proposed. This is because of the widely shared concern that such approaches contribute to regulatory capture and a lack of public trust and confidence in the regulatory process. From this perspective, an increase in licence and lease charges that 
defrays the incremental cost to government of the proposed framework would be preferable to one that is determined by these incremental costs.

\section{SECURITY OF TENURE FOR GOOD OPERATORS AND SITES}

We were told by industry representatives that one of the major problems created for the industry by the current regulatory framework is the limited tenure it provides to licensed operators. In Nova Scotia, a first licence is issued for 10 years. Each subsequent licence lasts for 5 years. In contrast, in New Brunswick, licences are for 3 years; however, leases are issued for periods of 10 years for shell-fish and 20 years for fin-fish. In addition, approvals to operate under the Clean Environment Act are issued for 5 years. In other jurisdictions, there is a great variety of approaches to the duration of licences, leases and approvals.

The problem that short licensing periods create for industry is one of financing. We were told that financing is more difficult and expensive than it otherwise would be due to the concern of lenders that a licence may not be renewed before the operator has the opportunity to repay the amount that typically has to be borrowed to finance aquaculture operations. We were told that the barrier this creates for growth in the industry is accentuated by the fact that the government does less in Nova Scotia to support the industry's access to working capital than do the governments of each of the other Atlantic provinces.

We assume that the current framework starts with a 10-year licence as an accommodation to the financing needs of industry. It is, however, difficult to understand why it subsequently limits renewals to 5 years, since the need for financing will remain, and given that the decision to renew can be made with the benefit of better information on both the operator and the site than would be available for the initial licensing decision.

We think the licensing framework should give longer security of tenure to aquaculture businesses. However, it should do so by creating stronger connections between the duration and renewal of licences and the ability of licence holders to demonstrate their suitability as operators and the suitability of their operations for their location. The concept is one of "progressive licensing," under which operators who successfully develop sites in accordance with the regulations, and operators who achieve highest standard third-party certification earn renewal under longer-term licences and associated leases. In contrast, operators who by their performance show they are not willing or able to operate in compliance with the regulations and are not showing leadership in low-impact aquaculture either lose their licence or are limited to renewal on more limited terms, depending on the nature and the extent of their failures to meet and maintain regulatory requirements.

Specifically, we recommend that the tenure of approved aquaculture operations be structured as follows:

a. The initial licence would continue to be for 10 years. The initial lease would be granted for 20 years, subject to the holder of the lease continuing to hold a licence. 
b. The initial licence would be comprehensively reviewed after the first growing cycle ${ }^{179}$ to ensure aquaculture in accordance with the licence as originally granted generally meets regularly requirements, including environmental performance requirements. While termination of the licence (and lease) could occur at this time (as it could at any other time where warranted by sufficiently serious non-compliance or failure to meet environmental performance standards), the more typical outcomes would be for either the continuation of the licence on its original terms and conditions or an amendment of those terms and conditions to better align the scale and nature of the licensed activities with the biophysical and other conditions of the site.

c. Renewal of licences would be decided by an open, transparent and participatory process, which would give members of the public ample opportunity to be informed about and to contribute to the process. Licenses should be renewed, and the regulatory framework should be clear they will be renewed, where operators have conducted business in compliance with the regulations.

d. The appropriate length of licence renewals should be determined based on the environmental performance of the site under previous licences and the compliance record of the operator. The licence given on renewal would be for a term that is comparable to the maximum terms for which aquaculture sites are licensed in other provinces of Atlantic Canada for wellperforming sites with compliant operators. Operators with less than ideal track records that are still considered to be capable of operating responsibly and within acceptable parameters would be granted shorter renewals. Leases would generally be renewed for a 20 -year term, which could be increased if the operation of the site has a solid track record of compliance and of meeting or exceeding environmental performance standards.

e. Any licence would of course be subject to revocation for regulatory infractions or a pattern of regulatory non-compliance that would make revocation an appropriate, fair and just sanction.

\footnotetext{
${ }^{179}$ In the feedback we received on our draft report, two concerns were raised about this recommendation. One response, from an industry perspective, was that a licence that expires after the first growing cycle would be one that nobody would want and that no banker would finance. To be clear, the recommendation is not that licences expire after the first grow-out cycle but that they be reviewed after the first grow-out cycle. If site selection and licensing are done effectively, the result of this review should typically be confirmation that the aquaculture continues as originally licensed. Sometimes (again, assuming proper site selection and licensing) the result would be an adjustment in terms and conditions to bring it better into line with site conditions. This should contribute to the longer-term stability of the licensed operation. Where review leads to a decision to revoke, this will be due to problems that cannot be fixed by an adjustment of licence terms. In other words, it will be because of problems that should lead to revocation whether or not there is a review after the first grow-out cycle. The other response we received was that a review after the first growing cycle was too early to identify certain kinds of issues that typically only occur or are only detectable later in the development of a site. We accept that this is the case. However, the logic of suggesting a review after the first grow-out cycle was early detection and correction of problems or potential problems that are detectable at that stage. The authority and responsibility of the regulator to detect and take action on issues that arise subsequently would in no way be affected or reduced. On the other hand, the core objective of our recommendation is that a comprehensive review happen during the first licence period prior to the review that happens when the licence is due to expire. If there is a more logical time for that review than after the first growing cycle, then by all means the review should happen at that time.
} 


\section{TRANSFERS, EXPANSIONS AND OTHER CHANGES}

We have discussed the importance of social licence in various parts of this report. The relationship between the operator and those who have a stake in how an operation is run is critical to social licence. The relationship between operator and the community can also depend on the nature and scale of the operation. Changes in operator or in licence terms and conditions therefore have the potential to disrupt relationships and injure social licence if they are not done carefully and in an open and transparent process that gives people the opportunity to know what is proposed, to express their views on the proposed changes and, in the case of transfers, to establish a relationship with the proposed operator.

The other consideration is the risk that decision making on transfers or on the revision of terms and conditions can undermine the trust and confidence placed in, and the effectiveness of, the front-end licensing process. A rigorous licensing process that provides ample opportunity for participation and accountable decision making will be less effective in accomplishing its objectives and in gaining and maintaining public trust if the outcomes are undone or substantially changed through subsequent decision making on transfers or on revision of terms and conditions that is not open and transparent.

As a result, it is important that the process for transfers in ownership or operator and for change in terms and conditions be clear, and that it be open and transparent. ${ }^{180}$ In our view this means that any request for transfer or for a material change in terms and conditions should be made public as soon as it is received and considered. There should be an opportunity for meaningful public input into the decision-making process. Depending on the circumstances, a notice-and-comment-style procedure may be appropriate. In other circumstances, a more extensive engagement process may be called for where, for example, the proposed changes to the scale or nature of the operation are more significant. Where the changes proposed are transformative of the licensed operation, there will be a strong argument for a process that would be akin to the process that would apply to the application for a new licence. In all applications for transfers and requests for material change to terms and conditions, careful consideration will have to be given to whether the proposed changes have the potential to increase the impact on natural systems or on other coastal users.

A key factor in approval of a transfer in ownership or operator is whether the proposed operator or owner can demonstrate their capacity and readiness to interact constructively with other coastal users and affected communities. Where the new operator or owner is already an owner or operator of other sites, another key consideration should be their compliance record at those sites.

\footnotetext{
${ }^{180}$ There was partial support at the Roundtable for a recommendation that "if a site lease is transferred between operators or there is a change in species grown and there may be a substantial change in environmental impact, a review of the licence or permit should be carried out including public input. There should also be a public comment period at the time of licence renewal.” (Roundtable Final Report, 15)
} 


\section{PROTECTION FOR WILD SALMON POPULATIONS}

As we have explained, it is clear to us that the regulatory framework for aquaculture must pay particular attention to the potential interactions of marine-based salmon aquaculture with wild salmon. It is clear that concern for wild salmon populations is an important part of the global work taking place in multiple forums to reduce the environmental impact and improve the sustainability of fin-fish aquaculture, including by improving the regulation of aquaculture. ${ }^{181}$ If Nova Scotia wants to be part of this path for the industry's future, it needs to be doing its part to ensure that aquaculture is conducted in Nova Scotia with due regard for the health and well-being of Nova Scotia's wild salmon populations.

The protection of wild salmon populations is one of the objectives of the current regulatory framework. We believe, however, that the framework must be stronger in relation to this objective. This is one of the reasons why we have recommended the explicit inclusion of precaution into the regulatory framework. More broadly, the legitimate concerns about how the growth and conduct of the industry might impact wild salmon are among the concerns that have led us to make the recommendations we have made elsewhere in this document on a number of core elements of the regulatory framework, including site selection and utilization, fallowing and stocking densities, and fish health and well-being. Although all our recommendations on these and other topics are designed to ensure that the regulatory framework contributes to the industry's general progress toward a low-impact/high-value future, they are intended more specifically to ensure that aquaculture is conducted with due regard for the health and well-being of Nova Scotia's wild salmon populations.

The regulatory framework should, however, also include a number of elements that are more specifically directed to the protection of wild salmon. To that end, we have already recommended that protection of wild salmon populations be listed in the legislative framework as one of the criteria to be considered in leasing and licensing decisions. Here, we make two further recommendations for specific protection of wild salmon.

First, the regulatory framework should be clear and explicit about the need for appropriate physical separation between marine-based aquaculture and salmon rivers and known salmon migration

\footnotetext{
${ }^{181}$ See, for example, the Williamsburg Resolution of the North Atlantic Salmon Conservation Organization (NASCO), Resolution by the Parties to the Convention for the Conservation of Salmon in the North Atlantic Ocean to Minimise Impacts from Aquaculture, Introductions and Transfers, and Transgenics on the Wild Salmon Stocks. This includes a commitment to develop and apply appropriate risk assessment methodologies in accordance with the precautionary approach, and more specific commitments, such as to minimize escapes of farmed salmon and to minimize disease and parasite transmission to wild salmon stocks as a result of aquaculture activities. Specific guidelines to achieve these aims include the possible "establishment of 'wild salmon protection areas' where salmon aquaculture is restricted or prohibited” (p. 7). NASCO has additionally provided a separate document, Guidance on Best Management Practices to address impacts of sea lice and escaped farmed salmon on wild salmon stocks. It is "intended to supplement the Williamsburg resolution and to assist the Parties and jurisdictions: in managing salmon aquaculture, in cooperation with their industries; [and] in developing future NASCO Implementation Plans," among other matters. Sea lice and escaped salmon are specifically identified as "continuing challenges both for industry and the wild stocks” (p. 1). Lastly, see also NASCO Implementation Plan for the period 2013-2018 (Canada). In this report, Canada's main objectives are listed as "1. Safeguard the genetic diversity of wild Atlantic salmon; 2. Maintain habitat and ecosystem integrity; and 3. Manage fisheries for sustainable use and benefit” (p. 4).
} 
routes. ${ }^{182}$ This could be a fixed separation distance. Such an approach is attractive because it is simple and does not depend on the exercise of regulatory discretion. The problem with such approaches however is that they invariably provide too much restriction in some applications and too little in others. They tend not to reflect the variable circumstances that can call for more restriction in some cases and less restriction in others than would be provided by an across-theboard rule. The other difficulty is that such approaches often do not evolve as circumstances (such as evolving technology) change. We think a better approach would be one that allows the extent of the physical separation that is specified in the licensing of any particular site to be determined on a case-by-case basis, but under a legislative framework that makes it clear that appropriate distances between marine-based aquaculture and wild salmon must be established and maintained through the leasing and licensing process.

Of course, the DFA would continue to be bound by any decisions taken by the DFO in relation to minimum protection for wild salmon. Where the DFO does not make a decision but instead provides advice to the DFA, it would continue to be the case that the DFA would rely heavily on that advice. But as we have discussed earlier, it should be a clear element of the regulatory framework that the DFA will go beyond what is recommended by the DFO where the DFA determines that an additional level of protection for wild salmon is called for.

Our second recommendation for specific attention to the protection of wild salmon is that the regulatory framework should deal more extensively with the prevention of escapes. ${ }^{183}$ The current framework requires licensees to report every escape, which is a more demanding reporting requirement than in other jurisdictions, which only require escapes to be reported when they involve a certain number of fish. Nevertheless, concerns were expressed about whether this requirement is being complied with or enforced. There is also scepticism about whether it could be enforced. The more serious concern in our view is that the regulatory framework should do more to ensure that escapes are being prevented. It should require operators to adopt, implement, and track and report on the performance of a comprehensive containment system that aims - to the greatest extent practicable using best management practices and best available technology - to prevent escapes.

Many encouraged us to recommend an approach in Nova Scotia similar to the one in place in Maine. The following is a description of what is called a containment management system in that state:

A CMS is a process control system built on seven principles which, when implemented together, form a logical and realistic system for minimizing the escape of farmed salmon. CMS systems are based on a Hazard Analysis Critical Control Point (HACCP) system and the aquaculture industry's October 1998 Code

\footnotetext{
${ }^{182}$ We note that research is being led by scientists is the region on biocontainment options that would complement physical separation and escape prevention measures: see DFO report by Tillman J. Benfey, "Biocontainment measures to reduce/mitigate potential post-escape interactions between cultures Europeanorigin and wild native Atlantic salmon in Newfoundland.”

${ }^{183}$ In addition to the sources cited earlier in this report, see Eva B. Thorstad et al., Incidence and Impacts of Escaped Farmed Atlantic Salmon Salmo salar in Nature. This paper raises concerns about the genetic impacts of interbreeding, and other concerns.
} 
of Practice. HACCP systems were originally developed by NASA to ensure quality control and safety in the space program. The HAACP approach has been adopted by the Food and Drug Administration Food Safety Program and has been used widely in the seafood processing industry. It is therefore familiar to the industry and the federal regulators. HAACP systems consist of a company specific, business confidential HAACP plan, a paper trail that documents operational performance, and an auditing system. A standard Containment Management System will be developed for the Maine salmon farming industry based on the following seven principles: 1 . Assessment of the hazards and risks. 2. Determination of critical control points. 3. Establishment of critical limits and tolerances. 4. Establishment of limit monitoring procedures and schedules. 5. Establishment of predetermined corrective actions. 6. Establishment of record keeping systems and procedures. 7. Establishment of a verification system. ${ }^{184}$

The following provisions from the general discharge permit under which individual aquaculture operations are approved in Maine spells out the obligations of approved sites with respect to the adoption of a containment management system as follows:

6. Containment management system. The permittee must employ a fully functional marine Containment Management System (CMS) designed, constructed, operated, and audited so as to prevent the accidental or consequential escape of fish to open water.

a) Each CMS plan must include a site plan or schematic; site plan description; procedures for inventory control, predator control, escape response, unusual event management, and severe weather; provisions for employee training, auditing methods, and record keeping requirements. The CMS must identify critical control points where escapes could potentially occur, specific control mechanisms for each of these points, and monitoring procedures to verify the effectiveness of controls.

b) The permittee must prepare a written CMS plan prior to fish being first introduced into a facility and must maintain a current copy of the plan at the facility.

c) The CMS must be audited by a qualified third party at least once per calendar year for all facilities with fish stocked in net pens.

d) No later than December 31 of each calendar year, the permittee must submit a written report of each annual audit required by Section 6(c) of this condition to the Department.

e) The CMS must also be audited by a qualified third party within thirty (30) days of a reportable escape required by Section 7 of this condition or notification that a commercially-reared Atlantic salmon is found in a river within the range of the Gulf of Maine distinct population segment of Atlantic salmon, as defined by the [Fish and Wildlife] Services. The Department, in consultation with the Army Corps of Engineers and the [Fish and Wildlife] Services, may exempt a facility from any

184 Penobscot Bay Watch, Framework for a Salmon Aquaculture Containment Policy in the State of Maine. 
additional third-party audits when the facility from which the fish escaped can be identified or when circumstances preclude the possibility that the facility was the source of the escaped fish. The permittee must submit a written audit report to the Department, with a copy to the Services, within thirty (30) days of the facility becoming aware that an audit is necessary.

f) Any time that a CMS audit identifies deficiencies, the written report must contain a corrective action plan, including a timetable for implementation and provisions for re- auditing, unless waived by the Department, to verify completion of all corrective actions.

g) The permittee must maintain for a period of at least five (5) years complete records, logs, reports of internal and third-party audits and documents related to the CMS for each facility. The submission of standing inventory at the facility, including all transfers in and out, losses associated with disease, predation or escapes as reported to the Department of Marine Resources at the pen level of detail on a monthly basis pursuant to the requirements of Leases and Special Licenses, 12 M.R.S.A. § 6077, must meet the requirements of the CMS. 185

An additional element of Maine's system is that all farmed salmon are required to have a genetic marker that allows recaptured fish to be traced back to the farm from which they escaped. We have been told and we have read that this is a very powerful regulatory tool for monitoring the effectiveness of each company's containment system. Indeed, we have been told that this requirement accounts for the virtual elimination of escapes from Maine’s farms.

We note the Roundtable recommendation that "the regulatory framework should include a salmonid Containment Management Code similar to the Maine Model, which includes marking fish for site-specific identification. The Code should address the use of high-quality twine resistant to UV to prevent escapes." 186 This recommendation received only partial support. There was a concern on the part of some Roundtable members that they did not have enough information about Maine's system, and also a concern that regulations should not prescribe the use of a certain kind of twine.

We understand that Maine's system to prevent escapes is an elaborate one that could be expensive to adopt in Nova Scotia. This may be especially true of the genetic tracking system. We recognize that not all of the Maine system may be required, suitable or feasible for adoption in Nova Scotia. We also recognize that a Nova Scotian version of Maine's approach would have to be implemented over time. Nevertheless, we think that the regulatory framework for salmon aquaculture in Nova Scotia should encompass a system to prevent escapes that is comparable to the one that has been successfully implemented in Maine, recognizing that it would not be expected to be identical to Maine’s system in all respects. The key is to develop and implement a comprehensive and

\footnotetext{
${ }^{185}$ Maine, Department of Environmental Protection, General Permit - Net Pen Aquaculture at 19-20. The full permit can be accessed at http://www.maine.gov/dep/water/wd/atlantic_salmon_aquaculture/MEG130000-2014permit.pdf.

${ }^{186}$ Roundtable Final Report, 24.
} 
integrated system that is equally effective as the Maine system is in preventing escapes, not to duplicate the mechanisms Maine has used to achieve that outcome. ${ }^{187}$

\section{MONITORING COMPLIANCE AND ENFORCEMENT PROVISIONS}

Concern about the will and capacity of the provincial government to require the industry to comply with regulations was one of the concerns we heard most frequently. This concern lies at the centre of the scepticism that many have about whether a new regulatory framework will make a difference.

In our view, a new regulatory framework will not obtain the public trust and confidence it needs to be successful unless it includes a strong commitment to effective monitoring of compliance and to effective and transparent enforcement. Without this commitment and sustained action that matches the commitment, regulation will not make the contribution to the social licence of the industry that regulation must make if the industry is to develop with stronger support than it currently enjoys in the communities in which it operates. In addition, although we were not tasked to conduct the kind of operational analysis of the current regulatory framework that would allow us to independently evaluate its effectiveness, what we have heard in our process leads us to conclude that monitoring and enforcement must be significantly elevated and enhanced if the regulatory framework we have proposed is to accomplish the range of objectives in this sector that regulation must accomplish.

We have already made many recommendations that are either intended to improve monitoring and enforcement or that will have a positive effect on monitoring and enforcement if they are effectively implemented. For example, we have recommended the following:

- A significant increase in regulatory capacity is required, a good deal of which should go directly into monitoring and enforcement.

- The Department of Environment should become responsible for the administration of the Environmental Monitoring Program to ensure the independence and rigour of that aspect of monitoring of the industry's activities.

- The DFA's regulatory activities should be separated within the DFA from its non-regulatory activities in supporting the development of the industry. ${ }^{188}$

\footnotetext{
187 In response to our draft report, the CFIA expressed support for our recommendation that the regulatory system address the risk of escaped animals through a "written, verified and audited containment management system.” It suggested that Nova Scotia should familiarize itself with the requirement that CFIA places on "all regulated parties" to have a "preventive control plan" that deals with "all regulated hazards/risks the business enterprise could encounter" to ensure that the approach adopted in Nova Scotia is in line with the Canadian federal approach. This makes sense so long as there is a specific and targeted focus, on the part of Nova Scotia's regulatory framework, on addressing the problem of escaped salmon along the lines of what has been done in Maine. That is the matter of critical concern in the protection of wild salmon.

${ }^{188}$ There was some indication to us during consultations on our draft report that the DFA either has stopped or plans to stop getting involved in the non-regulatory aspects of the government's role in the development of
} 
- The legislative framework should rely less on regulatory discretion and more on clear legislative statement both of regulatory requirements and of the process to be used in key parts of the regulatory process, including the leasing and licensing process.

- Transparency should be mandated to make regulators accountable for how they exercise their regulatory mandate and the industry more accountable to the public for its compliance with regulatory requirements.

- The renewal of licences and leases should take into account the track record of operators in complying with regulations.

In this section, we make recommendations more directly related to how compliance with the proposed regulatory framework should be monitored and enforced.

Our information is that the DFA has six inspectors and that only one of these is fully trained for inspections on aquaculture. More fully trained inspectors need to be employed and put into the field.

Currently, there is a minimum of one scheduled inspection in each year for each site. Other inspections happen in response to complaints. The number of inspections should be increased. Scheduled inspections should be complemented by a significant number of unscheduled inspections. The capacity of the DFA to respond in a timely way to complaints must be increased.

Inspection should be automatic after changes to gear configurations or to the setup of a site. They should also be automatic after significant storm events.

The DFA should have additional options for carrying out inspections. It needs additional vessels or more access to vessels other than the vessels of the industry. It should explore the role that aerial surveillance could play in the monitoring of the industry.

As compared to other kinds of aquaculture, marine-based fin-fish aquaculture should generally be subject to more inspections, more unscheduled inspections and generally a higher level of regulatory scrutiny. ${ }^{189}$ This is because of its greater potential to cause environmental harm in addition to harm to wild fish and marine animals if it is not conducted in accordance with regulatory requirements.

Within each sector of aquaculture, the level of regulatory attention that each operation receives should reflect its track record of compliance. It should also reflect its relative potential to cause serious harm to regulatory objectives if it is not conducted in accordance with the regulations. For example, a fin-fish site operating in a relatively open bay with a high rate of flushing and a relatively deep bottom would receive less attention than a site operating in a setting where the

the industry. We would see this as a very positive step toward establishing the credibility of the DFA as the regulator of the industry.

${ }^{189}$ We received feedback on our report that our view that the level of regulatory scrutiny should generally be different between fin-fish and shell-fish operations and as between operators with different compliance track records would create an unfair two-tier system that was biased against fin-fish aquaculture. Our view is that recognition of these differences is critical to making the regulatory system proportionate, risk-based and effective. 
maintenance of oxic conditions may be more difficult even when the circumstances of the site are properly taken into account in the terms and conditions on which the site was approved. ${ }^{190}$

Essentially, what we are recommending is an approach to inspections that includes more inspections but targets the increased inspections to the kinds of aquaculture and operator that warrant an additional level of scrutiny. To do that, an approach such as the HACCP (Hazard Analysis and Critical Control Point) approach might be used to calibrate the relative amount and kind of monitoring and enforcement that would be directed to different parts of the industry and to different operators based on their track record and particular circumstances. In our view, this would be consistent with the unanimous recommendation of the Roundtable, to "establish a QMP/HAACCP [sic] compliance model that clearly establishes industry and government responsibilities for monitoring and compliance.”191

Currently, where there is non-compliance, a warning may be issued to the operator. If the warning does not achieve compliance, a Ministerial Order may be issued, requiring that the non-compliance be addressed. A broader range of enforcement options is called for. Inspectors should have their own authority to issue orders. It should be clear that non-compliance with orders can lead to prosecution or, as discussed below, to termination of lease and licence and refusal of applications for new leases and licences.

Decision-making authority relative to the pressing of charges should lie at the bureaucratic level of the DFA, which would, like other regulatory bodies, be advised by the Public Prosecution Service. Where conviction occurs, the court should have the authority to impose significant penalties where the court determines that they are warranted on established sentencing principles for regulatory offences. The sentencing discretion of the court should also encompass what is generally referred to as creative sentencing, which can, among other things, include sentences that require a company to take responsibility publicly for its actions, to have owners, managers or employees undergo training or adopt other measures to prevent reoccurrence, or to make presentations at industry gatherings on what it has learned from being prosecuted and the steps it is taking to ensure future compliance.

In addition, it should be clearly understood that monitoring and inspection is conducted on the understanding of the following:

- A strong and positive compliance record should be a precondition for being able to acquire the right to operate additional sites, either by applying for new sites or by acquiring an existing site from another operator. Demonstrated unwillingness or inability to comply with applicable regulatory requirements should make an operator ineligible for a significant number of years.

190 With regard to the maintenance of oxic conditions, the following recommendation obtained qualified support at the Roundtable: “The current Environmental Quality Objective of the Environmental Monitoring Program to maintain oxic conditions should be enforced. Enforcement measures could include a change in licence conditions, remediation or licence cancellation. The current NSDFA formula used to categorize the environmental status of a site should be changed to ensure that Oxic (Normal), Hypoxic (Polluted), and Anoxic (Grossly Polluted) conditions are fairly represented.” (Roundtable Final Report, 28)

191 See Roundtable Final Report at page 29. 
- The ultimate penalty for serious non-compliance or persistent refusal to address noncompliance is licence and lease revocation.

We think these recommendations are consistent with the unanimously supported recommendation of the Roundtable, that "Regulations and licence requirements must be enforced. Penalties must be significant to act as a deterrent. Ongoing lack of compliance should be associated with lease termination.” 192

Another unanimous recommendation from the Roundtable on monitoring and enforcement was that "community members should be encouraged to participate in monitoring as observers in field sampling in order to increase transparency and build trust." 193 We agree with this recommendation but recognize that it would have to be implemented in ways that are consistent with industry responsibilities in areas such as biosecurity and fish health.

Finally, we recommend that members of the public be provided with an opportunity set out in legislation to apply to have a lease revoked where there is clear evidence of biophysical unsuitability of the site, or where there is a clear pattern of substantial non-compliance with terms and conditions of the licence. In our draft report, we proposed that such applications would be made to the Minister of Fisheries and Aquaculture. The feedback we received on our draft report pointed out that this was in conflict with our recommendation that administration of the regulatory framework be moved from the ministerial level to the administrative level of the DFA. As a result, we recommend that an independent board be established to consider licence revocation applications. As indicated earlier in this report, this board could also have the role of conducting or overseeing a review of the role of the DFA in regulating compliance with fish health requirements while also providing veterinarian services to the industry. It could also have the jurisdiction to hear appeals from licensing and leasing decisions.

\section{INDEPENDENT AQUACULTURE REVIEW BOARD}

In the previous section, we recommended the creation of an independent board to hear and determine applications from the public to have a licence revoked where there is clear evidence of biophysical unsuitability of the site, or where there is a clear pattern of substantial non-compliance with terms and conditions of the licence. ${ }^{194}$

\footnotetext{
192 See Roundtable Final Report at page 30.

193 See Roundtable Final Report at page 29.

${ }^{194}$ In providing feedback to our draft report, people and associations in the industry expressed concern about our recommendation that members of the public could apply to have a licence revoked. We understand the importance of this concern to the industry. It should, however, be noted that we are not, contrary to what was said in some of the feedback we received, recommending that the public have authority to revoke a licence. We are recommending they have the opportunity to apply to have a licence revoked. The rationale is to provide an avenue of recourse within the regulatory system for those who think the DFA is not revoking a licence where revocation is appropriate. The standard applicable to the determination of such an application would be the same standard as would apply to the exercise by the DFA of its authority to revoke a licence on its own motion. The standard would be a high one, as we have tried to indicate in the language we have used
} 
As to the constitution, jurisdiction, powers and make-up of this board, we are only able to provide general guidance, as follows:

- To ensure its independence, jurisdiction and authority, such a board would have to be established in legislation.

- The jurisdiction and powers of the board would also have to be set out in legislation.

- One of the matters to decide is whether the authority of the board on applications to revoke should be limited to granting or denying the application or expanded to include broader powers to order changes in the management or conduct of the licensed operation.

- The legislation should make it clear that the process to be used by the board in considering applications for licence revocation should be at the high end of the procedural fairness spectrum, in light of the serious issues at stake for both the licensed operator and those concerned about the operation.

- The legislation should address the scope of the board's ancillary powers, such as whether or not it is to have the authority to order costs.

- The board should be required to give written reasons for its decisions.

- The legislation should deal with the number of persons who can be appointed, and it should deal with the authority of the board to hear applications (or appeals if it is given the authority to hear appeals from licensing decisions) in panels. We anticipate that a board with five members would be both large enough for the workload and small enough to be kept staffed on a continuing basis. We think the board should have the authority to hear matters as a full board or in panels of three, and it should have the option of allowing procedural (case management) matters to be dealt with by the Chair or a single board member.

- Qualifications for appointment to the board should be generally described in the legislation. Relevant expertise based on a combination of education and experience should be the main qualification. Board members should have expertise in law, regulation, relevant science disciplines, environmental regulation or management, aquaculture, or in regulated industries more generally.

- Appointment to the board would be on a part-time basis for a specified term of duration adequate to allow board members to develop their expertise.

- The board should have the authority and ability to engage the service of third-party advisors where that is necessary for the fair and informed adjudication of a revocation application (or an appeal from a licence decision or the conduct of a review of the work of the Provincial Fish Veterinarian, if the board is given those additional mandates).

in our report when referencing the enforcement mechanism of revocation. As in other regulated industries, revocation would be justified only in circumstances where it is the fair and proportionate remedy.

Revocation, whether by the DFA on its own motion or on application from the public, would be subject to appeal to the courts. Finally, where revocation happens because of a determinations of the limitation of the site, the regulatory framework would require the DFA to make another site available to the licence holder. This applies whether the revocation results from an application or by the DFA's own action. 
- Decisions of the board on revocation applications, as well as on appeals from licence decisions if the board is given that jurisdiction, should be subject to appeal to the Nova Scotia Supreme Court.

\section{EMERGING ISSUES}

The regulatory framework we have recommended must carefully consider emerging issues. The key emerging issues that have been brought to our attention are discussed below.

The use of genetically modified organisms (GMOs) in Nova Scotia aquaculture seems to us to be inconsistent with the precautionary approach, and would likely undermine efforts to position the Nova Scotia industry as a high-value, low-impact industry with high social licence. While we did not hear much about this issue, our recommendation would be to not permit GMOs in Nova Scotia aquaculture. ${ }^{195}$

Offshore aquaculture appears to be on the verge of becoming technically viable. Moreover, Nova Scotia entrepreneurs that have been highly successful in the development of other sectors are playing leading roles in its development. In designing its regulatory system and in discussions with federal regulators, we recommend that Nova Scotia consider carefully how this emerging sector should be developed and regulated, should opportunities for its development in the Nova Scotia offshore materialize. An important starting point will be to determine whether such operations would be subject to federal regulation only, or whether the province will play a role in the regulation of offshore operations.

As the industry diversifies, it is reasonable to expect that additional species of fish will be proposed for farming in Nova Scotia. This will put increasing pressure on regulators to consider the risk of invasive aquatic species. The literature is clear that prevention of introduction is the only effective method for controlling invasive aquatic species. 196 We therefore recommend that a precautionary approach be taken to invasive species. In our view, the appropriate approach would be to not permit the introduction of non-native species, except in rare circumstances where there is clear scientific consensus that the species in question will not become invasive in Nova Scotia's waters.

We have been told that integrated multi-trophic aquaculture (IMTA) holds much promise with respect to the management and minimization of environmental impacts of fin-fish aquaculture in coastal waters. ${ }^{197}$ In particular, there appear to be opportunities to reduce benthic impacts from fin-

\footnotetext{
195 Our understanding is that triploid stock or eggs are not GMOs, although they were sometimes mistakenly referred to as such in our process.

196 See, for example, M. Doelle, “The Quiet Invasion: Legal and Policy Responses to Aquatic Invasive Species in North America.”

197 For a discussion of IMTA in the context of southwest New Brunswick, see DFO, "Review of the Organic Extractive Component of Integrated Multi-trophic Aquaculture (IMTA) in Southwest New Brunswick with Emphasis on the Blue Mussel," which examines IMTA developmental pilot-scale work and “address[es] questions related to factors influencing the ecological effects/effectiveness of IMTA, the ability of IMTA to reduce benthic loading, the scale at which impacts of salmon aquaculture might be mitigated, and the scale at
} 
fish operations through the use of IMTA. While more experience is needed to fully understand its potential, we do feel that the regulatory system should be designed in anticipation that IMTA will be increasingly used in the future to reduce the environmental impact of aquaculture.

As noted earlier, the consequences of climate change for aquaculture have to be monitored, studied and addressed. The issues include the role that climate change may have on aquaculture's environmental impact as well as the impact it may have on the potential for the different kinds of aquaculture in the coastal waters of Nova Scotia.

\section{SITE CLOSURE AND CLEANUP}

The issue of the cleanup of aquaculture sites when production comes to a close or a business is wound up was raised on a number of occasions during our process. People in local communities referenced situations where gear has been abandoned in the water and debris left floating in the water and on shorelines. They also referenced situations in other jurisdictions, where the apparatus for conducting aquaculture has been simply left in the water when operations at a site have come to an end. In response, people from the industry often commented that the industry conducts itself very differently now in these respects than it did formerly. That said, they also acknowledged that not all operators are responsible in cleaning up their sites. They also generally acknowledged the normative point, that operators should be responsible for leaving their sites in a clean condition when their operations come to a close.

In addition, it would be typical for a regulatory framework that authorizes physical infrastructure to be built in a public space for the purpose of economic activity that uses public resources to require those who are authorized to construct the infrastructure to remove it and all associated debris when the operation comes to an end.

At the Roundtable, the following recommendation received unanimous support: "The regulatory framework should require operator responsibility for decommissioning and remediation standards for both on and off-lease clean-up, including shoreline remediation.”198 We agree with this recommendation.

We also think that the regulatory framework should authorize the Minister of Fisheries and Aquaculture to undertake necessary cleanup where an operator fails to do so at all or to the standard required by the Minister. As under environmental and natural resources legislation in other sectors, the cost incurred by the Minister in doing cleanup work that is not completed by the operator should be a debt owed by the operator to the Minister. To ensure that the Minister can recover on this debt, licensed operators should be required to post a bond with the DFA when they

which IMTA might have measurable impacts on other aspects of the ecosystem.” See also the range of research projects on IMTA being pursued by the NSERC Canadian Integrated Multi-Tropic Aquaculture Network, described at http://www.cimtan.ca/.

198 See Roundtable Final Report at page 27. Also, there was partial support for the recommendation that "bottom sampling at the time of decommissioning should be carried out, to be paid by the operator," though some members of the Roundtable stated that this specific requirement already exists. 
are licensed, in an amount proportionate to the cost likely to be incurred in cleaning up their site should their operations come to an end. ${ }^{199}$ This would be repayable where the cleanup is completed by the operator to the satisfaction of the Minister.

In addition, failure to clean up a site to the standard acceptable to the Minister should preclude the operator in question from being given any new licences or having existing licences renewed.

\section{RELATIONSHIP OF REGULATION TO INDUSTRY CODES OF PRACTICE}

A code of practice is typically a set of standards that an industry develops for itself and that businesses belonging to that industry adopt voluntarily or as a condition of their membership in an industry association. Often, the existence of a code of practice leads regulators to adopt more limited or more general regulations than might otherwise be the case. In this way, a code of practice often starts where a set of regulations leave off. Sometimes, the existence of a code of practice takes the place of state regulation altogether.

Codes of practice can be integrated into a regulatory framework in various ways. Sometimes compliance with some or all of a code of practice is a regulatory requirement. Sometimes provisions of a code of practice are written into regulations, and sometimes regulations incorporate provisions of a code of practice by reference. Another scenario is where regulations are written to give regulated businesses a choice between complying with a provision of the regulations or with a provision of a code of practice that deals with the same issue.

We have thought carefully about whether the regulatory framework for Nova Scotia's aquaculture industry should provide for the development and implementation of an industry code of practice. ${ }^{200}$ This is the approach taken in Scotland, which is generally regarded as having a very progressive regulatory framework. In that jurisdiction, the law requires the industry's association to develop a code of practice that meets with the approval of the regulatory authority. Various provisions in the code of practice are made mandatory by the regulatory framework. Other provisions in the code

\footnotetext{
${ }^{199}$ This recommendation is consistent with the following one, which received qualified support at the Roundtable: "The framework should require the operator to post a bond at the time the licence is issued to cover the cost of remediation.” Those who gave qualified support asked about the success of bonding arrangements and consideration of other types of financial instruments. If other kinds of financial arrangements can be shown to work as well as or better than bonding arrangements, they should certainly be considered as alternatives to a bonding approach. On the effectiveness of bonding, this may depend on the willingness of the regulatory authority to require adequate bonds and to insist upon meaningful remediation, as well as on other factors. (Roundtable Final Report, 27)

${ }^{200}$ We are speaking in this section of a general code of practice that aims to guide industry practice on many different aspects of the conduct of aquaculture. Such a code of practice is distinct from a more specialized code of practice to deal with a specific issue or set of specific issues, such as biosecurity or fish health. As discussed earlier in this report, the regulatory framework we are proposing would encompass or provide for a number of the latter kind of codes of practice.
} 
have to be implemented unless the business achieves the same objective by another means. A third category of provisions is treated as purely voluntary. ${ }^{201}$

The Aquaculture Association of Nova Scotia is in the process of developing a code of practice that its members would be required to follow. We regard this as a very positive step on the part of the Association. We have considered whether this project should continue outside and in parallel to the regulatory framework or whether it should instead be carried on within the regulatory framework with a view to some or all of it being adopted as part of the regulatory framework.

Regulatory frameworks that include an industry-developed code of practice or that work in conjunction with such a code of practice are thought to have various strengths. For example, standards set in codes of practice may be superior to those set by regulators due to the superior knowledge that people in the industry may have of the industry and the options for achieving regulatory objectives. Furthermore, businesses may simply be more inclined to comply with, or less inclined to ignore, standards that are developed by peers instead of by politicians or bureaucrats. In addition, by requiring or utilizing a code of practice, a regulatory framework essentially makes the industry responsible for policing itself and its individual members. It is said by some that this can generate a sense of internal responsibility, which leads to higher levels of compliance with regulatory obligations.

These strengths of a code of practice as a regulatory tool depend on the reality that codes of practice are instruments of self-regulation. This is what leads others to lack trust and confidence in any regulatory framework that significantly relies on a code of practice. Regulators can try to address these concerns by assuming control or oversight of the process through which the code of practice is developed or by requiring the industry to include other stakeholders in the process. These actions can, however, reduce the effectiveness of a code of practice in gaining industry's cooperation with the regulatory process.

In Nova Scotia’s aquaculture industry, low trust and confidence in the current regulatory framework is one of that framework's core weaknesses. We do not think this problem can be addressed by the adoption of a new framework under which regulation of the industry would be through a code of practice developed by the industry. ${ }^{202}$ In part, this is because trust and confidence in the industry is not high at this time, but more fundamentally, it is because of the widespread view that the industry is already too heavily self-regulating. In addition, we are concerned that the Nova Scotia industry may not currently have the capacity it would need to play the kind of role that the Scottish industry played in developing the code of practice that is the basis of Scotland's regulatory framework.

We wish, however, to reiterate that we are very supportive of the Association's work on a code of practice. This is the kind of initiative needed from the industry if it is to gain and maintain the trust and confidence of the communities in which it is located, and of the people of Nova Scotia more broadly. If done effectively, it can help to ensure that trust and confidence in the industry depends

\footnotetext{
201 For more discussion of Scotland's approach to industry codes of practice, see pages 9-13 of Cecilia Engler's Analysis of Aquaculture Legislation report on the aquaculture framework in Scotland.

${ }^{202}$ Neither did the Roundtable, which did not support a recommendation that, "the regulatory framework should incorporate industry Codes of Practice.” (Roundtable Final Report, 26)
} 
on more than compliance with regulations. An industry-developed code of practice can also play an important role in helping to ensure that a new regulatory framework is effectively implemented throughout the industry. It can be particularly helpful in making regulatory compliance feasible and cost-effective for smaller businesses. For these reasons, we think the DFA should be supportive of the efforts of the Association to develop a code of practice.

It is particularly encouraging that the Association is working on codes of practice through an open process that welcomes participation and contribution from communities, municipalities, lobster fishers, salmon anglers and environmentalists. A good first step in this direction was taken by the Association when it invited members of the Roundtable to attend a discussion on codes of practice held in conjunction with the Association's recent AGM and annual conference. We encourage the Association to stay on this course. Such an approach will help to ensure not only that a strong code of practice is developed but also that it is developed through a process that builds and strengthens relationships between people in the industry and people who are interested in the industry. In this way, the process and the code of practice it produces can contribute to the stronger social licence the industry needs. By the end of our process, we saw tangible evidence of this happening, as some community members spoke positively to us about the positive interactions they have had with the Association since the beginning of our process.

\section{RELATIONSHIP OF REGULATION TO THIRD-PARTY CERTIFICATION}

There have been important developments with respect to third-party certification in the aquaculture sector over the past decade. As is the case in other industry sectors, certification has become an important governance tool to improve the environmental and social performance of the industry. We are encouraged by recent developments in this regard, particularly with respect to fin-fish aquaculture. Consistent with the goal of maximizing value while minimizing risk and negative social and environmental impacts, we feel strongly that certification with third-party certification bodies that offer industry-leading standards and practices should be encouraged.

At the same time, we do not think that it would be appropriate to formally link the regulatory process in a significant way to third-party certification. Our reasoning for this conclusion is essentially the same as our reasoning for concluding that the regulatory framework should not require or incorporate industry codes of practice. Rather, the regulatory process should stand on its own, while supporting and rewarding where appropriate efforts by operators to demonstrate leadership through third-party certification that involves industry-leading standards and practices.

At the same time, while certification should not be required or relied upon as a regulatory instrument, industry and regulators should be encouraged to follow certification developments and adopt best practices. In particular, the province should identify appropriate leading-edge certification standards as a precondition for financial assistance. Furthermore, certification could be one of the factors regulators can take into account in regulatory decisions, such as in considering applications for a licence or determining the length of licensing period on licence renewals. 
Of the certification standards we had the opportunity to review, the Aquaculture Stewardship Council (ASC) standard appears to be the current leading standard. ${ }^{203}$ Others may have superior standards in particular areas, but overall, the ASC standard appears to be, and to be recognized as, the leading standard in the industry. We recognize, of course, that this may change over time, as other standards evolve and as industry practice and technology catches up and perhaps overtakes this standard. We also recognize that the ASC standard is not the standard for what the regulatory framework in Nova Scotia should demand of operators. For example, it does not require maintaining oxic conditions, as our proposed framework does. It does however appear to be the leading third-party certification standard for marine-based salmon farming. We therefore conclude it would be better in terms of the industry's development in the direction of low-impact and highvalue aquaculture if the regulatory framework, as well as decision making in areas such as eligibility for provincial assistance with working capital, rewarded companies for being certified to or above the ASC standard. ${ }^{204}$ The important proviso to this is that certification would not be a substitute for compliance with regulatory requirements. Specifically, it would not excuse certified operators from complying with any regulatory requirement, such as the one we propose on oxic conditions, that is higher or more demanding than the ASC standard. 205

With the same qualifications clearly in place, the ASC standard would appear to us to be a potential source of standards for the selection of additional regulatory standards for Nova Scotia as the regulatory framework continues to evolve in future. Among the issues addressed in the ASC standard that Nova Scotia should look to are the following, while considering carefully for each standard whether the ASC's chosen threshold is sufficient in light of the regulatory goals and principles set out in this report:

- Standards on benthic biodiversity and benthic effects

- Standards on water quality, including biological oxygen demand (BOD)

\footnotetext{
${ }^{203}$ The ASC Salmon Standard (version 1.0 June 2012) can be found at http://www.ascaqua.org/upload/ASC\%20Salmon\%20Standard_v1.0.pdf. There was partial support at the Roundtable for the recommendation that "any finfish operation in Nova Scotia should be required to meet the Aquaculture Stewardship certification standards and conditions," though discussions on this point later suggested that more-appropriate regulatory tools are available. Nevertheless, there was recognition that such certification programs will likely contribute to the development of best management practices in the industry. (Roundtable Final Report, 28)

${ }^{204}$ We understand we do not have the authority to prescribe which certification standard should be recognized by Nova Scotia. Ours is a purely advisory role. In that role, our advice is that the regulatory framework should give credit in the ways we have suggested to companies that are certified under a high certification standard, and our advice is that the ASC standard be used for that purpose.

${ }^{205}$ In the feedback we received at the public meeting we held in Halifax and from the EAC, concern was expressed that we were recommending adoption of the ASC standard. One concern was that the ASC standard does not require maintaining of oxic conditions. The broader concern was that the ASC standard is not an acceptable certification standard despite being the currently most demanding standard. We are not recommending adoption of any certification standard. The standards required of the industry under the proposed regulatory framework will be those contained in the regulatory framework, including the one we have proposed on oxic conditions. We are simply saying that in making decisions on which discretion is to be exercised, or in areas beyond but closely related to the operational regulation of the industry, the DFA and other decision makers should take account of whether or not a company is certified to the highest available certification standard, which currently is the ASC but which in future may be another certification standard.
} 
- Standards on nutrients, with a focus on "fines" from feed

- Standards on interaction of operations with wildlife, such as birds and mammals, including the use of acoustic harassment devices, mortalities from entanglement, a focus on non-lethal deterrence, and transparency on efforts and results

- Transparency about unexplained loss of fish

- Requirements for net strength testing to prevent escapes

- Fish meal and fish oil ratios in feed

- Veterinary service standards

- Transparency on any treatment of fish to the public and to buyers of the product

- Requirement for only single-year classes of fin-fish on any site

\section{BAY MANAGEMENT}

We heard a variety of perspectives on bay management. It seems that bay management has been an effective tool in some jurisdictions, such as New Brunswick, to manage disease and pest outbreaks. ${ }^{206}$ At the same time, we have heard that bay management approaches have created challenges for smaller operators, contributing to the consolidation of the industry in some jurisdictions. Furthermore, a number of participants in our process have expressed the view that the industry in Nova Scotia is currently not large enough or sufficiently concentrated to warrant a large-scale application of bay management.

In light of these views and considerations, we conclude that a wide-scale application of bay management in Nova Scotia is not warranted at this stage of the industry. However, it would seem prudent to experiment with bay management in areas that are particularly suitable for pilots, such as bays with multiple operators and multiple grow-out sites.

It is important to note that bay management is a tool to achieve alignment between the assimilative or carrying capacity of a bay and the aquaculture operations that are licensed to take place in that bay. What is critical for an effective regulatory framework is that it insist upon this alignment, whether it uses bay management or other tools to achieve it.

It is also important to note that from everything we heard, we understand that fallowing is critical whether or not it is combined with or done through comprehensive bay management.

\footnotetext{
206 This view of the effectiveness of bay management in New Brunswick was questioned in the feedback we received on our draft report. We have stayed with the language we used in our draft report because it is tentative language that does not state a firm conclusion but is consistent with most of what we heard about bay management in New Brunswick. In any event, the larger point is that overall we heard different views about the effectiveness of bay management and its potential applicability in Nova Scotia. That is why we have not recommended its general or widespread adoption but instead have suggested it might be tried where it does seem to have application. It is also why we have not suggested that bay management where it is tried would be in place of any part of the regulatory framework we have recommended.
} 


\section{ONGOING REGULATORY ADVISORY COMMITTEE}

Our process benefited greatly from our Roundtable and our Advisory Committee. Both committees offered invaluable insights into the range of perspectives that have to be considered in developing fair processes and reaching fair conclusions on issues related to the regulation of the aquaculture industry. We also feel that both committees served as important forums for mutual learning among some of the key parties involved in and affected by the industry.

The DFA's effectiveness as a regulator would benefit if a mechanism were created to establish an ongoing multi-constituency forum for the discussion of the regulation of aquaculture. We therefore recommend that an ongoing Regulatory Advisory Committee (RAC) be struck to continue to meet at least once a year to advise the DFA on the implementation of aquaculture regulations, on possible changes to the regulatory framework in the future, on significant policy issues relating to regulation as they arise and on the overall effectiveness of the regulatory framework. The RAC could also be a forum for the discussion of emerging issues in the regulation of aquaculture or in the aquaculture industry that may call for a regulatory response. The RAC should be made up of approximately 10 members and include representation from the Mi'kmaq and the following interests:

- Municipalities

- Aquaculture industry

- Fishing industry

- Coastal communities

- Environmental and conservation organizations

- Economic development and tourism interests

The RAC should be independently facilitated. It could play an important role in ensuring that regulations keep up with science and technology and, more generally, that they continue to be updated in pursuit of the regulatory goals set out in this report. In our view, it would help to ensure the continuing improvement of the regulatory framework as it is being applied. We note in this regard that improvement of the new regulatory framework on an ongoing basis should not wait until it is time for the five-year review, which we subsequently recommend. We also note that at the Roundtable there was qualified support for a five-year review but unanimous support for the recommendation that "the regulatory framework should include a process to strive to ensure continuous improvement, rather than waiting for a five-year review.”207

Another important benefit of the creation of an RAC is that it could ensure that the dialogue on the regulation of aquaculture that has taken place in this process continues and develops after our process comes to an end. By itself, this would be an important reason for having an RAC. It could help to ensure that issues that have the potential to be polarizing and divisive have a forum in which they can be proactively and constructively discussed and addressed before they actually become polarizing and divisive.

${ }^{207}$ Roundtable Final Report, 22. 


\section{SCIENCE ADVISORY COMMITTEE/NETWORK/MECHANISM}

The Panel has been fortunate to have the benefit of access to first-rate scientific and local knowledge advice through the Knowledge Roster we established as part of our process. We have had access to academic and community experts in a range of fields relevant to the aquaculture industry and the regulation of aquaculture.

We recommend that the DFA establish an ongoing mechanism for consulting with experts on the science of aquaculture and its regulation. ${ }^{208}$ This could be a standing advisory committee or a broader network such as our Knowledge Roster or some combination of the two approaches. Alternatively, the DFA and experts who are willing to participate may identify a third and superior mechanism. However constructed, the idea would be that a standing mechanism would link the DFA with a community of experts in the science of aquaculture to facilitate the DFA's access to the combined expertise of that community. At the same time, experts who agree to participate would have a channel through which to contribute to the effectiveness of regulation, and to decision making in the aquaculture sector more broadly. Our experience suggests that many experts across Atlantic Canada are fully prepared to make this kind of contribution and would welcome an avenue to do so on a continuing basis.

The issues or questions that would be considered would include those identified by the DFA on an ongoing basis. There would be an emphasis on issues and questions of relatively direct relevance to the regulation of aquaculture. Participants in the process would also have an opportunity to identify issues or questions that warrant discussion. The important limitation is that the issues and questions from either direction should be of a general nature. This would not be a mechanism through which the DFA would seek advice on specific regulatory decisions, such as whether a particular application should be approved or the terms and conditions that should be attached to an approval. Instead, the focus would be on science issues and questions that are relevant to general policy issues in regulation or to the general functioning of the regulatory framework. For example, the question of how to structure an analytical framework or a decision model for identifying Green, Yellow and Red areas for fin-fish aquaculture might be a topic to be discussed in this forum. The characterization of a particular part of the coast as Green, Yellow or Red would not be.

One of the topics to be addressed would be the identification on a continuing basis of the gaps in knowledge of how aquaculture operations interact with the natural environment, particularly in a Nova Scotia context. ${ }^{209}$ Options for addressing those gaps would also be an important part of the mechanism's rationale. In this way, the mechanism we have in mind could be very helpful to the DFA's capacity to carry out the expanded and more proactive approach to research that we have proposed as a foundational element to the new regulatory framework.

\footnotetext{
208 There was qualified support at the Roundtable for the recommendation that "the development of regulations, indicators, standards and thresholds should be science-based and should be integrated with local ecological knowledge.” (Roundtable Final Report, 18)

${ }^{209}$ Clearly, the interaction between aquaculture and climate change in a Nova Scotia context is one of the issues on which there are currently knowledge gaps.
} 
In seeking out members of academia and holders of traditional, local and community knowledge to participate in this mechanism, the DFA should endeavour to include experts from a wide range of fields of relevance to identifying and answering the questions that are relevant to ensuring that the regulation of aquaculture is evidence-based as it develops and evolves. Experts in the following fields and subjects would be included:

- $\quad$ Fish health

- Benthic impacts of aquaculture

- Hydrogeological and oceanographic conditions

- Climate change

- Wild fish populations

- Invasive species

- Sea lice

- Disease management

- Local ecosystems

- Socio-economic issues pertaining to aquaculture at multiple scales (i.e., local, regional, provincial, national and international)

Like the RAC, a more formal mechanism for continuing contribution to the regulatory framework from members of the scientific, traditional and local knowledge communities would help to ensure the continuing improvement of the regulatory framework as it is being implemented and developed on an ongoing basis. Therefore, as with the RAC, the science and traditional knowledge mechanism we recommend would be responsive to the recommendation that found qualified support at the Roundtable, that "the regulatory framework should include a process to strive to ensure continuous improvement, rather than waiting for a five-year review.”

\section{ROLE FOR INDUSTRY ASSOCIATIONS IN SUPPORTING COMPLIANCE}

In light of what we have proposed, the regulatory framework will be more demanding for current operators and those that want to enter the aquaculture business. The cost of compliance with the regulations and of getting approval from the regulator could be more expensive. The technical capacity and resources of business will be more important to their ability to work successfully and profitably under the new regulatory framework.

This will pose particular challenges for small businesses and for start-ups. Many of these work in shell-fish aquaculture, a sector of the industry in which growth may attract greater support. But the new framework will pose challenges for those in fin-fish aquaculture as well.

This is relevant not only from a business profitability and industry diversity perspective, but also from a regulatory effectiveness perspective. If regulated businesses are not able to meet regulatory requirements, the regulatory framework will not be as fully implemented as it otherwise would be. 
Many regulators develop and deliver programs to help regulated companies (especially small and medium-sized companies) know, understand and comply with their regulatory obligations. We think the DFA should consider such options.

Another option would be for the industry associations to which aquaculture businesses in Nova Scotia belong to develop and deliver such programs as part of the service they provide to their members. We understand from the ACFFA that it already does this, and that services of this nature are provided to the industry by the Canadian Aquaculture Industry Alliance. We also understand that the Aquaculture Association of Nova Scotia is working to become more active in this respect, including through its initiative to develop a code of practice for its membership.

The advantage of these approaches is twofold: they get businesses the assistance and support they may need to achieve compliance in cost-effective ways while protecting the regulator from the perception of being in conflict as the regulator and the enabler of regulatory compliance. The formation of the Regulatory Advisory Committee we recommend creates the opportunity for the industry associations to develop or expand their capacity-building programs with input from the larger range of constituencies interested in the regulation of aquaculture.

\section{WORKING CAPITAL (AQUACULTURE LOANS BOARD)}

Many in the industry raised the issue that they believe the Nova Scotia industry receives less assistance from government in acquiring working capital than does the industry in the rest of Atlantic Canada. Although some may question whether this is a regulatory issue, it should be noted that the Fisheries and Coastal Resources Act establishes the Fisheries and Aquaculture Loan Board and mandates it to provide loans to aquaculture as well as fisheries. More broadly, it is well recognized that governments can encourage regulated industries to act in accordance with regulatory objectives by helping them obtain the working capital that makes compliance with regulations more feasible and worthwhile. Conversely, government can make eligibility for participation in industry promotion programs conditional on a strong track record of regulatory compliance.

The issue of the level and the nature of the financial support that the Province of Nova Scotia provides to the industry is therefore already a part of the regulatory framework broadly conceived. We have not heard enough on the matter to make detailed or extensive recommendations. We can, however, offer the following observations:

- There is a perception in the aquaculture industry that it suffers because the priority of the Fisheries and Aquaculture Loan Board is the fisheries sector and because the Board is not set up to understand or give equitable consideration to the issues and opportunities facing aquaculture.

- To the extent that public money is to be made available to support the development of the aquaculture industry, it should be made available on fair and equitable terms to the industry as a whole. 
- Assistance with financing should be used not only to support the growth of the industry but to support growth that moves the industry in the direction of the low-impact/high-value production we have argued should be Nova Scotia's overriding objective in the aquaculture sector. This could mean:

o No eligibility for funding unless there is a strong track record of regulatory compliance

o No eligibility for funding for organizations that could be functioning under one of the stronger and well-recognized certification standards, such as the ASC standard, unless they are certified or in the process of obtaining certification

o An advantage for companies applying for financing that will use the assistance to improve their environmental performance, social licence or general capacity to produce higher-value products while reducing their impact on the environment

We have two further observations on this topic. The first is that in their meeting with us, representatives of the Atlantic Canada Opportunity Agency strongly expressed the view that aquaculture could play an important role in Nova Scotia's development if it were conducted to high standards of sustainability. Our sense was that they saw economic development programs as one of the tools governments could use in conjunction with strong regulation to move the industry in the direction of what we have described as low-impact/high-value aquaculture.

Second, the meetings we held in communities around the coastline of Nova Scotia made it abundantly clear to us that where the government's financial contribution to a specific company reaches a certain magnitude or scale, the willingness and ability of government regulators to rigorously regulate that company will be widely questioned. This may be especially so where the funding comes from the DFA rather than from another government department (such as Economic and Rural Development and Tourism) or an arm's-length economic development agency.

\section{MANDATORY INDEPENDENT FIVE-YEAR REVIEW (WITH ADVISORY COMMITTEE)}

At the Roundtable, there was qualified approval for the recommendation that "the new regulatory framework should include a five-year review by a committee including government, First Nations and stakeholders." 210 The qualification related to a concern about the specification that the review would be carried out by a review committee.

Five-year reviews have been included in a number of statutes in recent years, including the Environment Act and the Environmental Goals and Sustainable Prosperity Act. In both cases, the review process resulted in a range of amendments to the statute being reviewed, which reflected lessons learned in the operation of the statute during the review period as well as changes in the

${ }^{210}$ See Roundtable Final Report at page 32. 
conditions that affected the effectiveness of the statute. ${ }^{211}$ In both cases, the review process was an open one that provided all Nova Scotians with opportunities to contribute.

In short, in legislation that has similarity with the Fisheries and Coastal Resources Act, a mandatory five-year review has proven to be useful in Nova Scotia to improving legislation. In our view, the same can be expected from a review of a broader regulatory framework; it would include not only the amendments made to the Act and regulations to implement the framework but also the role of the DFA in making the framework operational through licensing and leasing, monitoring and enforcement and working with the DFO and other federal regulators and scientific and regulatory advisory groups.

Another important rationale for a mandatory and independent five-year review is that it puts the DFA on notice that it will be accountable at the end of five years for showing that the regulatory framework has been diligently and effectively implemented. This will help to ensure that the commitment to producing a world-class regulatory framework that was expressed when we were appointed to develop a new regulatory framework will be maintained through the process of translating our recommendations into effective action. At the same time, a mandatory independent review after five years will ensure that the ongoing process of improving the regulation of aquaculture in Nova Scotia has the opportunity to improve on the framework we have recommended where experience shows that our recommendations were inadequate or mistaken. ${ }^{212}$

As to the structure for the review, a range of options is available. We have noted the preference for some on the Roundtable for the review committee to include government, First Nations and stakeholders while other Roundtable members expressed reservation about being prescriptive on the involvement of a review committee. We would also note that review committees can be structured in a number of different ways. One way that was supported by the majority of Roundtable members is a review committee made up of representatives of the key constituencies. This is the approach adopted under the Environmental Goals and Sustainable Prosperity Act. Another option is a committee consisting of persons who are appointed because of their professional experience and expertise and their independence of both government and stakeholders. This, more or less, has been the approach followed under the Environment Act and some other statutes.

In our view, what matters is that the review be mandated so that it is clear from the beginning that it will happen. It matters also to be clear that the review will be conducted independently and not by the DFA or another part of the provincial government. It matters, in other words, that it be an external and not an internal self-review. What also matters is that the review be participatory, meaning that all who are interested in contributing their perspectives have full opportunity to do so whether or not they are directly represented by those mandated to carry out the review.

\footnotetext{
${ }^{211}$ For the most recent five-year review of the Environment Act, see http://novascotia.ca/nse/dept/division.pcs.policy.evironment.act.review.asp; for the review of the Environmental Goals and Sustainable Prosperity Act, see: http://novascotia.ca/nse/dept/egspa.review.asp.

${ }^{212}$ The Roundtable gave unanimous approval to the recommendation that "the regulatory framework should include a process to strive to ensure continuous improvement, rather than waiting for a five-year review." (Roundtable Final Report, 32)
} 
In addition, we suggest it would be important to structure the review in such a way as to be sure it is suited to deal with the details of regulatory design and administration as well as with broad policy issues. This may lean toward the expert review model explained above more than it does to the stakeholder review model. An advisory committee, such as the one that was established to help us in the development of this framework, could be formed to ensure that the experts appointed to do the review work with the benefit of advice from government, the Mi'kmaq and the full range of stakeholders interested in aquaculture.

\section{IMPLEMENTATION AND TRANSITION}

\subsection{Introduction}

In this section, we make recommendations on implementation and transition issues. We do so under the part of our mandate that requires us to identify "a recommended process and plan for implementing the recommended regulatory framework”.

We have not tried to articulate a detailed and prescriptive implementation plan. Instead we have limited ourselves to making recommendations on some key elements of the process of developing and implementing the proposed framework that we think could be crucial to its successful and timely implementation. We have taken this relatively high-level approach for a number of reasons. First, we are very conscious that we are not well positioned to lay out a detailed implementation plan, given the breadth of the overhaul of the regulatory system we are recommending. Within the context of such an overhaul, the implementation process will have to change and evolve as implementation proceeds and issues and questions arise. In addition, we are sure we do not know as much as DFA does about the detailed work that will be needed and the processes that will have to be followed to translate our general recommendations into an operating regulatory framework. There is therefore a good possibility that detailed recommendations on implementation may prove unhelpful.

Another consideration is that the implementation of the new regulatory framework will have to take place while the DFA continues to address its other responsibilities, including the ongoing regulation of aquaculture. While we can make suggestions as to how to further develop and implement the proposed framework, we cannot say very much on how this work can or should be combined with the DFA's other and ongoing responsibilities. To do so would, in any event, take us beyond our mandate.

Finally, we have limited ourselves to high-level advice on implementation and transition in light of the fact that our mandate includes "working with the Department of Fisheries and Aquaculture to develop the legislative, regulatory and policy instruments needed for effective implementation of the Panel's recommendations." Our advice on implementation, if provided in real time in response to issues that arise during implementation, may be of more value to the DFA than the detailed advice we might provide before implementation has even begun.

Accordingly, we limit ourselves to providing high-level advice on some of the critical aspects of the process and plan for implementing the framework we have recommended. We address the following issues: 
1. Resourcing and prioritization

2. Early actions

3. Options for efficient adoption of legislative changes

4. An "implement as ready" approach to implementation

5. The respective roles and interaction of administrative and legislative action

6. Ongoing improvement beyond initial implementation of the new framework

7. Applying the new framework to applications for new fin-fish licences and leases

8. Applying the new framework to existing operations

9. Transparency

10. Consultations with the Mi'kmaq

\subsection{Resourcing and Prioritization}

We have recommended an extensive overhaul of the regulatory framework for Nova Scotia's aquaculture industry. Implementing the framework we have recommended will require the design and drafting of extensive changes to legislation. It will require the development or extensive rebuilding of administrative and information systems, the reorganization of bureaucratic structures and significant changes in the relationship between the DFA and other parts of government, particularly the Department of Environment. New or additional capacity will have to be built in the DFA and in the Department of Environment, which invariably takes time. Significant policy work will have to be done on some aspects of the framework we have proposed before those elements will be ready to be drafted into legislation. The prime examples of this are the proposed system for classifying coastal areas or sites for their relative suitability for fin-fish aquaculture and the proposed and more-structured licensing process. An additional variable will be that a good deal of the necessary work cannot be done by the DFA, or by DFA alone. Significant contributions will be needed from other parts of government, and in particular from the Departments of Justice and Environment and the Office of the Legislative Counsel, and from the central agencies of government.

For all of these reasons, implementing the framework we have proposed is likely to take some time. It is not the work of a couple of weeks or months. The equally important point, however, is that it will take longer if the implementation process is not adequately resourced and made a priority not only within the DFA but across government more broadly. This could have very negative consequences for companies who may be waiting to invest in aquaculture in Nova Scotia and who are either unable to do so because of the current moratorium on fin-fish licences (in place until the new framework is in place) or who may be unwilling to invest until they have more confidence about what the future regulatory framework will look like. Avoidable delay in implementation could, in other words, adversely affect development of the industry.

A prolonged implementation process could also erode the support that the feedback we have received on our draft report seems to suggest now exists for the framework we have proposed. It could therefore limit the value that Nova Scotia derives from the time and resources that have already been invested in developing a new regulatory framework for its aquaculture industry. 
Therefore, our first recommendation is that the implementation process and the associated process of transitioning the industry and the DFA from the current regulatory framework to the proposed one be adequately resourced and made a priority within the DFA and for government more broadly.

\subsection{Early Actions}

Impetus and momentum can be given to the process of transitioning the industry from the old to the new regulatory framework if a decision on the framework as a whole is made as a first order of business. Similarly, the implementation process is likely to be more efficient and coherent if it is guided by a comprehensive implementation plan that is developed and released as soon as possible. The overall duration and effectiveness of the implementation process can also be enhanced if action is taken quickly on those aspects of the proposed framework that can be quickly implemented while work on implementing of the broader framework continues and on those aspects of the framework that are likely to require significant development to make them ready for implementation.

\subsubsection{Early Decision on the Framework As a Whole}

We recommend that a decision on acceptance or rejection of the regulatory framework we have proposed be made and announced as soon as possible. We think it is important that the decision be made at the level of the framework as a whole rather than at the level of each of our specific recommendations. We have three rationales for proposing this approach.

First, our fundamental conclusion is that the system of regulation has to be fundamentally overhauled, and we doubt that this can be done by making a series of discrete changes to the current regulatory framework. Instead, a new regulatory framework is called for. That is what we were mandated to recommend.

Second, in the generally positive feedback we heard on our draft report, the concern was frequently expressed that government would "pick and choose" among our recommendations rather than make the fundamental overhaul of regulation that we have called for. A related concern was simply the risk that the attention of the DFA and of government would be diverted from the implementation of the framework before implementation is completed, given that implementation is likely to take place over a significant period of time. On the assumption that government's decision will be to accept the framework we have proposed, both of these concerns can be addressed, or at least mitigated, if it is made clear early in the process that government's decision on our report has been made at the level of the overall framework we have proposed rather that at the level of the individual recommendations for specific improvements to how aquaculture is regulated. 213

\footnotetext{
${ }^{213}$ We would not suggest that acceptance of the framework we have proposed depends on adoption or acceptance of each and every recommendation we have made. We accept that the further analysis that would be part and parcel of the implementation process could show that some of the specific elements of the framework we have proposed may have to be reconsidered or adjusted or addressed in other ways. We would therefore view our framework as having been adopted if all of the core elements of it were adopted and implemented and if the new regulatory framework that is adopted as a result of our report can be said, when
} 
Third, we believe implementation is more likely to proceed efficiently if a decision made on the framework as a whole comes at the beginning of the implementation process, thus sending a clear message that the framework as a whole will be implemented. It will send an equally clear message that the process is an implementation process, not an open-ended policy-making process in which the question of how the industry is to be regulated will be reconsidered. These clear messages at the beginning of the implementation process will help give the industry certainty as to the regulatory framework they will be working under when implementation is completed. It will therefore make it more likely that the industry is ready for the framework as and when it becomes operational.

\subsubsection{Development and Release of a Comprehensive Implementation Plan}

We also recommend that an early step in implementation of the framework should be the development and release of a comprehensive implementation plan. This plan should lay out the proposed stages of the implementation process in a way that addresses the sequencing that will be needed between the legislative and administrative actions that will be taken to implement the proposed framework and move the industry from the current regulatory framework to the new one. The plan should clearly identify the expected dates by which the significant elements of the proposed framework will have been adopted and made operational. It should also identify the roles that legislative changes, policy changes and administrative changes will each play in bringing the new framework into existence. Related to this, the plan should identify the aspects of the proposed framework that will ultimately be embodied in legislation but that may be adopted on an interim basis through changes to policy or administrative practice.

The rationale behind this recommendation is simple: a complex and multi-faceted transformation of a regulatory system, which is likely to take some time and involve many different players, including multiple parts of government, is likely to be more successful if it is organized and directed by a comprehensive implementation plan that is laid out at the beginning of the process. A comprehensive implementation plan will also help to reinforce the message that the objective of the exercise is adoption and implementation of the framework as a whole and not just some discreet recommendations. It will therefore help to ensure that the adoption of the framework is the outcome of the process. In part, this will be because of the accountability such a plan will create for keeping the implementation process on track.

\subsubsection{Early Action on Implementation of Certain Elements of the Framework}

We recommend that early action should be taken to implement certain elements of the proposed framework early in the implementation process. The establishment of the Regulatory Advisory Committee should be one of those early actions. Although the committee should ultimately be provided for in legislation, it could be established on an interim basis under the DFA's existing authority to establish advisory committees so that it can play a role in the implementation process

viewed as a whole, to have accomplished a fundamental overhaul of the regulatory system that is broadly consistent with (a) our analysis of what is wrong with the current system; (b) our conclusions as to how the regulation of aquaculture in Nova Scotia has to be changed, improved and enhanced; and (c) the low-impact and high-value philosophy, the regulatory goals and principles and the foundational elements of the regulatory framework we have articulated. 
and the further development of the framework that will necessarily take place within that process. The committee can also play a role in keeping stakeholders aware of the status of the implementation process. It can be a forum for advice and consultations on significant choices that have to be made during the course of the implementation process. It can also play a role in ensuring that the implementation process makes timely progress.

Another area where early action will be important is development of the more-detailed and specific criteria for the site selection and utilization classification system that will be needed to make that system operational. An early focus on these criteria, as well as on the processes that will be used to implement the classification system, will send a clear message that the framework as implemented will include this core element of the framework as proposed. It will also help to ensure that development and implementation of the classification system does not cause delay in lifting the current moratorium on new marine-based fin-fish licences, which should continue until the new framework is in place. By the same token, an early emphasis on getting the classification system ready for implementation will ensure that the classification process is part of the regulatory framework when the moratorium is lifted.

Early action should be considered in a number of other areas. For example, the building of capacity in the DFA and in the Department of Environment should be given priority so that it will be in place when the new framework becomes operational. Priority action on concrete and specific measures to make the regulatory process more transparent and to strengthen the monitoring and enforcement systems would also do much to lay the foundations for the effective operation of the broader framework at the point at which it becomes fully operational.

More generally, we urge early action on elements of the proposed framework that can be implemented without legislative changes, ${ }^{214}$ including those elements we have said should be embodied in legislation but which can be adopted on an interim basis by changes to policy and administrative and regulatory practices. The fact that significant aspects of the proposed framework cannot be implemented without changes to legislation or will ultimately have to be embodied in legislation should not delay action on those aspects of the framework that can be implemented either on a permanent or interim basis without changes to legislation. This will help to ensure that stakeholders see real change in the functioning of regulation while the process of developing legislation and developing and implementing the larger framework is taking place. It will help to build trust and confidence in the DFA and in its commitment to the fundamental change in how regulation is conducted that we have concluded is called for.

\footnotetext{
${ }^{214}$ There are, of course, many recommendations in our report that will not solely or even primarily be implemented through changes to the Act or Regulations. Examples include aspects of the improvement of the transparency of the regulatory process that do not require legislative amendments; reorganization and strengthening of capacity in the DFA and the Department of Environment; aspects of improving the sharing of relevant information about the industry, the receiving environment, and other uses of coastal waters with the public and the industry; action to fill knowledge gaps through the support of research; and the development of more constructive relationships among all stakeholders. These non-legislative efforts can and should be initiated in parallel with work on required legislative changes.
} 
Two limitations on early action should be observed. First, to avoid the danger of the implementation process becoming diverted by litigation, aspects of the proposed framework that may require more explicit legislative authority than is currently provided by the Fisheries and Coastal Resources Act or other legislation should be adopted only after the legislative authority issue has been addressed. Second, the focus on implementing certain elements of the regulatory framework as they can be acted upon, including by changing policy and administrative practice under existing legislation, must not be allowed to divert effort from, or delay action on, the development and adoption of the larger framework, including the legislative changes that are needed to ensure that the new framework is strongly based on a new legislative foundation and not simply on policy and administrative and regulatory practice.

\subsection{Options for Efficient Adoption of Legislative Changes}

The new regulatory framework we have proposed requires a range of changes in the legislation under which regulation of aquaculture happens. We have considered whether to recommend a new act, or whether to recommend a combination of amendments to the existing act and making additional regulations under the existing act as amended.

We have concluded that the regulatory system we have proposed should be implemented largely through changes to the Fisheries and Coastal Resources Act, in combination with the development and promulgation of new regulations under that Act. One of the main reasons for this conclusion is that the Act as currently written emphasizes that regulation of aquaculture is part of the broader management of coastal resources. This is a good thing. Another reason is that the scope of the Act is broad enough to enable the adoption and implementation of the regulatory framework we have proposed. A third reason is that it is likely that working with the current Act and regulations can contribute to the more rapid adoption of the legislative changes that the regulatory framework calls for than would the development and adoption of a new act. ${ }^{215}$

We are sensitive to the fact that the development of parts of the aquaculture industry has effectively been on hold pending the completion of our process and that this will continue while the implementation of the framework is proceeding. Speedy and effective implementation of the new regulatory system will therefore be important to the industry. Our strong sense is that it is also important to many who participated in our process as critics of the industry and of the current regulatory framework. Their concern is that if the proposed framework is not acted upon relatively quickly, it might not be acted upon at all.

This is an additional reason for enacting the legislative changes we have proposed as regulations under the Fisheries and Coastal Resources Act and, to the extent legally necessary, for making amendments to the Act. As compared to the alternative of developing and adopting a new statute, this approach should facilitate and expedite the legislative component of bringing the new framework into operation. As ongoing experience with the framework develops, it will also help to ensure that subsequent legislative changes determined to be necessary can be made more quickly

\footnotetext{
${ }^{215}$ We recognize that our recommendation that responsibility for the administration of the Environmental Monitoring Program to the Department of Environment will almost certainly require changes to the legislation under which the Department of Environment is mandated as well as to legislation under which the DFA functions.
} 
and responsively than would likely be the case if the framework's legislative provisions were embodied in the Act or another statute.

Our review of the Fisheries and Coastal Resources Act suggests that many of the regulations needed to implement the new regulatory framework can be adopted under the authority to make regulations already found in the Act. Assuming we are correct on this point, we recommend that this authority be used to its full scope and that statutory amendment be minimized. For legislative provisions outside existing regulation-making authority, we recommend that the Act be amended to establish the necessary regulation-making power. We also recommend that while these amendments to the Act are in process, the regulations that will be made under the expanded regulation-making authority should be developed at the same time. This will help to ensure that both these regulations and the regulations already authorized by the Act can be in place soon after amendments to the Act to expand the authority it confers to make regulations come into effect.

Although we think that the legislative changes needed to adopt and implement the proposed regulatory framework should in general be adopted as regulations under the Fisheries and Coastal Resources Act, a thorough assessment should be carried out to identify the specific elements of the framework that either have to be or should be embodied in the Act (or another statute) rather than in regulations. This assessment should go on in parallel with the development of comprehensive implementing regulations so that all of the substance of the legislation required for the new framework is ready for adoption and implementation either as regulations or as amendments to the Act (or another statute) when the assessment of the need for amendments to the Act or other statutes is completed.

\subsection{An "Implement as Ready" Approach to Implementation}

We have considered whether developing and implementing the proposed framework should be conceived as a two-step process - in which the first step is exclusively concerned with getting ready to implement and the second stage is exclusively concerned with implementation - or as an integrated and iterative process in which specific elements of the framework are adopted as they become ready for adoption while the overall implementation process carries on toward the ultimate goal of full implementation.

We conclude that the implementation and transition process should follow the second of these two models. Under this approach, elements of the proposed framework would be implemented as they become ready for implementation. Where it is possible to implement elements of the proposed framework by making changes to how regulation under the current regulatory framework is conducted, this would be done, including where the change is one that would be eventually embodied in legislation.

The basic rationale for this approach is that there is no reason why implementation of elements of the proposed framework that can be implemented should be delayed simply because other elements of the framework cannot be implemented until a later date. In fact, we think that implementing specific elements of the new framework as it becomes possible to implement them will help to build and sustain momentum toward achievement of the ultimate goal of full implementation of the framework as a whole. It could also help to build and maintain trust and confidence in the commitment and capacity of the DFA to achieve the fundamental change we have called for in how aquaculture is regulated. Finally, a further advantage of a process under which implementation 
happens step-by-step while the broader process of implementation continues is that lessons learned in operationalizing specific elements of the new framework can inform the larger and ongoing implementation process.

An important limitation on this "implement as ready" approach is that interrelated elements of the regulatory framework should be implemented in a sequence that addresses the nature and extent of their interconnection. Additionally, the "implement as ready" approach may carry a risk that the operationalization of specific elements of the new framework while work on implementing the broader framework continues can drain resources from the broader process and perhaps reduce the urgency for completing the larger project. These risks can be mitigated by some of our earlier recommendations, including the early announcement of a decision on the framework as a whole, the adoption of a comprehensive implementation plan and the formation of the Regulatory Advisory Committee. In addition, to keep itself and others on track relative to the broader goal of full implementation as it proceeds with implementation of specific elements of that framework, the DFA should consider a reporting and accountability mechanism, such as quarterly implementation reports on its progress relative to the path laid out in its implementation plan.

\subsection{The Respective Roles and Interaction of Administrative and Legislative Action}

As we note earlier, many aspects of the framework we have proposed can be implemented under existing legislation. Moreover, some aspects of the proposed framework would not typically be prescribed or even provided for in legislation. For example, our recommendations that more inspections be carried out and that more inspections be conducted without prior notification are classic examples of recommendations that go to regulatory practice, not to the content of legislation.

These aspects of the regulatory framework will be implemented by changing policies and administrative and regulatory practices or procedures. They can be contrasted to elements of the regulatory framework that could be implemented without changes to legislation but on which we have recommended legislative changes because we have concluded that this will improve the regulation of aquaculture in Nova Scotia. The question may arise: should such recommendations be implemented on an interim basis by changing policies or administrative practices while the legislation that is needed to address them in legislation is under development?

In principle, we recommend that this question be answered affirmatively. This approach will help to ensure that the substance of regulation changes more quickly than might otherwise be the case. It may also mean that the experience gained with some of these recommendations through the process of implementing them on an interim basis can help to fine-tune them before they are embodied in legislation.

There are three important qualifications. The first is that interim implementation through the changing of policy or practice should not be used where there is a risk that it could generate legal action, for example, on the basis that the policy or administrative practice constitutes a fetter on the Minister's discretion or an unauthorized change in the terms and conditions under which aquaculture has been previously approved. The second is that this approach should only be used where any additional effort involved in first implementing a recommendation on an interim 
administrative basis and then adopting it on a legislative basis is shown to be worth it, as compared to the alternative of simply waiting until the recommendation can be fully implemented on a legislative basis. The third is that the use of this approach cannot be allowed to become a rationale for leaving matters that we have concluded should be addressed in legislation in the realm of discretion, policy and administrative practice.

\subsection{Ongoing Improvement beyond Initial Implementation of the Framework}

One of the overriding objectives of the regulatory framework we have proposed is to ensure that regulation continues to improve once our proposed framework has been implemented. For example, this is one of the main rationales for recommending a Regulatory Advisory Committee and a standing forum or mechanism for collaboration between regulators and researchers.

Consistent with this objective, we recommend that the process of implementing the proposed framework be regarded as the beginning of an ongoing process of continuous regulatory improvement, rather than as a one-time, time-limited process of regulatory reform that ends with the implementation of our recommendations. We are confident that over time, through the regular review of the operation of the proposed framework and the lessons learned through its ongoing operation, additional opportunities for improving the regulation of the industry will be identified.

For example, although we have aimed to be as comprehensive as possible in identifying the changes in legislation, policy and regulatory practice that must be made to give Nova Scotia a state-of-the art regulatory framework that integrates economic, environmental and social considerations, we expect that the process of implementing and operationalizing our framework will demonstrate that additional changes to legislation or to administrative and regulatory practices or systems may be needed to ensure the framework's optimal effectiveness. Likewise, we are aware that experience may show that some of the specific changes we have proposed are unnecessary or ineffective. In both scenarios, changes and adjustments should be made to ensure that the framework is based on the legislative provisions and the regulatory practices that will assure its effectiveness and success.

More specifically, it should be anticipated that experience under the framework will bring to light opportunities for improving and strengthening the framework's legislative foundations. For example, where elements of the proposed framework that are initially adopted by changing policy or administrative or regulatory practice prove successful, it may become appropriate to embody the policy or the practice in legislation to make it a permanent feature of the regulatory framework. Conversely, where changes to legislation that we have recommended prove ineffective or problematic, these should be amended, replaced or simply eliminated in accordance with the lessons learned from the experience of working with them.

Experience under the framework may also indicate that either more or less prescriptive legislation is needed on specific aspects of regulation to ensure the effectiveness of the framework. For example, where the implementation of the framework builds trust and confidence in the rigour, dependability and effectiveness of regulation, a move in the direction of legislative provisions that emphasize performance may be in order. On the other hand, a move in the direction of more prescriptive legislation could be in order if experience under the framework suggests this is 
necessary to ensure both regulatory effectiveness and trust and confidence in regulatory effectiveness.

More generally, the process of implementing the regulatory framework will have to be ongoing to ensure that the framework stays up to date with changes in the conditions and circumstances that will shape its effectiveness. These may include changes in a number of areas: the industry and the technology and practices it deploys and uses; general environmental conditions, whether due to climate change or other developments; conditions and circumstances in coastal communities; research-based understanding of the impacts of aquaculture, both positive and negative; and the practice and methodology of regulation, both in aquaculture and in other industries or regulatory fields from which the regulation of aquaculture can learn.

In all of these respects, the framework we have proposed must to some extent be regarded as a living framework, even though it must at the same time be a source of regulatory stability and certainty for the industry and those who are stakeholders in the development of the industry. For this balance to be properly struck and maintained, the process of implementing and developing the proposed framework must to some extent be an ongoing one that continues after the initial work of transitioning the industry from the existing regulatory framework to the proposed one is completed.

\subsection{Applying the New Framework to Applications for New Fin-fish Licences and Leases}

At the start of our process, the Government of Nova Scotia committed to not processing any applications for new marine-based fin-fish operations during our process. The clearly understood intent was that any applications for a licence or lease for new operations would be processed under the new regulatory framework, assuming that government accepted the framework we proposed.

This commitment has been an important step in establishing trust in the work of the Panel in communities in which concern about marine-based fin-fish operations is high. It will be important for this commitment to continue during the implementation process so that any applications for new marine-based fin-fish licences are considered and evaluated under the new regulatory framework. This will ensure that new fin-fish operations are licensed under a regulatory framework designed to ensure that fin-fish aquaculture is effectively regulated. It will also help to ensure that they are licensed under a framework that has been designed to address legitimate concerns that people have with the current regulatory framework. Finally, it will be seen as keeping faith with those who participated in our process on the understanding that it would result in a new regulatory framework and that applications for new licences would be considered under that framework.

At the same time (and as we have noted above) we understand that this approach presents a difficulty for those who would like to apply for licences and leases for new fin-fish operations. To the extent that we are correct that fin-fish aquaculture can contribute to sustainable prosperity when conducted responsibly in appropriate locations under rigorous regulation, it also poses difficulty for Nova Scotia’s response to the call for action laid out in the One Nova Scotia Commission.

We have taken these difficulties into account in the content of the regulatory framework we have proposed. For example, while we have proposed a framework that requires coastal areas to be classified for their suitability for fin-fish aquaculture before an application for a licence can be considered, we have also made it clear that we think classification can take place as the first step in 
the licensing process. The result is that licensing of new fin-fish sites can occur without the completion of a comprehensive classification of all coastal areas.

We have also taken the difficulties posed to the industry by the current moratorium into account in making these recommendations on implementation. For example, one of our rationales for recommending that legislative changes be made in regulations under the Fisheries and Coastal Resources Act where this is legally possible is that legislative changes can be adopted more expeditiously in this way.

In addition, it is important to again note that the duration of the implementation process will in significant measure be determined by the resources that are dedicated to it and by the priority that is attached to it, not only by the DFA but by government more generally. It is also important for all concerned to have a realistic and practical view of what it should mean to say that the moratorium should stay in effect until the new regulatory framework is "fully" implemented. We do not intend this to mean that each and every one of our recommendations has been fully adopted. We recognize, for example, that a number of the features of the regulatory framework we have proposed address areas of regulatory practice that are always subject to improvement. We also recognize that some of the specific recommendations we have made may prove unnecessary, counterproductive or ineffective within the general improvement in regulation we have said is required.

In that context, the view we take, as noted earlier, is that the proposed framework will be fully implemented when two benchmarks have been reached. The first will be reached when all the core elements of the framework we have proposed have been substantially adopted and implemented. ${ }^{216}$ The second will be reached when it can be said that a fundamental overhaul of the whole of the regulatory system has taken place - an overhaul that is broadly consistent with (a) our analysis of what is wrong with the current system, (b) our conclusions as to how the regulation of aquaculture in Nova Scotia must change, and (c) the low-impact and high-value philosophy, the regulatory goals and principles and the foundational elements of effective regulation we have articulated. In other words, our view would not be that full implementation depends on adoption or acceptance of each and every specific recommendation we have made but rather on the progress that has been made in implementing the fundamental overhaul of regulation that we have concluded is required and warranted. ${ }^{217}$

\subsection{Applying the New Framework to Existing Operations}

As promised when we were appointed to conduct our review, existing facilities should not be grandfathered. It is critical for the effectiveness of the new regulatory framework that all existing

\footnotetext{
${ }^{216}$ In relation to the licensing of fin-fish aquaculture, the core elements of the framework we have proposed include our recommendations on the classification system for site selection and utilization, the licensing process, the Environmental Monitoring Program, statutory conditions, compliance monitoring and enforcement, animal health and well-being, and the protection of wild salmon, including the proposed comprehensive containment management system.

${ }^{217}$ As noted earlier, we accept that the further analysis, reflection and consultations that would be part and parcel of the implementation process may show that some of the specific elements of the framework we have proposed may not be as effective as alternative regulatory approaches would be in contributing to the overall success of the framework in changing regulation on the scale and to the extent we have said is necessary.
} 
facilities be subject to all rules that can reasonably be applied to existing operations, including all statutory conditions, transparency provisions, rules for changes to and renewals of licences and leases, and to monitoring and reporting obligations.

We are not in a position to suggest the specific time frame in which this should occur. We assume it would vary for different kinds of operations and for different operators, based on their individual circumstances. We also assume that existing operations may transition to the new framework in stages, both as elements of the framework are adopted by DFA and as existing operations make the specific adjustments required to comply with different elements of the new framework.

Our recommendation is that the DFA should set a time frame after which all existing operations will be subject to the new regulatory system. The time frame should be set to allow operators reasonable time to adjust to the new rules, but no longer.

\subsection{Transparency}

Throughout this report we have emphasized the importance of transparency - and the associated accountability - to regulatory effectiveness and to public confidence in regulation. It is very important that the implementation of the framework we have proposed model the transparency that is intended to be a cornerstone of the framework once implemented. In this way, the implementation process can start to address the social licence issues that the new framework is intended to address. It can also help to ensure that the new framework takes effect under conditions that are likely to be conducive to its effectiveness.

\subsection{Consultations with the Mi'kmaq}

Finally, it is important that consultations with the Mi'kmaq take place. ${ }^{218}$ These should be made a priority within the process for developing and implementing the regulatory framework we have proposed. The Mi'kmaq have an important role to play in the design and implementation of an effective regulatory system for the aquaculture industry. Members of that community participated on our Advisory Committee and on our Roundtable, contributed to our Knowledge Roster, and attended a number of our community meetings. Through these contributions to our process, we have come to understand that Mi'kmaw communities not only are existing and potential owners and operators of aquaculture facilities but also have concerns about the social and environmental impacts and risks associated with certain kinds of aquaculture. We have made every effort to reflect these views as they were shared with us in our recommendations. The interests and concerns of the Mi'kmaq should, however, be explored in direct discussions between them and the Province of Nova Scotia, through the forums that exist for those kinds of consultations, before the new regulatory system is finalized.

\footnotetext{
${ }^{218}$ On the duty to consult in a natural resources context, see Dwight Newman, Natural Resource Jurisdiction in Canada, 41-44, and Ronalda Murphy, Richard Devlin and Tamara Lorincz, "Aquaculture Law and Policy and the Duty to Consult with Aboriginal Peoples.”
} 


\section{REFERENCES}

Ambec, Stefan, Mark Cohen, Stewart Elgie, and Paul Lanoie, The Porter Hypothesis at 20: Can Environmental Regulation Enhance Innovation and Competitiveness? (Resources for the Future, 2011).

Aquaculture Regulatory Review for Nova Scotia [The Doelle-Lahey Panel], www.aquaculturereview.ca.

Aquaculture Stewardship Council, ASC Salmon Standard (version 1.0 June 2012). Accessed at http://www.asc-aqua.org/upload/ASC\%20Salmon\%20Standard_v1.0.pdf.

Benfey, Tillman J., "Biocontainment measures to reduce/mitigate potential post-escape interactions between cultures European-origin and wild native Atlantic salmon in Newfoundland.” DFO Can. Sci. Advis. Sec. Res. Doc. 2013/nn.

Better Regulation Task Force, Principles of Good Regulation (UK: Better Regulation Task Force, 2003).

Carr, J.W., J.M. Anderson, F.G. Whoriskey, and T. Dilworth.. “The occurrence and spawning of cultured Atlantic salmon in a Canadian river,” ICES Journal of Marine Science 54 (1997): 1064-73.

Cohen, The Honourable Bruce I., The Uncertain Future of Fraser River Sockeye: Volume 2 Causes of the Decline (Commission of Inquiry into the Decline of Sockeye Salmon in the Fraser River, 2012).

Craik, Neil, Subsidiarity and Environmental Federalism: The Emergence of "New Governance" in Finfish Aquaculture in Canada (2009). Accessed at http://ssrn.com/abstract=1468617.

Doelle, M., "The quiet invasion: Legal and policy responses to aquatic invasive species in North America,” International Journal of Marine and Coastal Law 18(2) (2003): 261-94.

— - "The Role of Strategic Environmental Assessments (SEAs) in Energy Governance: A Case Study of Tidal Energy in Nova Scotia’s Bay of Fundy,” (2009) 27 Journal of Energy and Natural Resources Law 112.

[DFO] Fisheries and Oceans Canada, "Review of the Organic Extractive Component of Integrated Multi-trophic Aquaculture (IMTA) in Southwest New Brunswick with Emphasis on the Blue Mussel.” DFO Can. Sci. Advis. Sec. Sci. Advis. Rep. 2013/056. Accessed at http://www.dfompo.gc.ca/Library/349878.pdf.

[ECELAW], Aquaculture Regulation in Nova Scotia: Overview of the Regulatory Framework and Considerations for Regulatory Reform (East Coast Environmental Law, 2013). Accessed at http://www.ecelaw.ca/85-aquaculture-regulation-in-nova-scotia-overview-of-the-regulatoryframework-and-considerations-for-regulatory-reform.html.

- Comparative Analysis of Aquaculture Regulatory Frameworks in Maine and Nova Scotia (2014). Accessed at http://www.ecelaw.ca/93-aquaculture-regulation-comparative-analysismaine-and-ns.html. 
Comparative Analysis of Five Aquaculture Regulatory Frameworks in Canada (2014). Accessed at http://www.ecelaw.ca/94-aquaculture-regulation-comparative-analysis.html.

FORCE. Accessed at http://fundyforce.ca.

Engler, Cecilia, Analysis of Aquaculture Legislation and Regulation in Scotland (Halifax: Schulich School of Law, 2014).

Ernst, W., K. Doe, A. Cook, L. Burridge, B. Lalonde, P. Jackman, J.G. Aubé, and F. Page, “Dispersion and toxicity to non-target crustaceans of azamethiphos and deltamethrin after sea lice treatments on farmed salmon, Salmo salar,” Aquaculture 424-425 (2014): 104-112.

FAO, Building an Ecosystem Approach to Aquaculture, FAO Fisheries and Aquaculture Proceedings 14 (Food and Agriculture Organization of the United Nations, 2007).

Gardner Pinfold, Feasibility of Land-Based Closed-Containment Atlantic Salmon Operations in Nova Scotia (2014).

Gunningham, Neil, “Regulating Small and Medium Sized Enterprises,” Journal of Environmental Law (2002) 14(1).

Hargrave, Barry T., "A Traffic Light Decision System for Marine Finfish Aquaculture Siting,” Ocean and Coastal Management 45 (2002): 215-35. Accessed at http://www.academia.edu/1481378/A_traffic_light_decision_system_for_marine_finfish_aqua culture_siting.

Hishamunda, Nathanael, Neil Ridler, and Elisabetta Martone (), Policy and Governance in Aquaculture: Lessons Learned and Way Forward, FAO Fisheries and Aquaculture Technical Paper 577 (Food and Agriculture Organization of the United Nations, 2014).

Howarth, William, “Global Challenges in the Regulation of Aquaculture,” in David VanderZwaag and Gloria Chao (eds.), Aquaculture Law and Policy: Towards Principled Access and Operations (London and New York: Routledge, 2006).

Hutchings, J.A., I.M. Côté, J.J. Dodson, I.A. Fleming, S. Jennings, N.J. Mantua, R.M. Peterman, B.E. Riddell, A.J. Weaver, and D.L. VanderZwaag, Sustaining Canada's Marine Biodiversity: Responding to the Challenges Posed by Climate Change, Fisheries, and Aquaculture (The Royal Society of Canada: The Academies of Arts, Humanities and Sciences of Canada, 2012). Accessed at https://rscsrc.ca/sites/default/files/pdf/RSCMarineBiodiversity2012_ENFINAL.pdf

Hutchings, K., S. Porter, B.M. Clark, and K. Sink (), Strategic Environmental Assessment: Identification of Potential Marine Aquaculture Development Zones for Fin Fish Cage Culture, Draft (prepared for the Directorate for Sustainable Aquaculture Management: Aquaculture Animal Health and Environmental Interactions, South Africa Department of Agriculture, Forestry and Fisheries, 2011). Accessed at http://www.anchorenvironmental.co.za/Documents/Pdfs/SEA\%20MADZ/Draft\%20SEA\%20 Report\%20for\%20web.pdf.

Maine, Department of Environmental Protection, General Permit - Net Pen Aquaculture, Maine Pollutant Discharge Elimination System Permit and Maine Waste Discharge License (April 
10, 2014). Accessed at http://www.maine.gov/dep/water/wd/atlantic_salmon_aquaculture/MEG1300002014permit.pdf.

Maine, Department of Marine Resources, Aquaculture Lease Regulations, 13188 CMR ch 2 at s 2.37.

Martin, Paul, Robyn Bartle, Jack Sinden, Neil Gunningham, and Ian Hannam, Developing a Good Regulatory Practice Model for Environmental Regulations Impacting on Farmers, (Australian Farm Institute and Land \& Water Australia, 2007).

Morton v. British Columbia (Minister of Agriculture and Lands) [2009] B.C.J. No. 193, 92 B.C.L.R. (4th) 314 (B.C.C.A) [hereinafter “Morton”]

Murphy, Ronalda, Richard Devlin, and Tamara Lorincz, "Aquaculture law and policy and the duty to consult with aboriginal peoples” in David VanderZwaag and Gloria Chao (eds.), Aquaculture Law and Policy: Towards Principled Access and Operations (London and New York: Routledge, 2006).

[NASCO] North Atlantic Salmon Conservation Organization, Guidance on Best Management Practices to Address Impacts of Sea Lice and Escaped Farmed Salmon on Wild Salmon Stocks, SLG(09)5 (revised 2010). Accessible at http://www.nasco.int/pdf/aquaculture/BMP\%20Guidance.pdf.

-, NASCO Implementation Plan for the period 2013-18 (Canada), CNL(13)51. Accessible at http://www.nasco.int/pdf/2013\%20papers/CNL(13)51\%20FINAL.pdf.

-, Resolution by the Parties to the Convention for the Conservation of Salmon in the North Atlantic Ocean to Minimise Impacts from Aquaculture, Introductions, and Transfers, and Transgenics on the Wild Salmon Stocks [The Williamsburg Resolution] (2006). Accessible at http://www.nasco.int/pdf/agreements/williamsburg.pdf.

Newman, Dwight, Natural Resource Jurisdiction in Canada (Markham: LexisNexis, 2013).

OECD, “OECD Principles for Regulatory Quality and Performance,” in OECD, Regulatory Policy and Governance: Supporting Economic Growth and Serving the Public Interest (OECD Publishing, 2011).

- The Governance of Regulators, OECD Best Practice Principles for Regulatory Policy (OECD Publishing, 2014).

Penobscot Bay Watch, Framework for a Salmon Aquaculture Containment Policy in the State of Maine (May 1, 2001). Accessed at http://penbay.org/aq/aqdeal.html.

Price, Carol S., and James A. Morris, Jr., Marine Cage Culture and the Environment: Twenty-First Century Science Informing a Sustainable Industry, NOAA Technical Memorandum NOS NCCOS 164 (National Oceanic and Atmospheric Association of the US Department of Commerce, 2013). Accessed at http://www.noaanews.noaa.gov/stories2013/pdfs/2013_PriceandMorris_MarineCageCulturea ndTheEnvironment(5).pdf. 
Summerfelt, Steven, Thomas Waldrop, Christopher Good, John Davidson, Phillip Backover, Brian Vinci, and Jonathan Carr, Freshwater Growout Trial of St John River Strain Atlantic Salmon in a Commercial-scale, Land-based, Closed-containment System (The Conservation Fund and the Atlantic Salmon Federation, 2013).

Thorstad, Eva B., Ian A. Fleming, Philip McGinnity, Doris Sato, Vidar Wennevik, and Fred Whoriskey. 2008. Incidence and Impacts of Escaped Farmed Atlantic Salmon Salmo salar in Nature, Norwegian Institute of Nature Research (NINA) Special Report 36 (2008). Accessed at http://www.fao.org/3/a-aj272e.pdf.

Victoria State Services Authority, Review of the Rationalization and Governance of Regulators (Melbourne: State Services Authority, 2009). Accessible at http://www.ssa.vic.gov.au/images/stories/product_files/933_Review_Regulators_Governance. pdf.

Walters, Bradley B., “Competing use of marine space in a modernizing fishery: salmon farming meets lobster fishing on the Bay of Fundy,” The Canadian Geographer 51(2) (2007): 139-59.

Wiber, Melanie G., et al., "Impact of aquaculture on commercial fisheries: fishermen's local ecological knowledge,” Human Ecology 40(1) (2012): 29-40.

Wilson, A., S. Magill, and K. Black (2009), "Review of environmental impact assessment and monitoring in salmon aquaculture," in Environmental Impact Assessment and Monitoring in Aquaculture: Requirements, Practices, Effectiveness and Improvements, FAO Fisheries and Aquaculture Technical Paper 527 (Food and Agricultural Organization of the UN, 2009). 